MARCIO DE SOUZA SANTOS

\title{
INFERÊNCIA BAYESIANA NA AVALIAÇÃO DA SEGURANÇA DE FUNDAÇÕES EM ESTACAS DE DESLOCAMENTO
}

São Paulo 
MARCIO DE SOUZA SANTOS

\section{INFERÊNCIA BAYESIANA NA AVALIAÇÃO DA SEGURANÇA DE FUNDAÇÕES EM ESTACAS DE DESLOCAMENTO}

Dissertação apresentada à Escola Politécnica da Universidade de São Paulo para a obtenção do Título de Mestre em Engenharia

São Paulo 
MARCIO DE SOUZA SANTOS

\section{INFERÊNCIA BAYESIANA NA AVALIAÇÃO DA SEGURANÇA DE FUNDAÇÕES EM ESTACAS DE DESLOCAMENTO}

Dissertação apresentada à Escola Politécnica da Universidade de São Paulo para a obtenção do Título de Mestre em Engenharia

Área de concentração: Engenharia de Solos

Orientador: Prof. Titular Waldemar Coelho Hachich

São Paulo 


\section{FICHA CATALOGRÁFICA}

Santos, Marcio de Souza

Inferência Bayesiana na avaliação da segurança de fundações em estacas de deslocamento / M.S. Santos. -- São Paulo, 2007. 128 p.

Dissertação (Mestrado) - Escola Politécnica da Universidade de São Paulo. Departamento de Engenharia de Estruturas e Geotécnica.

1. Inferência Bayesiana (Inferência estatística) 2. Estacas pré-moldadas 3. Segurança estrutural I. Universidade de São Paulo. Escola Politécnica. Departamento de Engenharia de Estruturas e Fundações II. t. 


\section{DEDICATÓRIA}

Dedico esse trabalho, de início, às três mulheres que constituem a base firme de minha vida:

À Vera Lúcia, minha mãe idolatrada, ao mesmo tempo fonte e objeto de amor inesgotável, doutora da vida.

À Telminha, esposa, amiga, amada. De doçura e sensibilidade inigualáveis. Apresentou-me a possibilidade de um amor eterno e irrestrito.

À Carolina, minha adorável filha. Essa "piquininha" trouxe ainda mais sentido à minha vida.

Grandes homens também merecem essa dedicatória:

Ao meu avô Geraldo (in memorian), sábio pedreiro que idealizou o neto engenheiro. Tuas "inferências" estavam absolutamente corretas.

Ao meu pai, Milton. Em tempo, pude perceber o grande pai com que fui agraciado por Deus, e como é admirado por todos.

Ao meu irmão Léo, companheiro inseparável, leal e verdadeiro amigo. Decerto será um engenheiro muito melhor que o irmão! 


\section{AGRADECIMENTOS}

A Deus, infinita fonte de provisão. "As minhas obras não sou eu quem as realiza, mas a força de Deus-Pai que permeia os céus e a terra";

Ao professor Waldemar Hachich. Indevidamente intitulado como "prof. Livre-Docente" no exame de qualificação, pra mim és muito mais que isso. Os ensinamentos desse legítimo

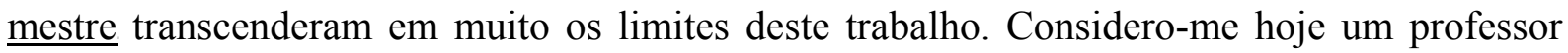
melhor por ter sido seu aluno!

Ao professor Fernando Rebouças Stucchi, pelas brilhantes sugestões e críticas efetuadas no exame de qualificação;

Ao engenheiro Dr. Werner Bilfinger, da Vecttor Projetos, por sua contribuição e ensinamentos no exame de qualificação;

Ao engenheiro Eugênio Pabst Vieira da Cunha, da Interact, pelo material fornecido e pelo incentivo.

Aos professores, secretárias e demais funcionários do Departamento de Engenharia de Estruturas e Geotécnica da Escola Politécnica da USP, pelo apoio e constante disposição no auxílio aos alunos;

Às bibliotecárias da Biblioteca da Engenharia Civil, pelo constante auxílio;

Aos amigos de mestrado da sala 25 da Poli-Civil, Fernando ("o Colômbia"), Carlos Rezende (“o Aracajú"), Rafael (“o Maringá”), Alexei, Raúl e Arturo, pelo incentivo e companheirismo;

Ao economista, professor, compadre e amigo Marcos Paulo de Oliveira, pelo entusiasmo com que acompanhou o desenvolvimento deste trabalho. Parceiro de grandes discussões; 
Ao meu irmão Leandro, sempre solícito e companheiro.

À minha cunhada Fernanda, pela paciência com que me ouviu, não raramente, falar do mestrado como se estivesse expondo palestras técnicas.

Aos meus colegas e amigos da perícia judicial, Fábio Fernandes, Fernando Neves, Sidney Machado ("sidoca"), Marcio Mônaco, Gilberto Lobo e Carlos Polacco, pelo incentivo e pelos constantes votos de confiança no meu trabalho. Esses votos também me motivaram a prosseguir nos estudos;

Aos meus colegas professores da Universidade Paulista, pelo incentivo e pelas discussões filosóficas proporcionadas;

Ao meu sogro Carlão e sua esposa Edna, pelo incentivo.

À minha esposa Telma e minha filha Carolina, pelo amor e alegria do convívio familiar;

À mamãe e papai, pelo apoio constante e incondicional, desde que manifestei a vontade de ser um “engenheiro da USP”, ainda na infância. 
“A verdade é um espelho que caiu das mãos de Deus e se quebrou.

Cada um recolhe um pedaço e diz que toda a verdade está naquele caco” Provérbio Iraniano 


\section{RESUMO}

O tema "segurança de fundações" tem merecido especial atenção, tanto na lide acadêmica quanto na prática profissional, em virtude da necessidade de se buscar soluções cada vez mais otimizantes para a dicotomia custo versus segurança, soluções essas que diferem pela forma de tratamento das incertezas envolvidas no projeto e execução das fundações. As provas de carga sobre as fundações têm desempenhado papel central na redução dessas incertezas.

Ultimamente, tem-se discutido muito, particularmente no âmbito da revisão da NBR 6122 , o papel das provas de carga na redução das incertezas inerentes a qualquer obra de fundações. Se é ponto pacífico que as provas de carga devem reduzir as incertezas, já não há consenso quanto aos níveis dessa redução em função do tipo e da quantidade de provas de carga, nem tampouco como a variabilidade dos resultados das provas de carga efetuadas em dada obra influenciam no fator de segurança.

Desta feita, o presente trabalho apresenta uma formulação consistente para combinação das previsões de capacidade de carga de estacas de deslocamento com as informações derivadas da realização de provas de carga estáticas conduzidas até a ruptura ou ensaios de carregamento dinâmico, propiciando a atualização racional dos indicadores de segurança, segundo os conceitos da inferência bayesiana.

Os resultados permitem consignar que a inferência bayesiana se apresenta com grande vantagem em relação à inferência clássica, pois permite a incorporação das informações anteriores existentes, muitas vezes de caráter subjetivo, sendo menos dependente de amostragem. Além disso, a inferência bayesiana se mostrou um instrumento legítimo para a incorporação dos resultados de provas de carga, decorrendo em medidas de segurança fundamentadas e com paralelo na prática da engenharia de fundações.

Palavras-chave: Segurança de fundações. Segurança de estruturas. Inferência bayesiana. Provas de carga. Métodos Probabilistas. 


\begin{abstract}
The theme of "foundations safety" deserves special attention in theory and practice, due to the need to find optimized solutions, which balance cost and safety, solutions that differ in their method of uncertainty treatment. An important way of coping with these uncertainties is the proof pile load tests.

Recently, the importance of proof load tests in the reduction of uncertainty has been widely discussed, mainly in the context of the NBR 6122 update. Despite their importance, there is no universally accepted standard regarding how the type and the number of proof load tests influence the safety factor.

This work uses the bayesian inference concepts to present a consistent approach, which matches predictions of precast pile capacity with proof pile load tests results, thus providing a rational updating of safety indicators.

The results of this study lead to the conclusion that bayesian inference methods have advantages compared with classical approaches. Since they allow the consideration of previous information, sometimes of a subjective nature, these methods do not require as large a sample as frequency approaches do. Furthermore, these methods have proved to be more robust than classical approaches whilst providing results which are consistent with current practice of foundation engineering.
\end{abstract}

Keywords: Foundations safety. Structural safety. Bayesian inference. Proof load tests. Probabilistic Methods. 


\section{ÍNDICE}

1. INTRODUCÃO 1

2. FATORES DETERMINANTES NO ESTABELECIMENTO DE CRITÉRIOS DE

SEGURANCA

2.1. A INCERTEZA 5

2.1.1. INCERTEZA INTRÍNSECA

2.1.2 INCERTEZA DE MODELO

2.1.2.1. Modelo de previsão da capacidade de carga 7

2.1.2.2. Modelo probabilista $\quad 10$

2.1.3. INCERTEZA DE PARÂMETROS 11

2.2. OS ERROS HUMANOS 13

2.3. AS CONSEQÜÊNCIAS DE UMA EVENTUAL RUÍNA 15

2.3.1. PROBABILIDADE DE RUÍNA PRESCRITA: 16

2.3.2. MAXIMIZAÇÃO DA UTILIDADE 18

3. OS DIVERSOS MÉTODOS DE INTRODUCÃ̃O DA SEGURANCA

3.1. MÉTODO DAS TENSÕES ADMISSÍVEIS $\quad 23$

3.2. MÉTOdo dos Estados LiMITES

3.2.1 FORMULAÇÕES DETERMINISTAS 25

3.2.2 MÉTODO SEMI-PROBABILISTA 26

3.2.3 DISCUSSÃO DOS MÉTODOS DETERMINISTAS

3.2.4 MÉTODOS PROBABILISTAS

3.2.4.1. Métodos de Nível I

3.2.4.2. Métodos de Nível II $\quad 33$

3.2.4.3. Métodos de Nível III

4. $\quad$ CONCEITOS DE INFERÊNCIA BAYESIANA

$\begin{array}{lll}\text { 4.1. INTRODUÇÃo } & 43\end{array}$

4.2. O TEOREMA DE BAYES

4.2.1 O TEOREMA DE BAYES NO PROCESSAMENTO DE INFORMAÇÕES

4.2.2 A DISTRIBUIÇÃO A PRIORI E O PROCESSO DE ELICIAÇÃO:

4.2.3 AS DISTRIBUIÇÕES CONJUGADAS:

4.3. UTILIZAÇÃO DA INFERÊNCIA BAYESIANA PARA REAVALIAÇÃO DA SEGURANÇA DE ESTACAS APÓS A EXECUÇÃO DE PROVAS DE CARGA

4.3.1 INFORMAÇÕES ANTERIORES RELEVANTES PARA A ATRIBUIÇÃO DA DISTRIBUIÇÃO A PRIORI: $\quad 57$

4.3.1.1. Correlações entre capacidade observada e prevista 58

4.3.1.2. Variabilidade dentro de uma mesma obra 60 
4.3.2 A CONJUGAÇÃO PROPOSTA PARA A OBTENÇÃO DA DISTRIBUIÇÃO POSTERIOR - CASO DE VARIÂNCIA DESCONHECIDA

4.3.3 INFERÊNCIA PARA O CASO DE VARIÂNCIA CONHECIDA

4.3.4 CRÍTICAS À ATUALIZAÇÃO A POSTERIORI DO FATOR DE SEGURANÇA.

5. DISTINCẼ̃O DOS FATORES DE SEGURANCA EM FUNCÃO DO TIPO DE \begin{tabular}{lr} 
PROVA DE CARGA & 78 \\
\hline
\end{tabular}

$\begin{array}{lll}\text { 5.1. } & \text { GENERALIDADES } & \mathbf{7 8}\end{array}$

5.2. CORRELAÇÃO ENTRE AS PROVAS DE CARGA ESTÁTICAS E DINÂMICAS

6. $\quad$ EXEMPLOS DE SIMULAÇ̃̃O $\quad 87$

6.1. EXEMPLO 01: PROVA DE CARGA ESTÁTICA E PRECISÃo INTRA-CANTEIRO $\begin{array}{ll}\text { DESCONHECIDA } & \mathbf{8 7}\end{array}$

6.1.1. INFORMAÇÕES ANTERIORES REFERENTES À VARIABILIDADE INTRA-CANTEIRO

6.1.2 INFORMAÇÕES ANTERIORES RELATIVAS AO MÉTODO DE PREVISÃO 88

6.1.3 PREVISÃO E RESULTADOS DE PROVAS DE CARGA ESTÁTICA

6.1.4 ATUALIZAÇÃO BAYESIANA 90

6.1.5 INFLUÊNCIA DA VARIABILIDADE DOS RESULTADOS DAS PROVAS DE CARGA

6.1.6 INFLUÊNCIA DO NÚMERO DE PROVAS DE CARGA EXECUTADAS NO FATOR DE SEGURANÇA 94

6.2. EXEMPLO 02: PROVA DE CARGA DINÂMICA E PRECISÃO INTRA-CANTEIRO DESCONHECIDA $\quad 98$

6.3. EXEMPLO 03: PROVA DE CARGA ESTÁTICA E PRECISÃO INTRA-CANTEIRO CONHECIDA $\quad 102$

6.3.1 INFORMAÇÕES ANTERIORES REFERENTES À VARIABILIDADE INTRA-CANTEIRO 103

6.3.2. INFORMAÇÕES ANTERIORES RELATIVAS AOS MÉTODOS DE PREVISÃO 104

6.3.3. PREVISÃO E RESULTADOS DE PROVAS DE CARGA ESTÁTICA 104

6.3.4 ATUALIZAÇÃO BAYESIANA

6.3.5 VARIAÇÃO DO FATOR DE SEGURANÇA COM A PRECISÃO INTRA-CANTEIRO 106

6.3.6 VARIAÇÃO DO FATOR DE SEGURANÇA COM O NÚMERO DE PROVAS DE CARGA 108

6.4. EXEMPLO 04: PROVA DE CARGA DINÂMICA E PRECISÃO INTRA-CANTEIRO CONHECIDA $\quad 110$

\begin{tabular}{llr}
7. & CONCLUSÕES & 116 \\
\hline
\end{tabular}

8. BIBLIOGRAFIA 121

APÊNDICE A

APÊNDICE B 


\section{LISTA DE FIGURAS}

Figura 2.1 - Tipos de incerteza (Hachich, 1998b).

Figura 2.2 - Variabilidade das caudas de algumas Funções Densidade de Probabilidade (Borges e Castanheta, 1971).

Figura 2.3 - Família de distribuições normais da magnitude do erro como função do tempo de inspeção (Madsen et al, 1986).

Figura 2.4 - Riscos admitidos pela sociedade, de acordo com o Departamento de Planejamento de Hong Kong (à esquerda) e com o ANCOLD (Baecher e Christian, 2003).

Figura 2.5 - Probabilidade de ruína para algumas estruturas, em função das conseqüências da ruptura (Whitman, 1984).

Figura 2.6 - Minimização do custo esperado.

Figura 2.7 - Valor de projeto da aceleração em função do número de fatalidades, para as diversas classificações do LQI (Sánchez-Silva e Rackwitz, 2004).

Figura 3.1 - Abordagens do método das tensões admissíveis.

Figura 3.2 - Diferentes abordagens consideradas no Método dos Estados Limites.

Figura 3.3 - Definição da resistência característica.

Figura 3.4 - Coeficiente de segurança versus segurança (adaptado de Lacasse e Goulois, 1989).

Figura 3.5 - Variação da coesão em duas obras hipotéticas.

Figura 3.6 - Delimitação do domínio seguro e do domínio de ruptura.

Figura 3.7 - Definição de índice de segurança à partir da margem de segurança média e do domínio de ruptura (Christian, 2004).

Figura 3.8 - Fator de segurança central versus índice de confiabilidade, para diversos coeficientes de variação da resistência $\left(V_{R}\right)$ e solicitação $\left(V_{S}\right)$.

Figura 3.9 - Delimitação dos domínios seguro e de falha, dependendo da especificação da função de desempenho (Veneziano, 1974). 
Figura 3.12 - Detalhe da figura anterior. A expressão 3.23 representa a integral da curva verde da figura supra.

Figura 4.1 - Partição do espaço amostral S.

Figura 4.2 - Ocorrência de um evento A qualquer.

Figura 4.3 - Relação da capacidade prevista ao arrancamento $(P)$ e da capacidade medida ao arrancamento (Q) das fundações de seis torres de transmissão, avaliadas por nove engenheiros. O gráfico foi construído com os dados apresentados por Kondziolka e Kandaris, 1996 apud Christian, 2004.

Figura 4.4 -Algumas variações da Função Densidade de Probabilidade do tipo Gama.

Figura 4.5 - Distribuições Gama representativas da precisão intra-canteiro (Baecher e Rackwitz, 1982).

Figura 4.6 - Variação do fator de segurança com o valor de K (para uma prova de carga) e com o índice de confiabilidade, considerando-se os parâmetros da distribuição gama identificada por "mais ampla” na Tabela 4.4 (Baecher e Rackwitz, 1982).

Figura 4.7 - Variação do fator de segurança com o valor de K (para uma prova de carga) e com o índice de confiabilidade, considerando-se os parâmetros da distribuição gama identificada por "mais apertada" na Tabela 4.4 (Baecher e Rackwitz, 1982).

Figura 4.8 - Variação do FS em função de Kmed e CV de duas provas de carga, considerando-se $\beta=3$.

Figura 4.9 - Variação do fator de segurança com o fator de viés (K) para diversos métodos (Baecher e Rackwitz, 1982).

Figura 4.10 - Variação do fator de segurança em função do número de provas de carga (Kay, 1976).

Figura 4.11 - Diferentes abordagens da inferência bayesiana: a) incorporação da informação de forma sequencial e b) incorporação da informação de uma só vez.

Figura 5.1 - Correlações obtidas com uso dos dados apresentados nos diferentes Stresswave Conferences (Likins e Rausche, 2004).

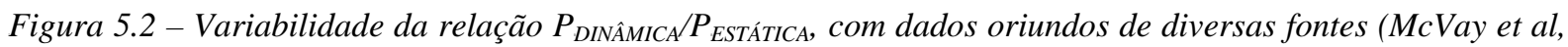
2000). Os ensaios dinâmicos foram efetuados no final da cravação (“End of Driving” - EOD).

Figura 5.3 - Esquema de obtenção da variável Pdin/Pprev à partir das variáveis Pestat/Pprev e Pdin/Pestat. 84 
Figura 5.4 - Distribuições log-normais da variável Pobs/Pprev para prova de carga estática e para ensaios dinâmicos, considerando-se várias fontes de informação para a variável Pdin/Pestat (por exemplo, DIN-Gates significa capacidade de carga observada por ensaio dinâmico, considerando-se a relação entre Pdin/Pestat informada por Gates).

Figura 6.1 - Função densidade do tipo Gama, representativa da precisão intra-canteiro $\left(1 / \sigma^{2}\right)$ (Baecher e Rackwitz, 1982).

Figura 6.2 - Variação do Fator de Segurança em função da média e do Coeficiente de Variação dos resultados de duas provas de carga efetuadas na obra, considerando-se o método de Aoki-Veloso.

Figura 6.3 - Variação do Fator de Segurança em função da média dos resultados das provas de carga (Kmed) e da variabilidade dos resultados, aqui representada pela relação entre $k 2$ e k1, considerando-se o método de Decourt-Quaresma.

Figura 6.4 - Variação de FS com Kmed e com o número de provas de carga efetuadas, considerando-se o método de Aoki-Veloso e Coeficiente de Variação dos resultados das provas de carga seja zero (CV = 0\%). 95

Figura 6.5 - Ampliação da figura anterior, destacando uma faixa de valores mais prováveis para Kmed.

Figura 6.6 - Variação do FS com Kmed e com o número de provas efetuadas, considerando-se um coeficiente de variação da variável $K$ de $C V=15 \%$.

Figura 6.7 - Variação do FS com o valor de K = Pobs/Pprev para o método de Aoki-Veloso e em função do tipo de prova de carga, considerando-se a relação Pdin/Pestat oriunda dos bancos de dados de Paikowsky, Gates e PDA cases, como informado em MacVay et al (2000).

Figura 6.8 - Variação do FS com o valor de K = Pobs/Pprev para o método de Decourt-Quaresma e em função do tipo de prova de carga, considerando-se a relação Pdin/Pestat oriunda dos bancos de dados de Paikowsky, Gates e PDA cases, como informado em MacVay et al (2000).

Figura 6.9 - Variação do FS com o valor de $K$ = Pobs/Pprev para o método de Aoki-Veloso e em função do tipo de prova de carga, considerando-se duas provas de carga com $\mathrm{CV}=0 \%$.

Figura 6.10 - Variação do FS com o valor de $K$ = Pobs/Pprev para o método de Aoki-Veloso e em função do tipo de prova de carga, considerando-se duas provas de carga com $C V=20 \%$.

Figura 6.11 - Fatores de segurança em função de $K$, para o método de A\&V, considerando-se $\beta=3$ e a execução de uma prova de carga. Foram considerados os mesmos informes anteriores apresentados na Tabela 6.1 .

Figura 6.12 - Fatores de segurança em função de Kmed, para o método de A\&V, considerando-se $\beta=3$ e a execução de duas prova de carga.

Figura 6.13 - Variação de FS com a média dos resultados dos valores de K verificados na obra e com o número de provas de carga, para o método de Aoki-Veloso. 
Figura 6.14 - Ampliação da figura anterior, considerando-se uma faixa mais provável de valores de Kmed. 109

Figura 6.15 - Variação de FS com Kmed e com o número de provas de carga dinâmica, para o método de AokiVeloso, considerando-se $\sigma=0,08$ (alta precisão).

Figura 6.16 - Variação de FS com Kmed e com o número de provas de carga dinâmica, para o método de AokiVeloso, considerando-se $\sigma=0,15$ (média precisão).

Figura 6.17 - Variação de FS com Kmed e com o tipo de prova de carga, com base nos informes apresentados na Tabela 6.19.

Figura 6.18 - Variação de FS com Kmed e com o tipo de prova de carga, com base nos informes apresentados na Tabela 6.20. 


\section{LISTA DE TABELAS}

Tabela 2.1 - Fator de viés para diversos métodos de previsão da capacidade de carga (McVay et al, 2000). 10

Tabela 2.2 - Coeficiente de Variação [V(x)] das propriedades resistentes dos solos (Cardoso, 2002).

Tabela 2.3 - Incerteza associada à cinco testes comumente efetudos in-loco (Baecher e Christian, 2003).

Tabela 3.1 - Coeficientes de segurança parciais (Maranha das Neves, 1994)

Tabela 4.1 - Informações anteriores consideradas.

Tabela 4.2 - Probabilidades anteriores e posteriores à amostragem.

Tabela 4.3 - Algumas distribuições conjugadas normalmente utilizadas na inferência bayesiana (Ang e Tang, 1984).

Tabela 4.4 - Valores das variáveis $K\left(P_{\text {obs }} / P_{\text {prev }}\right)$ e $R=\log \left(P_{\text {obs }} / P_{\text {prev }}\right)$, para alguns métodos de previsão da capacidade de carga de estacas. A fonte de onde se extraiu o banco de dados está referenciada em parênteses, na primeira coluna.

Tabela 4.5 - Variabilidade intra-canteiro da capacidade de carga de estacas $\quad$ (Kay, 1993).

Tabela 4.6 - Parâmetros das distribuições Gama obtidas por Baecher e Rackwitz (1982).

Tabela 4.7 - Informações anteriores relativas aos quatro métodos analisados por Baecher e Rackwitz (1982). 71

Tabela 5.1 - Valores da variável da média e desvio da variável Pdin/Pestat com base em vários autores, para a cravação e recravação. Carga de ruptura da prova estática obtida utilizando-se o critério de Davisson (MacVay et al, 2000).

Tabela 5.2 - Coeficientes de variação de diversos métodos de estimativa da capacidade de carga (Vrouwenvelder, 1992).

Tabela 5.3 - Fatores de segurança global preconizados na norma Finlandesa (Bilfinger, 2002).

Tabela 5.4 - Fatores de Segurança Parciais preconizados pela Ontário Bridge Code (Bilfinger, 2002).

Tabela 6.1 - Valores de $K=$ Pobs/Pprev e $R=\log K$ decorrentes das publicaçôes originais de Aoki eVeloso (1975) e Decourt e Quaresma (1978). 
Tabela 6.5 - Fatores de segurança em função do valor de Kmed e do Coeficiente de Variação dos resultados das provas de carga, para o método de Aoki-Veloso, considerando-se a execução de 2 provas de carga.

Tabela 6.6 - Fatores de segurança em função da média e coeficiente de variação dos resultados de K, para o método de Decourt-Quaresma.

Tabela 6.7 - Fatores de segurança propostos para o método de Aoki-Veloso considerando-se a realização de uma prova de carga que tenha decorrido em um valor de $K$, para $\beta=3$. Os informes de $R$ relativos às provas dinâmicas estão apresentados na tabela do Apêndice B.

Tabela 6.8 - Fatores de segurança propostos para o método de Decourt-Quaresma considerando-se a realização de uma prova de carga que tenha decorrido em um valor de $K$, para $\beta=3$. Os informes de $R$ relativos às provas dinâmicas estão apresentados na tabela do Apêndice $B$.

Tabela 6.9 - Fatores de segurança propostos para o método de Aoki-Veloso considerando-se a realização de duas provas de carga que tenham decorrido em um valor de Kmed, para $\beta=3$ e CV = 0\% (k1 = k2).

Tabela 6.10 - Fatores de segurança propostos para o método de Aoki-Veloso considerando-se a realização de duas provas de carga que tenham decorrido em um valor de Kmed, para $\beta=3$ e CV $=20 \%$.

Tabela 6.11 - Distinção ad hoc das classes de precisão, em função dos valores de $\sigma[R]$ apresentados por vários autores. Os valores entre parênteses serão os valores representativos de cada classe.

Tabela 6.12 - Previsão da capacidade de carga e resultado da prova de carga da obra hipotética.

Tabela 6.13 - Fatores de segurança obtidos para os métodos de Aoki-Veloso e Decourt-Quaresma, com fulcro nas informações anteriores apresentadas na Tabela 6.1 e nos resultados expostos na Tabela 6.12, considerandose $\beta=3$ e $\sigma=0,08$.

Tabela 6.14 - Fatores de segurança para o método de Aoki-Veloso, em função do resultado de K na obra e da precisão intra-canteiro, considerando-se uma prova de carga $(n=1)$ e $\beta=3$.

Tabela 6.15 - Fatores de segurança para o método de Aoki-Veloso, em função da média dos valores de K para duas provas de carga e da precisão intra-canteiro.

Tabela 6.16 - Variação de FS com a precisão intra-canteiro e com o valor de Kmed para o método de A\&V, considerando-se a execução de 2 provas de carga dinâmicas. 
Tabela 6.17 - Variação de FS com a precisão intra-canteiro e com o valor de Kmed para o método de A\&V, considerando-se a execução de 3 provas de carga dinâmicas.

Tabela 6.18 - Variação de FS com a precisão intra-canteiro e com o valor de Kmed para o método de A\&V, considerando-se a execução de 4 provas de carga dinâmicas.

Tabela 6.19 - Variação de FS com Kmed e com o tipo de prova, considerando-se a realização de 2 ensaios de carregamento dinâmico e $\sigma=0,08$ (alta precisão). Os informes relativos à variável Pdin/Pestat são decorrentes dos bancos de dados de Paikowsky e Gates, sintetizados em McVay et al (2000).

Tabela 6.20 - Variação de FS com Kmed e com o tipo de prova, considerando-se a realização de 2 ensaios de carregamento dinâmico e $\sigma=0,15$ (média precisão). 


\section{LISTA DE SÍMBOLOS}

\begin{tabular}{|c|c|}
\hline $\mathrm{K}$ & Fator de viés \\
\hline $\mathrm{k}$ & Particular realização da variável $\mathrm{K}$ \\
\hline $\mathrm{R}$ & Logaritmo do fator de viés \\
\hline $\mathrm{r}$ & Particular valor da variável $R$ \\
\hline Pobs & Capacidade de carga medida (observada) \\
\hline Pprev & Capacidade de carga prevista \\
\hline $\mathrm{G}(\mathrm{X})$ & Função de desempenho ou função Estado Limite \\
\hline $\mathrm{X}$ & Vetor de variáveis básicas \\
\hline $\mathrm{x}_{1}, \mathrm{x}_{2}, \ldots, \mathrm{x}_{\mathrm{n}}$ & Variáveis básicas \\
\hline $\mathrm{x}_{1, \mathrm{extr}}, \mathrm{x}_{2, \mathrm{extr}}, . ., \mathrm{x}_{\mathrm{n}, \mathrm{extr}}$ & Valores extremos das variáveis básicas determinantes da resistência \\
\hline $\mathrm{y}_{1, \mathrm{extr}}, \mathrm{y}_{2, \mathrm{extr}}, . ., \mathrm{y}_{\mathrm{m}, \mathrm{extr}}$ & Valores extremos das variáveis básicas determinantes da solicitação \\
\hline$Z_{\mathrm{R}}$ & Variável aleatória resistência \\
\hline$Z_{S}$ & Variável aleatória solicitação \\
\hline$\phi, \gamma$ & Fatores de ponderação da resistência e solicitação, respectivamente \\
\hline $\mathrm{R}_{\mathrm{n}}$ & Resistência nominal da estaca \\
\hline Q & Solicitações \\
\hline $\mathrm{Rk}, \mathrm{Sk}$ & Resistência e solicitação características \\
\hline$\overline{\mathrm{R}}, \overline{\mathrm{S}}$ & Resistência e solicitação médias \\
\hline $\mathrm{z}_{\alpha}$ & Constante, função do nível de significância. \\
\hline $\mathrm{V}_{\mathrm{R}}, \mathrm{V}_{\mathrm{S}}$ & Coeficiente de variação da resistência e solicitação. \\
\hline $\mathrm{M}_{\mathrm{R}, \mathrm{S}}\left(\mathrm{Z}_{\mathrm{R}}, \mathrm{Z}_{\mathrm{S}}\right)$ & Função Margem de Segurança \\
\hline $\mathrm{E}[]$. & Esperança matemática \\
\hline$\sigma^{2}[\cdot]$ & Variância \\
\hline$\sigma[]$. & Desvio-padrão \\
\hline$\beta$ & Índice de confiabilidade \\
\hline FS & Fator de segurança central \\
\hline $\mathrm{Pc}$ & Confiabilidade \\
\hline$P_{f}$ & Probabilidade de ruína \\
\hline $\mathrm{f}_{\mathrm{RS}}\left(\mathrm{Z}_{\mathrm{R}}, \mathrm{Z}_{\mathrm{S}}\right)$ & Função densidade conjunta das variáveis resistência e solicitação \\
\hline
\end{tabular}


$f_{R}, f_{S}$

$\mathrm{F}_{\mathrm{S}}($.

D

A, B

$\theta$

$\mathrm{P}^{\prime}[\theta]$

$\mathrm{P}^{\prime \prime}[\theta]$

$f^{\prime}[\theta]$

$f^{\prime \prime}[\theta]$

$\mathrm{Z}_{\mathrm{k}}$

$\mathrm{P}\left[\mathrm{z}_{\mathrm{k}} \mid \theta\right]$

$\mathrm{L}\left(\theta \mid \mathrm{z}_{\mathrm{k}}\right)$

$\mathrm{N}$

h

$v^{\prime}, v^{\prime}$

v", v"

$\mu$

$\mu^{\prime}, \mu^{\prime \prime}$

n

n'

n"

$\mathrm{m}_{\mathrm{R}}$

$\mathrm{S}^{2} \mathrm{R}$

$\mathrm{H}$

$\mathrm{r}_{\mathrm{o}}$

P DINÂMica, Pdin

Pestática, Pestat
Funções densidade de probabilidade da resistência e solicitação

Função distribuição da variável solicitação

Domínio de falha

Eventos quaisquer.

Parâmetro geotécnico

Probabilidade anterior do parâmetro $\theta$

Probabilidade posterior do parâmetro $\theta$

Densidade anterior do parâmetro $\theta$

Densidade posterior do parâmetro $\theta$

Vetor representativo das informações decorrentes da amostragem

Verossimilhança

Função de verossimilhança

Constante de normalização

Precisão intra-canteiro

Parâmetros da Função Gama anterior

Parâmetros da Função Gama anterior

Valor médio da variável $\mathrm{R}$

Média anterior e posterior de $\mathrm{R}$

Tamanho da amostra

Tamanho equivalente da amostra para a media de $\mathrm{R}$

Tamanho da amostra posterior

Média amostral da variável $\mathrm{R}$

Variância amostral de R

Parâmetro da distribuição t-Student

Valor particular de R, para um dado índice de confiabilidade

Capacidade de carga obtida por ensaio dinâmico.

Capacidade de carga obtida por prova de carga estática 


\section{LISTA DE SIGLAS}

\begin{tabular}{ll} 
EOD & End of Driving. \\
BOR & Beginning of Restrike. \\
CAPWAP & Case Pile Wave Analysis Program \\
ALARP & As low as reasonably possible \\
ANCOND & Australian National Committee on Large Dams \\
LQI & Life Quality Index \\
PIB & Produto Interno Bruto \\
FOSM & First Order Second Moment \\
LRFD & Load and Resistance Factor Design \\
FDP & Função Densidade de Probabilidades \\
MPC & Método Probabilista Condicionado \\
MPP & Método Probabilista Puro \\
PDA & Pile Driving Analyser \\
ENR & Engineering News Record \\
FDOT & Florida Department of Transportation \\
SV & Stresswave Conferences \\
\hline
\end{tabular}




\section{INTRODUCÃ̃}

Toda estrutura concebida pelo homem deve atender a requisitos pré-estabelecidos, sejam eles relacionados ao conforto, durabilidade, estética, aspectos econômicos, dentre outros.

Decerto, um dos requisitos mais importantes de uma estrutura é a sua segurança contra comportamentos indesejáveis, em particular contra o colapso. A despeito da presumida "segurança absoluta", perseguida nas diversas instâncias da sociedade, o fato é que colapsos continuarão ocorrendo, sejam por erros humanos ou por fatos tão extraordinários que, convenientemente, são imaginados como decorrentes de caso fortuito, como "Acts of God", a exemplo das rupturas da barragem de Malpasset na França (1959), da ponte de Tacoma nos Estados Unidos (1940) e do Edifício Itália, em São José do Rio Preto (1997) (Stucchi, 2002).

Inclusive, a respeito da ruptura da barragem de Malpasset, mostra-se cabente no presente contexto transcrever um trecho da solidária carta de Terzaghi enviada ao engenheiro André Coyne (1891-1960), autor do projeto, na qual afirmou que:

[...] Conhecendo-o bem há muitos anos, estou seguro de que a ruptura não decorreu de um erro de seu projeto. Ela servirá, portanto, ao propósito vital de destacar um fator que não recebeu no passado atenção merecida. Não lhe cabe culpa por terem as implicações desse fator se manifestado numa obra sua, pois que a ocorrência de falhas nas fronteiras de nosso conhecimento é governada por leis estatísticas que se manifestam ao acaso. Nenhum de nós a elas está imune [...]

Se é certo que a segurança é um dos principais requisitos de qualquer obra de engenharia geotécnica, já não há consenso na forma de introduzi-la no projeto, nem tampouco sobre a sistemática de como informações adicionais obtidas na obra podem reduzir a incerteza inerente à qualquer projeto geotécnico.

O binômio segurança versus incerteza tem desafiado a comunidade geotécnica desde tempos pretéritos. Terzaghi (1929) já enfatizava a importância de pequenos detalhes geológicos na concepção de obras de engenharia geotécnica, ou seja, aspectos que divergem 
de comportamentos esperados ou médios. Na época, Terzaghi recomendou que os projetistas adotassem a situação mais desfavorável (Christian, 2004). Mais tarde, diante da invencível inviabilidade de se conceber obras que atendessem sempre às condições mais desfavoráveis, o próprio Terzaghi propôs a conhecida abordagem do "learn as you go" como forma de se incorporar a incerteza no projeto e construção de forma incremental.

A questão da incerteza no projeto geotécnico foi novamente trazida à baila na célebre Terzaghi Lecture ministrada por Casagrande (1965), da qual restaram, como pontos principais, que os riscos são inerentes à qualquer projeto e que devem ser explicitamente reconhecidos, como forma de encontrar um equilíbrio entre economia e segurança.

Posteriormente, em sua magistral Rankine Lecture, Peck (1969) introduziu as bases do que se conhece por "observational method", um dos marcos referenciais da Engenharia Geotécnica, reconhecendo explicitamente a incerteza dos modelos.

O determinismo inicialmente prevalecente tem sido gradualmente substituído por métodos mais racionais de introdução da segurança, como os fatores de segurança parciais, preconizados pelos Eurocódigos. Porém, inobstante à desejável racionalização, a quase totalidade das normas técnicas vigentes, inclusive a norma brasileira de fundações -NBR 6122, carece de fundamentação conceitual inequívoca, a qual só pode ser obtida mediante a quantificação das incertezas pela consideração de uma probabilidade de ruína ou de algum índice a ela associada.

Enquanto que os demais campos colaterais da engenharia já fazem uso dos conceitos de probabilidade aplicada há meio século, em obras civis, embora se reconheça implicitamente que à toda estrutura está associada uma probabilidade de ruína não nula, não há a incorporação explícita disso em projeto de modo incontroverso, qual seja, pela consideração expressa de um valor numérico para a dita probabilidade de ruína.

O evento ruína normalmente constitui-se um evento raro, ou seja, ao evento ruína estão associadas pequenas probabilidades. Assim sendo, a proposição de um modelo probabilista com fulcro na inferência clássica, calcada na teoria da amostragem, implicaria na necessidade de amostras com tamanhos economicamente inviáveis, haja vista que toda a informação seria obtida tão somente da própria amostra. Ademais, a inferência clássica 
também se depara com outro óbice importante na avaliação probabilista da segurança de obras geotécnicas: cada obra de engenharia geotécnica é, no senso estrito, um protótipo único.

À luz dessa realidade, fica evidenciada a vantagem da utilização da Estatística Bayesiana na avaliação da segurança de obras geotécnicas, dada a possibilidade de se considerar o grau de convicção prévio acerca do parâmetro a ser estimado, informação essa aglutinada pela distribuição a priori do parâmetro, de caráter subjetivo. É essa distribuição apriorística que permite a inclusão de argumentos físico-dedutivos em modelos de probabilidade.

No particular caso de fundações em estacas de deslocamento, os métodos probabilistas, e muito particularmente aqueles baseados na Estatística Bayesiana, têm se mostrado muito úteis — internacionalmente e em diversos contextos — para a incorporação das incertezas intervenientes no projeto e execução, mediante combinação de informações anteriores (previsões de capacidade resistente) com aquelas derivadas de experimentação insitu, tais como provas de carga, medidas de nega e repique, com o fito de promover a atualização racional dos indicadores de segurança.

A instrumentação é o meio pelo qual o engenheiro verifica a aderência do modelo de cálculo adotado em relação às condições reais da obra, observando, dentro de uma faixa coerente de valores, se os resultados verificados na obra se coadunam com aqueles obtidos no modelo. Certamente são de grande valia para obras de engenharia geotécnica, em particular de fundações, por permitir a reavaliação da segurança quando da obra implantada.

Assim sendo, o presente trabalho tem como objetivo a apresentação dos conceitos da inferência bayesiana e sua utilização na incorporação dos resultados de provas de carga, para avaliação da segurança de estacas de deslocamento. Importante salientar que, muito embora o presente estudo tenha por objeto as estacas de deslocamento, a metodologia apresentada pode ser utilizada, sem prejuízo, a outros tipos de estaca.

O trabalho ora proposto será restrito à análise de estacas isoladas, não objetivando o estudo de grupos de estacas, uma vez que raramente são feitas provas de carga sobre o grupo. Tal fato não diminui a generalidade dos métodos apresentados, uma vez que normalmente as normas estabelecem fatores de segurança para estacas individuais. 
No capítulo 2 são apresentados os fatores determinantes no estabelecimento dos critérios de segurança.

O capítulo 3 apresenta os diversos métodos de introdução da segurança, dispostos de tal forma que se vislumbre a ordem evolutiva dos mesmos.

O capítulo 4 apresenta os conceitos da inferência bayesiana e seu uso na atualização da segurança de estacas, posteriormente à execução de provas de carga.

No capítulo 5 segue exposta uma metodologia para proposição de fatores de segurança, ainda no âmbito da inferência bayesiana, em função do tipo de prova de carga que se realiza: se provas de carga estáticas ou ensaios de carregamento dinâmico.

No capítulo 6 apresenta-se a aplicação das formulações bayesianas a quatro exemplos elucidativos, discutindo-se os resultados obtidos.

O capítulo 7 apresenta as conclusões alcançadas e explicita propostas de pesquisas futuras. 


\section{FATORES DETERMINANTES NO ESTABELECIMENTO DE CRITÉRIOS DE SEGURANCAA}

\subsection{A INCERTEZA}

A discussão sobre a segurança das fundações somente se justifica em razão das incertezas intervenientes nas diversas fases que envolvem uma obra de engenharia geotécnica.

Imagine-se uma situação hipotética na qual a máxima carga axial de compressão atuante sobre uma estaca fosse de $800 \mathrm{kN}$ e a capacidade de carga fosse, invariavelmente, $1000 \mathrm{kN}$. À luz dessa situação, poderia-se consignar, em termos de Estado Limite Último, que a estaca estaria sempre segura, sendo improcedente qualquer discussão a respeito de eventual ruptura.

No entanto, as incertezas existentes sobre as solicitações e particularmente sobre resistências fazem com que seja necessária uma distância adequada entre valores médios ou então valores característicos dessas variáveis (Aoki, 2002).

Deste modo, fica evidenciado que a adoção de um fator de segurança já é o reconhecimento, ao menos implicitamente, da incerteza existente nos parâmetros de projeto.

Os tipos de incerteza que determinam os critérios de segurança são bem discriminados por Hachich (1998b), a saber: 


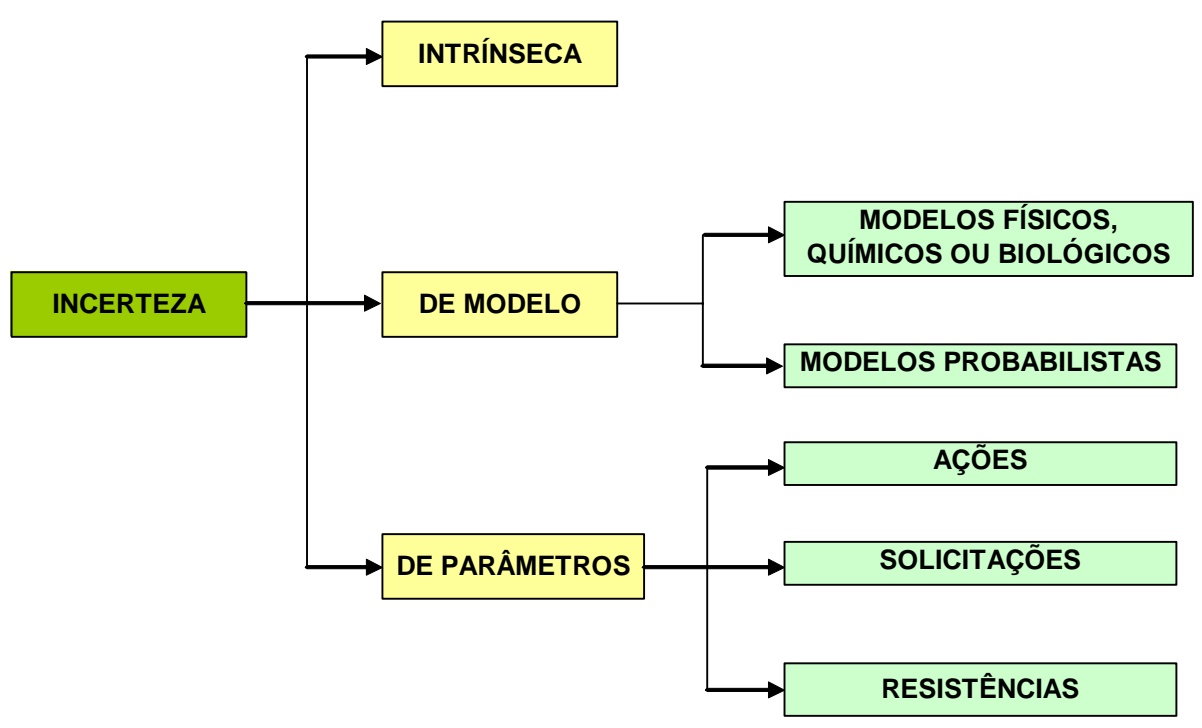

Figura 2.1 - Tipos de incerteza (Hachich, 1998b).

Cada um dos tipos de incerteza acima distinguidos passa a ser discutido a seguir.

\subsubsection{Incerteza intrínseca}

A incerteza intrínseca (também conhecida como natural ou ainda fundamental) é própria do caráter aleatório dos fenômenos, e por isso é dita irredutível. É aquela que melhor caracteriza os fenômenos aleatórios, ou seja, fenômenos que, se possíveis de serem repetidos sob as mesmas condições iniciais, podem conduzir a resultados distintos.

Um exemplo de fenômeno tipicamente aleatório é o lançamento de um dado. Mesmo que tenhamos um histórico dos resultados de lançamentos não é possível afirmar os resultados dos lançamentos futuros, sendo possível, tão somente, fazer juízos probabilistas.

Mas uma questão que urge é: qual seria a origem da aleatoriedade dos fenômenos? Demókritos, um conhecido filósofo grego, postulou que a natureza é essencialmente determinista, ou seja, é possível explicar os porquês de uma dada estrutura e prever ou controlar qualquer fenômeno natural desde que se tenha informação suficiente acerca do aludido fenômeno. Sob este prisma, conclui-se que o único aleatório que pode existir é o aleatório subjetivo, entendido como sendo apenas um outro nome para a falta de conhecimento da natureza, das causas que regem determinado fenômeno. 
Epikurus, filósofo opositor das idéias de Demókritos, defendia a aleatoriedade objetiva ou ausência de causas, ou seja, para ele a aleatoriedade estava associada a estruturas e processos que não são determinados por nenhuma causa. Sob este aspecto, seria impossível descrever completamente o fenômeno.

Laplace, na sua famosa obra "Theorie Analytique des Probabilités". defendeu claramente as idéias postuladas por Demókritos, afirmando o seguinte:

[...] se imaginarmos uma inteligência capaz de conhecer todas as forças que animam a Natureza e conhecer o estado de todas as partes da qual ela é composta - uma inteligência suficientemente grande para analisar todos esses dados - então ela seria capaz de numa fórmula expressar o movimento dos maiores corpos do universo, bem como o dos menores átomos. Para tal inteligência nada seria incerto e o futuro, bem como o passado, estariam abertos a seus olhos.

Para Laplace, inobstante ao fato de a natureza ser determinista, ela se comportaria como "um relógio de tamanho e complexidade gigantescos", de tal sorte que seria conveniente, mas não estritamente necessário, tratar alguns fenômenos naturais como aleatórios subjetivos.

O físico Albert Einstein também comungou com as idéias de Laplace quando proferiu sua célebre frase "Deus não joga dados com o Universo".

Mais tarde, o próprio Einstein, quando do desenvolvimento das pesquisas para sua "Teoria Unificadora", se viu obrigado a aceitar a hipótese de que, de fato, existem alguns fenômenos que não podem ser cabalmente explicados, reconhecendo a existência da aleatoriedade objetiva na natureza.

\subsubsection{Incerteza de modelo}

\subsubsection{Modelo de previsão da capacidade de carga}

A concepção de obras de engenharia geotécnica comumente passa pela idealização da estrutura real, com a finalidade de se prever as respostas futuras da mesma quando em

\footnotetext{
${ }^{1}$ LAPLACE, P.S. Theorie Analytique des Probabilités, 1812.
} 
serviço.

Essa idealização da estrutura real se dá na forma de modelos, os quais podem ser entendidos como um conjunto de hipóteses estabelecidas a priori sobre o comportamento de um fenômeno, com base em teorias tais como a da elasticidade, plasticidade ou do equilíbrio limite. A informática tem permitido atualmente ao engenheiro trabalhar com modelos cada vez mais sofisticados, buscando representar o comportamento real da estrutura da maneira mais fidedigna possível.

Inobstante à adoção de modelos que melhor tentem representar a realidade, os resultados obtidos da simulação raramente se coadunam com aqueles observados. De Mello et al (2002) têm alertado para as "espantosamente frustrantes" conclusões dos desafios previsão contra comportamento. Segundo aqueles autores, nossa missão não é a de "acertar na mosca o que vai acontecer em um caso único" mas sim, por segurança, o que não vai acontecer (comportamento indesejado ou ruptura), acoplado ao desejo ou necessidade de conseguir tal feito com um mínimo custo.

A incerteza de modelo fica mais evidente quando consideramos a realidade inexorável de que cada obra é um protótipo único e, assim sendo, um determinado modelo só pode fornecer, quando muito, um resultado próximo daquele verdadeiramente observado na estrutura real.

Essa realidade sob o enfoque probabilista nos conduz à conclusão de que eventual probabilidade de ruína calculada com base em um determinado modelo não pode ser simplesmente denotada por P[ruína], mas sim P[ruína | modelo] (leia-se: probabilidade de ruína dado um modelo), uma vez que a probabilidade está condicionada ao modelo adotado. Hachich (1998b) informa que as condicionantes são todas as hipóteses do modelo escolhido, apresentando um exemplo onde a probabilidade de ruína, calculada considerando-se um modelo de equilíbrio limite e superfície circular, seria denotada por P[ruína | equilíbrio limite, superfície circular].

Baecher e Christian (2003), estudando estabilidade de taludes, destacaram três fontes de incerteza relacionadas ao modelo: 
a) Efeitos 3-D existentes na estrutura real, modelada como 2-D;

b) Falhas na obtenção da superfície crítica;

c) Erros numéricos e arredondamentos.

Os referidos autores informam que os fatores supra expostos introduzem, em conjunto, uma incerteza sistemática da ordem de $7 \%$.

Cumpre salientar que os fatores retro apresentados, particularmente os fatores (a) e (b), somente têm sentido em um modelo teórico, oriundo de aplicações de conceitos de física. $\mathrm{Na}$ prática do projeto de fundações em estacas há intensa utilização de modelos semiempíricos (como por exemplo os métodos de Aoki-Veloso e Decourt-Quaresma), em detrimento dos modelos teóricos, os quais, inclusive, muitas vezes são tidos como não confiáveis (Cintra e Aoki, 1999).

Por esta razão a incerteza de modelo no projeto de fundações em estacas tem sido considerada mediante o fator de viés ("bias factor”), o qual vem definido conforme segue (McVay et al, 2000):

$$
K=\frac{P_{\text {obs }}}{P_{\text {prev }}}
$$

Onde $\mathrm{K}=$ fator de viés, Pobs é o valor da resistência medida (no estudo dos autores, é a resistência obtida pela aplicação do método de Davisson ao ensaio de prova estática) e Pprev a resistência prevista por qualquer dos métodos disponíveis (métodos dinâmicos, fórmulas dinâmicas ou fórmulas estáticas).

Ang e Tang (1984) expõem que o viés pode surgir de fatores não contemplados no modelo, os quais podem decorrer em resultados tendenciosos, em uma ou outra direção.

A tabela a seguir, extraída de McVay et al (2000) apresenta os fatores de viés para diversos métodos de previsão da capacidade de carga. 


\begin{tabular}{|c|c|c|}
\hline Categoria do Método & Método de Previsão & Fator de viés ("bias factor") \\
\hline \multirow{8}{*}{$\begin{array}{l}\text { MÉTODOS } \\
\text { DINÂMICOS }\end{array}$} & CAPWAP (EOD ${ }^{1}$, base de dados da Flórida) & 1,597 \\
\hline & CAPWAP (BOR ${ }^{2}$, base de dados da Flórida) & 1,260 \\
\hline & CAPWAP (EOD, base de dados nacional) & 1,626 \\
\hline & CAPWAP (BOR, base de dados nacional) & 1,158 \\
\hline & "Energy Approach" (EOD, base de dados da Flórida) & 1,110 \\
\hline & "Energy Approach" (BOR, base de dados da Flórida) & 0,836 \\
\hline & "Energy Approach" (EOD, base de dados nacional) & 1,084 \\
\hline & "Energy Approach" (BOR, base de dados nacional) & 0,785 \\
\hline \multirow{2}{*}{$\begin{array}{l}\text { FÓRMULAS } \\
\text { DINÂMICAS }\end{array}$} & Gates (EOD, base de dados da Flórida) & 1,742 \\
\hline & Gates (EOD, base de dados nacional) & 1,787 \\
\hline \multirow{8}{*}{$\begin{array}{l}\text { MÉTODOS } \\
\text { ESTÁTICOS }\end{array}$} & Método Alpha, argila tipo $\mathrm{I}^{3}$ & 1,104 \\
\hline & Método Alpha, argila tipo II $^{4}$ & 2,340 \\
\hline & Método Beta & 1,032 \\
\hline & Cone elétrico & 1,030 \\
\hline & Método Lambda, argila tipo I & 1,020 \\
\hline & Método Lambda, argila tipo II & 0,840 \\
\hline & SPT - Método de Meyerhof & 1,300 \\
\hline & SPT - Método de Schmertmann & 1,371 \\
\hline
\end{tabular}

Tabela 2.1 - Fator de viés para diversos métodos de previsão da capacidade de carga (McVay et al, 2000).

Hachich (1998b) informa que a incerteza de modelo também surge na verificação de alguns estados limites de utilização, tal como na limitação de deslocamentos de estruturas de arrimo e valas escoradas, quando aplicamos coeficientes globais ou parciais sobre os resultados decorrentes da adoção de um modelo de equilíbrio limite, o qual não explicita o campo de deslocamentos. Assim sendo, essa inexatidão tem que ser compensada na verificação da segurança da estrutura, pela adoção de coeficientes de segurança que a contemplem, além da variabilidade de ações e resistências.

\subsubsection{Modelo probabilista}

Uma outra classe de incerteza de modelo a ser posteriormente discutida com profundidade é a incerteza relacionada ao modelo probabilístico adotado.

Inevitavelmente, para o cálculo da probabilidade de ruína, há a necessidade de se considerar um dos vários modelos probabilísticos disponíveis (distribuição Normal, Lognormal, Extremos, Weibull, entre outras). Uma vez feita essa escolha, as probabilidades calculadas também estarão condicionadas ao modelo probabilista adotado.

A escolha de um determinado modelo probabilista para representação de um fenômeno raramente pode ser feita com fulcro na observação do histograma de freqüências de rupturas de estruturas similares. Borges e Castanheta (1971) mostram que diversos modelos 
probabilistas apresentam funções densidade parecidas nos trechos centrais, porém muito diferentes nas caudas, como mostra a figura a seguir:
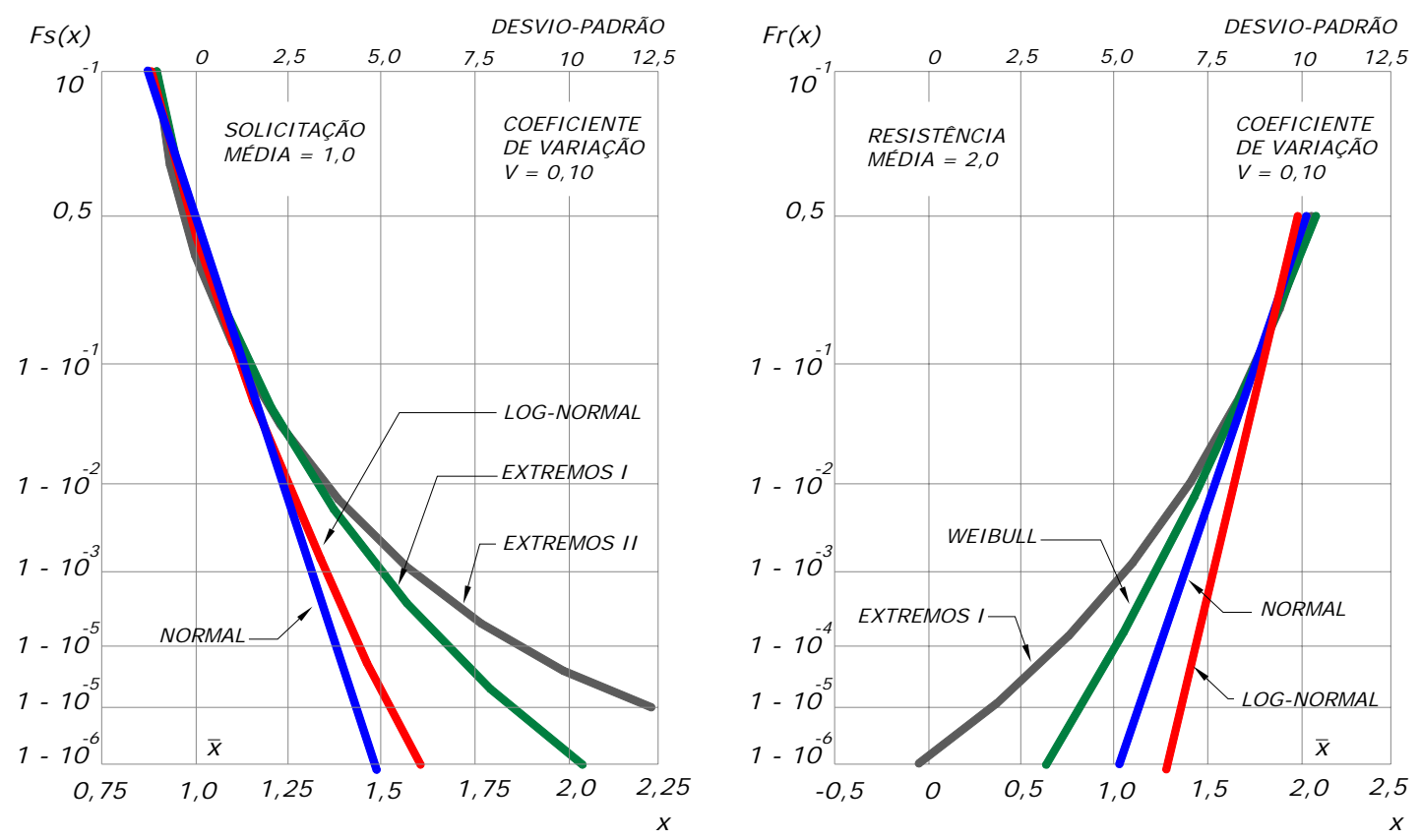

Figura 2.2 - Variabilidade das caudas de algumas Funções Densidade de Probabilidade (Borges e Castanheta, 1971).

Por esta razão, a delimitação das caudas da função densidade de probabilidades com base na teoria da amostragem demandaria uma amostra de tamanho tal que tornaria a abordagem por freqüência economicamente inviável, em vista do fato de a ruína se constituir um evento raro.

Como será visto posteriormente, a adoção de um modelo probabilista deverá ter como fulcro argumentos subjetivos, sob a ótica da estatística bayesiana.

\subsubsection{Incerteza de parâmetros}

Normalmente, os parâmetros utilizados nos modelos, quer modelos teóricos, quer empíricos, são obtidos por meio de amostragem. Uma vez disponível uma amostra com os valores observados de um certo parâmetro, uma questão que surge naturalmente é qual o valor a ser adotado como representativo deste parâmetro, valor esse a ser utilizado posteriormente no modelo. Esse é um problema típico de inferência estatística, ou seja, com base em uma amostra de valores de um certo parâmetro pretende-se estimar qual seria o valor 
representativo desse parâmetro para todo o solo que compõe uma determinada obra.

Intuitivamente, quanto maior o número de elementos na amostra (ou quanto maior o número de ensaios), menor a incerteza sobre o valor do parâmetro a ser introduzido no modelo. Diz-se, portanto, que essa incerteza é redutível.

Num primeiro momento, somente medidas de tendência central (particularmente o valor médio) da amostra coletada bastavam para a caracterização do parâmetro, em vista do fato de que muitos fenômenos possuem um comportamento condicionado por médias.

Posteriormente, em virtude do desenvolvimento dos métodos de introdução de segurança, as medidas de dispersão (tais como o desvio-padrão e o coeficiente de variação) também se mostraram necessárias para subsidiar a escolha dos modelos probabilistas utilizados nas análises.

Cardoso (2002) apresenta faixas de valores para o coeficiente de variação das propriedades resistentes dos solos, com base em diversos autores.

\begin{tabular}{c|c|c}
\hline \multirow{2}{*}{ Parâmetro (X) } & Média - Xmed (kPa) & $\begin{array}{c}\text { Coeficiente de } \\
\text { Variação - V(X) (KPa) }\end{array}$ \\
\hline \multirow{2}{*}{$C_{u}$} & $50-150$ & $0,26-0,82$ \\
\cline { 2 - 3 } & $150-300$ & $0,19-0,66$ \\
\cline { 2 - 3 } & $>300$ & $0,13-0,0,53$ \\
\cline { 2 - 3 } & Todas as classes & $0,12-0,85(0,34)$ \\
\hline \multirow{2}{*}{$\phi$} & $<30^{\circ}$ & $0,10-0,22$ \\
\cline { 2 - 3 } & $30^{\circ}-40^{\circ}$ & $0,03-0,15$ \\
\cline { 2 - 3 } & Todas as classes & $0,05-0,25(0,13)$ \\
\hline $\operatorname{tg} \phi^{\prime}$ & & $0,07-0,15$ \\
\hline
\end{tabular}

Tabela 2.2 - Coeficiente de Variação [V(x)] das propriedades resistentes dos solos (Cardoso, 2002).

Baecher e Christian (2003) apresentam estimativas do coeficiente de variação de diversos testes in-situ, a saber: 


\begin{tabular}{|c|c|c|c|c|c|c|}
\hline \multirow[b]{2}{*}{ Teste } & \multirow[b]{2}{*}{ Sigla } & \multicolumn{5}{|c|}{ Coeficiente de Variação, COV (\%) } \\
\hline & & Equip. & Processo & Aleatório & Total & $\begin{array}{c}\text { Intervalo } \\
\text { mais provável }\end{array}$ \\
\hline $\begin{array}{c}\text { Teste de } \\
\text { penetração padrão }\end{array}$ & SPT & $5-75$ & $5-75$ & $12-15$ & $14-100$ & $15-45$ \\
\hline $\begin{array}{c}\text { Teste de } \\
\text { penetração de } \\
\text { Cone (mecânico) }\end{array}$ & MCPT & 5 & $10-15$ & $10-15$ & $15-22$ & $15-25$ \\
\hline $\begin{array}{c}\text { Teste de } \\
\text { penetração de } \\
\text { Cone (elétrico) }\end{array}$ & ECPT & 3 & 5 & $5-10$ & $8-22$ & $5-15$ \\
\hline Vane test & VST & 5 & 8 & 10 & 14 & $10-20$ \\
\hline $\begin{array}{c}\text { Teste } \\
\text { dilatométrico }\end{array}$ & DMT & 5 & 5 & 8 & 11 & $5-15$ \\
\hline
\end{tabular}

Tabela 2.3 - Incerteza associada à cinco testes comumente efetudos in-loco (Baecher e Christian, 2003).

Modelos mais realistas demandam o conhecimento, além dos valores médios e das medidas de dispersão, das correlações espaciais dos parâmetros em uma dada obra, com base na premissa de que "elementos de solo vizinhos tendem a ter propriedades mais parecidas". Esse tipo de incerteza também é redutível, haja vista que uma amostra de tamanho suficiente pode fornecer informações acerca da estrutura de correlação espacial subjacente.

\subsection{OS ERROS HUMANOS}

Os erros humanos certamente são dominantes na concorrência de colapsos de estruturas, e por isso devem ser minimizados (De Mello et al, 2002). Diante dessa realidade, tais erros têm sido freqüentemente abordados em trabalhos aplicados, com diversos graus de refinamento. Inobstante serem objeto de estudos recentes, os erros humanos ainda não são bem compreendidos. 
Os meios mais efetivos pelos quais os erros humanos podem ser controlados são a checagem dos projetos por entidades independentes e procedimentos de controle de qualidade. Tais procedimentos, embora sejam de fato importantes, não são, inequivocadamente, livres de erros. Madsen et al (1986) citam um exemplo hipotético onde um determinado projeto está sendo checado por um examinador independente. Se boa parte deste projeto foi competentemente executada, o examinador tende a perder efetividade na sua análise crítica, tornando-se menos diligente e mais susceptível de cometer, ele mesmo, um erro de checagem.

Estes mesmos autores sugerem que a distribuição dos erros em determinado projeto segue uma família de curvas normais, todas com média zero, e variâncias dependentes do tempo de checagem, conforme explicita a expressão 2.2 a seguir:

$$
P_{E}(x, t)=\frac{1}{\sqrt{2 \pi} \cdot s} \cdot \exp \left[-\frac{x^{2}}{2 s^{2}} \cdot\left(1+\frac{t}{t_{0}}\right)\right]
$$

onde:

$\mathrm{P}_{\mathrm{E}}(\mathrm{x}, \mathrm{t})=$ função densidade da distribuição dos erros, para uma dada magnitude " $\mathrm{x}$ " de erro e após um tempo " $\mathrm{t}$ " de checagem;

$\mathrm{S}=$ desvio-padrão inicial dos erros (para $\mathrm{t}=0)$;

$\mathrm{t}_{0}=$ constante;

Fazendo:

$$
P_{E}(t)=\left(1+\frac{t}{t_{0}}\right)^{-1 / 2}
$$

e

$$
\sigma_{\mathrm{F}}=\mathrm{s} \cdot \mathrm{P}_{\mathrm{E}}(\mathrm{t})
$$

a expressão 2.2 pode ser reescrita da seguinte forma:

$$
\mathrm{P}_{\mathrm{E}}(\mathrm{x}, \mathrm{t})=\mathrm{P}_{\mathrm{E}}(\mathrm{t}) \cdot \mathrm{N}\left(0,{\sigma_{\mathrm{F}}}^{2}\right)
$$

onde: 
$\mathrm{P}_{\mathrm{E}}(\mathrm{t})=$ probabilidade da ocorrência de erro após um tempo $\mathrm{t}$ de checagem;

$\mathrm{N}\left(0, \sigma_{\mathrm{F}}^{2}\right)=$ distribuição normal de probabilidades, com média zero e variância $\sigma_{\mathrm{F}}^{2}$;

A equação 2.5 explicita claramente que os erros, em um determinado tempo $t$ de checagem, seguem distribuição normal com média zero e desvio-padrão proporcional à probabilidade de erro nesse mesmo instante t. Paralelamente, a referida equação permite apurar o decremento exponencial da probabilidade de erro com o tempo de checagem.

Da equação 2.5 decorre o gráfico apresentado a seguir:

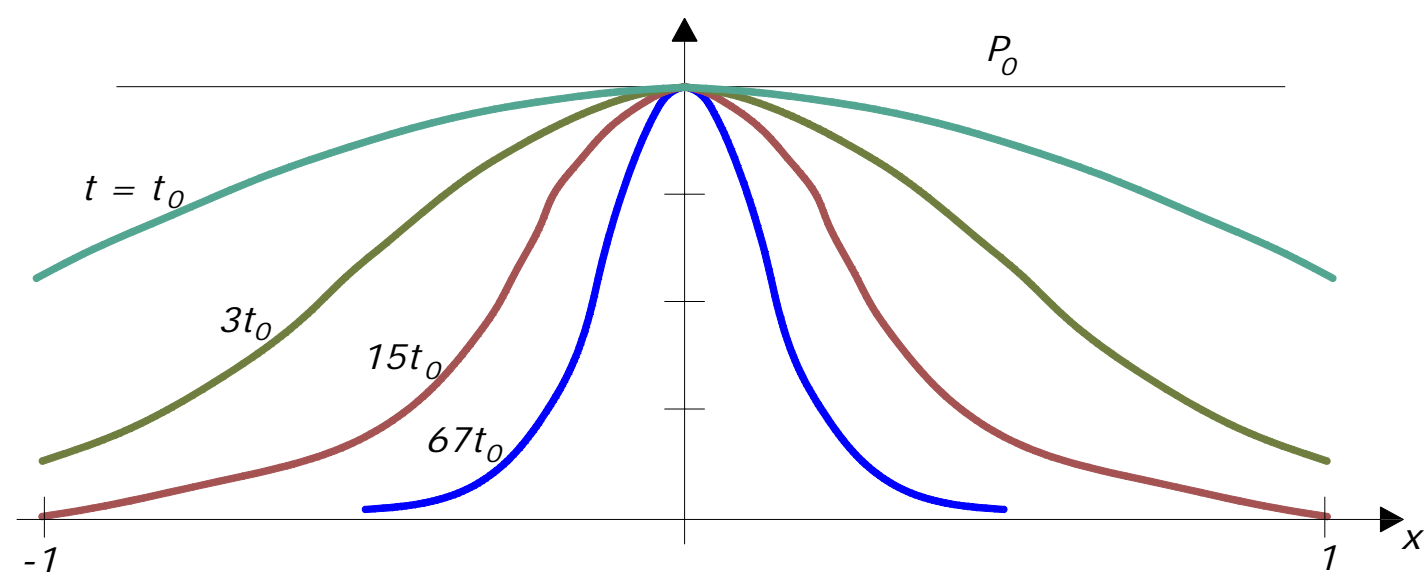

Figura 2.3 - Família de distribuições normais da magnitude do erro como função do tempo de inspeção (Madsen et al, 1986).

Do gráfico supra, conclui-se que quanto maior o tempo de checagem de determinado projeto, maior a probabilidade se encontrar erros com magnitudes próximas à zero, ou seja, as curvas normais são mais afiladas e se concentram em torno de zero.

Importante informar que esse modelo é eminentemente teórico, não tendo sido submetido à comprovação empírica.

Uma crítica que pode ser feita a esse modelo é que o mesmo não leva em conta a competência do verificador.

\subsection{AS CONSEQÜÊNCIAS DE UMA EVENTUAL RUÍNA}

A forma de se considerar as conseqüências de uma eventual ruína ainda é um dos pontos mais controversos da introdução da segurança no projeto. 
Os primeiros métodos de introdução da segurança, em particular aqueles baseados em um coeficiente de segurança único, não levavam em conta a "importância" da estrutura, representada pelas conseqüências de um colapso. Só com o advento do método semiprobabilístico é que as conseqüências da ruína foram explicitamente consideradas, através do "fator probabilístico".

A despeito do reconhecido avanço do método semi-probabilístico na consideração das conseqüências da ruína, o fator probabilístico tem sido proposto ainda de forma ad-hoc.

Invariavelmente, os métodos mais racionais de se considerar as conseqüências da ruína utilizam a probabilidade de sua ocorrência como parâmetro, de modo que são identificados dois critérios: ou se adota uma probabilidade de ruína prescrita, em função de riscos admitidos pela sociedade ou então uma probabilidade que maximiza uma utilidade (por exemplo, a economia por vida salva).

\subsubsection{Probabilidade de ruína prescrita:}

Segundo este critério, a probabilidade de ruína calculada é comparada com uma probabilidade de ruína prescrita, relacionada com o risco admitido pela sociedade.

Importante deliberar sobre do termo "risco admitido". Como assevera Christian (2004), se a sociedade pudesse ser consultada acerca dos riscos sob os quais aceitaria estar sujeita, possivelmente os valores informados seriam diferentes dos riscos sob os quais a sociedade está sujeita de fato, em valores deslocados para cenários mais seguros. Desta feita, o "risco admitido" não é o risco conscientemente aceito pela sociedade, mas sim um risco implicitamente aceito, ao menos por parte da sociedade.

Assim, cabe ao engenheiro projetar e construir estruturas que apresentem diminutas probabilidades de ruína, comparáveis àquelas probabilidades de riscos inevitáveis ligados a outras atividades humanas, como vaticina De Zagottis, 1974. O referido autor entende ser admissível para estruturas probabilidades de ruína da ordem de $10^{-3}$ e $10^{-6}$, fundamentando sua assertiva com base na probabilidade de uma pessoa em perfeitas condições físicas e mentais falecer antes de terminar o dia $\left(\mathrm{P}=10^{-5}\right)$ e na probabilidade de uma pessoa ser morta 
em um acidente de trânsito $(\mathrm{P}=0,7 \%)$.

Atualmente, para efeito de políticas públicas, têm sido muito utilizados os diagramas "F-N", que relacionam a freqüência da ocorrência de acidentes com $\mathrm{N}$ ou mais vítimas (denotada por $\mathrm{F}$ ) com o número de fatalidades propriamente dito $(\mathrm{N})$, como apresentam Baecher e Christian, 2003.
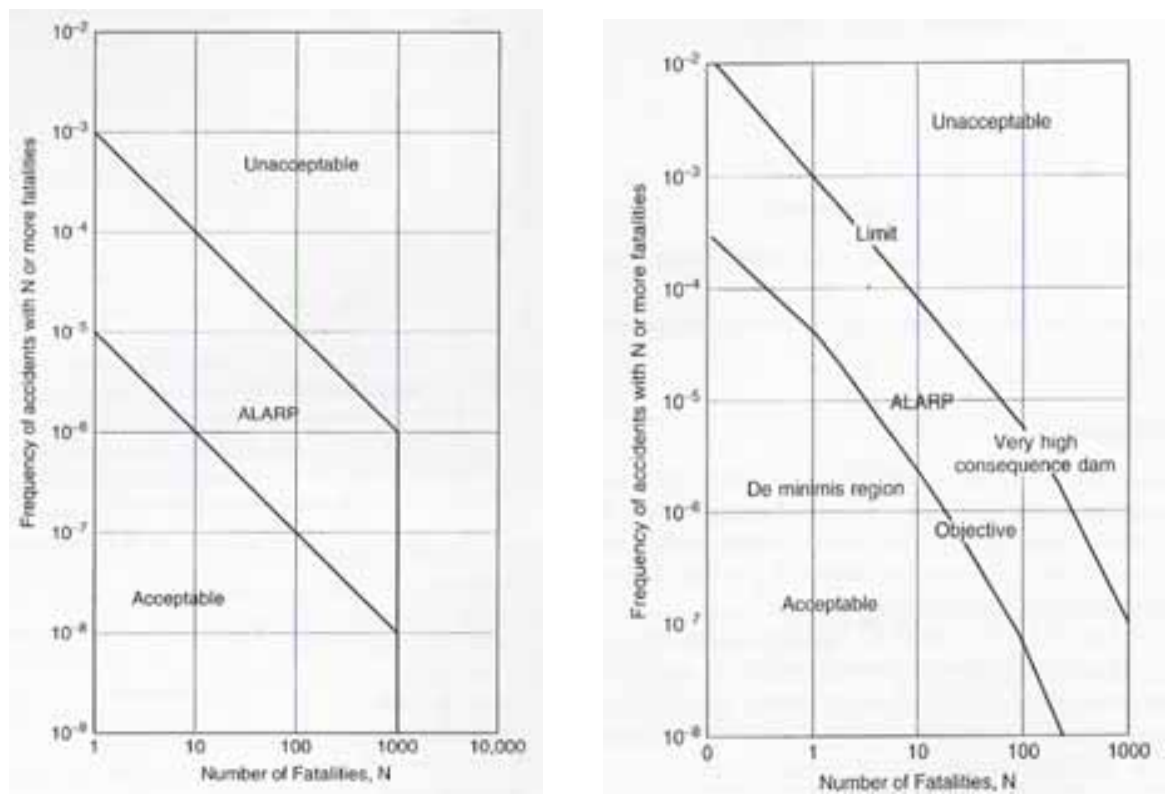

Figura 2.4 - Riscos admitidos pela sociedade, de acordo com o Departamento de Planejamento de Hong Kong (à esquerda) e com o ANCOLD (Baecher e Christian, 2003).

Normalmente, os gráficos F-N distinguem três regiões, quais sejam: a região de risco aceitável, a região de risco inaceitável e uma região intermediária, denotada por ALARP (“As low as reasonably possible"), região essa onde se deseja riscos tão baixos quanto possíveis. Assim sendo, ALARP pode ser entendida como uma região onde os riscos são marginalmente aceitos.

A Figura 2.5 (Whitman, 1984) apresenta a probabilidade de ruína aceita e marginalmente aceita em função das conseqüências da ruína, para diversos tipos de estruturas. 


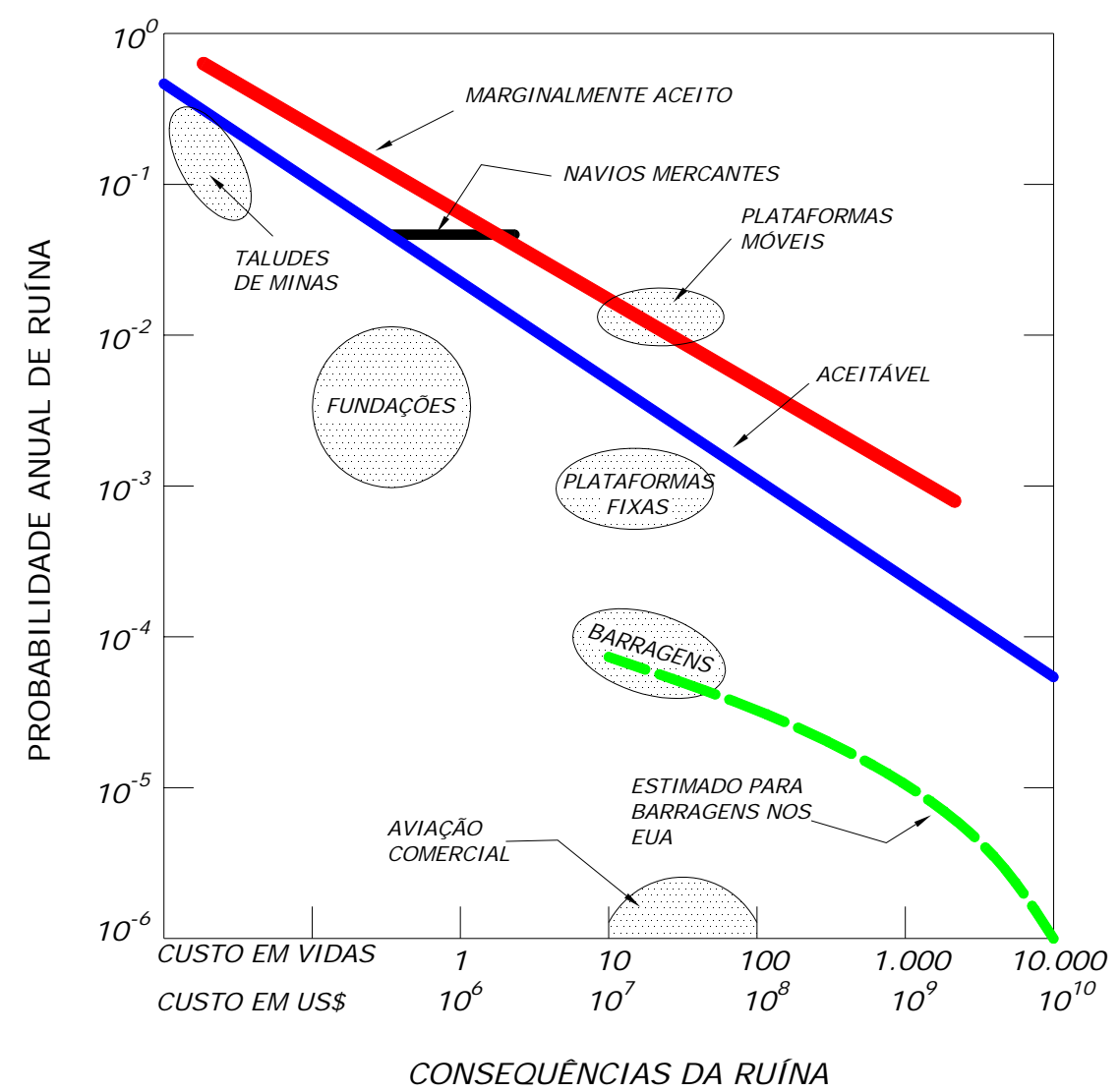

Figura 2.5 - Probabilidade de ruína para algumas estruturas, em função das conseqüências da ruptura (Whitman, 1984).

\subsubsection{Maximização da utilidade}

A maximização da utilidade esperada é tida por muitos autores como o estágio final da evolução dos critérios de segurança nas obras de engenharia (Hachich, 1998a; Madsen et al, 1986).

Segundo esse critério, a probabilidade de ruína não é prescrita em função de riscos admitidos na sociedade, mas deduzida em função dos custos relacionados à uma eventual ruptura, dedução esta feita com fulcro na Análise de Decisões.

Hachich (1998b) informa que a maximização da utilidade esperada permite acomodar comportamentos não neutros ao risco (tais como aversão ou propensão ao risco) e conseqüências não mensuráveis monetariamente. Muitos trabalhos preconizam que a função objetivo a ser considerada no cálculo da probabilidade de ruptura é da seguinte forma: 
$\mathrm{C}_{\mathrm{E}}=\mathrm{C}_{\mathrm{I}}+\sum \mathrm{P}_{\mathrm{i}} \cdot \mathrm{C}_{\mathrm{i}}$

onde:

$\mathrm{C}_{\mathrm{E}}=$ custo esperado;

$\mathrm{C}_{\mathrm{I}}=$ custo inicial (construção) acrescido dos custos de manutenção menos o valor da construção no final de sua vida útil;

$\mathrm{P}_{\mathrm{i}}=$ probabilidade de ocorrência do tipo de ruptura " $\mathrm{i}$ ";

$\mathrm{C}_{\mathrm{i}}=$ custos relacionados à ocorrência do tipo de ruptura " $\mathrm{i}$ ";

A parcela referente ao custo inicial $\left(\mathrm{C}_{\mathrm{I}}\right)$ da função objetivo apresentada na expressão 2.6 aumenta quando se impõe uma maior segurança (menor probabilidade de ruptura) e as parcelas relacionadas às conseqüências da ruína $\left(\mathrm{P}_{\mathrm{i}}: \mathrm{C}_{\mathrm{i}}\right)$ diminuem quanto menor a probabilidade de ruína, permitindo representar, em um mesmo gráfico, a variação do custo esperado e de cada uma das parcelas da expressão 2.6, como mostra a figura a seguir:

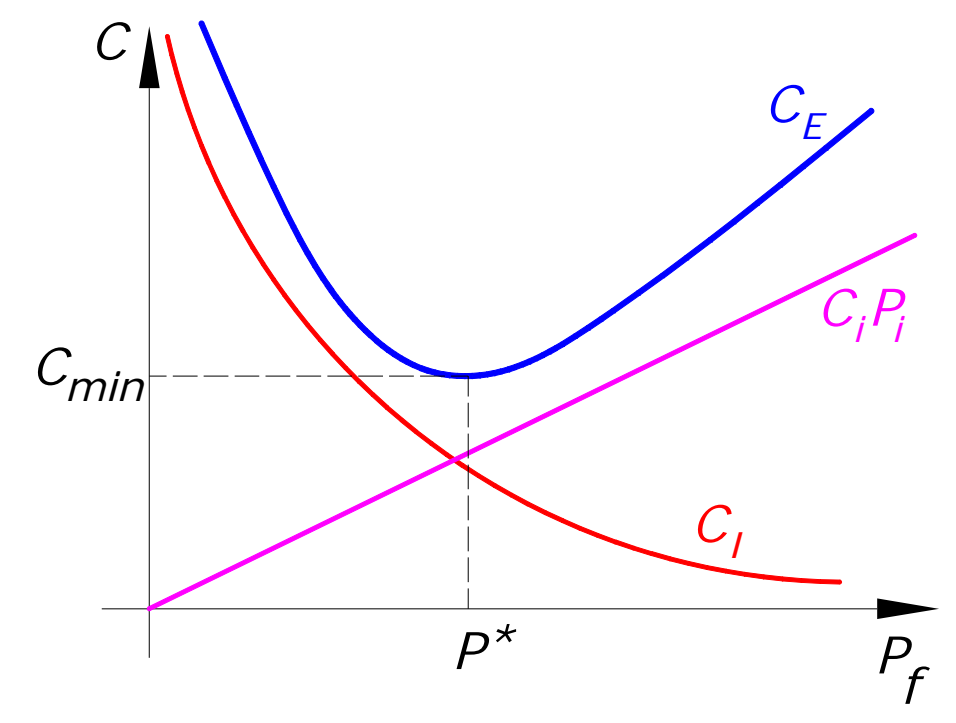

Figura 2.6 - Minimização do custo esperado.

Recentemente, alguns autores apresentam uma nova abordagem para consideração de aspectos sócio-econômicos no projeto, mediante o uso do conceito de Índice de Qualidade de Vida (“Life Quality Index”- LQI), como apresentado por Sánches-Silva e Rackwitz (2004).

Segundo estes autores, o referido índice deriva do conceito de utilidade marginal, de onde se obtém a seguinte expressão aproximada: 
$\mathrm{LQI} \approx \mathrm{g}^{\mathrm{w}} \mathrm{e}^{(1-\mathrm{w})}$

Onde

wé o tempo despendido com trabalho;

g é o PIB per capita;

$e$ é a expectativa de vida.

Sánches-Silva e Rackwitz (2004) destacam que o referido índice não depende do "valor vida" na data do nascimento ou do Produto Interno Bruto, aduzindo ainda que, dessa metodologia, emergem três possíveis classificações dos países: High (Europa Ocidental, Estados Unidos e Japão), Moderate (América Latina e Caribe) e Low (países menos desenvolvidos).

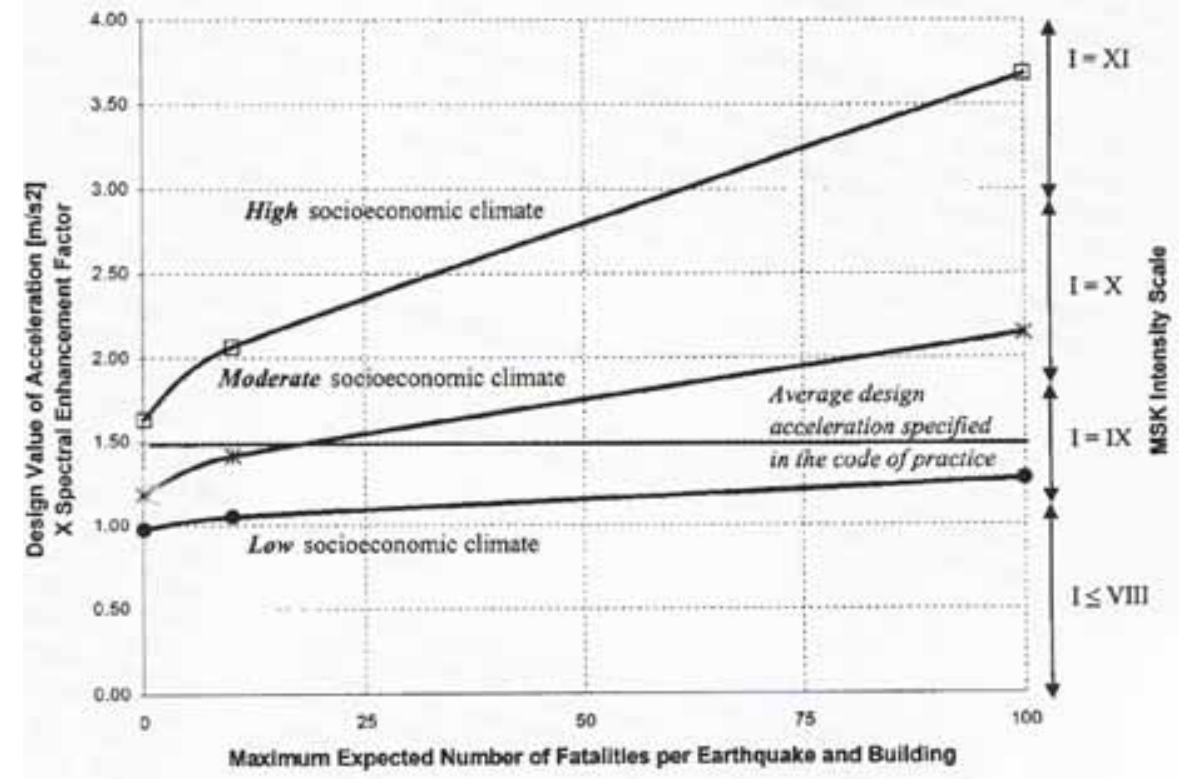

Figura 2.7 - Valor de projeto da aceleração em função do número de fatalidades, para as diversas classificações do LQI (Sánchez-Silva e Rackwitz, 2004).

Analisando-se o gráfico supra, observa-se que a segurança associada aos países classificados como High deve ser maior que aquela associada aos países classificados como Low. Evidentemente que esse critério, como todos os outros baseados na análise de custobenefício, é passível de rigorosas críticas. 


\section{OS DIVERSOS MÉTODOS DE INTRODUČ̃̃̃ DA SEGURANÇA}

O primeiro passo para a consideração da segurança nas obras civis foi possivelmente baseado inteiramente na intuição. $\mathrm{O}$ estado da arte do conhecimento acerca das propriedades geomecânicas dos solos prevalecentes antigamente bem como a ausência de experiência anterior não nos permitia considerar a segurança de outra forma que não com fulcro no julgamento intuitivo.

Com o passar do tempo e o contínuo exercício da atividade laboral do engenheiro, a experiência adquirida em obras "similares" delineou a forma de se introduzir a segurança empiricamente em obras de engenharia geotécnica.

No século XX, o ferramental matemático já disponível foi um convite ao desenvolvimento dos métodos de análise estrutural, em detrimento do desenvolvimento dos métodos de introdução da segurança.

Tal desenvolvimento foi postergado até meados de 1950, quando Brinch Hansen (1956) propôs que a incerteza fosse distribuída entre os fatores intervenientes no projeto, lançando a base para o desenvolvimento dos coeficientes de segurança parciais em substituição a um único coeficiente que guardasse toda a informação acerca da incerteza existente (coeficiente de segurança global).

Mais recentemente, a engenharia geotécnica incorporou os conceitos de probabilidade e estatística já utilizados em outras áreas do conhecimento para o desenvolvimento de métodos mais racionais de introdução da segurança, em prejuízo dos métodos essencialmente deterministas.

Hachich (1998a) certifica que o conjunto de trabalhos desenvolvidos a partir da década de 60 delineava a seguinte evolução dos métodos de introdução da segurança, a saber: 
- Determinação da variabilidade dos coeficientes de segurança, principalmente através de métodos de primeira ordem e segundo momento (FOSM - First Order Second Moment);

- Substituição dos coeficientes de segurança prescritos por índices de segurança prescritos, que já incorporassem a variabilidade (como, por exemplo, o coeficiente $\beta$ ), fornecendo melhores indicadores de segurança, porém ainda não incorporando o tipo de distribuição probabilística nem tampouco as responsabilidades da obra, ou seja, as conseqüências de uma eventual ruína;

- Substituição de índices de segurança prescritos por probabilidades de ruína prescritas, após a adoção criteriosa de funções densidade de probabilidade;

- Substituição de probabilidades de ruína prescritas por probabilidades de ruína decorrentes da maximização de alguma utilidade (por exemplo o custo por vida salva);

Atualmente existem uma série de critérios de segurança, diferenciando-se pela forma como a mesma é introduzida e pela escolha do(s) seu(s) indicador(es), distinguindo-se dois grandes grupos: os deterministas e os probabilistas.

Os diferentes critérios serão apresentados como sugere Hachich (1998b), a saber:

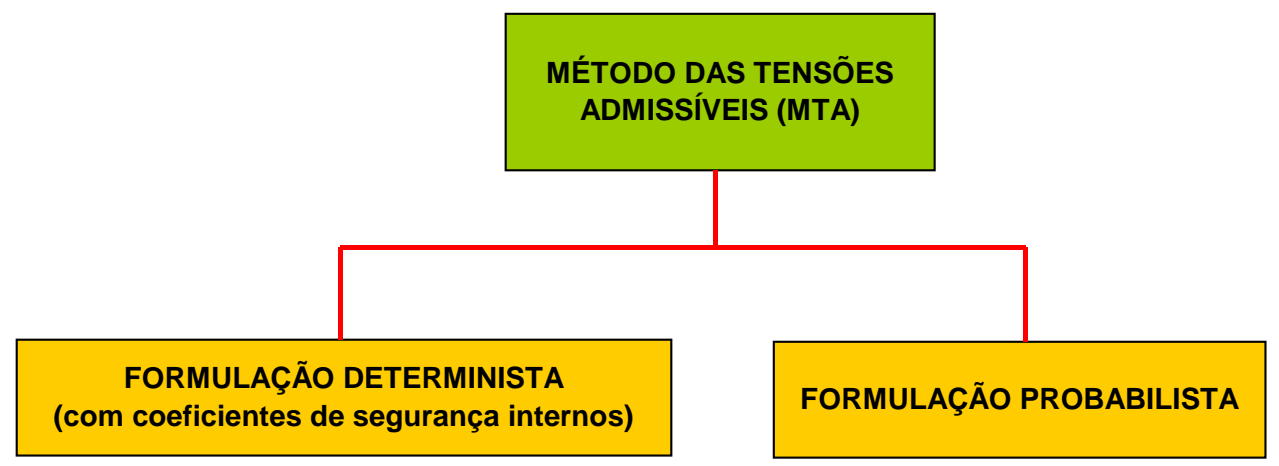

Figura 3.1 - Abordagens do método das tensões admissíveis. 


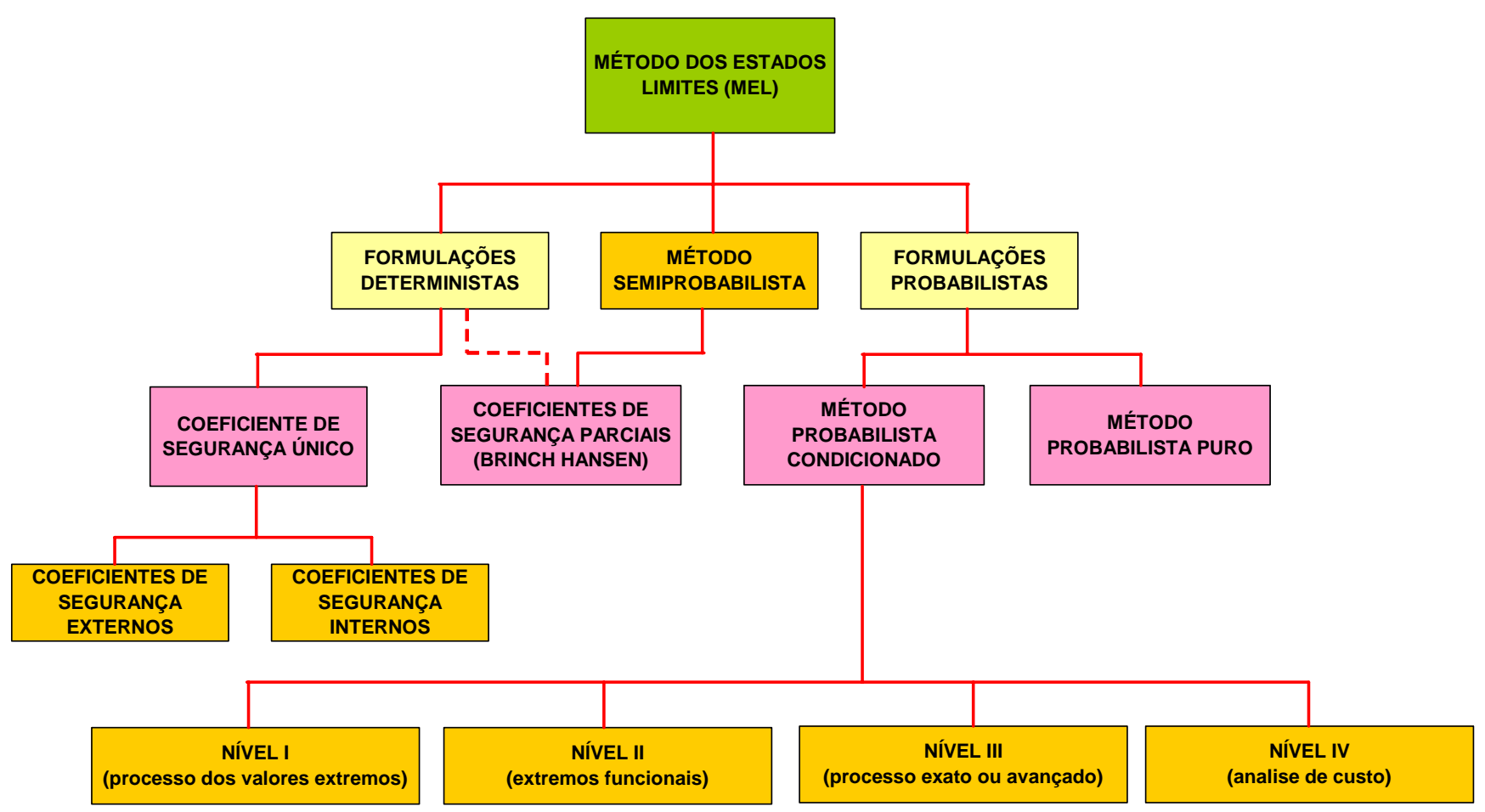

Figura 3.2 - Diferentes abordagens consideradas no Método dos Estados Limites.

\subsection{MÉTODO DAS TENSÕES ADMISSÍVEIS}

O método das tensões admissíveis foi o critério utilizado inicialmente na avaliação da segurança das estruturas. O referido método preconiza que em nenhum ponto da estrutura a tensão atuante poderia ultrapassar a tensão admissível do material, esta última entendida como sendo a tensão de ruptura do material minorada por um coeficiente de segurança adequado, como mostra a expressão 3.1. Por atuar sobre as resistências, esse coeficiente se segurança é considerado um coeficiente de segurança interno.

$Q \leq Q_{a d m}=\frac{Q_{u l t}}{F S}$

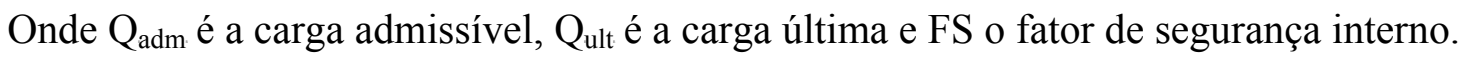

Hachich (1978) mostra que o método das tensões admissíveis conduzia à soluções excessivamente conservadoras se fosse considerada a freqüente não linearidade das relações entre ações e tensões, particularmente na iminência de um estado-limite último.

Nesse método, embora se reconhecesse implicitamente que materiais com propriedades mais variáveis mereciam maiores coeficientes de segurança, tais coeficientes não eram calculados com base em algum modelo probabilista, pelo menos nas aplicações 
iniciais. Em última análise, pode-se consignar que tais coeficientes eram propostos por um consenso do meio técnico (Alonso, 1991).

A despeito do fato de ser plenamente possível, a aplicação dos conceitos de probabilidade para determinação do coeficiente de segurança interno não ganhou fôlego em razão da desvantagem supra apresentada bem como da dificuldade adicional de se propor uma densidade de probabilidade adequada para modelagem das resistências.

Tal método foi derivado da engenharia de estruturas, onde teve aplicação mais efetiva particularmente em estruturas reticuladas, para as quais é relativamente fácil o cálculo das tensões mediante os conceitos da Resistência dos Materiais. Na engenharia geotécnica, o método em comento não chegou a ser amplamente utilizado em razão da dificuldade inicial em se calcular as tensões atuantes na estrutura do solo, o que demanda, pelo menos, conceitos da Teoria da Elasticidade.

\subsection{MÉTODO DOS ESTADOS LIMITES}

O Método dos Estados Limites permite tanto a majoração das ações (coeficiente de segurança externo) quanto a minoração das resistências (coeficiente de segurança interno), esta última plenamente justificável em estruturas nas quais o peso próprio é a ação principal, como no caso de taludes.

Segundo Maranha das Neves (1994), a idéia base do conceito de dimensionamento pelo método dos estados limites fundamenta-se no seguinte:

a) Identificação de todos os potenciais estados limites (modos de ruptura e deformação excessiva);

b) Verificação, em separado,de cada estado limite;

c) Demonstrar que a ocorrência dos estados limites tem pequena probabilidade.

O referido método é calcado em alguma função de desempenho ou função estado limite $\mathrm{G}(\mathrm{X})$, onde $\mathrm{X}=\left(\mathrm{x}_{1}, \mathrm{x}_{2}, \ldots ., \mathrm{x}_{\mathrm{n}}\right)$ representa o vetor de parâmetros de entrada, normalmente parâmetros relacionados às características geométricas da estrutura, das propriedades dos materiais e das ações atuantes sobre a mesma. A função de desempenho é 
definida de tal forma que a ruptura vem representada pela condição $G(X)<y$, onde y é uma constante. A situação na qual $\mathrm{G}(\mathrm{X})$ = y é denominada de condição estado limite e $\mathrm{G}(\mathrm{X})>\mathrm{y}$ denota o estado seguro.

Uma função de desempenho normalmente utilizada em problemas de verificação de segurança e a margem de segurança, definida pela expressão abaixo (Li et al, 1993):

$\mathrm{G}(\mathrm{X})=\mathrm{Z}_{\mathrm{R}}-\mathrm{Z}_{\mathrm{S}}$

Nesse caso, a ruptura vem definida por $\mathrm{G}(\mathrm{X})<0$. Outra função de desempenho também bastante utilizada é o fator de segurança, definido por:

$\mathrm{G}(\mathrm{X})=\mathrm{Z}_{\mathrm{R}} / \mathrm{Z}_{\mathrm{S}}$

Diversas outras funções de desempenho podem ser propostas, bem como diversas são as abordagens de se tratar a segurança $(G(X)>y)$. Os tópicos seguintes apresentam algumas dessas formas.

\subsubsection{Formulações deterministas}

As primeiras formulações deterministas do Método dos Estados Limites preconizavam a utilização de um coeficiente de segurança global, ou seja, ou um coeficiente de segurança interno (minoração das resistências) ou externo (majoração das ações).

Ao tentar cobrir todas as incertezas inerentes ao processo de dimensionamento por meio de um único fator de segurança, tal método se mostra pouco racional, por não permitir uma decisão que seja função da diferente variabilidade dos diversos parâmetros condicionantes (Cardoso, 2002).

Bilfinger (2002) faz uma discussão a este respeito, apresentando um exemplo hipotético de um edifício que pode estar apoiado em dois tipos de fundação distintos:

- Fundação em estacas pré-moldadas;

- Fundação em "brocas", escavadas manualmente e concretadas na obra, com o mesmo diâmetro e comprimento das anteriores;

As ações atuantes nas fundações são idênticas porém, intuitivamente, as incertezas 
quanto à capacidade de carga são diferentes, sendo esperado incertezas menores no caso da estaca pré-moldada. Assim, não seria lícito aplicar os mesmos coeficientes de segurança globais nos dois casos.

Em que pese este fato, a maior parte das normas, inclusive a norma brasileira de projeto e execução de fundações - NBR 6122 - não condiciona a escolha do fator de segurança global em função do tipo de estaca a ser utilizado.

Decerto, os trabalhos desenvolvidos por Brinch Hansen $(1956,1967)$, inobstante ao fato de possuírem ainda uma vertente determinista, representaram um marco significativo na evolução dos métodos de introdução da segurança, eis que já contemplavam as incertezas das variáveis envolvidas, abandonando a idéia de um fator de segurança único.

Embora tenham representado um avanço no tratamento da incerteza das variáveis envolvidas, os coeficientes parciais propostos por Brinch Hansen não tiveram sua utilização difundida no meio técnico, em particular no Brasil, pelo fato de que a estimativa da capacidade de carga de estacas é geralmente feita com base em formulações empíricas baseadas no SPT. Como a normalização aplicável não preconiza qualquer coeficiente parcial em relação a esse índice, tal metodologia não encontrou aplicação na prática corrente.

\subsubsection{Método semi-probabilista}

Esse método preconiza tanto a majoração das ações quanto a minoração das resistências, através da aplicação de coeficientes de ponderação que transformam valores característicos das grandezas em valores de projeto (ou seja, valores extremos). O referido método introduz ainda um coeficiente de ponderação relacionado às conseqüências de uma eventual ruína. A condição de verificação da segurança é que as solicitações de cálculo sejam menores que as solicitações-limite de cálculo. No âmbito do LRFD ("Load and Resistance Factor Design”) (AASHTO, 1999 apud Zhang et al, 2001), essa relação pode ser expressa por:

$\phi \cdot \mathrm{R}_{\mathrm{n}} \geq \eta \cdot \Sigma \mathrm{Q}_{\mathrm{i}} \cdot \gamma_{\mathrm{i}}$

Onde $\mathrm{R}_{\mathrm{n}}$ é a resistência nominal, $\phi$ é o fator de resistência, $\mathrm{Q}_{\mathrm{i}} \mathrm{o}$ efeito das ações, $\gamma_{\mathrm{i}}$ o fator de majoração das cargas e $\eta$ é um fator de ponderação que leva em conta efeitos de ductilidade, 
redundância e importância operacional.

Os valores característicos da resistência e das ações normalmente correspondem à quantis de alguma Função Densidade de Probabilidades (FDP). Para as resistências, são adotados quantis localizados na cauda esquerda do modelo probabilístico, como mostra a figura a seguir:

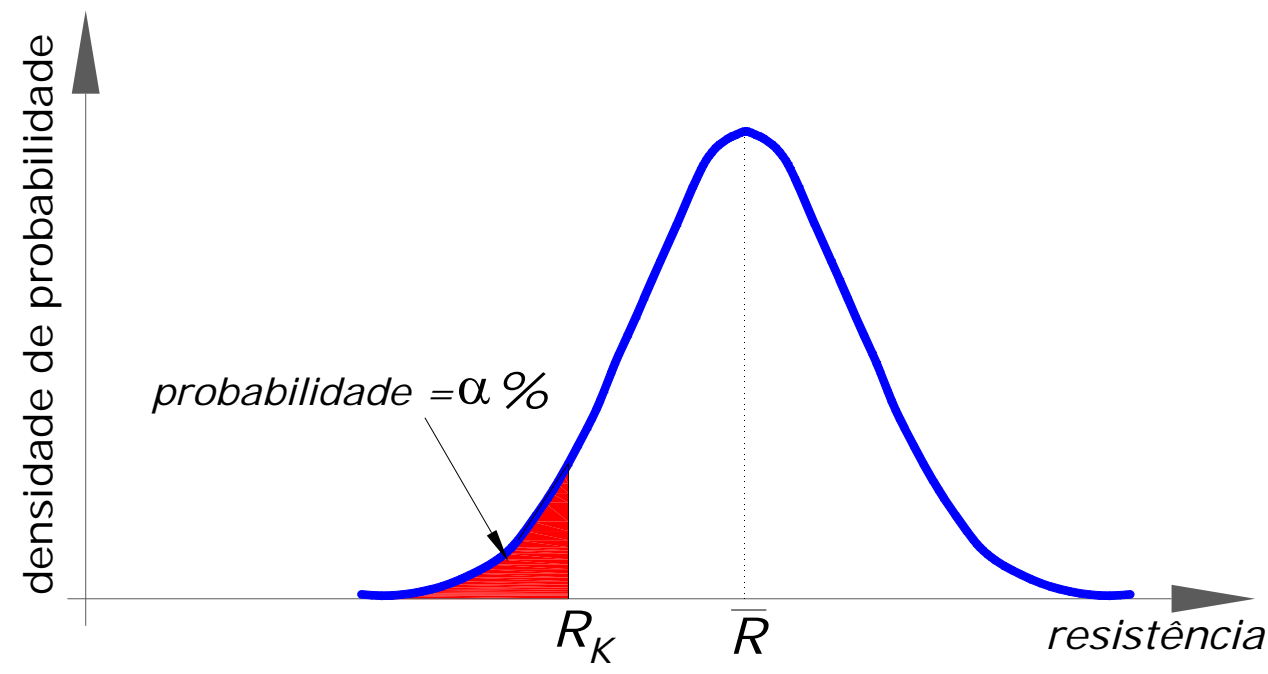

Figura 3.3 - Definição da resistência característica.

A Figura 3.3 mostra que a resistência característica representa um valor tal que possui somente $\alpha \%$ de não ser atingida. Como exemplo, a resistência característica do concreto vem definida pelo quantil correspondente à $\alpha=5 \%$.

A determinação do valor característico da resistência é feita a partir da resistência média através da expressão a seguir:

$\mathrm{R}_{\mathrm{k}}=\overline{\mathrm{R}} \cdot\left(1-\mathrm{Z}_{\alpha} \cdot \mathrm{V}_{\mathrm{R}}\right)$

onde Rk é a resistência característica, $\overline{\mathrm{R}}$ é a resistência média, $\mathrm{Z}_{\alpha}$ é uma constante (função do quantil selecionado) e VR é o coeficiente de variação da resistência.

Importante salientar que a definição de resistência para obras geotécnicas não está relacionada ao quantil de 5\%. Em geotecnia, a resistência característica vem definida pela própria resistência média. 
Com relação às ações, a cauda de interesse é a direita, e os valores característicos das podem ser obtidos mediante a seguinte expressão:

$\mathrm{S}_{\mathrm{k}}=\overline{\mathrm{S}} \cdot\left(1+\mathrm{Z}_{\alpha} \cdot \mathrm{V}_{\mathrm{S}}\right)$

Onde $\mathrm{S}_{\mathrm{k}}$ é a ação característica, $\overline{\mathrm{S}}$ é o valor médio da ação considerada, $\mathrm{Z}_{\alpha}$ uma constante dependente do quantil de interesse e $\mathrm{V}_{\mathrm{S}}$ é o coeficiente de variação da ação.

Salienta-se que, em estruturas e obras hidráulicas, também é comum a caracterização de ações extremas com fulcro no conceito de tempo de retorno.

A transformação dos valores característicos em valores de cálculo (de projeto) é feita mediante a aplicação de fatores de segurança parciais, tanto sobre as ações quanto sobre as resistências.

Os coeficientes de segurança parciais têm representado o atual estado da arte da introdução da segurança nas diversas normas de projeto de geotecnia. Maranha das Neves (1994) apresentou uma interessante discussão acerca do uso dos coeficientes de segurança parciais no âmbito do Eurocódigo.

O referido autor expõe a seguinte tabela com os coeficientes parciais preconizados pela norma retro citada:

\begin{tabular}{|c|c|c|c|c|c|c|c|}
\hline \multirow{3}{*}{ Caso } & \multicolumn{3}{|c|}{ Ações } & \multicolumn{4}{|c|}{ Propriedades do terreno $\left(\gamma_{\mathrm{m}}\right)$} \\
\hline & \multicolumn{2}{|c|}{ Permanentes $\left(\gamma_{\mathrm{G}}\right)$} & \multirow{2}{*}{$\begin{array}{l}\text { Variáveis }\left(\gamma_{\mathrm{Q}}\right) \\
\text { Desfavoráveis }\end{array}$} & \multirow{2}{*}{$\operatorname{tg} \phi^{\prime}$} & \multirow{2}{*}{$c^{\prime}$} & \multirow{2}{*}{$\mathrm{c}_{\mathrm{u}}$} & \multirow{2}{*}{$\mathrm{q}_{\mathrm{u}}$} \\
\hline & Desfavoráveis & Favoráveis & & & & & \\
\hline A & 1,00 & 0,95 & 1,50 & 1,1 & 1,3 & 1,2 & 1,2 \\
\hline $\mathrm{B}$ & 1,35 & 1,00 & 1,50 & 1,0 & 1,0 & 1,0 & 1,0 \\
\hline $\mathrm{C}$ & 1,00 & 1,00 & 1,50 & 1,25 & 1,4 & 1,4 & 1,4 \\
\hline
\end{tabular}

Tabela 3.1 - Coeficientes de segurança parciais (Maranha das Neves, 1994) 
$\mathrm{O}$ autor destaca que os casos $\mathrm{A}, \mathrm{B}$ e $\mathrm{C}$ se referem, respectivamente, ao equilíbrio estático da estrutura, aos elementos estruturais envolvido no projeto de fundações e, por último, aos aspectos relacionados estritamente à geotecnia.

O método sugere que os fatores de segurança parciais devam ser propostos em função da variabilidade das variáveis envolvidas. Tal variabilidade não é explicitada, nas diversas normas que preconizam o uso do método semi-probabilista, através de uma medida conceitualmente correta, tal como a variância ou o coeficiente de variação. Desta feita, em diversos trabalhos, tem sido proposta a calibração dos coeficientes parciais de segurança com base nos conceitos de confiabilidade, como apresentado por McVay et al (2000).

\subsubsection{Discussão dos métodos deterministas}

Os Fatores de Segurança Globais não possuem uma relação biunívoca com a segurança propriamente dita, pois fatores de segurança iguais podem resultar em seguranças (medidas pelas probabilidades de ruína) distintas. Da mesma forma, probabilidades de ruína iguais podem decorrer em fatores de segurança distintos, dependendo da variabilidade das grandezas envolvidas. A figura abaixo (Lacasse e Goulois, 1989) permite constatar a falha conceitual existente nos Fatores de Segurança Globais:

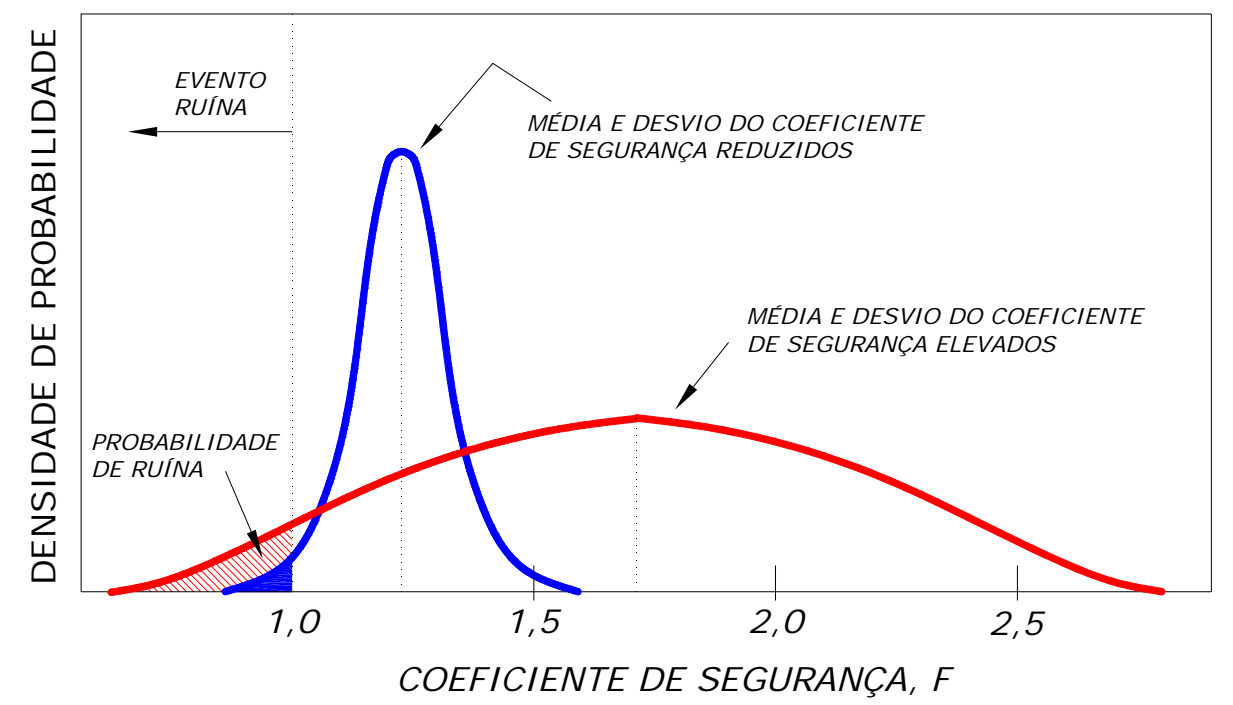

Figura 3.4 - Coeficiente de segurança versus segurança (adaptado de Lacasse e Goulois, 1989).

De Zagottis (1974) informa que a crítica fundamental que se pode fazer ao método das tensões admissíveis é que há apenas uma preocupação com o estabelecimento de uma conveniente distância entre a situação de utilização da estrutura e aquela que corresponderia a 
uma ruptura da estrutura (desagregação do material) ou um colapso da estrutura (perda de capacidade portante). Não há preocupação com a verificação de outras condições que possam invalidar a utilização da estrutura, como por exemplo o excesso de deformabilidade.

A despeito do reconhecido avanço que o método semi-probabilístico tenha representado, o referido método, tal como preconizado na maioria das normas técnicas, também padece do mesmo mal: os fatores de segurança parciais não levam em conta a variabilidade das grandezas em uma obra particular.

Como exemplo, admitamos que, em duas obras distintas, denotadas por A e B, serão utilizados métodos teóricos para determinação da capacidade de carga de estacas, com utilização da coesão e do ângulo de atrito. Vamos admitir ainda que, através de ensaios efetuados in-situ em quantidade suficiente para se ter poder discriminatório, as coesões nas duas obras possam ser representadas pelas densidades a seguir:

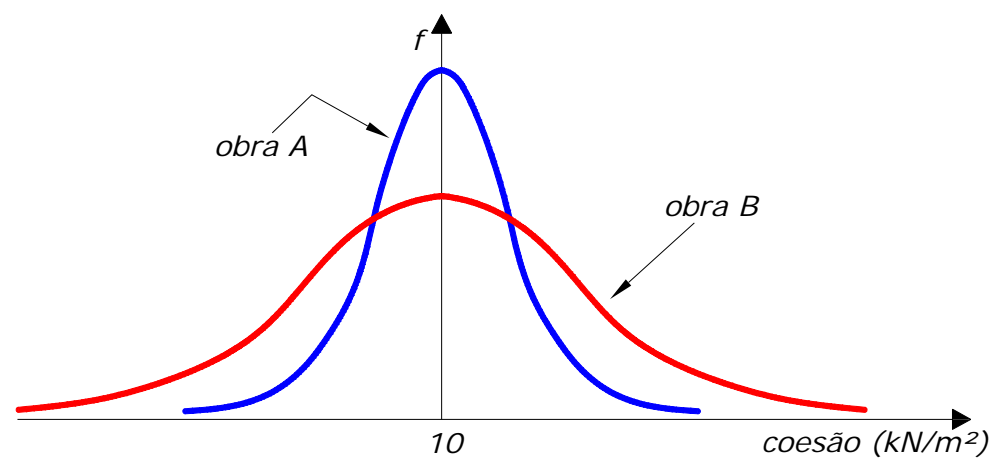

Figura 3.5 - Variação da coesão em duas obras hipotéticas.

Analisando-se a figura supra, nota-se que ambas as obras possuem a mesma coesão média $\left(10 \mathrm{kN} / \mathrm{m}^{2}\right)$, mas a variabilidade da coesão na obra $\mathrm{B}$ é nitidamente maior que a da obra A. Inobstante possuírem diferentes variabilidades, os valores de coesão a serem utilizados nos modelos teóricos seriam idênticos, haja vista que o coeficiente de ponderação da coesão independe da variabilidade em uma dada obra.

Desta feita, tem-se que tanto os métodos essencialmente deterministas quanto o método semi-probabilistico, este último em menor grau, não decorrem em uma medida única de segurança. 


\subsubsection{Métodos probabilistas}

Os métodos probabilistas possibilitaram a correção da falta de unicidade entre fator de segurança e segurança propriamente dita, ainda prevalecente nos métodos deterministas e mesmo no método semi-probabilístico.

Através do uso dos métodos probabilistas, é possível calcular uma medida que guarda uma correspondência única e mais adequada, do ponto de vista conceitual, para mensurar a segurança das estruturas: a probabilidade de ruína.

Duncan (2000) defende que, nas verificações da segurança de estruturas, deve-se mensurá-la através de sua medida mais inequívoca, qual seja, a probabilidade de ruína. $\mathrm{Na}$ visão do referido autor, com um pequeno esforço de cálculo adicional, apenas o necessário à realização de análises de confiabilidade, obtém-se uma visão muito mais profunda da questão da segurança da estrutura em estudo. De Mello et al (2002) também apresentam uma aplicação da estatística e da teoria das probabilidades em geotecnia. Na visão dos autores

[...] o que precisamos é definitivamente questionar e rechaçar as RECEITASDOGMAS, e começar a empregar a "estatística-probabilidades E.P." mínima rudimentar que seja absolutamente convidativa, para priorizar a constituição de amplo banco de dados, estimulando a vantagem pelo número, em comparação com a presumida "qualidade teórica quantificada segundo o modelo idealizado".

Muito embora a comunidade geotécnica há muito tempo reconheça as incertezas atinentes ao projeto e empreendeu maneiras práticas de considerá-las, a mesma tem sido relutante em aplicar métodos mais racionais e formais de se considerar a incerteza.

Hachich (1978) afirma que, à qualquer estrutura, fixada sua vida útil, está associada uma probabilidade de ruína positiva. Diante dessa realidade inexorável, o mais racional seria incorporar essa probabilidade de ruína nas atividades de concepção do engenheiro. A despeito do fato de ser este o caminho mais racional, na prática, a adoção de uma probabilidade de ruína em projeto suscita óbices da sociedade, em favor de uma impossível "segurança absoluta".

Os métodos probabilistas apresentam uma primeira divisão dicotômica, qual seja: o 
Método Probabilista Condicionado (MPC) e o Método Probabilista Puro (MPP).

No Método Probabilista Condicionado a verificação da segurança é feita com base na análise determinista da configuração de ruína da estrutura, ou seja, fixada uma configuração de ruína, as demais variáveis são reconhecidas como variáveis aleatórias. Destarte, nesse método, a verificação da segurança fica condicionada à configuração de ruína escolhida deterministicamente, normalmente fulcrada na teoria disponível. Por exemplo, ao analisarmos a capacidade de carga de uma estaca com ponta em argila, podemos utilizar um dos diversos modelos teóricos existentes (Meyerhof, 1951; Skempton, 1951). Qualquer análise de segurança levada a efeito posteriormente à escolha do modelo fica, então, condicionada ao mesmo.

No Método Probabilista Puro a configuração de ruína também é aleatória, e não está associada à análise determinista da estrutura. Desta feita, tem-se que o MPC é um caso particular do MPP (Hachich, 1998b). Sendo a configuração da ruptura também aleatória, devemos descrever a distribuição dos diversos modos de ruptura de uma certa estrutura através de Funções de Probabilidade, no caso discreto (número finito de modos de ruína) ou por uma Densidade de Probabilidade, no caso contínuo.

A consideração dos diversos modos de ruptura através de distribuições probabilistas introduz tamanha complexidade à análise que conduz o MPP à condição de um modelo estritamente teórico. Mesmo no meio acadêmico, o referido método tem sido pouco abordado em trabalhos. Naturalmente que, não obstante teórico, o MPP tem importância singular no desenvolvimento dos métodos probabilistas.

O Método Probabilista Puro não será tratado em profundidade no presente texto. $\mathrm{O}$ referido método se encontra discutido com relativa profundidade em De Zagottis (1974).

No âmbito no MPC, distinguem-se três níveis de aplicação, com diferentes graus de generalidade, quais sejam: Nível I, Nível II e Nível III. A diferença entre os três níveis está na forma e no rigor de se descrever as variáveis aleatórias envolvidas no cálculo.

Alguns autores informam a existência de um quarto nível (Nível IV), no qual a probabilidade de ruína é obtida à partir de uma análise de custo/benefício (Madsen et al, 
1986).

Madsen et al (1986) ressaltam ainda a importância dos níveis superiores na calibração de metodologias inseridas em níveis inferiores, como por exemplo a calibração dos coeficientes de segurança parciais através dos métodos de Primeira Ordem e Segundo Momento, como feito em McVay et al (2000).

\subsubsection{Métodos de Nível I}

O Nível I do MPC, também conhecido como processo dos valores extremos, utiliza o conceito de valor característico e valores de cálculo das variáveis aleatórias consideradas.

A condição básica a ser verificada, segundo esse critério, é a seguinte:

$\mathrm{Z}_{\mathrm{S}}\left(\mathrm{x}_{1, \mathrm{extr}}, \mathrm{x}_{2, \mathrm{extr}}, \ldots \ldots \ldots, \mathrm{x}_{\mathrm{n}, \mathrm{extr}}\right) \leq \mathrm{Z}_{\mathrm{R}}\left(\mathrm{y}_{1, \mathrm{extr}}, \mathrm{y}_{2, \mathrm{extr}}, \ldots \ldots \ldots, \mathrm{y}_{\mathrm{N}, \mathrm{extr}}\right)$

onde:

$\mathrm{Z}_{\mathrm{S}}\left(\mathrm{x}_{1, \mathrm{extr}}, \mathrm{x}_{2, \mathrm{extr}}, \ldots \ldots \ldots, \mathrm{x}_{\mathrm{n}, \mathrm{extr}}\right)=$ solicitação atuante na estrutura, função das variáveis $\mathrm{x}_{\mathrm{i}, \mathrm{extr}}$; $\mathrm{X}_{\mathrm{i}, \text { extr }}=$ valores extremos (característicos ou de cálculo) dos parâmetros utilizados no cálculo da solicitação;

$\mathrm{Z}_{\mathrm{R}}\left(\mathrm{y}_{1, \mathrm{extr}}, \mathrm{y}_{2, \mathrm{extr}}, \ldots \ldots \ldots, \mathrm{y}_{\mathrm{m}, \mathrm{extr}}\right)=$ resistência da estrutura;

$\mathrm{y}_{\mathrm{i}, \text { ext }}=$ valores extremos (característicos ou de cálculo) dos parâmetros utilizados no cálculo da resistência;

Nota-se que o Nível I do MPC é bastante similar ao Método Semi-probabilístico, sendo a diferença que, neste último, todos os fatores intervenientes na segurança são considerados no cálculo (como por exemplo as conseqüências da ruína).

Hachich (1998b) informa que, num certo sentido, o Método Semi-probabilistico é um aprimoramento do Nível I do MPC. Alguns autores não fazem a distinção entre o Método Semi-probabilistico e o Nível I do MPC (Cardoso, 2002; Maranha das Neves, 1994).

\subsubsection{Métodos de Nível II}

Os métodos de Nível II do MPC, também conhecidos por processos dos extremos funcionais ou Métodos do Índice de Confiabilidade (Maranha das Neves, 1994), utilizam 
explicitamente duas medidas sobre cada variável aleatória utilizada no cálculo, uma delas relacionada à tendência central (por exemplo, a média) e outra relacionada à variabilidade (desvio-padrão, variância ou coeficiente de variação). Eventualmente, há também a consideração de uma medida de variabilidade conjunta entre duas variáveis envolvidas no cálculo, tal como a covariância ou o coeficiente de correlação (Madsen et al, 1986).

Por outro lado, Cardoso (2002) informa que os métodos de Nível II consideram que as diversas variáveis seguem distribuições normais ou lognormais e sejam independentes, de modo que não são utilizadas medidas de correlação.

Os métodos de Nível II incluem os métodos baseados no primeiro e segundo momentos das variáveis aleatórias envolvidas, tais como o Método de Primeira Ordem e Segundo Momento (FOSM - "First Order Second Moment").

Cornell (1969) foi um dos precursores do FOSM, o qual utiliza a função de desempenho conhecida como MARGEM DE SEGURANÇA $\left(\mathrm{M}_{\mathrm{RS}}\right)$, qual seja:

$\mathrm{M}_{\mathrm{R}, \mathrm{S}}\left(\mathrm{Z}_{\mathrm{R}}, \mathrm{Z}_{\mathrm{S}}\right)=\mathrm{Z}_{\mathrm{R}}-\mathrm{Z}_{\mathrm{S}}$

Onde $\mathrm{M}_{\mathrm{R}, \mathrm{S}}\left(\mathrm{Z}_{\mathrm{R}}, \mathrm{Z}_{\mathrm{S}}\right)$ é a margem de segurança, calculada para valores particulares das variáveis resistência e efeito das ações, valores esses denotados por $Z_{R}$ e $Z_{S}$ respectivamente. Com base na expressão 3.8, pode-se definir estado limite da estrutura, condição esta exposta na expressão abaixo:

$\mathrm{M}_{\mathrm{R}, \mathrm{S}}\left(\mathrm{Z}_{\mathrm{R}}, \mathrm{Z}_{\mathrm{S}}\right)=0$

Já o domínio seguro vem representado pela desigualdade a seguir:

$\mathrm{M}_{\mathrm{R}, \mathrm{S}}\left(\mathrm{Z}_{\mathrm{R}}, \mathrm{Z}_{\mathrm{S}}\right)>0$

E o domínio de ruptura vem representado por:

$\mathrm{M}_{\mathrm{R}, \mathrm{S}}\left(\mathrm{Z}_{\mathrm{R}}, \mathrm{Z}_{\mathrm{S}}\right)<0$

O gráfico abaixo sintetiza as regiões supra discriminadas: 


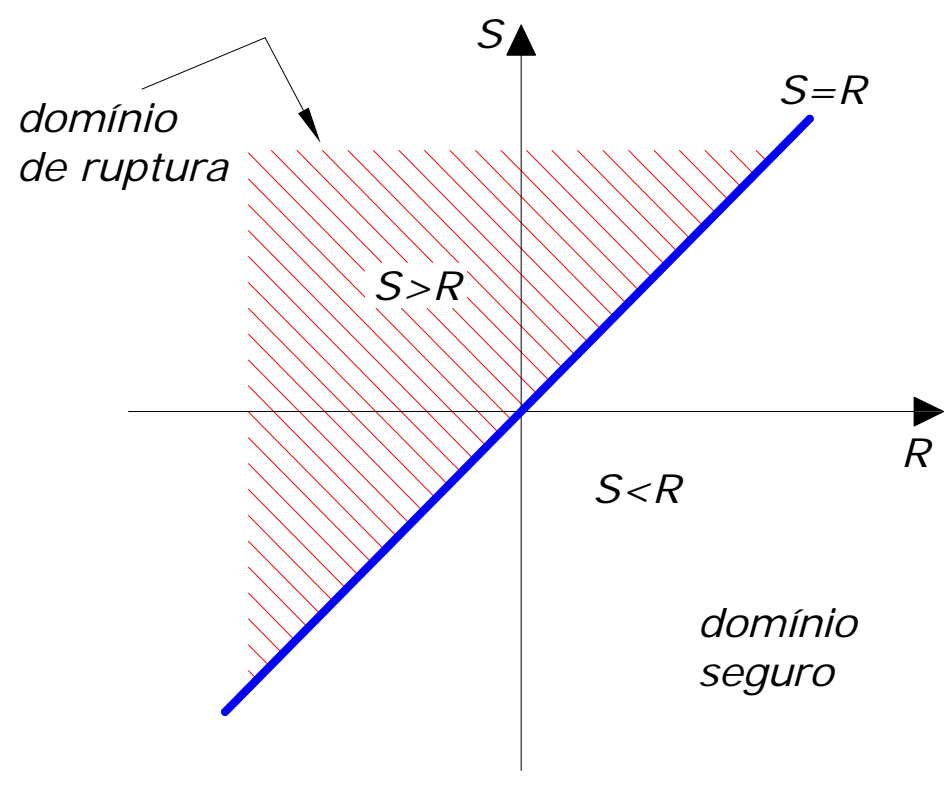

Figura 3.6 - Delimitação do domínio seguro e do domínio de ruptura.

Os valores de $Z_{R}$ e $Z_{S}$ dependem de outras variáveis, tais como das características geométricas da estrutura, das propriedades dos materiais e das ações atuantes sobre a mesma. Tais variáveis são conhecidas como variáveis básicas. Assim, os efeitos das ações e os fatores intervenientes na resistência da estrutura podem ser escritos como funções das variáveis básicas, a saber:

$\mathrm{Z}_{\mathrm{R}}=\mathrm{g}_{\mathrm{R}}\left(\mathrm{x}_{1}, \mathrm{x}_{2}, \ldots \ldots \ldots, \mathrm{x}_{\mathrm{n}}\right)$

$\mathrm{Z}_{\mathrm{S}}=\mathrm{g}_{\mathrm{S}}\left(\mathrm{y}_{1}, \mathrm{y}_{2}, \ldots \ldots \ldots, \mathrm{y}_{\mathrm{m}}\right)$

Onde:

$\mathrm{Z}_{\mathrm{R}}, \mathrm{Z}_{\mathrm{S}}=$ resistência e solicitação;

$\mathrm{x}_{1}, \mathrm{x}_{2}, \ldots, \mathrm{x}_{\mathrm{n}}=$ variáveis básicas que determinam a resistência da estrutura;

$\mathrm{y}_{1}, \mathrm{y}_{2}, \ldots, \mathrm{y}_{\mathrm{m}}=$ variáveis básicas que determinam a solicitação sobre a estrutura;

A idéia básica do FOSM é obter os dois primeiros momentos (média e variância) das variáveis resistência e solicitação a partir dos dois primeiros momentos das variáveis básicas. Tal feito é realizado utilizando-se a expansão de Taylor, desconsiderando-se as parcelas de ordem superior (Benjamin e Cornell, 1970). Assim, a média da variável dependente, no caso a 
resistência, seria aproximada por:

$$
\mathrm{E}[\mathrm{R}] \approx \mathrm{g}_{\mathrm{R}}\left(\mathrm{m}_{\mathrm{x} 1}, \mathrm{~m}_{\mathrm{x} 2}, \ldots . ., \mathrm{m}_{\mathrm{xn}}\right)+\left.\frac{1}{2} \sum_{i=1}^{n} \sum_{j=1}^{n} \frac{\partial \mathrm{g}_{\mathrm{R}}^{2}}{\partial \mathrm{x}_{\mathrm{i}} \partial \mathrm{y}_{\mathrm{j}}}\right|_{\mathrm{m}} \cdot \operatorname{cov}\left[\mathrm{x}_{\mathrm{i}}, \mathrm{x}_{\mathrm{j}}\right]
$$

A variância da resistência $(\operatorname{Var}[\mathrm{R}])$ seria aproximada por:

$$
\left.\left.\operatorname{Var}[\mathrm{R}] \approx \sum_{i=1}^{n} \sum_{j=1}^{n} \frac{\partial \mathrm{g}_{\mathrm{R}}}{\partial \mathrm{x}_{\mathrm{i}}}\right|_{\mathrm{m}} \frac{\partial \mathrm{g}_{\mathrm{R}}}{\partial \mathrm{x}_{\mathrm{j}}}\right|_{\mathrm{m}} \cdot \operatorname{cov}\left[\mathrm{x}_{\mathrm{i}}, \mathrm{x}_{\mathrm{j}}\right]
$$

Se as variáveis $\mathrm{x}_{\mathrm{i}}$ e $\mathrm{x}_{\mathrm{j}}$ forem independentes $\left(\operatorname{cov}\left[\mathrm{x}_{\mathrm{i}}, \mathrm{x}_{\mathrm{j}}\right]=0\right.$, se $\left.\mathrm{i} \neq \mathrm{i}\right)$, as expressões supra ficam:

$$
\begin{aligned}
& \mathrm{E}[\mathrm{R}] \approx \mathrm{g}_{\mathrm{R}}\left(\mathrm{m}_{\mathrm{x} 1}, \mathrm{~m}_{\mathrm{x} 2}, \ldots . ., \mathrm{m}_{\mathrm{xn}}\right)+\left.\frac{1}{2} \sum_{\mathrm{i}=1}^{\mathrm{n}} \frac{\partial \mathrm{g}_{\mathrm{R}}^{2}}{\partial \mathrm{x}_{\mathrm{i}}^{2}}\right|_{\mathrm{m}} \cdot \operatorname{Var}[\mathrm{xi}] \\
& \operatorname{Var}[\mathrm{R}] \approx \sum_{\mathrm{i}=1}^{\mathrm{n}}\left(\left.\frac{\partial \mathrm{g}_{\mathrm{R}}}{\partial \mathrm{x}_{\mathrm{i}}}\right|_{\mathrm{m}}\right)^{2} \cdot \operatorname{Var}[\mathrm{xi}]
\end{aligned}
$$

A mesma expansão é válida para calcular os dois primeiros momentos da solicitação, à partir das variáveis básicas.

Uma vez obtidas a média e a variância da resistência e da solicitação, pode-se calcular a média e a variância da margem de segurança, através das seguintes expressões (assumindo-se independência entre resistência e solicitação):

$$
\begin{aligned}
& \mathrm{E}[\mathrm{M}]=\mathrm{E}[\mathrm{R}]-\mathrm{E}[\mathrm{S}] \\
& \sigma^{2}[\mathrm{M}]=\sigma^{2}[\mathrm{R}]+\sigma^{2}[\mathrm{~S}]
\end{aligned}
$$

Na metodologia proposta por Cornell (1969), o índice de confiabilidade ( $\beta$ ) vem definido como sendo o número de desvios-padrão de $\mathrm{M}(\sigma[\mathrm{M}])$ que separa o valor médio da margem de segurança e o estado de ruína $(\mathrm{M}<0)$, como mostra a figura abaixo (Christian, 2004): 


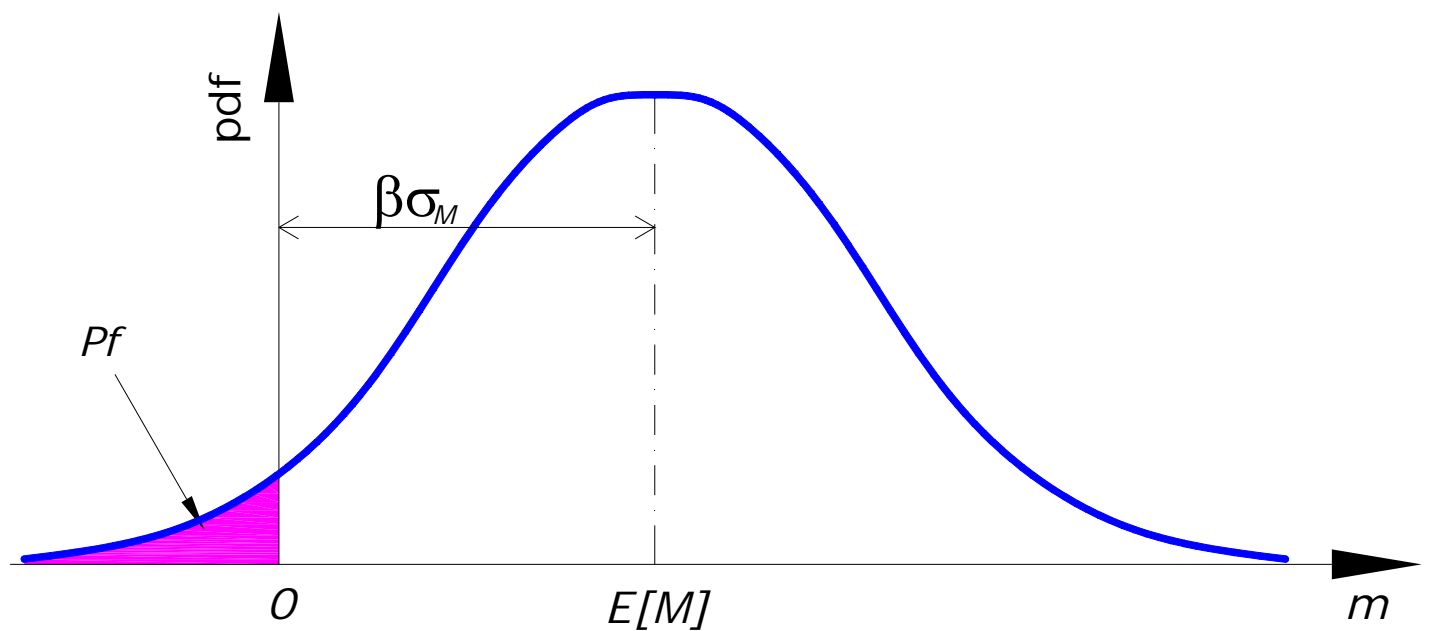

Figura 3.7 - Definição de índice de segurança à partir da margem de segurança média e do domínio de ruptura (Christian, 2004).

Desta feita, o índice de confiabilidade pode ser escrito da seguinte forma:

$\beta=\frac{\mathrm{E}[\mathrm{M}]}{\sigma[\mathrm{M}]}=\frac{\mathrm{E}[\mathrm{R}]-\mathrm{E}[\mathrm{S}]}{\sqrt{\sigma^{2}[\mathrm{R}]+\sigma^{2}[\mathrm{~S}]}}$

Para efeito de calibração do coeficiente de segurança, muitos autores o têm relacionado com o índice de confiabilidade, como apresenta Leporati (1979):

$\mathrm{FS}=\frac{\mathrm{E}[\mathrm{R}]}{\mathrm{E}[\mathrm{S}]}=\frac{1+\beta \cdot \sqrt{\mathrm{V}_{\mathrm{R}}^{2}+\mathrm{V}_{\mathrm{S}}^{2}-\beta^{2} \cdot \mathrm{V}_{\mathrm{R}}^{2} \cdot \mathrm{V}_{\mathrm{S}}^{2}}}{1-\beta^{2} \cdot \mathrm{V}_{\mathrm{R}}^{2}}$

Com base na expressão supra apresenta-se o gráfico a seguir, que relaciona o índice de confiabilidade com o fator de segurança central, conforme segue: 


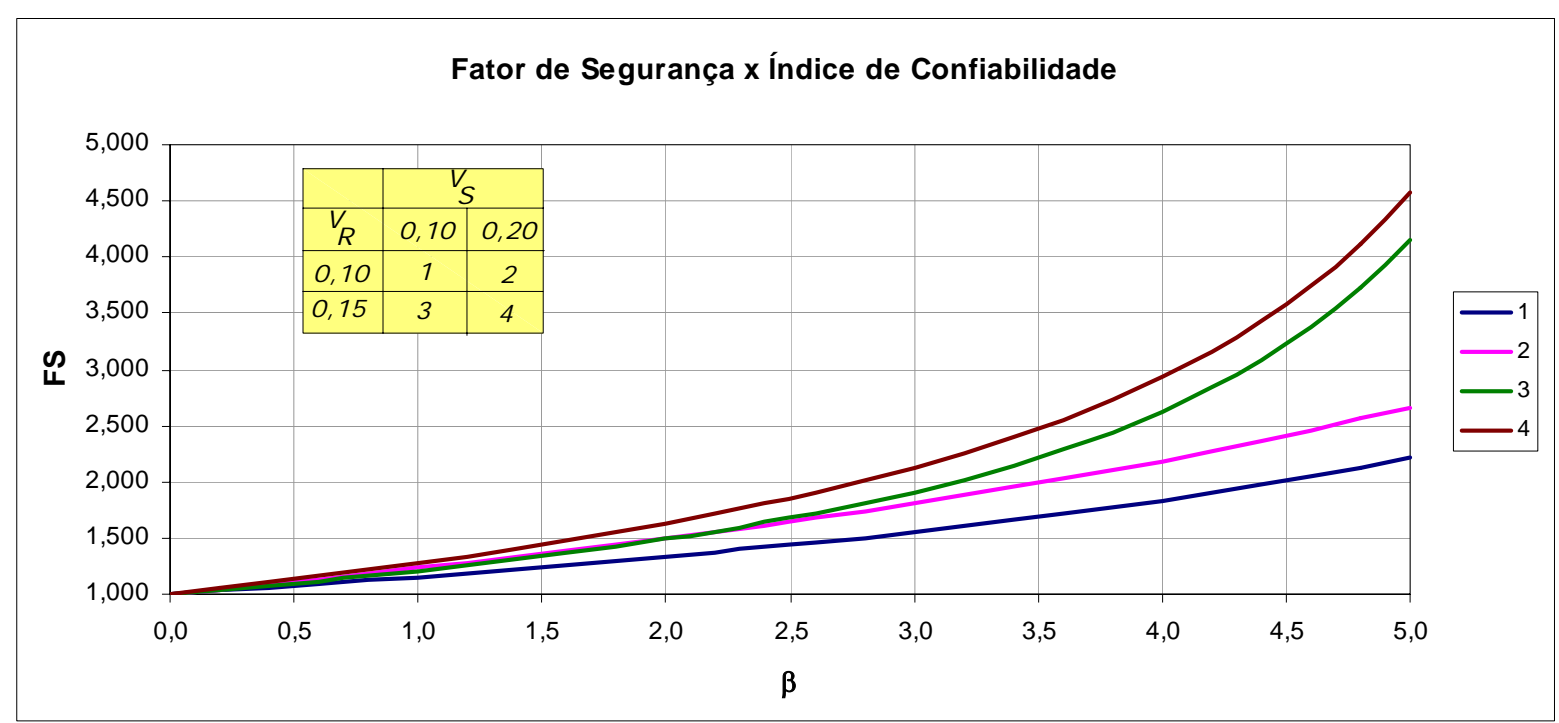

Figura 3.8 - Fator de segurança central versus índice de confiabilidade, para diversos coeficientes de variação da resistência $\left(V_{R}\right)$ e solicitação $\left(V_{S}\right)$.

A Figura 3.8 mostra claramente que a um determinado fator de segurança central (FS) estão associados diversos valores de $\beta$, dependendo da variabilidade das variáveis resistência e solicitação.

Uma crítica freqüentemente feita aos métodos de primeira ordem e segundo momento é a falta de invariância ("lack of invariance”) ocasionada à medida de segurança ( $\beta$ ), a qual depende da especificação da função de desempenho. Tomemos como exemplo as seguintes funções de desempenho, relacionando resistência $(R)$ e solicitação $(S)$ :

$$
\begin{aligned}
& Z=R-S<0 \\
& Z=(R-S)^{3}<0 \\
& Z=(R / S)-1<0 \\
& Z=\ln (R / S)<0
\end{aligned}
$$

As quatro funções de desempenho definidas acima permitem consignar se a estrutura se encontra no domínio seguro ou no domínio de falha, dependendo dos valores de R e S.

Veneziano (1974) mostra que às quatro funções de desempenho supra estão associados diferentes domínios de ruptura, decorrendo em diferentes valores do índice de segurança $(\beta)$, como ilustra a figura a seguir: 


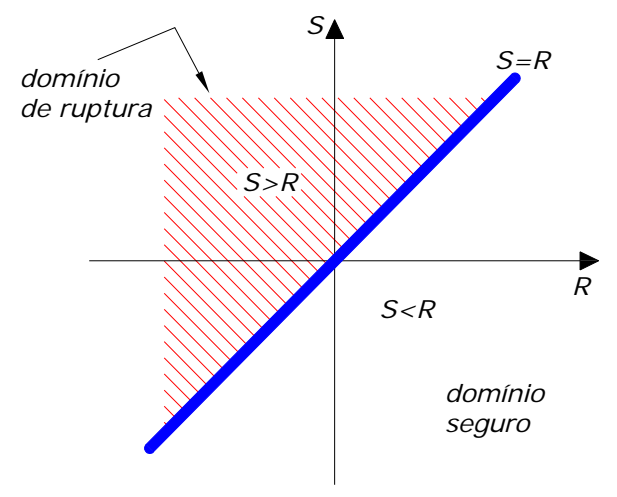

a) $r-s>0$

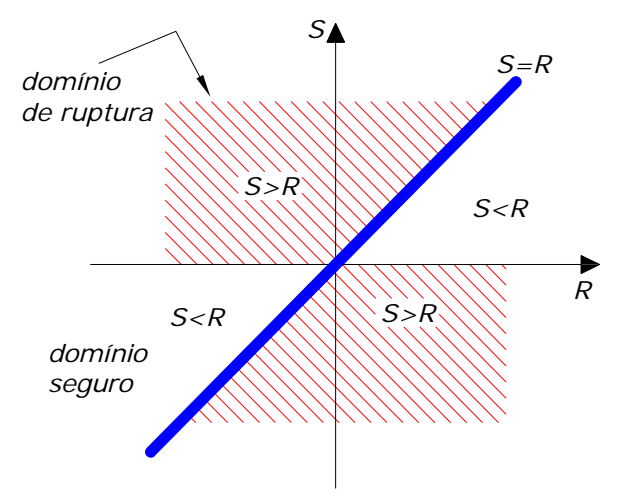

c) $r / s-1>0$

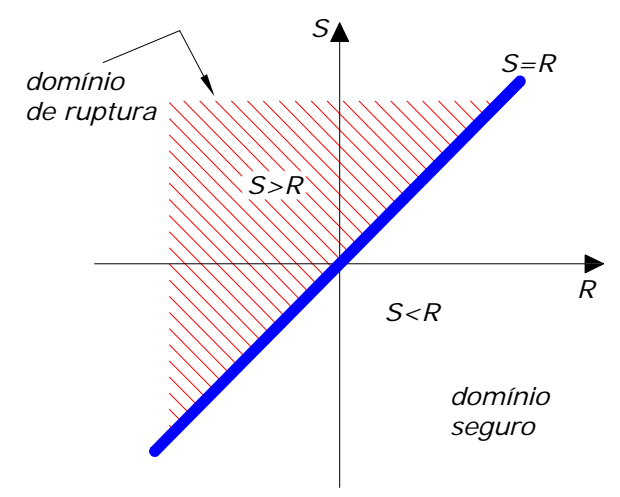

b) $(r-s)^{3}>0$

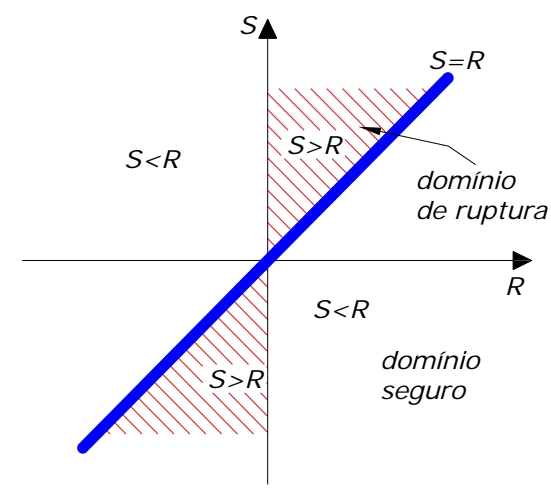

d) $\ln (r / s)>0$

Figura 3.9 - Delimitação dos domínios seguro e de falha, dependendo da especificação da função de desempenho (Veneziano, 1974).

Da figura supra, pode-se reparar que diferentes funções de desempenho podem conduzir a diferentes domínios seguros e de falha, o que configura a falta de invariância do método.

Alguns métodos, ainda no âmbito no Nível II, representaram evoluções em relação ao FOSM, tais como o Índice de Confiabilidade de HASOFER-LIND (Hasofer e Lind, 1974) e o AFOSM (“Advanced First Order Second Moment”) (Ang e Tang, 1984).

\subsubsection{Métodos de Nível III}

O Nível III, também conhecido como processo exato, é o mais completo método probabilista, no âmbito do MPC. Tal nível inclui, por exemplo, os métodos baseados no conceito de confiabilidade. Segundo Rao (1992), confiabilidade é a probabilidade de uma estrutura desempenhar as funções para as quais foi concebida durante um período de tempo especificado sob determinadas condições de operação. Observa-se que a confiabilidade está 
diretamente relacionada com a probabilidade de falha da estrutura, através da seguinte expressão:

$\mathrm{P}_{\mathrm{C}}=1-\mathrm{P}_{\mathrm{F}}$

Alguns autores consideram que a confiabilidade da estrutura, formalmente, deve considerar todos os modos de falha (Hachich, 1998b). Sob este prisma, o conceito de probabilidade somente seria plausível no âmbito do Método Probabilista Puro (MPP).

A aplicação deste nível requer o conhecimento das Funções Densidade de Probabilidade (FDP's) das variáveis envolvidas, bem como a correta delimitação do domínio seguro e do domínio de falha para um dado estado limite.

Uma vez conhecido o domínio de falhas $\mathrm{D}$ e a distribuição conjunta das variáveis resistência e solicitação, a probabilidade de ruína pode ser calculada através da seguinte expressão:

$$
P_{f}=P\left(Z_{R}-Z_{S} \leq 0\right)=\iint_{D} f_{R S}\left(Z_{R}, Z_{S}\right) d r d s
$$

A probabilidade $\mathrm{P}_{\mathrm{f}}$ de ruína é igual ao volume sob a superfície da função densidade conjunta que recai no domínio de falha (D), como ilustra a Figura 3.10 apresentada na página seguinte.

Devido à dificuldade de se calcular a integral exposta na expressão, muitas vezes de ordem elevada, freqüentemente se recorre à simulações ou integração numérica. 


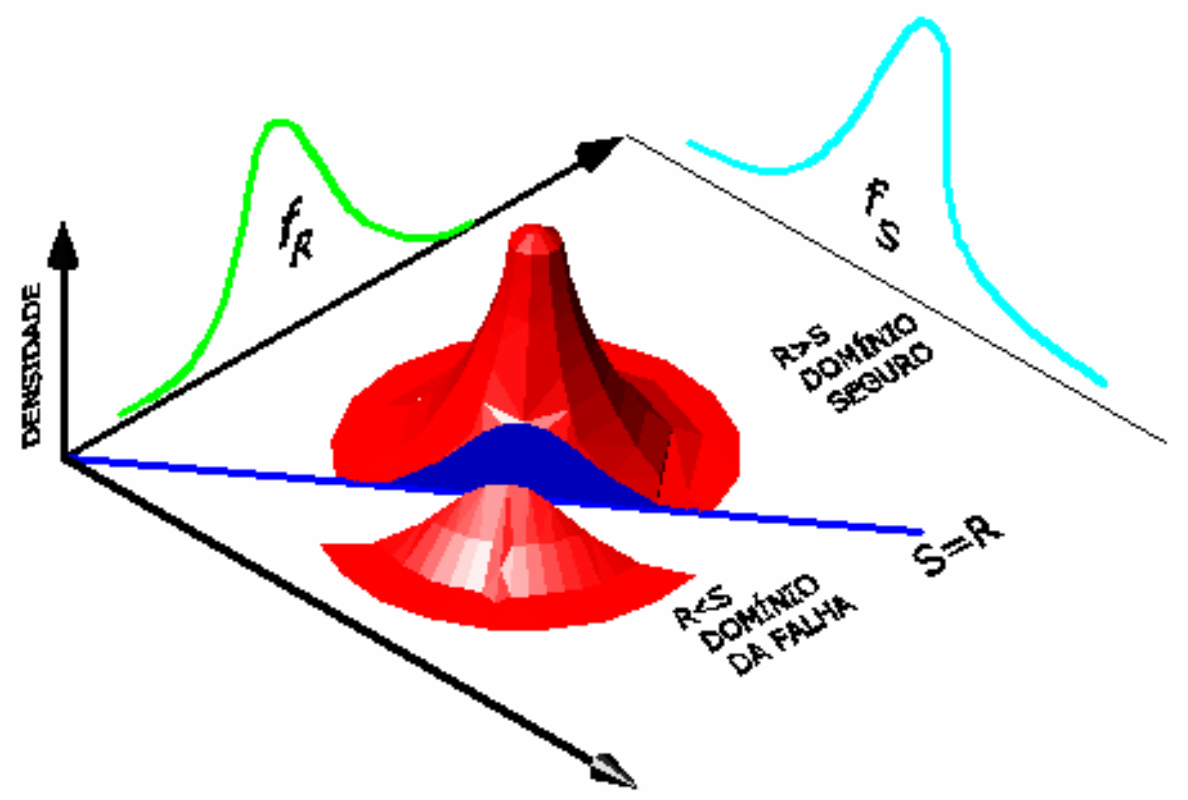

Figura 3.10 - Distribuição conjunta das variáveis R e S e delimitação da probabilidade de ruína.

Cardoso (2002) mostra que, no caso de as variáveis resistência e solicitação forem independentes, a confiabilidade da estrutura pode ser calculada por:

$$
P_{C}=\int_{-\infty-\infty}^{\infty} \int_{S}^{r} f_{S}(s) \cdot f_{R}(r) d s d r
$$

A expressão supra pode ser reescrita em termos da Função Distribuição da variável resistência, a saber:

$$
\mathrm{P}_{\mathrm{C}}=\int_{-\infty}^{\infty} \mathrm{F}_{\mathrm{S}}(r) \cdot \mathrm{f}_{\mathrm{R}}(\mathrm{r}) \mathrm{dr}
$$

E, com base na definição de probabilidade de ruína (Equação 3.19), a equação supra pode ser reescrita conforme segue:

$$
P_{f}=\int_{-\infty}^{\infty}\left[1-F_{S}(r)\right] \cdot f_{R}(r) d r
$$

Cardoso (2002) mostra ainda que integral supra representa a área sob a curva 
delimitada pela Função Densidade Conjunta e é um tipo de integral de convolução, como apresenta a figura a seguir:

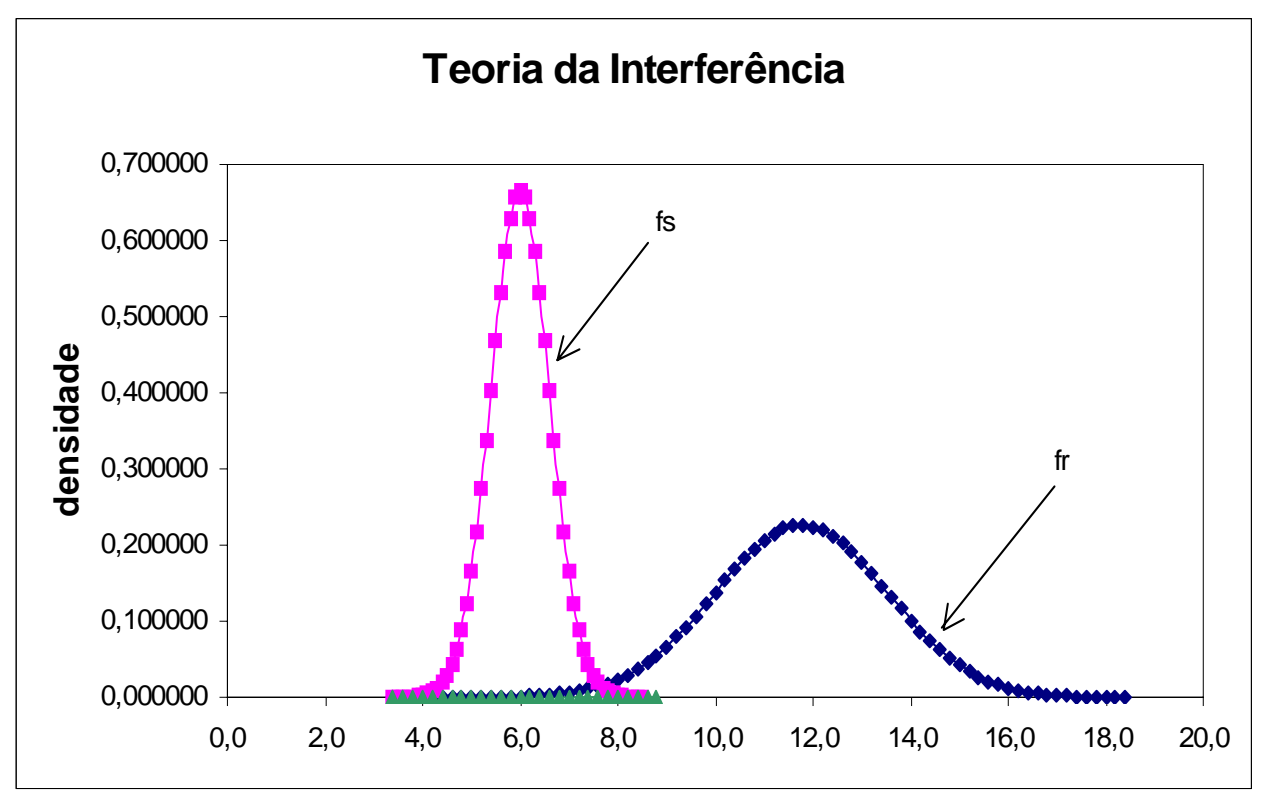

Figura 3.11 - Exemplos de funções densidade de probabilidade da resistência (fr) e das ações (fs).

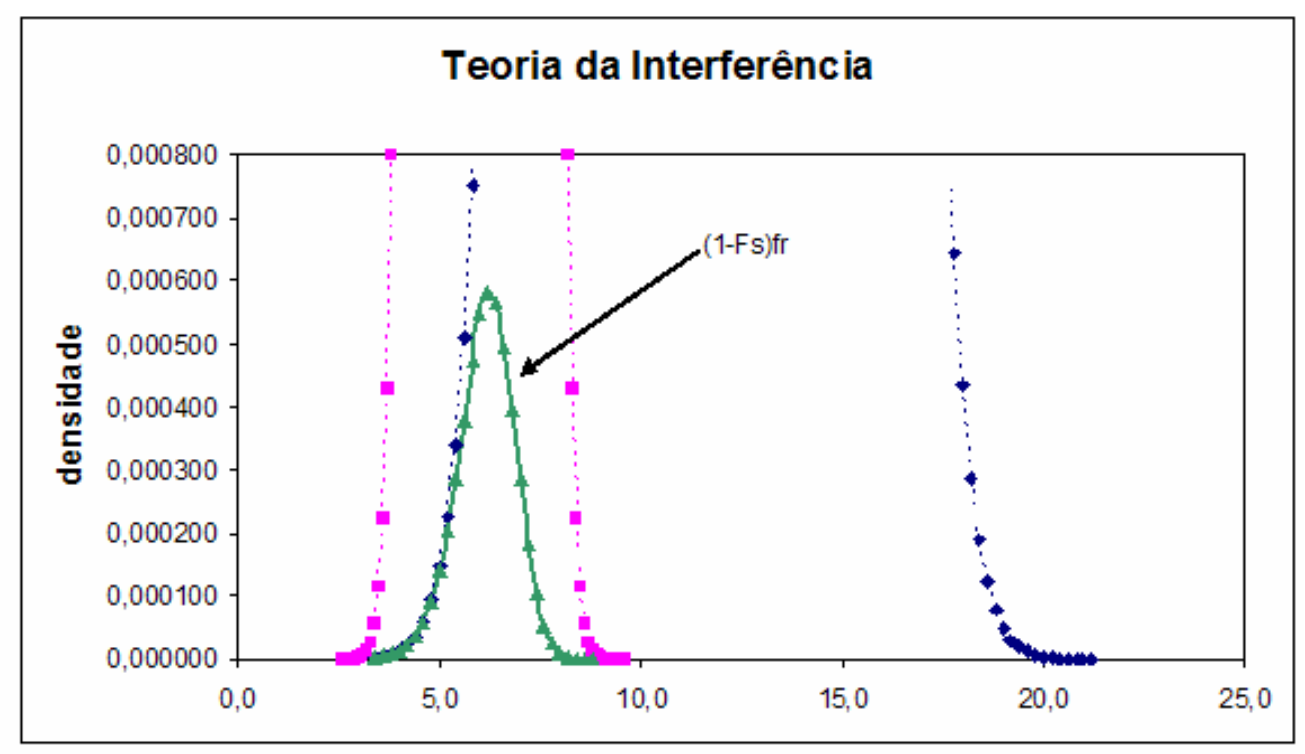

Figura 3.12 - Detalhe da figura anterior. A expressão 3.23 representa a integral da curva verde da figura supra. 


\section{CONCEITOS DE INFERÊNCIA BAYESIANA}

\subsection{INTRODUÇÃO}

Inevitavelmente, para o cálculo da probabilidade de ruína de qualquer obra de engenharia, é necessário o conhecimento da Função Densidade de Probabilidades (FDP) das variáveis aleatórias, no caso contínuo, ou da Função de Probabilidade, no caso discreto, esta última pouco usual na modelagem de variáveis de interesse na engenharia.

Nas demais áreas da engenharia, como na aeronáutica, mecânica ou elétrica, existe a possibilidade de se efetuar intensa testagem dos sistemas, através de amostragem repetida. Desta feita, pode-se conseguir tantas amostras quantas necessárias (e viáveis, do ponto de vista econômico) para o estudo probabilista das variáveis envolvidas. Este tipo de abordagem é conhecido como ABORDAGEM FREQUENTISTA e se alicerça no fato de que a probabilidade de um evento pode ser obtida empiricamente através da execução de um número grande o suficiente de observações repetidas do fenômeno e na verificação da freqüência de ocorrência do evento em questão (Martz e Waller , 1982).

$\mathrm{Na}$ engenharia civil a abordagem freqüentista também encontra aplicações importantes, particularmente no controle de qualidade de alguns materiais de construção (concreto e aço, por exemplo). Se dispusermos de uma amostra adequada de corpos de prova de concreto, a estatística clássica, calcada na teoria da amostragem, permite-nos fazer inferências sobre a resistência de todo um lote de concreto (população).

Por outro lado, sabe-se que a ruína é um evento raro. Muito se fala em probabilidades de ruína da ordem de $10^{-3}$ a $10^{-5}$. (De Zagottis, 1974), ou seja, as probabilidades de interesse estão localizadas nos extremos das caudas das distribuições probabilísticas.

Diversos estudiosos certificam que é muito pouco provável que consigamos definir adequadamente as caudas das distribuições probabilistas quando as probabilidades de interesse possuem valores reduzidos (Borges e Castanheta, 1971; Hachich, 1998b). 
Benjamin e Cornell (1970) mostram que a probabilidade de se ajustar uma função densidade de probabilidade a partir de um histograma de freqüências é de apenas 2/9 $(22,22 \%)$ e decresce rapidamente para $0 \%$ conforme o aumento do tamanho da amostra. Diante da raridade do evento ruína, a qual ocorre com pequena probabilidade, a magnitude do erro de ajustamento de uma densidade a partir do histograma é inadmissível.

Ademais, a abordagem freqüentista encontra importantes restrições no estudo da segurança de estruturas geotécnicas em vista do fato de que cada obra é um protótipo único (De Mello et al, 2002). Tal fato reforça a idéia de que as Funções Densidade de Probabilidade das variáveis aleatórias envolvidas no cálculo da segurança de uma estrutura geotécnica não podem ser obtidas experimentalmente.

Por estas razões, a inferência bayesiana pode substituir com vantagens a inferência clássica no estudo da segurança de obras de engenharia geotécnica, haja vista que possibilita a inclusão de informações disponíveis antes da amostragem, não tendo a amostra como única fonte de informação. As informações disponíveis antes da amostragem são incorporadas ao modelo probabilista sob a forma de uma distribuição anterior, condicionada ao agente que interpreta tais informações, tendo, portanto, um caráter subjetivo. Esse é, em certo sentido, o ponto mais forte da inferência bayesiana e também seu maior alvo de críticas: a utilização das probabilidades subjetivas.

Os aspectos subjetivos não são características exclusivas da Inferência Bayesiana, mas também do próprio processo de indução. Veja-se a definição de população, um dos pilares da inferência estatística, como conceitua Costa Neto (2002):

\footnotetext{
População, ou universo, no sentido geral, é um conjunto de elementos com pelo menos uma característica comum. Essa característica comum deve delimitar inequivocadamente quais os elementos que pertencem à população e quais os elementos que não pertencem.
}

Com fulcro na definição supra, observa-se que, para subsidiar o processo de inferência, há a necessidade de se delimitar as características comuns que definem a população de interesse. A questão que urge é quais e quantas são as características comuns 
necessárias para se identificar uma população? Evidentemente, estas questões não admitem uma resposta única, configurando o subjetivismo implícito no âmago do processo de indução.

Hachich (1998b) mostra que, mesmo que não explicitamente, qualquer decisão de engenharia é fulcrada no grau de crença que o engenheiro tem sobre os diversos estados da natureza, como expõe no excerto abaixo:

[....] Sabe-se, no entanto, que o engenheiro toma decisões, age com base em uma hipótese admitida como verdadeira: se opta por fundação direta, está implicitamente recusando a hipótese de existência de solo mole; se escolhe estacas, está aceitando como válida aquela hipótese. Se ele preferiu uma opção à outra, conhecendo os custos relativos a cada uma e as conseqüências de um eventual insucesso, uma estruturação simples do seu processo decisório, utilizando Análise de Decisões, permite calcular por retroanálise qual a probabilidade por ele atribuída à existência de solo mole no local da fundação.

Desta feita, se é possível retroanalisar a decisão, chegando-se às probabilidades anteriores atribuídas (não explicitamente) pelo decisor, a postura mais racional seria considerar, explicitamente, os juízos probabilistas apriorísticos, feito este que é formalizado mediante o uso da inferência bayesiana.

Martz e Waller (1982) destacam outra vantagem da Inferência Bayesiana em problemas de confiabilidade, consignando que as probabilidades subjetivas possibilitam a consideração não somente de eventos, mas de proposições, como por exemplo "a usina nuclear Angra II sofrerá um derretimento do seu núcleo”.

Diversos autores têm proposto a utilização da abordagem bayesiana em vários contextos na engenharia: na inspeção de estruturas (Vrouwenvelder, 1992; Kawano, 1997), em problemas de retroanálise probabilista (Hachich, 1981; Ledesma et al, 1988), na redução da incerteza de correlações empíricas (Zhang et al, 2004) e na reavaliação da segurança de estacas à luz da realização de provas de carga (Kay, 1976 e 1977; Baecher e Rackwitz, 1982; Zhang, 2004).

\subsection{O TEOREMA DE BAYES}

O Teorema herdou o nome de seu precursor, o Reverendo Thomas Bayes, que lançou 
as bases do método em seu famoso artigo de 1763, o qual, devido à sua fundamental importância, foi republicado em 1958. No entanto, a forma usual do teorema, como atualmente conhecida, foi devida à Laplace, em 1782.

O Teorema de Bayes será apresentado aqui com a mesma formatação utilizada em Benjamin e Cornell (1970). Admita-se que os eventos B1, B2,..., Bk do Diagrama de Venn apresentado na figura a seguir formem uma partição do espaço amostral S, ou seja, tais eventos são mutuamente excludentes e coletivamente exaustivos.

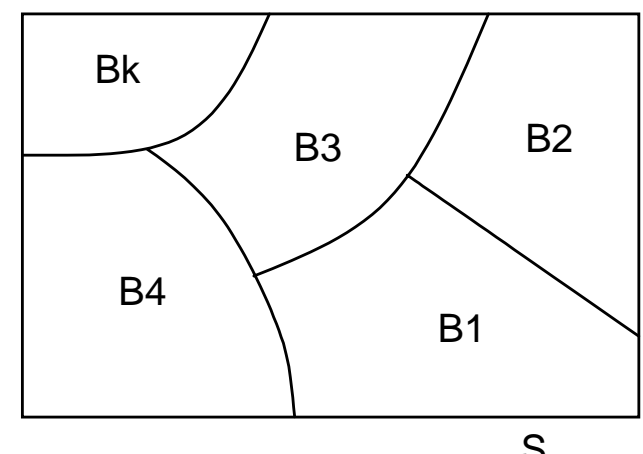

S

Figura 4.1 - Partição do espaço amostral S.

Suponha-se ainda que as probabilidades de cada um dos eventos do espaço amostral são conhecidas e denotadas por $\mathrm{P}(\mathrm{Bj}), \mathrm{j}=1, \ldots, \mathrm{k}$.

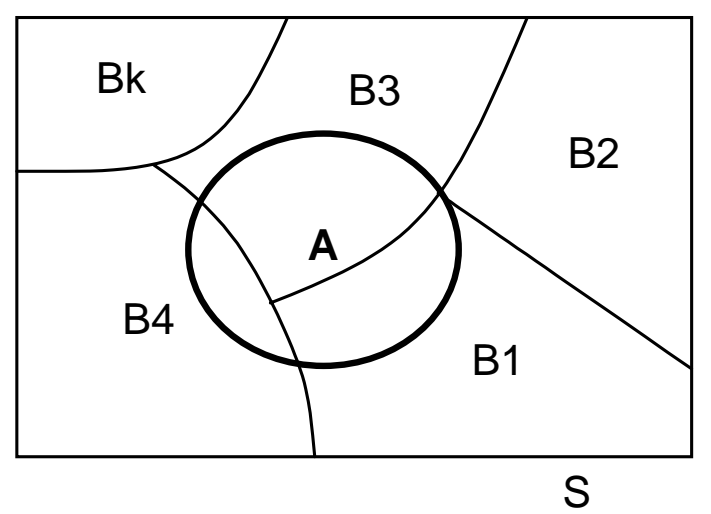

Figura 4.2 - Ocorrência de um evento A qualquer.

De posse da ocorrência de um evento A qualquer (Figura 4.2), o Teorema de Bayes possibilita recalcular as probabilidades de cada um dos eventos que constitui o espaço amostral, através da seguinte expressão: 
$P(B i / A)=\frac{P(A / B i) \cdot P(B i)}{\sum_{j=1}^{k} P(A / B j) \cdot P(B j)}$

Da formulação supra, observa-se que as probabilidades anteriores, traduzidas por $\mathrm{P}(\mathrm{Bi})$, são combinadas à informação adicional decorrente da observação do fenômeno, representada por $\mathrm{P}(\mathrm{A} / \mathrm{Bi})$, conduzindo a um estado de conhecimento atualizado, posterior à amostragem, representado por $\mathrm{P}(\mathrm{Bi} / \mathrm{A})$. Diz-se portanto que as probabilidades posteriores, $\mathrm{P}(\mathrm{Bi} / \mathrm{A})$, estão condicionadas à ocorrência de um evento A qualquer.

Bekman e Costa Neto (1980) informam que o Teorema de Bayes possibilita uma revisão de probabilidades decorrente de um novo estado de informação. Os referidos autores informam ainda que essa revisão de probabilidades é natural e intuitiva, citando o seguinte exemplo:

[...] Todos nós temos uma opinião a respeito, por exemplo, do evento "amanhã será um dia chuvoso" e teremos condições de externar essa opinião em termos probabilísticos. Digamos que, em nossa opinião, a probabilidade de "amanhã ser um dia chuvoso" seja de $30 \%$. É claro que esse número mudará profundamente se ligarmos o rádio e ouvirmos o locutor informar: “(...) a pior frente fria dos últimos meses se encontra agora a apenas 50 quilômetros de distância (...)”.

Podemos compreender melhor o funcionamento do referido Teorema mediante um exemplo ilustrativo (adaptado de Meyer, 1983), a seguir apresentado.

EXEMPLO: Estacas pré-moldadas fornecidas à uma determinada obra são fabricadas por três empresas, digamos empresas 1, 2 e 3. Admitamos que os dados relativos à estas três empresas são os seguintes:

\begin{tabular}{|c|c|c|c|}
\hline Informações relevantes & Empresa 1 & Empresa 2 & Empresa 3 \\
\hline Porcentagem de estacas fornecidas para a obra & $50 \%$ & $25 \%$ & $25 \%$ \\
\hline Porcentagem de estacas defeituosas & $2 \%$ & $2 \%$ & $4 \%$ \\
\hline
\end{tabular}

Tabela 4.1 - Informações anteriores consideradas.

Todas as peças estão armazenadas no depósito da obra, sem distinção entre as 
empresas. Suponha-se que uma estaca é retirada ao acaso do depósito e se verifique ser ela defeituosa. Qual a probabilidade de que tenha sido produzida pela empresa 1?

A solução pode ser obtida pela aplicação imediata do Teorema de Bayes (expressão 4.1), a saber:

$$
P(\text { empresal } / \text { defeituosa })=\frac{P(\text { defeituosa } / \text { empresa }) \cdot P(\text { empresa })}{\sum_{i=1}^{3} P(\text { defeituosa } / \text { empresa } i) \cdot P(\text { empresa } \mathrm{i})}
$$

Substituindo-se os dados, tem-se:

$P($ empresal $/$ defeituosa $)=\frac{0,02 \cdot 0,5}{0,02 \cdot 0,5+0,02 \cdot 0,25+0,04 \cdot 0,25}=0,40$

Pode-se proceder ao mesmo cálculo para atualizar as probabilidades da estaca ser proveniente das empresas 2 e 3. Procedendo-se aos cálculos, apresenta-se a seguir uma síntese dos resultados:

\begin{tabular}{|c|c|}
\hline Probabilidades Anteriores $[\mathrm{P}(\mathrm{Bi})]$ & Probabilidades Posteriores $[\mathrm{P}(\mathrm{Bi} / \mathrm{A}]$ \\
\hline $\mathrm{P}($ empresa 1$)=50 \%$ & $\mathrm{P}($ empresa $1 /$ defeito $)=40 \%$ \\
\hline $\mathrm{P}($ empresa 2$)=25 \%$ & $\mathrm{P}($ empresa $2 /$ defeito $)=20 \%$ \\
\hline $\mathrm{P}($ empresa 3$)=25 \%$ & $\mathrm{P}($ empresa3/defeito $)=40 \%$ \\
\hline
\end{tabular}

Tabela 4.2 - Probabilidades anteriores e posteriores à amostragem.

Da tabela supra, observa-se que, diante da observação de que a estaca escolhida possuía defeito, as probabilidades anteriores foram modificadas, decorrendo em um estado atualizado, traduzido pelas probabilidades posteriores.

\subsubsection{O teorema de Bayes no processamento de informações}

O Teorema de Bayes possibilita, de forma racional, processar as informações disponíveis antes da amostragem, incorporar a experiência prévia e fornecer um estado de conhecimento atualizado à luz da observação de um dado fenômeno (Hachich, 1998b). Para 
evidenciar essa capacidade, a expressão 4.1 necessita ser sensivelmente modificada, como apresentado em Benjamin e Cornell (1970).

Considere-se um determinado parâmetro $\theta$ (por exemplo, o fator de segurança) e uma função de probabilidades anteriores atribuídas ao estado da natureza denotada por $\mathrm{P}^{\prime}\left[\theta_{\mathrm{i}}\right]$. Considere-se ainda que se dispõe do resultado de um experimento (informação adicional), representado por $\mathrm{z}_{\mathrm{k}}$. O objetivo agora é combinar o conhecimento prévio que se tem sobre o parâmetro (traduzido pela função de probabilidades anteriores) com a nova informação disponível decorrente do experimento, a fim de se obter um estado de conhecimento atualizado, representado pelas probabilidades posteriores.

Para tanto, Benjamin e Cornell (1970) apresentam a seguinte formulação:

$$
P^{\prime \prime}\left[\theta_{i}\right]=\frac{P\left[z_{k} \mid \theta_{i}\right] \cdot P^{\prime}\left[\theta_{i}\right]}{\sum_{j} P\left[z_{k} \mid \theta_{j}\right] \cdot P^{\prime}\left[\theta_{j}\right]}
$$

Os autores mostram que o Teorema de Bayes pode ser apresentado como o produto de três fatores, a saber:

$$
\left(\begin{array}{c}
\text { Probabilidade posterior } \\
\text { de } \theta
\end{array}\right)=\left(\begin{array}{c}
\text { Constante de } \\
\text { normalizaçäo }
\end{array}\right)\left(\begin{array}{c}
\text { Função de } \\
\text { Verossimilhança }
\end{array}\right)\left(\begin{array}{c}
\text { Probabilidade } \\
\text { anterior de } \theta
\end{array}\right)
$$

Reescrevendo a equação 4.2 com esta formatação, tem-se:

$$
P^{\prime \prime}\left[\theta_{i}\right]=P\left[\theta_{i} \mid z_{k}\right]=N \cdot P\left[z_{k} \mid \theta_{i}\right] \cdot P^{\prime}\left[\theta_{i}\right]
$$

Onde:

$$
N=\frac{1}{\sum_{j} P\left[z_{k} \mid \theta_{j}\right] \cdot P^{\prime}\left[\theta_{j}\right]}
$$

Benjamin e Cornell (1970) informam que o fator de normalização N se justifica simplesmente para transformar a distribuição posterior $\left(\mathrm{P}^{\prime \prime}\left[\theta_{\mathrm{i}}\right]\right)$ em uma função de probabilidades válida do ponto de vista axiomático.

Os referidos autores expõem ainda que a função de verossimilhança, denotada por 
$\mathrm{P}\left[\mathrm{z}_{\mathrm{k}} \mid \theta_{\mathrm{i}}\right]$, representa a probabilidade de se obter a amostra observada como função do verdadeiro estado da natureza $\theta_{\mathrm{i}}$.

A expressão 4.3 supra não se mostra muito útil em aplicações práticas, eis que somente se aplica a variáveis discretas, ou seja, variáveis que assumem um número finito de valores ou então um número infinito porém enumerável de valores (Montgomery e Runger, 2003).

Normalmente, as variáveis de interesse na engenharia geotécnica assumem valores dentro de um intervalo no domínio dos números reais, ou seja, são classificadas como variáveis contínuas.

Destarte, no caso de uma variável aleatória contínua, a expressão 4.3 assume a seguinte forma:

$$
f^{\prime \prime}(\theta)=N \cdot L\left(\theta \mid z_{k}\right) \cdot f^{\prime}(\theta)
$$

Onde:

$$
N=\frac{1}{\int_{-\infty}^{\infty} L\left(\theta \mid z_{k}\right) \cdot f^{\prime}(\theta) d \theta}
$$

Entre os bayesianos, é muito comum a apresentação da expressão 4.7, a qual mostra que a função densidade posterior é proporcional ao produto da função de verossimilhança com a distribuição anterior, a saber:

$$
f^{\prime \prime}(\theta) \propto L\left(\theta \mid z_{k}\right) f^{\prime}(\theta)
$$

A grande dificuldade em se utilizar a expressão 4.5 é que a integral nela constante, muitas vezes, só pode ser feita através de integração numérica ou por métodos de simulação. Essa dificuldade é contornada com o uso das distribuições conjugadas, como será apresentado posteriormente. 


\subsubsection{A distribuição a priori e o processo de eliciação ${ }^{2}$ :}

Essencialmente, o que distingue a inferência bayesiana da inferência clássica é a capacidade da primeira em incorporar a experiência existente acerca de um determinado fenômeno.

A experiência anterior, evidentemente, deve ser considerada na solução dos diversos problemas de engenharia. Como informam Martz e Waller (1982), muitos projetos de engenharia seguem um contexto evolucionário ao invés de revolucionário, contexto onde, por exemplo, um equipamento atualmente existente é modificado para se adequar a novos requisitos, dando origem a um "novo" equipamento.

$\mathrm{Na}$ geotecnia, o aspecto evolucionário do conhecimento pode ser também traduzido pelo método de observação de Terzaghi (“observational method”). Neste contexto, a evolução do conhecimento ocorre de forma incremental, reconhecendo-se os desvios possíveis em relação à hipótese de trabalho, valendo-se de uma instrumentação capaz de detectar esses desvios e, finalmente, preparando-se planos de contingência para fazer frente à eles.

A experiência anterior, traduzida pela distribuição a priori, é particularmente importante em problemas de segurança de obras geotécnicas, em razão da exigüidade de dados experimentais disponíveis.

Por estas razões, muitas vezes, o engenheiro geotécnico recorre a opiniões de experts e ao julgamento de engenharia para estabelecer valores para parâmetros de interesse.

A obtenção de informação relevante de especialistas sobre o assunto de interesse (ou "eliciação" da opinião do expert) tem sido objeto de alguns estudos (Vick, 2002; Paulino et al, 2003), muito embora seja ainda um assunto pouco compreendido.

\footnotetext{
2. O termo em inglês "elicitation" é traduzido no presente trabalho por eliciação, como também procederam Paulino et al (2003), a despeito do fato de que muitos trabalhos que tratam de aquisição de dados apresentam a tradução da referida palavra por "elicitação". Eliciação vem do verbo "eliciar", que significa, de acordo com o dicionário Aurélio: fazer sair; expulsar; extrair uma resposta ou reação de; extrair enunciados ou julgamentos lingüísticos de (informante)
} 
Christian (2004) apresenta interessantes conclusões sobre as probabilidades subjetivas e a eliciação de especialistas.

Uma das questões levantadas pelo autor é a dificuldade inicial de se identificar um expert. $\mathrm{O}$ autor questiona quem seria um especialista e quão bem qualificado o mesmo deveria ser, informando que a opinião particular do especialista sobre o seu "grau de especialidade" poderia estar viesada para mais ou para menos.

Mesmo diante dessa dificuldade inicial, o autor expõe ainda que duas conclusões advêem da literatura especializada sobre eliciação:

A primeira é que reconhecidos especialistas tendem a fazer boas estimativas de medidas de tendência (médias e medianas) dos parâmetros. Mais ainda, a média das opiniões de vários especialistas tende a ser ainda melhor.

A segunda conclusão é que os especialistas são, usualmente, muito confiantes em suas estimativas e tendem a subestimar a incerteza a elas associadas.

Kondziolka and Kandaris (1996) apud Christian (2004) procederam a um interessante estudo sobre eliciação de especialistas em engenharia geotécnica. Nove engenheiros de diversos graus de expertise foram solicitados à projetar contra o arrancamento seis fundações em sapata de torres de transmissão. As sapatas foram então construídas e posteriormente ensaiadas ao arrancamento. A capacidade de carga estabelecida em projeto por cada especialista foi denotada por P e a carga de ruptura obtida no ensaio foi denotada por Q. Os resultados da relação P/Q obtida pelos diversos especialistas estão apresentados na figura da página seguinte, dispostos em ordem decrescente de acurácia. 


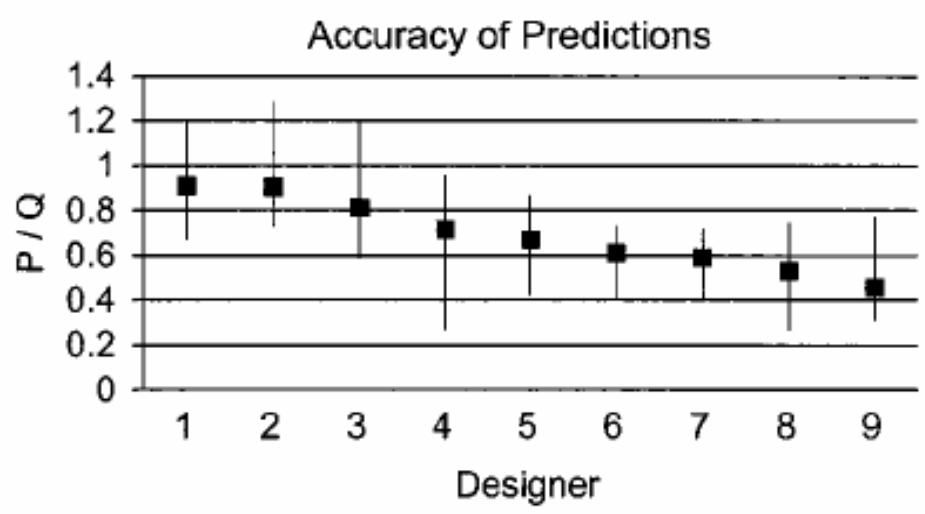

Figura 4.3 - Relação da capacidade prevista ao arrancamento (P) e da capacidade medida ao arrancamento (Q) das fundações de seis torres de transmissão, avaliadas por nove engenheiros. O gráfico foi construído com os dados apresentados por Kondziolka e Kandaris, 1996 apud Christian, 2004.

Os resultados permitiram aos autores concluir que há uma tendência de conservadorismo na atribuição da capacidade de carga por parte dos especialistas, ou seja, a relação $\mathrm{P} / \mathrm{Q}$ tende a ser menor que a unidade.

Os autores também concluíram que a experiência e formação dos diversos participantes não se correlacionaram de forma clara com os seus desempenhos no experimento. Por exemplo, os dois projetistas com melhor desempenho possuíam 14 e 30 anos de experiência, respectivamente, e o projetista com o pior desempenho possuía 22 anos de experiência. Surpreendentemente, o terceiro "melhor" projetista tinha experiência limitada (oito anos) e não tinha grau de mestrado nem de doutorado.

Christian (2004) vaticina que uma das lições a serem aprendidas com esses resultados é a dificuldade de se prever o desempenho de um expert com fulcro nas suas credenciais e experiência.

O autor ainda relata que um expert a ser eliciado deve ter não somente conhecimento e experiência, mas que também possua algo que o autor denota por "evaluated experience", que significa o "peso" ou importância da opinião de um determinado especialista. Neste contexto, especialistas com diferentes graus de expertise representariam diferentes "pesos" da informação a priori.

A variabilidade das opiniões dos experts e a falta de correlação entre experiência e acurácia das estimativas subjetivas suscitam críticas dos céticos em relação à abordagem 
bayesiana, inobstante ao fato de que, inexoravelmente, todo projeto geotécnico incorpora algum grau de subjetivismo.

\subsubsection{As distribuições conjugadas:}

Paulino et al (2003) informam que a seleção de uma distribuição a priori para modelagem probabilista de um fenômeno deve ser feita com base nos seguintes requisitos:

- Versatilidade para acomodar o maior número possível de crenças a priori;

- Acessibilidade interpretativa para facilitar o processo de sumarização dos seus membros;

- Simplicidade de derivação analítica da distribuição a posteriori.

Os referidos autores informam ainda que estes requisitos freqüentemente estão em dessintonia. A integral existente em 4.5 muitas vezes faz com que a derivação analítica da distribuição posterior se torne um processo complicado, assim como dificulta a interpretação de todos os membros da formulação.

Por esta razão, Raiffa e Schlaifer (1961) apresentaram, em seu célebre tratado, uma família de distribuições a priori que satisfizessem aos seguintes critérios:

- Tratabilidade analítica para determinação da distribuição posterior e das esperanças matemáticas;

- Flexibilidade para acomodar uma grande variedade de crenças apriorísticas;

- Fácil interpretação, de modo que os parâmetros da distribuição deveriam ser de tal forma que pudessem representar, de forma inteligível, as crenças do agente que faz a eliciação.

Tais distribuições foram denominadas de DISTRIBUIÇÕES CONJUGADAS. Esses tipos de distribuição anterior têm a interessante característica de gerar uma distribuição posterior que é do mesmo tipo que a distribuição a priori.

Deste modo, a expressão 4.5 reduz-se à simples relações algébricas entre as estatísticas da amostra (por exemplo, média e variância amostrais) e os parâmetros das densidades anterior e posterior (matematicamente conhecidos como hiperparâmetros, para distinguí-los dos parâmetros sobre os quais se deseja fazer inferências). 
A tabela da página seguinte apresenta as principais distribuições conjugadas utilizadas na inferência bayesiana.

A presente dissertação apresenta o uso das distribuições conjugadas para incorporação dos resultados de provas de carga na avaliação da segurança de estacas, no âmbito da inferência bayesiana. 


\begin{tabular}{|c|c|c|c|c|}
\hline $\begin{array}{l}\text { Comportamento do fenômeno } \\
\text { subjacente }\end{array}$ & Parâmetro & Distribuição anterior e posterior & $\begin{array}{l}\text { Média e Variância do } \\
\text { parâmetro }\end{array}$ & Estatísticas Posteriores \\
\hline Binomial & & Beta & $E(\theta)=\frac{q}{q+r}$ & $q^{\prime \prime}=q^{\prime}+\mathrm{x}$ \\
\hline$p_{X}(\mathrm{x})=\left(\begin{array}{l}n \\
\mathrm{x}\end{array}\right) \theta^{\mathrm{x}}(1-\theta)^{n-\mathrm{x}}$ & $\theta$ & $f_{\theta}(\theta)=\frac{\Gamma(q+r)}{\Gamma(q) \Gamma(r)} \cdot \theta^{q-1}(1-\theta)^{r-1}$ & $\operatorname{Var}(\theta)=\frac{q r}{(q+r)^{2}(q+r+1)}$ & $r^{\prime \prime}=r^{\prime}+n-x$ \\
\hline Exponencial & & Gama & $E(\lambda)=\frac{k}{v}$ & $v^{\prime \prime}=v^{\prime}+\Sigma x$ \\
\hline$f_{X}(\mathrm{x})=\lambda \mathrm{e}^{-\lambda \mathrm{x}}$ & $\lambda$ & $f_{\Lambda}(\lambda)=\frac{v(v \lambda)^{k-1} e^{-v \lambda}}{\Gamma(k)}$ & $\operatorname{Var}(\lambda)=\frac{k}{v^{2}}$ & $\mathrm{k}^{\prime \prime}=\mathrm{k}^{\prime}+\mathrm{n}$ \\
\hline Normal (com $\sigma$ conhecido) & & Normal & $E(\mu)=\mu_{\mu}$ & $\mu_{\mu}^{\prime \prime}=\frac{\mu_{\mu}^{\prime}\left(\sigma^{2} / \mathrm{n}\right)+\overline{\mathrm{x}} \sigma_{\mu}^{\prime 2}}{\left(\sigma^{2} / \mathrm{n}\right)+\left(\sigma_{\mu}^{\prime}\right)^{2}}$ \\
\hline $\mathrm{X} \sim \mathrm{N}(\mu, \sigma)$ & $\mu$ & $f_{M}(\mu)=\frac{1}{\sqrt{2 \pi} \sigma_{\mu}} \exp \left[-\frac{1}{2}\left(\frac{\mu-\mu_{\mu}}{\sigma_{\mu}}\right)^{2}\right]$ & $\operatorname{Var}(\mu)=\sigma_{\mu}^{2}$ & $\sigma^{\prime \prime}=\sqrt{\frac{\left(\sigma^{\prime}\right)^{2}\left(\sigma^{2} / \mathrm{n}\right)}{\left(\sigma^{\prime}\right)^{2}+\sigma^{2} / \mathrm{n}}}$ \\
\hline Poisson & & Gama & $E(\mu)=k / v$ & $v^{\prime \prime}=v^{\prime}+\mathrm{t}$ \\
\hline$p_{X}(\mathrm{x})=\frac{(\mu \cdot \mathrm{t})^{\mathrm{x}}}{\mathrm{x} !} \exp [-\mu \cdot \mathrm{t}]$ & $\mu$ & $f_{M}(\mu)=\frac{v(v \mu)^{k-1} e^{-v \mu}}{\Gamma(k)}$ & $\operatorname{Var}(\mu)=k / v^{2}$ & $\mathrm{k}^{\prime \prime}=\mathrm{k}^{\prime}+\mathrm{x}$ \\
\hline
\end{tabular}




\subsection{UTILIZAÇÃO DA INFERÊNCIA BAYESIANA PARA REAVALIAÇÃO DA SEGURANÇA DE ESTACAS APÓS A EXECUÇÃO DE PROVAS DE CARGA}

Uma das primeiras aplicações da inferência bayesiana na reavaliação da segurança de estacas à luz dos resultados de provas de carga foi feita por Kay (1976 e 1977). Usos posteriores dessa metodologia, contemplando alguns avanços em relação à importante contribuição de Kay, foram apresentados por Vrouwenvelder (1992) e Zhang (2004). No entanto, foi o trabalho de Baecher e Rackwitz (1982) que, de fato, apresentou uma forma consistente e formal de se incorporar os resultados de provas de carga na segurança de estacas.

Inobstante à grande contribuição representada pelo artigo de Baecher e Rackwitz sobre o tema segurança de estacas, o mesmo continha alguns erros tipográficos que tornaram o seu entendimento difícil e, talvez, tenham postergado as aplicações da abordagem bayesiana na avaliação da segurança de estacas.

Desta feita, o presente trabalho pretende resgatar os importantes conceitos lançados por Baecher e Rackwitz, fornecendo subsídios para o desenvolvimento dos critérios de segurança de fundações por estacas de deslocamento.

\subsubsection{Informações anteriores relevantes para a atribuição da distribuição a priori:}

O engenheiro geotécnico normalmente dispõe, mesmo na fase de projeto, de informações apriorísticas importantes para o estudo da segurança de estacas.

Baecher e Rackwitz (1982) informam que a informação a priori para inferência da capacidade de carga de estacas provém de duas fontes: (i) de correlações entre a capacidade de carga observada e a prevista por algum método de estimativa da capacidade de carga (seja teórico ou empírico) e (ii) da variabilidade da capacidade de carga das estacas dentro uma mesma obra.

Estas duas fontes de informações a priori serão melhor discutidas nos tópicos que se seguem. 


\subsubsection{Correlações entre capacidade observada e prevista}

Vários autores têm apresentado dados que permitem confrontar a capacidade de carga observada (normalmente mediante provas de carga estática) com a capacidade de carga prevista por métodos empíricos ou teóricos (Olson e Flaate, 1964; Aoki e Veloso, 1975; Decourt e Quaresma, 1978). Essa confrontação origina a variável K, conhecida como fator de viés, a qual representa a relação entre a capacidade observada e a prevista pelo método, a saber:

$$
K=\frac{P_{\text {observado }}}{P_{\text {previsto }}}
$$

O uso dessa variável é bastante conveniente pelo fato de a mesma se apresentar de forma adimensionalizada, fazendo com que variáveis como comprimento e diâmetro da estaca não sejam avaliados diretamente.

É importante ressaltar que essa variável não é fixa para um determinado método de previsão, mas sim uma variável aleatória, em função das características peculiares da obra de interesse e da incerteza estatística inerente ao processo de indução do comportamento das estacas de uma obra através de provas de carga (Hachich, 1998a).

Diversos autores têm informado que a variável $\mathrm{K}$ pode ser representada por uma distribuição log-normal (Kay, 1976; Baecher e Rackwitz, 1982; Zhang, 2004). Diante dessa realidade, também é comum a apresentação, em muitos trabalhos, da variável $R$, a qual vem definida por:

$$
R=\log K=\log \left(\frac{P_{\text {observado }}}{P_{\text {previsto }}}\right)
$$

A tabela apresentada na página seguinte expõe a média e o desvio-padrão das variáveis $\mathrm{K}$ e $\mathrm{R}$ para alguns métodos de previsão da capacidade de carga, considerando-se execução de provas de carga estáticas.

Como freqüentemente a variável $\mathrm{K}$ é modelada por uma distribuição log-normal, a variável $\mathrm{R}=\log \mathrm{K}$ possui, por decorrência, distribuição normal (Benjamin e Cornell, 1970).

Baecher e Rackwitz (1982) consideram que a variável R possui distribuição normal 
com média $\mu$ e variância $\sigma^{2}$, ou seja:

$f_{R}\left(r_{i} \mid \mu, \sigma^{2}\right)=\frac{1}{\sqrt{2 \pi} \sigma} \cdot \exp \left[-\frac{1}{2 \sigma^{2}} \cdot\left(r_{i}-\mu\right)^{2}\right]$

\begin{tabular}{|c|c|c|c|c|}
\hline \multirow{2}{*}{$\begin{array}{c}\text { Método } \\
\text { (referência) }\end{array}$} & \multicolumn{2}{|c|}{$\mathrm{K}=\mathrm{P}_{\text {obs }} / \mathrm{P}_{\text {prev }}$} & \multicolumn{2}{|c|}{$\mathrm{R}=\log \left(\mathrm{P}_{\text {obs }} / \mathrm{P}_{\text {prev }}\right)$} \\
\hline & média $[\mathrm{K}]$ & desvio $[\mathrm{K}]$ & média[R] & desvio[R] \\
\hline $\begin{array}{c}\text { Aoki-Veloso } \\
\text { (Aoki e Veloso, 1975) }\end{array}$ & 1,014 & 0,235 & $-0,0051$ & 0,0976 \\
\hline $\begin{array}{c}\text { Aoki-Veloso } \\
\text { (Aoki et al, 2002) }\end{array}$ & 0,914 & 0,191 & $-0,048$ & 0,0955 \\
\hline $\begin{array}{c}\text { Decourt-Quaresma } \\
\text { (Decourt e Quaresma, 1978) }\end{array}$ & 1,058 & 0,341 & 0,0061 & 0,1240 \\
\hline $\begin{array}{c}\text { Janbu } \\
\text { (Olson e Flaate, 1964) }\end{array}$ & 1,130 & 0,690 & 0,016 & 0,165 \\
\hline $\begin{array}{c}\text { Hiley } \\
\text { (Olson e Flaate, 1964) }\end{array}$ & 1,418 & 1,147 & 0,087 & 0,216 \\
\hline $\begin{array}{c}\text { Dinamarqueses } \\
\text { (Olson e Flaate, 1964) }\end{array}$ & 0,905 & 0,522 & $-0,077$ & 0,156 \\
\hline $\begin{array}{c}\text { Gates } \\
\text { (Olson e Flaate, 1964) }\end{array}$ & 1,330 & 0,615 & 0,085 & 0,180 \\
\hline $\begin{array}{c}\text { Engineering News } \\
\text { (Olson e Flaate, 1964) }\end{array}$ & 1,075 & 0,806 & $-0,095$ & 0,348 \\
\hline
\end{tabular}

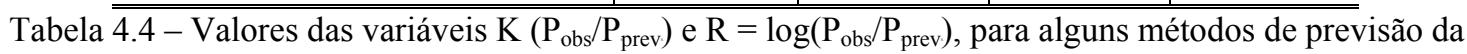
capacidade de carga de estacas. A fonte de onde se extraiu o banco de dados está referenciada em parênteses, na primeira coluna.

Do exposto, nota-se que uma vez que o engenheiro de fundações opta pelo uso de um determinado método de previsão da capacidade de carga da estaca, em uma localidade onde se dispõe de informação anterior, um valor de K (ou de R) fica determinado.

Importante salientar que a abordagem bayesiana não exige que a informação a priori advenha tão somente de estudos anteriores. Também seria lícito, no caso de inexistência destes estudos relativamente à localidade em questão, proceder à eliciação de um expert, 
como já informado no item 4.2.2 do presente trabalho.

\subsubsection{Variabilidade dentro de uma mesma obra}

A outra fonte de informação apriorística se refere à variabilidade da capacidade de carga das estacas em uma mesma obra. Devido às variabilidades inerentes às características geológicas do subsolo, à pormenores da cravação e outras especificidades locais e circunstanciais, a variável $\mathrm{R}=\log \left(\mathrm{P}_{\text {observado }} / \mathrm{P}_{\text {previsto }}\right)$ seria função da localização do ponto da obra onde se avalia a segurança da estaca.

Bilfinger (2002) informa que, em um mesmo universo geológico, pequenas variações de difícil detecção por investigações geotécnicas convencionais podem provocar alterações na capacidade de carga de estacas. O referido autor também apresenta algumas formas de se tratar a variabilidade intra-canteiro, todas de maneira ad hoc, a saber:

- Divisão da área em sub-áreas de influência para cada sondagem;

- Escolha de uma sondagem "média" como representativa;

- Escolha de uma sondagem "ruim" como representativa;

- Montagem de uma sondagem fictícia, baseada em valores médios para cada profundidade de todas as sondagens;

- Montagem de uma sondagem fíctícia, baseada em valores mínimos para cada profundidade de todas as sondagens.

Alguns autores apresentam valores fixos para a variabilidade no interior de uma mesma obra. Kay (1976) apresenta um desvio-padrão da variável $\mathrm{R}$ constante e igual à 0,12. Vrouwenvelder (1992) considera que o coeficiente de variação da capacidade de carga em determinada obra é constante e igual à 15\%. Zhang (2004) também considera constante a variabilidade intra-canteiro, propondo um coeficiente de variação da variável $\mathrm{K}=$ $\mathrm{P}_{\text {observado }} / \mathrm{P}_{\text {previsto }}$ de $20 \%$.

A tabela a seguir (Kay, 1993) também apresenta alguns valores para o coeficiente de variação da capacidade de carga de estacas, em algumas localidades. 


\begin{tabular}{c|c|c|c}
\hline $\begin{array}{c}\text { Localização } \\
\text { (referência) }\end{array}$ & Tipo de solo & $\begin{array}{c}\text { Número de estacas } \\
\text { ensaiadas }\end{array}$ & $\begin{array}{c}\text { Coeficiente de } \\
\text { variação }\end{array}$ \\
\hline Londres - Hendon & Argila muito mole & 9 & 0,12 \\
\hline Londres - Southall & Argila muito mole & 5 & 0,11 \\
\hline Londres - Brandon & Argila muito mole & 5 & 0,08 \\
\hline Houston - Texas & Argila mole/ & 11 & 0,08 \\
\hline \hline
\end{tabular}

Tabela 4.5 - Variabilidade intra-canteiro da capacidade de carga de estacas (Kay, 1993).

A consideração de um valor fixo para a variabilidade da capacidade de carga dentro de uma determinada obra só pode ser admitida quando existem informações suficientes relativas ao local da obra para dar fundamento a essa assunção.

Como será apresentado posteriormente, a inferência com variância conhecida facilita bastante os cálculos de estimativa do fator de segurança bem como possibilita a tabulação do fator de segurança para diversas classes de variabilidade intra-canteiro (por exemplo, sítios com alta, média e baixa variabilidade de capacidade de carga). A tabulação do fator de segurança condicionado à precisão intra-canteiro, inobstante desejada, ainda não é contemplada na maioria das normas e códigos de construção de fundações.

Como alternativa à inferência com variância intra-canteiro conhecida, Baecher e Rackwitz (1982) propuseram um tratamento consistente da incerteza associada à variável $\mathrm{R}=$ $\log \left(\mathrm{P}_{\text {observado }} / \mathrm{P}_{\text {previsto }}\right)$ no interior da obra, considerando a variabilidade intra-canteiro como uma variável aleatória.

Os referidos autores, adicionando informações de 13 obras às 3 obras analisadas por Kay (1976), exprimiram a variabilidade intra-canteiro através da variância do logaritmo da relação entre a capacidade observada e a prevista para uma determinada obra. Assim, admitindo-se que em uma determinada localidade tenham sido executadas $\mathrm{n}$ provas de carga, 
decorrendo na obtenção de $n$ valores da variável $R\left(r_{1}, r_{2}, \ldots . . ., r_{n}\right)$, pode-se calcular o valor da variância intra-canteiro pela expressão a seguir:

$\sigma^{2}=\frac{\sum_{i=1}^{n}\left(r_{i}-r_{\text {med }}\right)^{2}}{n-1}$

Onde $\mathrm{r}_{\text {med }}$ é o valor médio da variável $\mathrm{R}=\log \left(\mathrm{P}_{\text {observado }} / \mathrm{P}_{\text {previsto }}\right)$ na obra em questão e $\mathrm{r}_{\mathrm{i}}$ é um particular valor de $\mathrm{R}$ verificado na mesma obra.

Os autores ainda conceituam a variável precisão intra-canteiro (h), a qual vem definida como sendo o inverso da variância de R no interior do site, ou seja: $h=\frac{1}{\sigma^{2}}$

Como a variância é uma medida de dispersão, a variável precisão (h) deve ser interpretada como uma medida de concentração dos valores individuais de capacidade de carga no interior da obra em torno da capacidade média de carga da mesma obra (Martz e Waller, 1982).

Baecher e Rackwitz (1982), estudando 16 casos de obras, concluíram que a variável precisão pode ser admitida como aderente à uma densidade de probabilidade do tipo Gama. Tal distribuição possui a seguinte expressão matemática (Bekman e Costa Neto, 1980):

$$
f\left(h \mid \frac{v^{\prime}}{2}, \frac{v^{\prime} v^{\prime}}{2}\right)=h^{\frac{v^{\prime}}{2}-1} \cdot \frac{\left(\frac{v^{\prime} v^{\prime}}{2}\right)^{k-1}}{\Gamma\left(\frac{v^{\prime}}{2}\right)} \cdot \exp \left[-\frac{v^{\prime} v^{\prime}}{2} \cdot h\right]
$$

A figura abaixo ilustra a grande variedade de formatos possíveis para o referido modelo probabilista: 


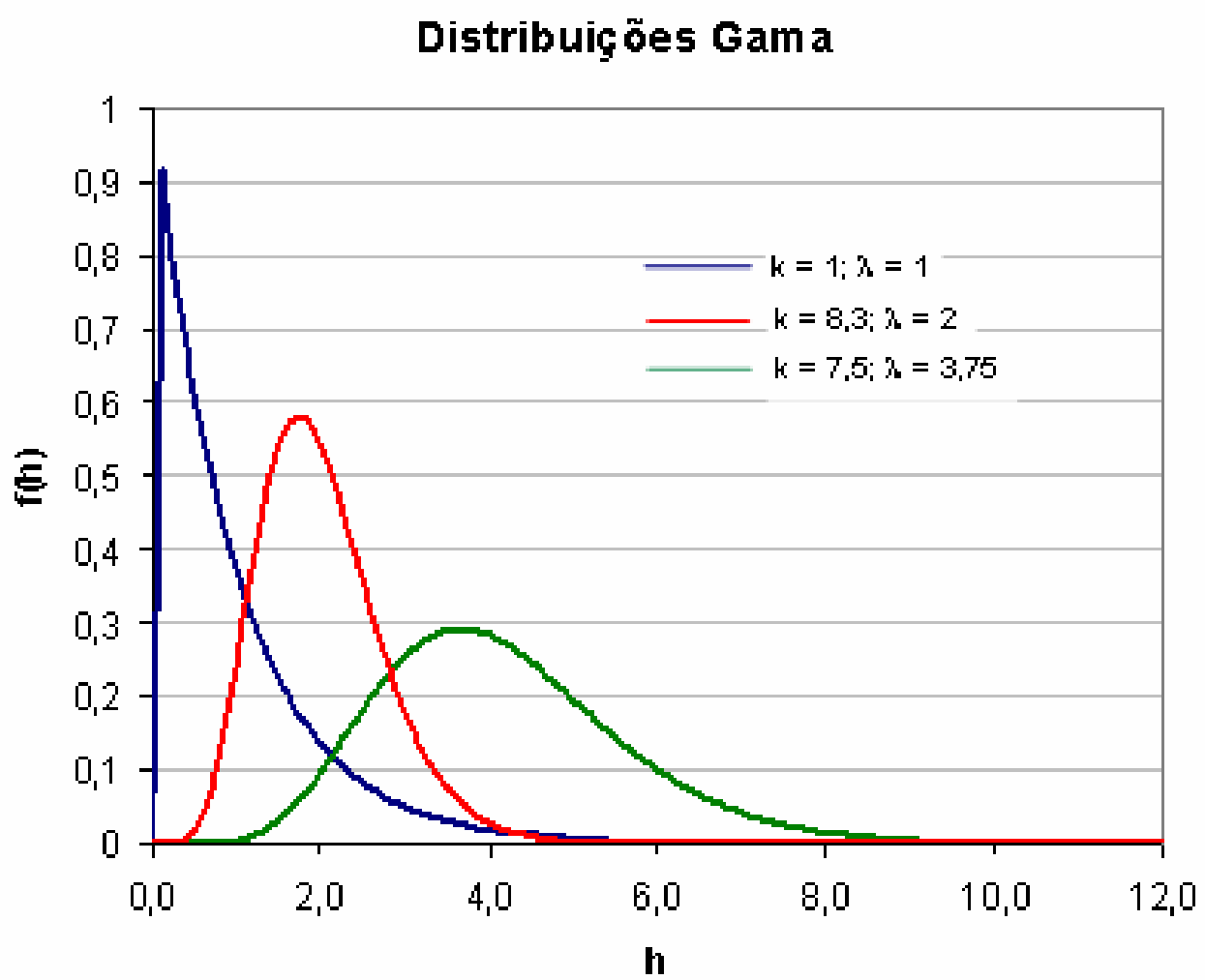

Figura 4.4 -Algumas variações da Função Densidade de Probabilidade do tipo Gama.

Benjamin e Cornell (1970) informam ainda que a densidade do tipo Gama é muito utilizada na modelagem de fenômenos de engenharia civil, mais pela sua variedade de formatos e conveniente forma matemática do que pela sua habilidade em simular o mecanismo subjacente à um fenômeno físico aleatório.

No caso do artigo de Baecher e Rackwitz (1982), foram propostas duas distribuições Gama, que os autores chamaram por "mais apertada" e "mais ampla", com os seguintes parâmetros.

\begin{tabular}{c|c|c}
\hline \multirow{2}{*}{ Distribuição } & \multicolumn{2}{|c}{ Parâmetros } \\
\cline { 2 - 3 } & De forma $\left(v^{\prime} / 2\right)$ & De escala (v'v'/2) \\
\hline "mais apertada" & 4,64 & 0,0705 \\
\hline "mais ampla" & 2,21 & 0,0269 \\
\hline \hline
\end{tabular}

Tabela 4.6 - Parâmetros das distribuições Gama obtidas por Baecher e Rackwitz (1982).

As distribuições Gama obtidas pelos autores seguem apresentadas abaixo: 


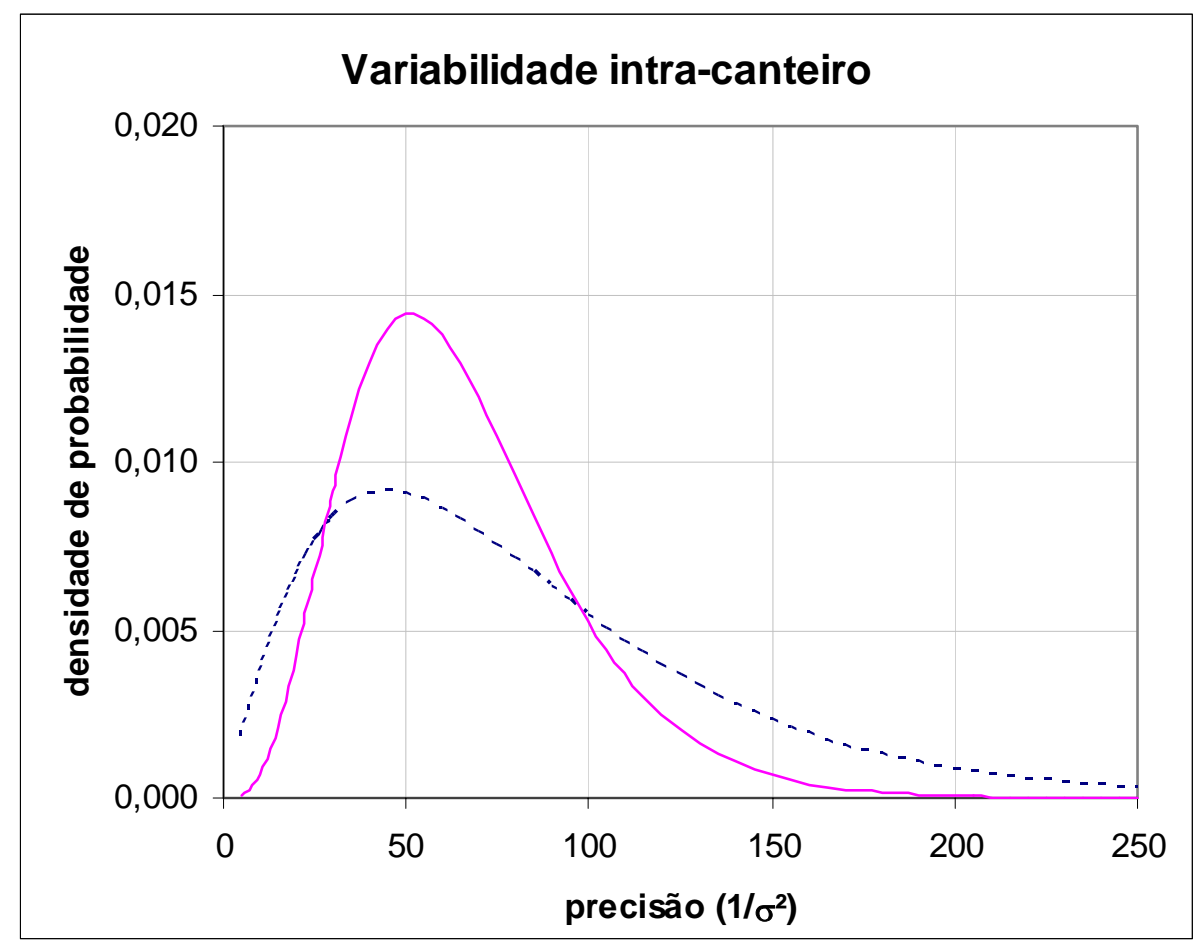

Figura 4.5 - Distribuições Gama representativas da precisão intra-canteiro (Baecher e Rackwitz, 1982).

Inobstante ao rigor formal da abordagem de Baecher e Rackwitz (1982) na consideração da precisão intra-canteiro, não parece prudente, na prática, derivar a distribuição da precisão intra-canteiro por comparação entre diversas obras. Dado o porte da maioria das obras de engenharia civil e a provável autocorrelação da capacidade de carga das estacas no interior de uma determinada obra, pode-se admitir que a variabilidade intra-canteiro seja consideravelmente menor que a variabilidade inter-canteiros, de forma que considerar a distribuição da precisão de $\mathrm{R}$ entre diversas obras incorpora uma incerteza adicional na análise.

\subsubsection{A conjugação proposta para a obtenção da distribuição posterior - caso de variância desconhecida}

As distribuições conjugadas devem ser escolhidas, sempre que possível, de modo a bem representar a incerteza contida nos parâmetros estudados.

Baecher e Rackwitz (1982) apresentam argumentos consistentes para a proposição de uma distribuição anterior conjugada da posterior, para ocasiões nas quais a variabilidade da capacidade de carga das estacas em uma determinada obra não possa ser admitida como 
conhecida e fixa. Os referidos autores postulam que diante da normalidade da variável $\mathrm{R}=$ $\log \left(\mathrm{P}_{\text {observado }} / \mathrm{P}_{\text {previsto }}\right)$ e também em decorrência do fato de a precisão intra-canteiro se ajustar bem à uma densidade do tipo Gama, a função densidade anterior a ser escolhida é a NormalGama, a saber:

$\mathrm{f}^{\prime}(\mu, h) \propto \mathrm{h}^{1 / 2} \cdot \exp \left(-\frac{1}{2} h n^{\prime}\left(\mu-\mu^{\prime}\right)^{2}\right) \cdot \exp \left(-\frac{1}{2} h v^{\prime} v^{\prime}\right) \cdot h^{1 / 2\left(v^{\prime}-1\right)}$

Onde:

$\mu, \mathrm{h}=$ parâmetros da distribuição de $\mathrm{R}$ no interior do canteiro;

n' = tamanho equivalente da amostra para a média de R;

$\mu^{\prime}=$ valor esperado anterior da média de R;

$v^{\prime}=$ graus de liberdade equivalente anterior da precisão h;

$v^{\prime}=$ parâmetro de locação da distribuição anterior de h.

A amostragem corresponde à execução de $\mathrm{n}$ de provas de carga em uma determinada obra, cada uma delas decorrendo em um valor $\mathrm{r}_{\mathrm{i}}$, particular ocorrência da variável $\mathrm{R}$. Deste modo, pode-se calcular a média e variância amostrais, através das expressões :

$$
\begin{aligned}
& \mathrm{m}_{\mathrm{R}}=\frac{1}{\mathrm{n}} \cdot \sum_{i=1}^{\mathrm{n}} r_{i} \\
& \mathrm{~s}_{\mathrm{R}}^{2}=\frac{\sum_{i=1}^{n}\left(r_{i}-\mathrm{m}_{\mathrm{R}}\right)^{2}}{\mathrm{n}-1}
\end{aligned}
$$

Como a função 4.14 pertence à família das distribuições conjugadas, a forma matemática da distribuição posterior terá o mesmo formato da referida função, com hiperparâmetros atualizados segundos as expressões a seguir (Martz e Waller, 1982):

$$
\begin{aligned}
& \mathrm{n}^{\prime \prime}=\mathrm{n}^{\prime}+\mathrm{n} \\
& \mu^{\prime \prime}=\left(\mathrm{nm}_{\mathrm{R}}+\mathrm{n}^{\prime} \mu^{\prime}\right) / \mathrm{n}^{\prime \prime} \\
& v^{\prime \prime}=\mathrm{n}+v^{\prime} \\
& v^{\prime \prime} v^{\prime \prime}=v^{\prime} v^{\prime}+(\mathrm{n}-1) \mathrm{S}_{\mathrm{R}}{ }^{2}+\mathrm{n} \mu^{\prime 2}+\mathrm{nm}_{\mathrm{R}}{ }^{2}-\mathrm{n}^{\prime \prime} \mu^{\prime \prime 2}
\end{aligned}
$$

Assim, de posse dos parâmetros atualizados à luz da amostragem, a distribuição 
posterior assume a seguinte forma:

$$
\mathrm{f}^{\prime \prime}(\mu, \mathrm{h})=\mathrm{f}(\mu, h \mid z) \propto \mathrm{h}^{1 / 2} \cdot \exp \left(-\frac{1}{2} h n^{\prime \prime}\left(\mu-\mu^{\prime \prime}\right)^{2}\right) \cdot \exp \left(-\frac{1}{2} h v^{\prime \prime} v^{\prime \prime}\right) \cdot h^{1 / 2\left(v^{\prime \prime}-1\right)}
$$

$\mathrm{Na}$ expressão supra, “z” representa o vetor de valores da variável R decorrentes da realização de provas de carga, ou seja, $z=\left(r_{1}, r_{2}, \ldots \ldots ., r_{n}\right)$. A expressão 4.21 representa a distribuição posterior dos parâmetros de R, ou seja, representa a distribuição posterior da média e da precisão intra-canteiro.

No entanto, interessa ao engenheiro fazer juízos probabilistas sobre a variável $\mathrm{R}=$ $\log \left(\mathrm{P}_{\text {observado }} / \mathrm{P}_{\text {previsto }}\right)$ e não sobre parâmetros de sua distribuição. Benjamin e Cornell (1970) informam que se deve primeiro atualizar os parâmetros da distribuição de $R(\mu \mathrm{e} h)$, através da expressão 4.5 (ou através de alguma distribuição conjugada), para posteriormente obter a distribuição do próprio R. Para obtenção da distribuição atualizada de R (e não de seus parâmetros), os autores apresentam a distribuição preditiva, definida pela expressão a seguir:

$$
\mathrm{f}_{\mathrm{R}}{ }^{\prime \prime}(\mathrm{r})=\mathrm{f}_{\mathrm{R}} "(\mathrm{r} \mid \mathrm{z})=\int \mathrm{f}_{\mathrm{R}}(\mathrm{r} \mid \mathrm{z}, \mu, \mathrm{h}) \cdot \mathrm{f} "(\mu, \mathrm{h}) \mathrm{d} \mu \mathrm{dh}
$$

Baecher e Rackwitz (1982) informam que a solução da integral supra decorre em uma distribuição da seguinte forma:

$$
\mathrm{f}_{\mathrm{R}}{ }^{\prime}(\mathrm{r} \mid \mathrm{z}) \propto\left[1+\frac{H}{v^{\prime \prime}}\left(r-\mu^{\prime \prime}\right)\right]^{1 / 2\left(v^{\prime \prime}-1\right)}
$$

Os autores aduzem que a expressão supra é uma distribuição t-Student, com $v^{\prime \prime}$ graus de liberdade e parâmetros $\mu^{\prime \prime}$ e H, este último dado por:

$$
\mathrm{H}=\frac{\mathrm{n}^{\prime \prime}}{(\mathrm{n} "+1) v^{\prime \prime}}
$$

A média e a variância do valor de $\mathrm{R}$ são dadas pelas expressões $4.25 \mathrm{e}$ 4.26 respectivamente: 
$\mathrm{E}[\mathrm{r} \mid \mathrm{z}]=\mu^{\prime \prime}$

$V[r \mid z]=\frac{v^{\prime \prime}}{v^{\prime \prime}-2} \cdot \frac{v^{\prime \prime}}{\mathrm{n}^{\prime \prime}}$

Conhecida a distribuição de $\mathrm{R}$ (t-Student), pode-se calcular um valor extremo negativo dessa variável, denotado por $\mathrm{r}_{\mathrm{o}}$. Tal valor é função da distância do valor médio $\mu$ " da distribuição, distância essa "medida" através do índice de confiabilidade, $\beta$. A relação de $r_{o}$ com o índice de confiabilidade é dada pelo que segue:

$r_{o}=\mu^{\prime \prime}+\frac{\beta}{\sqrt{H}}$

Baecher e Rackwitz (1982) relacionam o valor de $r_{0}$ com o fator de segurança, definido por:

$\mathrm{FS}=\frac{\text { Capacidade de carga prevista em projeto }}{\text { Capacidade de carga esperada }}$

A capacidade esperada é, na realidade, o valor da capacidade de carga observado por ocasião da prova de carga. Como o valor de $\mathrm{r}_{\mathrm{o}}$ representa a relação:

$\mathrm{r}_{\mathrm{o}}=\log \left[\frac{\mathrm{P}_{\text {observado }}}{\mathrm{P}_{\text {projeto }}}\right]$

Da expressão 4.29 em 4.28 tem-se:

$\mathrm{FS}=10^{-\mathrm{r}_{0}}$

A expressão 4.30 representa o fator de segurança que deve ser aplicado às previsões da capacidade de carga, de forma a assegurar um determinado índice de confiabilidade, posteriormente à execução de provas de carga.

Aplicando a metodologia retro exposta, Baecher e Rackwitz obtiveram os fatores de 
segurança declinados no gráfico a seguir, considerando-se os parâmetros da distribuição gama identificada por "mais ampla" na Tabela 4.6 e a realização de uma prova de carga, que tenha decorrido em um determinado valor de $\mathrm{K}=$ Pobs/Pprev. Os autores também consideraram os valores de n' e $\mu$ ' para a fórmula de Janbu (2,35 e 0,0082 respectivamente), considerando-se parcialmente o banco de dados apresentado por Olson e Flaate (1964).

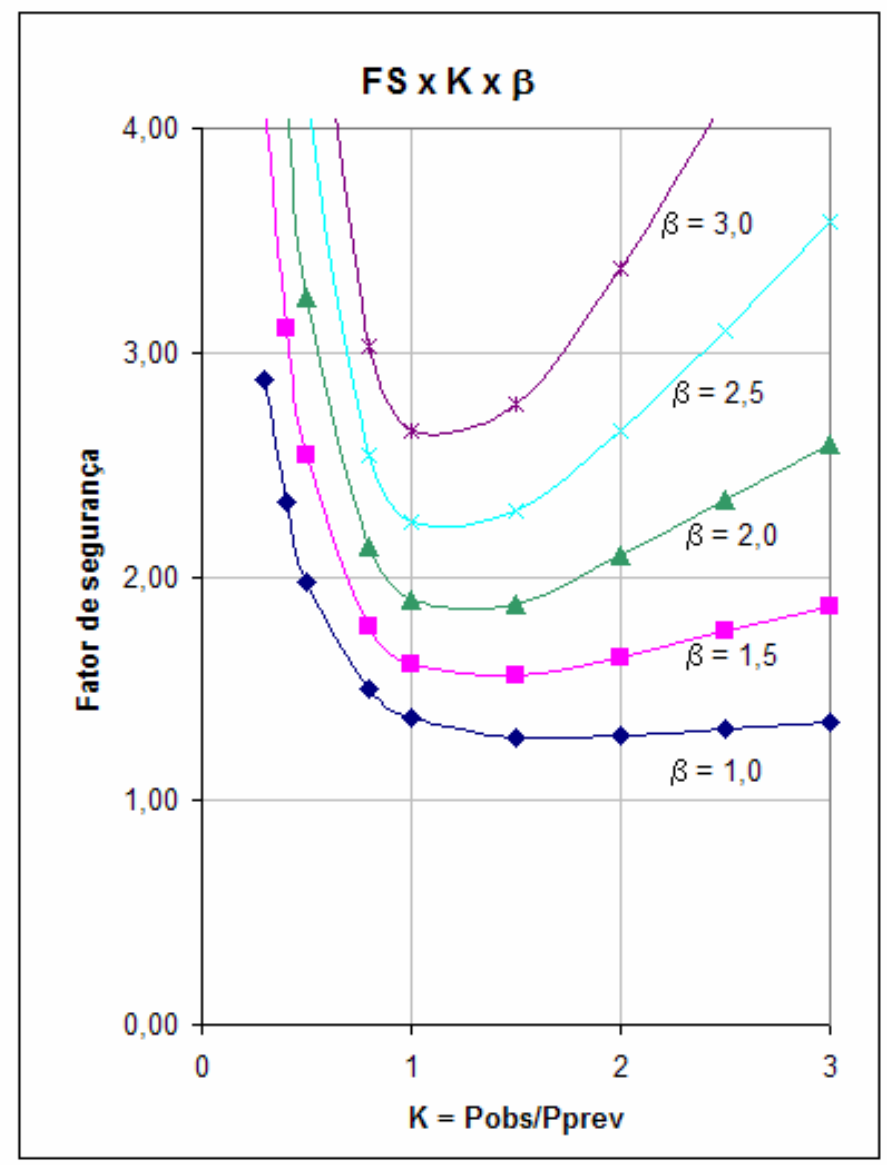

Figura 4.6 - Variação do fator de segurança com o valor de K (para uma prova de carga) e com o índice de confiabilidade, considerando-se os parâmetros da distribuição gama identificada por "mais ampla" na Tabela 4.6 (Baecher e Rackwitz, 1982).

Do gráfico supra nota-se que, coerentemente, maiores valores do índice de confiabilidade $(\beta)$ estão associados a maiores fatores de segurança. Segundo os autores para resultados de $\mathrm{K}$ menores que a unidade o fator de segurança aumenta em relação àquele requerido antes do teste.

Nota-se também que, para valores de $\mathrm{K}$ bastante maiores que a unidade o fator de segurança também volta a crescer, fato que, segundo os autores, parece não fazer sentido na prática da engenharia mas tem sentido no âmbito da estatística, uma vez que elevados valores 
de $\mathrm{K}$ indicam que o método de previsão é bastante impreciso para a localidade enfocada, demandando maiores fatores de segurança.

Com os mesmos informes utilizados para a construção do gráfico anterior, porém valendo-se dos parâmetros da distribuição "mais apertada" da Tabela 4.6, os autores obtiveram o gráfico seguinte.

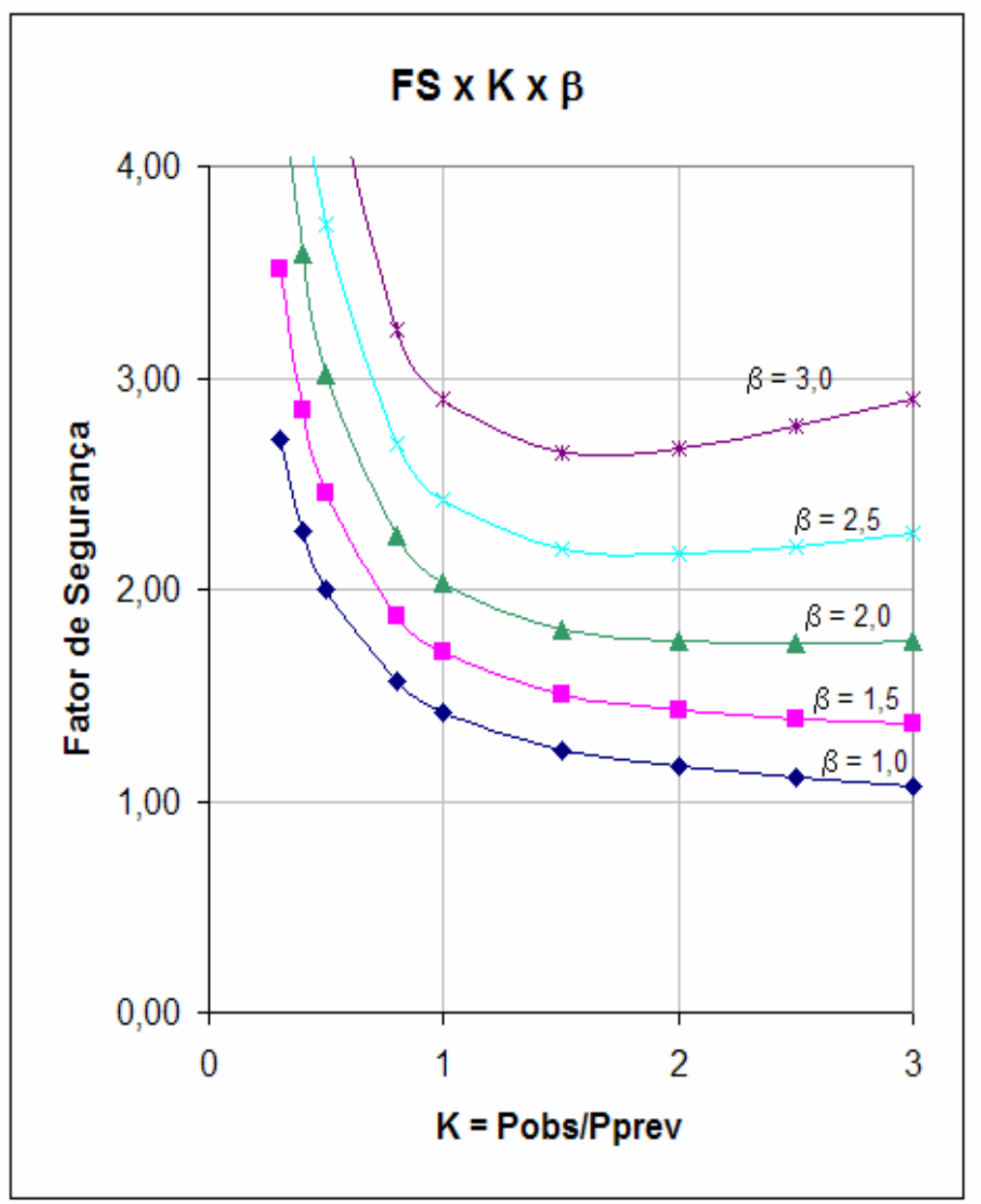

Figura 4.7 - Variação do fator de segurança com o valor de K (para uma prova de carga) e com o índice de confiabilidade, considerando-se os parâmetros da distribuição gama identificada por "mais apertada" na Tabela 4.6 (Baecher e Rackwitz, 1982).

Os autores consideraram que o comportamento apresentado na Figura 4.7 é mais realista, justificando essa assertiva no fato de que tal comportamento decorreu da utilização da distribuição gama "mais apertada", a qual foi concebida desconsiderando-se três obras com precisão bastante elevada, que parecem não ter paralelo com a prática.

Em que pese a justificativa apresentada pelos autores, não há como se certificar a 
predominância de uma distribuição gama em detrimento da outra, diante do fato de que ambas foram construídas com fulcro em observações de obras reais.

No caso da execução de duas provas de carga, decorrendo em dois valores de $\mathrm{K}=$ Pobs/Pprev, o fator de segurança pode ser tabulado como função do índice de confiabilidade ( $\beta$ ), da média de $\mathrm{K}$ (Kmed) e do coeficiente de variação de $\mathrm{K}(\mathrm{CV})$. O gráfico abaixo apresenta essa tabulação, considerando-se os mesmo informes relativos à distribuição anterior utilizados na confecção da Figura 4.7 (método de Janbu e distribuição gama "mais apertada").

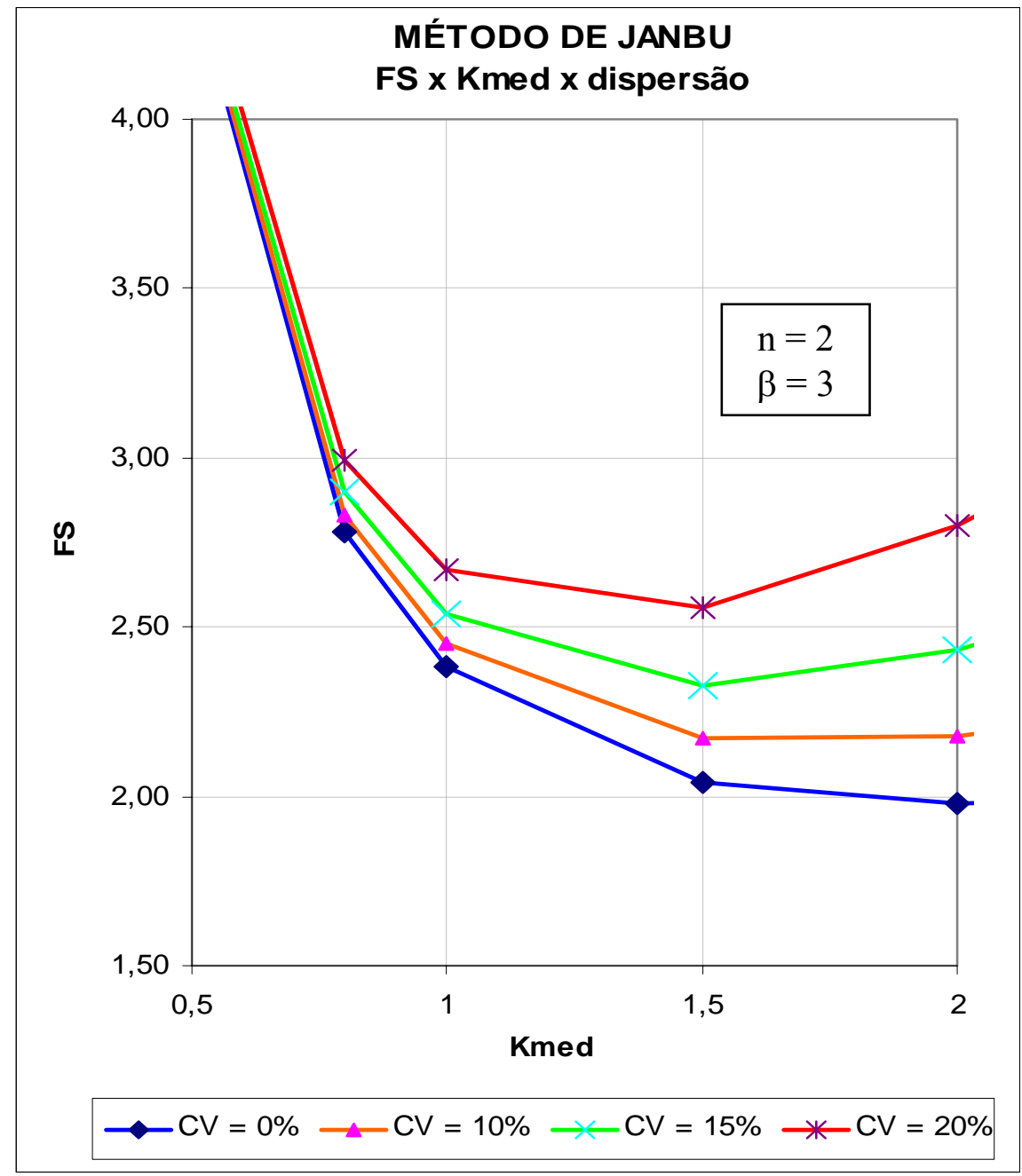

Figura 4.8 - Variação do FS em função de Kmed e CV de duas provas de carga, considerando-se $\beta=3$.

Do gráfico supra, nota-se claramente que não só o valor de Kmed é importante na definição do fator de segurança, mas também a variabilidade dos resultados das provas de carga efetuados na obra, representada pelo coeficiente de variação de K (CV). Quanto maior a 
variabilidade do valor de $\mathrm{K}$ em uma mesma obra, maior o fator de segurança exigido.

Baecher e Rackwitz (1982) ainda destacam que o fator de segurança é condicionado ao método de previsão da capacidade de carga. Para fundamentar essa assertiva, os autores consideraram informações anteriores disponíveis para quatro métodos de previsão de capacidade de carga de estacas de deslocamento, apresentadas na tabela a seguir:

\begin{tabular}{c|c|c}
\hline Método de Previsão & Média Anterior $\left(\mu^{\prime}\right)$ & $\mathbf{n}^{\prime}$ \\
\hline Janbu & 0,0082 & 1,55 \\
\hline Engineering News (ENR) & $-0,152$ & 0,145 \\
\hline Meyerhof & 0,0004 & 0,354 \\
\hline Rollberg & $-0,0016$ & 2,04 \\
\hline \hline
\end{tabular}

Tabela 4.7 - Informações anteriores relativas aos quatro métodos analisados por Baecher e Rackwitz (1982).

De posse dessas informações anteriores e considerando a execução de uma prova de carga, que tenha decorrido em um certo valor de K, os autores apresentaram a Figura 4.9, exposta na página seguinte, para $\beta=2$.

Com fulcro na figura retro mencionada, os autores concluíram que, inobstante serem considerados mais precisos (dentre aqueles analisados), os métodos de Rollberg e Janbu podem fornecer fatores de segurança até mesmo maiores que métodos considerados mais imprecisos, como o método do Engineering News, dependendo do resultado da prova de carga.

Esse comportamento é justificado pelos autores pelo fato de que um valor de $\mathrm{K}=$ Pobs/Pprev = 3 seria um resultado pouco esperado no caso da utilização de métodos "mais precisos", decorrendo no aumento do fator de segurança. Por outro lado, para métodos "menos precisos", um valor de $\mathrm{K}=3$ pode não ser inesperado, redundando na redução do fator de segurança.

Para valores de $\mathrm{K}$ próximos à unidade, a redução do fator de segurança é maior quanto mais preciso for o método de previsão. 
Importante salientar que os valores de $\mu^{\prime}$ e n' apresentados na Tabela 4.7 não podem ser encarados como valores intrínsecos do método a que se referem, haja vista que tais valores foram obtidos com base em uma gama bastante limitada de obras.

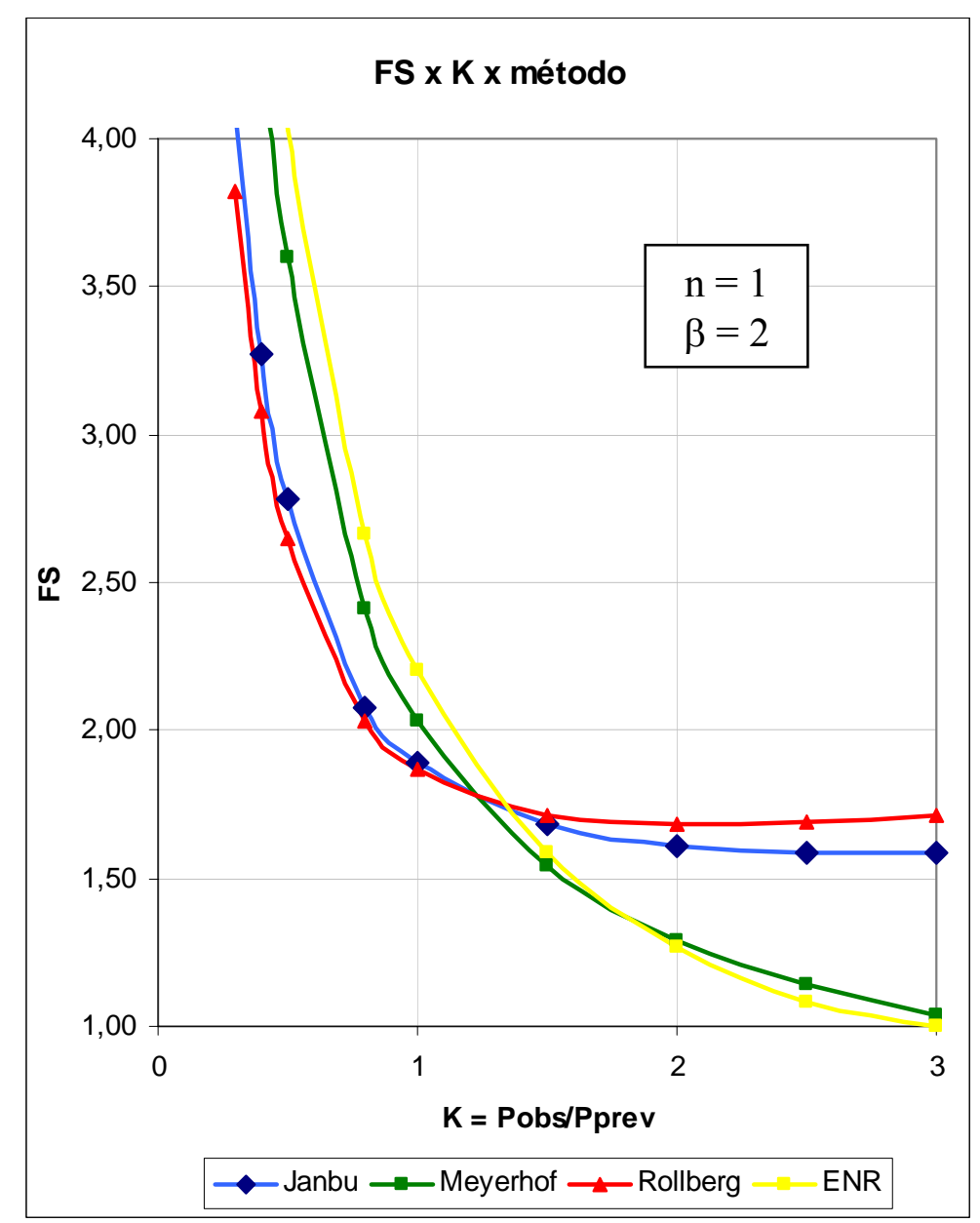

Figura 4.9 - Variação do fator de segurança com o fator de viés (K) para diversos métodos (Baecher e Rackwitz, 1982).

\subsubsection{Inferência para o caso de variância conhecida}

Há situações onde a variabilidade intra-canteiro pode ser arbitrada, para uma particular obra, em função do conhecimento prévio que se tem sobre o subsolo local e do tamanho do sítio. Nessas ocasiões, ao invés de considerar a variância como uma variável aleatória, que possui densidade de probabilidade ajustada às variabilidades de diversas obras, pode-se considerá-la fixa, de tal forma que a incerteza fique restrita ao valor médio da capacidade de carga para o local da obra. Essa variância suposta conhecida será denotada por 
$\sigma^{2}$

Diversos autores têm apresentado aplicações da inferência bayesiana com variância conhecida para incorporação dos resultados de provas de carga (Kay, 1976 e 1977; Vrouwenvelder, 1992; Zhang, 2004).

Considerando-se novamente que a distribuição anterior da média da variável $\mathrm{R}=\log \left(\right.$ Pobs/Pprev) seja do tipo normal, com parâmetros $\mu^{\prime}$ e $\mathrm{S}^{\text {’2}}$, e diante da realização de $\mathrm{n}$ provas de carga que resultaram em uma média $m_{R}$, a distribuição posterior da média de $R$ será também normal com hiperparâmetros dados pelas expressões a seguir, como apresentaram Martz e Waller (1982):

$$
\begin{aligned}
& \mu^{\prime \prime}=\frac{\sigma^{2} \cdot \mu^{\prime}+n \cdot S^{\prime 2} \cdot m_{R}}{\sigma^{2}+n \cdot S^{\prime 2}} \\
& S^{\prime \prime}=\sqrt{\frac{\sigma^{2} \cdot S^{\prime 2}}{\sigma^{2}+n \cdot S^{\prime 2}}}
\end{aligned}
$$

Onde:

$\mu "=$ valor esperado posterior da média de R;

$\mu^{\prime}=$ valor esperado anterior para a média de R;

$\mathrm{S}^{\prime 2}=$ variância anterior da média de $\mathrm{R}$;

$\mathrm{m}_{\mathrm{R}}=$ média amostral;

$\sigma^{2}=$ variância da variável R para o local da obra, suposta conhecida;

$\mathrm{n}=$ tamanho da amostra;

S" = desvio-padrão posterior da média de R;

Martz e Waller (1982) informam ainda que a distribuição preditiva, que é efetivamente utilizada para estimar a capacidade de carga de uma particular estaca, é também normal com média $\mu$ ” e desvio-padrão dado por:

$\sigma_{p}=\sqrt{\sigma^{2}+S^{\prime \prime 2}}$

Kay (1976), considerando uma variância da capacidade de carga no interior da obra fixa de 0,12 e utilizando as expressões 4.32 e 4.33 (aplicadas à variável capacidade de carga e não à variável $\mathrm{R}=\log (\mathrm{Ppobs} / \mathrm{Pprev}))$ concluiu que o fator de segurança a ser aplicado 
independe da média anterior e do resultado da prova de carga em si, dependendo tão somente do índice de confiabilidade $(\beta)$ e da variância da distribuição preditiva $\left(\sigma_{\mathrm{p}}\right)$, a qual se reduz a cada prova de carga efetuada.

Segundo Kay (1976), o fator de segurança a ser aplicado é expresso pela seguinte formulação:

$$
F S=10^{\beta \cdot \sigma_{P}+(\ln 10 / 2) \sigma_{p}^{2}}
$$

Onde $\sigma_{\mathrm{p}}$ e $\beta$ já foram definidos. Com fulcro na expressão supra, o autor construiu um gráfico similar ao apresentado a seguir:

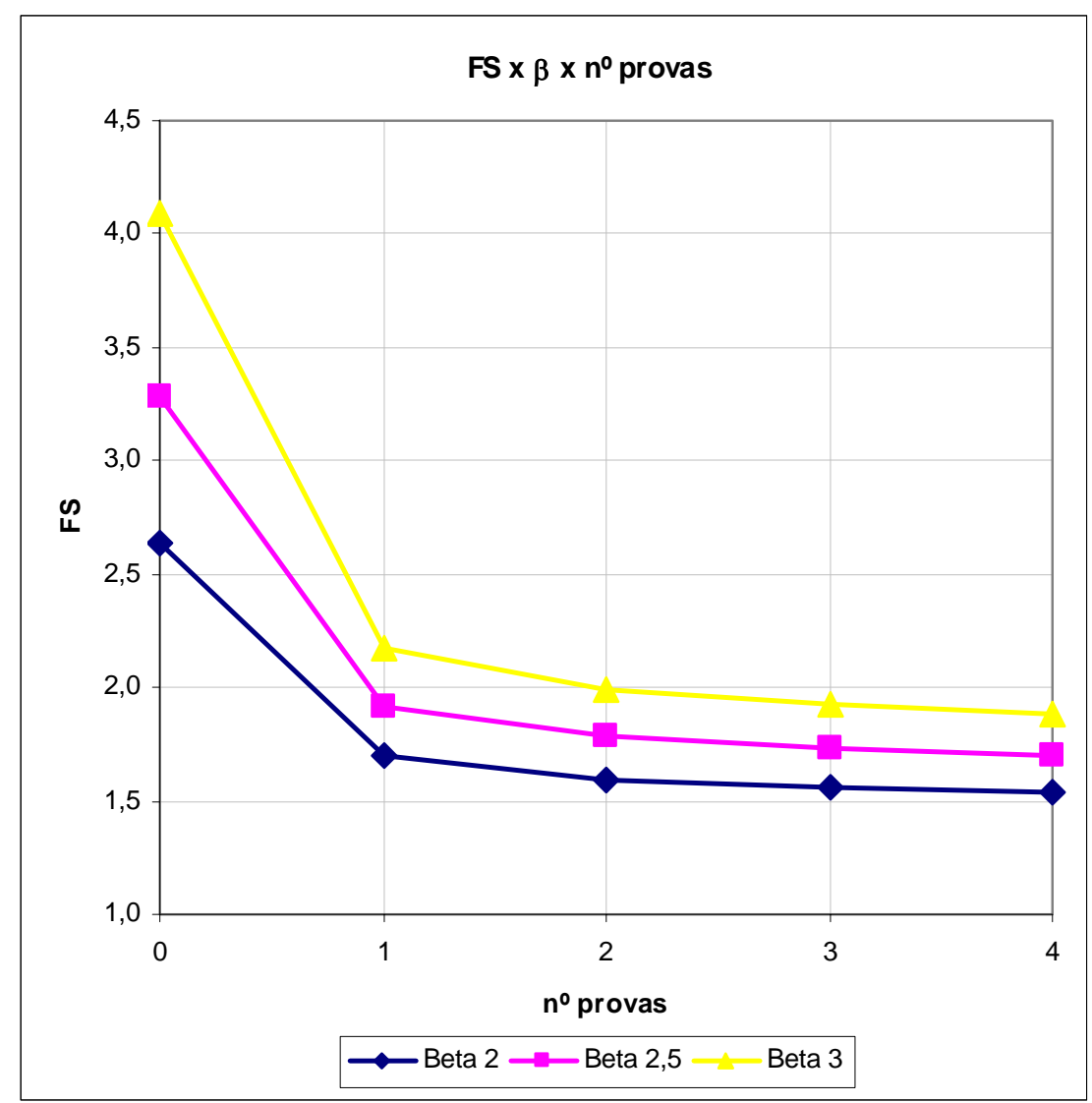

Figura 4.10 - Variação do fator de segurança em função do número de provas de carga (Kay, 1976).

Ao desconsiderar a média anterior e o resultado da prova de carga na proposição do fator de segurança, a metodologia proposta por Kay (1976) se mostra bastante divergente da prática e passível de críticas importantes.

A crítica fundamental que pode ser feita à metodologia proposta por Kay é que, inexoravelmente, o fator de segurança se reduz a cada prova de carga realizada, o que não parece prudente. Imagine-se, por exemplo, que uma determinada prova de carga tenha 
resultado em $\mathrm{k}=$ Pobs/Pprev $=0,3$. Mesmo diante dessa flagrante superestimativa do método de previsão (Pprev muito maior que Pobs), o fator de segurança seria diminuído.

Em vista das deficiências da metodologia apresentada por Kay, a conceituação do fator de segurança será feita da mesma forma como foi definida no caso de variância desconhecida, ou seja, a partir da variável $\mathrm{R}=\log ($ Pobs/Pprev), com fulcro nas expressões 4.28 a 4.30 .

Uma vez que se está de posse dos parâmetros da distribuição preditiva ( $\mu$ ” e $\sigma_{\mathrm{p}}$ ), pode-se calcular um particular valor da variável $\mathrm{R}$ (valor extremo), denotado por $\mathrm{r}_{\mathrm{o}}$, para um dado valor do índice de confiabilidade $(\beta)$, através da seguinte expressão.

$r_{o}=\mu^{\prime \prime}-\beta \cdot \sigma_{\mathrm{p}}$

e o fator de segurança é calculado novamente pela expressão 4.30, abaixo reproduzida:

$F S=10^{-r_{o}}$

Bekman e Costa Neto (1980) destacam uma importante propriedade do Teorema de Bayes: as informações adicionais obtidas podem ser incorporadas parceladamente, de forma incremental, ou então de uma única vez, obtendo-se, em ambos os casos, a mesma distribuição posterior.

Por exemplo, imagine-se uma determinada obra sobre a qual temos informações suficientes para propor uma distribuição anterior e que, por ocasião da construção, tenhamos efetuado três provas de carga. Desta feita, poderíamos incorporar as informações decorrentes das provas de carga segundo duas possibilidades, apresentadas na Figura 4.11. 


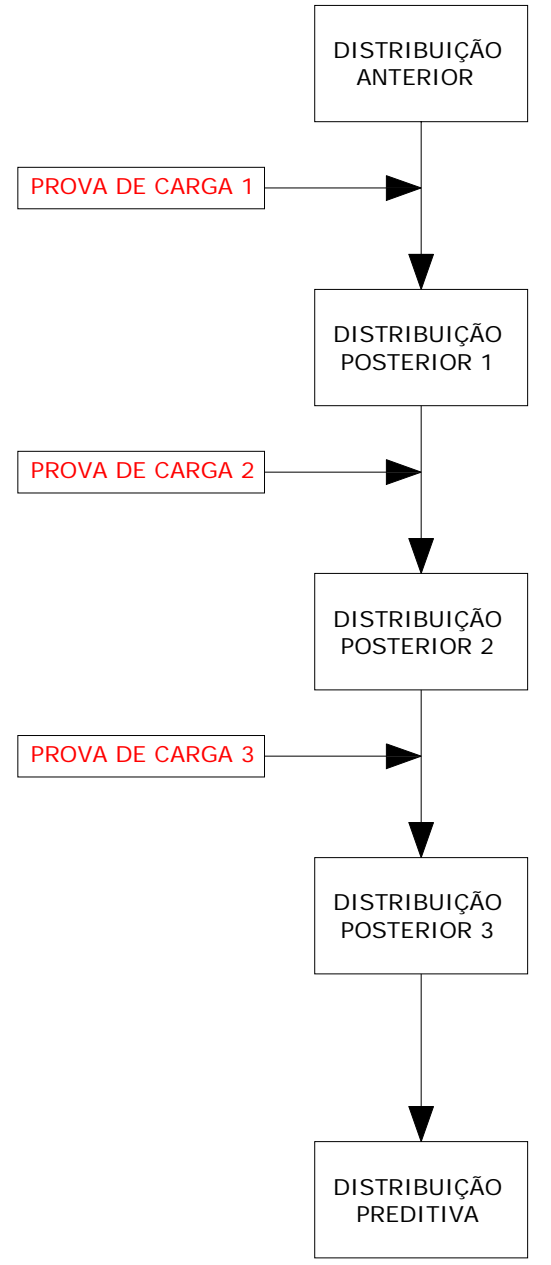

a)

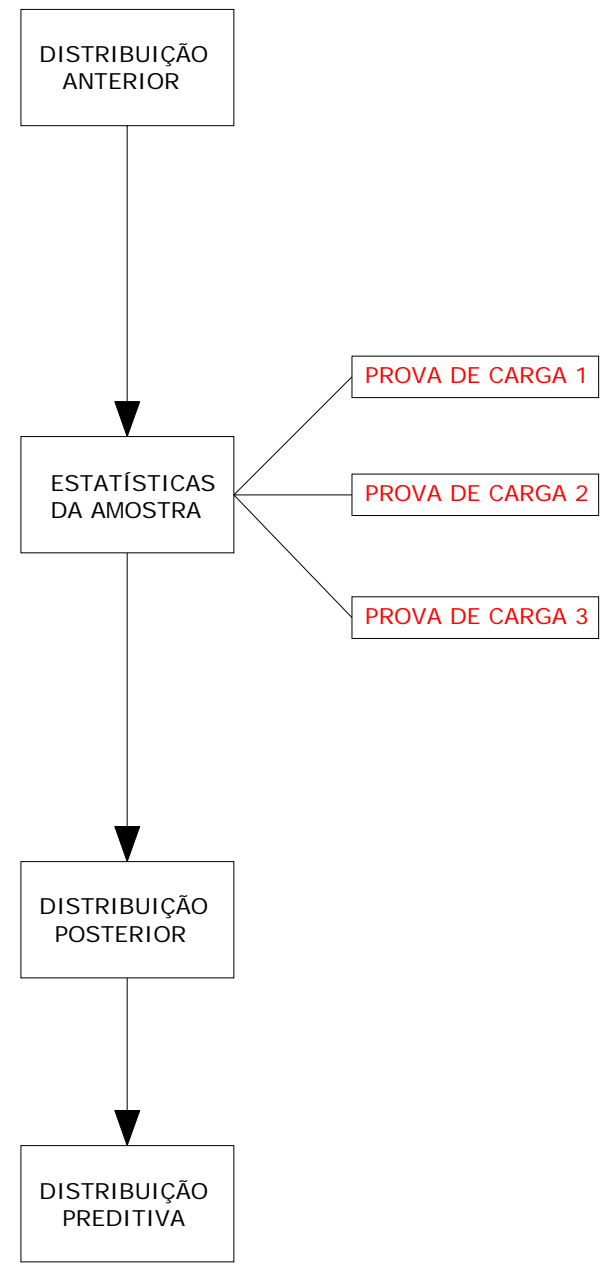

b)

Figura 4.11 - Diferentes abordagens da inferência bayesiana: a) incorporação da informação de forma sequencial e b) incorporação da informação de uma só vez.

\subsubsection{Críticas à atualização $a$ posteriori do fator de segurança}

Bilfinger (2002) questiona a real aplicabilidade da inferência bayesiana na prática de projeto, eis que, ao utilizar informações posteriores à execução de provas de carga, o método se apresenta com utilidade limitada. O referido autor exemplifica essa limitação do método na prática de projeto informando que somente depois de parte da obra já ter sido executada é que se pode deliberar sobre a redução (ou o que seria pior, o aumento) do fator de segurança para as estacas a serem executadas. $\mathrm{O}$ autor finaliza a discussão aduzindo que tal metodologia somente poderia ser levada a efeito no caso de obras nas quais se executam provas de carga prévias, para apoio ao projeto e antes da execução propriamente dita. 
Em que pese a limitação exposta pelo autor, limitação essa que é substantiva, destaca-se que a abordagem bayesiana, e a decorrente possibilidade de atualização da segurança a posteriori, é particularmente útil em obras de porte tal que permitam a implementação do método observacional, da redução da incerteza de forma incremental.

Ademais, o modelo bayesiano proposto pode ser um instrumento legítimo para calibração de métodos menos rigorosos, tais como os coeficientes parciais de segurança e os métodos de nível II, fulcrados no índice de confiabilidade. 


\section{DISTINCCÃO DOS FATORES DE SEGURANCCA EM FUNÇÃO DO TIPO DE PROVA DE CARGA}

\subsection{GENERALIDADES}

As provas de carga sobre estacas têm sido muito utilizadas na prática corrente, seja para prover dados para projeto, avaliar as fundações executadas em uma obra específica, estudar as características de comportamento do conjunto estaca versus solo ou verificar a conformidade da obra de fundação executada às premissas do projeto (Milititsky, 1991). Para efeito de avaliação da segurança da fundação, as provas de carga com interesse direto são aquelas efetuadas para se verificar se as premissas assumidas em projeto se coadunam com o comportamento real da estrutura (Hachich, 1998a).

A execução de provas de carga sobre estacas permite a implementação do conceito de "design as you go" na prática da engenharia geotécnica, possibilitando, por exemplo, a atualização da capacidade de carga das estacas de uma determinada obra. Vrouwenvelder (1992) informa que as estimativas de capacidade de carga feitas com base nas informações adicionais advindas das provas de carga permitem a redução da incerteza e justificam uma correspondente redução do fator de segurança a ser aplicado.

Zhang (2004) certifica que os resultados de provas de carga sugerem um valor de capacidade de carga mais realista, haja vista que os erros associados às medidas efetuadas durante as provas de carga são muito menores que aqueles associados às previsões de capacidade de carga.

Uma vez que se dispõe de uma amostra de provas de carga em uma determinada obra, a questão natural que surge ao engenheiro é como os resultados da amostra permitem a atualização da segurança de todas as estacas dessa mesma obra. Esse questionamento pode ser interpretado como um típico problema de indução, ou seja, a partir do comportamento verificado nas estacas ensaiadas (amostra) deseja-se inferir o comportamento de todas as estacas da obra (população). Como já visto, a Estatística Bayesiana oferece grandes vantagens 
para a execução de inferências relativas à capacidade de carga de estacas, em razão da freqüente exigüidade de provas de carga realizadas em uma determinada obra.

A importância das provas de carga na engenharia geotécnica, principalmente para redução da incerteza, é ponto pacífico aos profissionais atuantes no ramo de fundações. No entanto, não há consenso no meio técnico com relação aos fatores de segurança aplicados em função do tipo e do número de provas de carga efetuados.

Os dois tipos de ensaio frequentemente utilizados, as provas de carga estáticas e os ensaios de carregamento dinâmico, são de amplo conhecimento do meio técnico e objeto de inúmeros trabalhos (Rocha Filho, 1985; Niyama, 1991; Aoki, 1997; Niyama et al, 1998; Bilfinger, 2002) e também de normas técnicas (ABNT, 1991; ABNT, 1994), razão pela qual não se pretende dar ênfase nas suas definições, métodos de execução, etc. $O$ foco desta dissertação, no que concerne às provas de carga, é enfatizar as diferentes incertezas associadas às provas de carga estáticas e dinâmicas e como essa diferença pode subsidiar o modelo bayesiano para a proposição de fatores de segurança que sejam condicionados ao tipo de prova de carga.

\subsection{CORRELAÇÃO ENTRE AS PROVAS DE CARGA ESTÁticAS E DINÂMICAS}

Uma questão ainda controversa tanto na prática profissional do engenheiro geotécnico quanto nos diversos comitês de normalização é a diferenciação dos fatores de segurança a serem aplicados às provas de carga estáticas e dinâmicas.

Inegavelmente, existem diferenças entre os comportamentos dinâmicos e estáticos dos solos, a ponto de alguns autores concluírem pela restrita possibilidade de se correlacionar as capacidades de carga dinâmica e estática ou pela dificuldade de se prever comportamentos estáticos a partir de medições ou comportamentos dinâmicos (Brucy et al, 1991 apud Niyama, 1991).

No entanto, a maior parte dos trabalhos que relacionaram os resultados de provas dinâmicas com os resultados de provas estáticas aponta para uma correlação satisfatória entre 
ambos os procedimentos (Edde e Fellenius, 1992; Niyama e Aoki, 1991; Likins et al, 1996; Likins e Rausche, 2004; Likins, 2004).

Likins e Rausche (2004) compilaram os resultados de diversas provas de carga estáticas e dinâmicas apresentados por vários autores nos diversos Stresswave Conferences, obtendo os seguintes diagramas de dispersão.
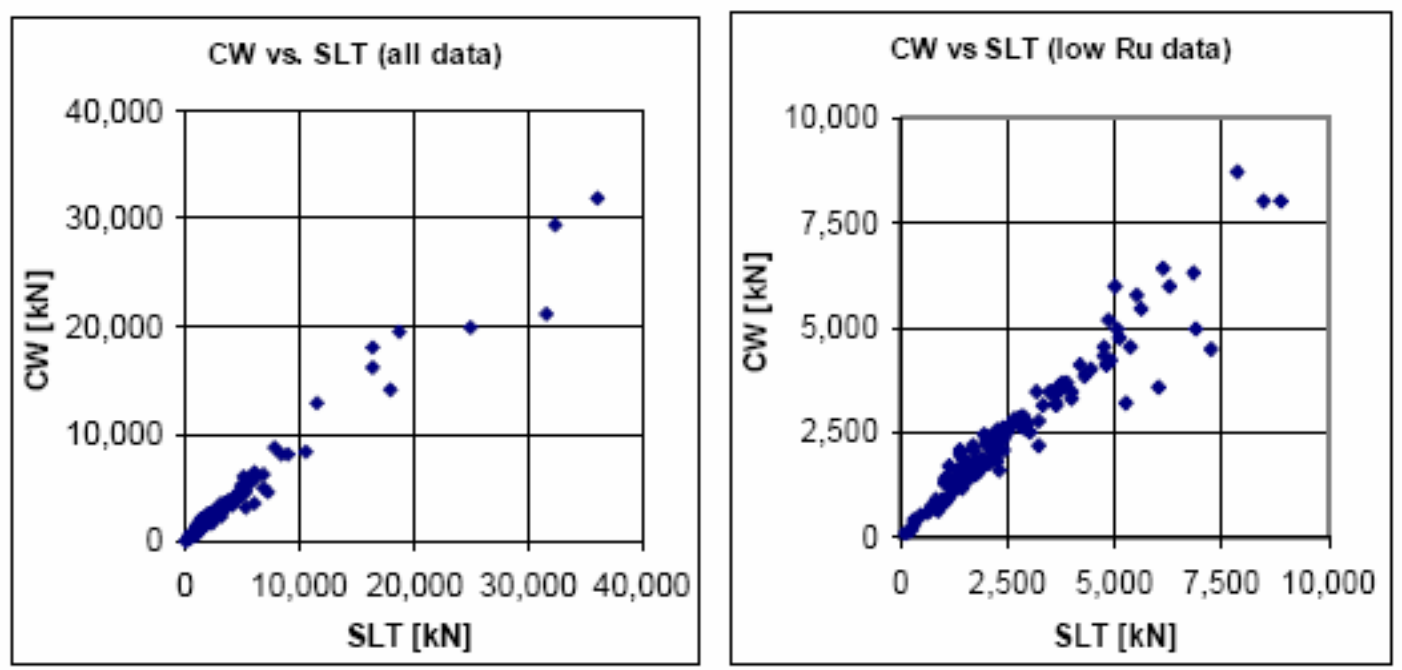

Figura 5.1 - Correlações obtidas com uso dos dados apresentados nos diferentes Stresswave Conferences (Likins e Rausche, 2004).

Com base no comportamento do diagrama de dispersão, os autores concluem pela elevada correlação entre os resultados de provas estáticas e dinâmicas, estas últimas analisadas pelo CAPWAP.

Combinando os informes oriundos dos diversos Stresswave Conferences com aqueles constantes do banco de dados dos próprios autores, totalizando um universo de 303 estacas analisadas, os mesmos obtiveram ainda os seguintes valores para a variável $\mathrm{P}_{\text {DinÂmica }} / \mathrm{P}_{\text {estática }}$ (Likins e Rausche, 2004).

$$
\begin{aligned}
& \text { - Média }\left[\mathrm{P}_{\text {DinÂmica }} / \mathrm{P}_{\text {EStÁtica }}\right]=0,98 . \\
& \text { - } \mathrm{CV}\left[\mathrm{P}_{\text {DinÂmica }} / \mathrm{P}_{\text {EStática }}\right]=0,169 .
\end{aligned}
$$

Dos resultados apresentados pelos autores, observa-se que, de fato, existe uma boa correlação entre os resultados de provas estáticas e dinâmicas, existindo uma pequena tendência das provas de carga dinâmicas subestimarem a "real" capacidade de carga da estaca. 
Bilfinger (2002) apresenta uma excelente discussão sobre os fatores que poderiam justificar essa tendência das provas de carga dinâmicas de subestimar a "verdadeira" capacidade de carga das estacas, informando que provas de carga dinâmicas executadas através de um golpe único tendem a fornecer resultados conservadores, haja vista que existe sempre a possibilidade de que não tenha sido mobilizada toda a resistência disponível. Aoki (1997) propôs a realização de ensaios de carregamento dinâmico com energias crescentes para garantir a mobilização de toda a capacidade de carga da estaca.

Outros autores, por outro lado, mostram a grande variabilidade da relação

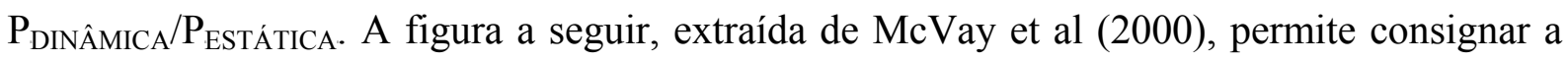
elevada gama de valores assumidos por essa variável, considerando-se que a carga de ruptura da prova estática tenha sido obtida pelo critério de Davisson:

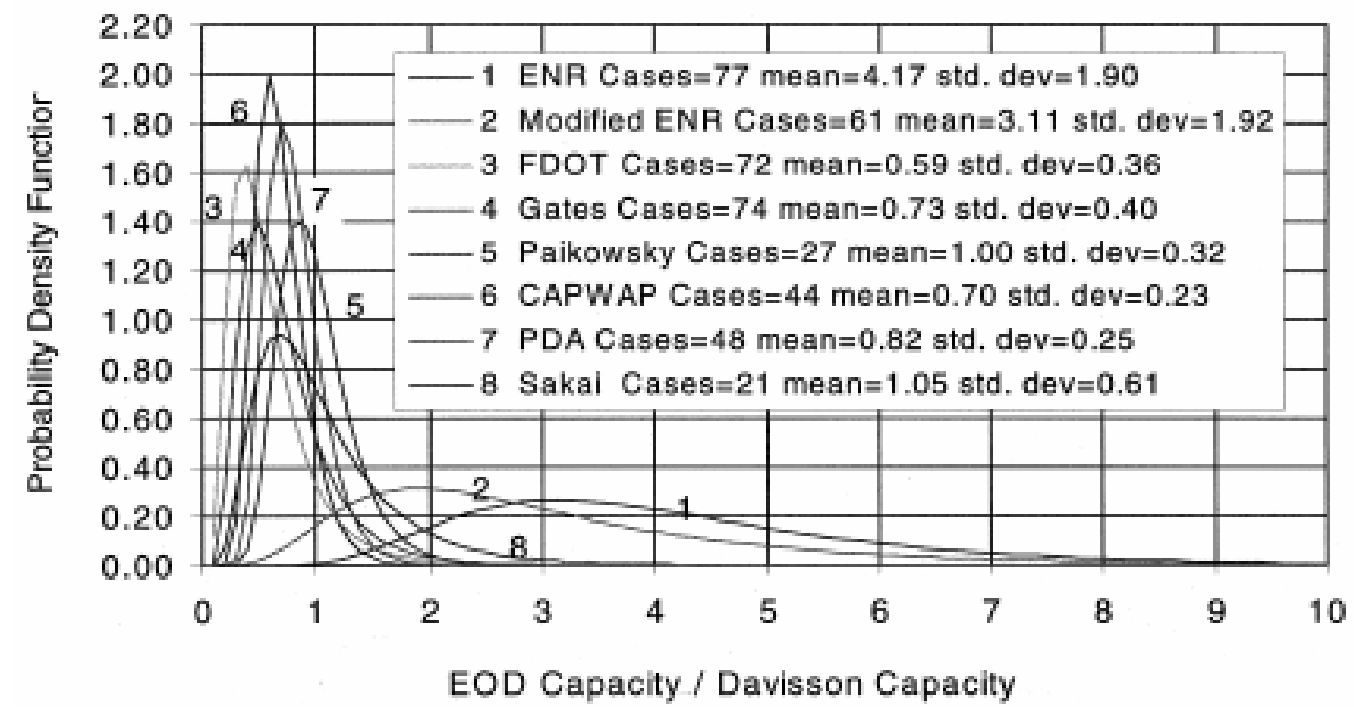

Figura 5.2 - Variabilidade da relação $\mathrm{P}_{\text {DINÂMICA }} / \mathrm{P}_{\text {ESTÁTICA }}$, com dados oriundos de diversas fontes (McVay et al, 2000). Os ensaios dinâmicos foram efetuados no final da cravação ("End of Driving” - EOD).

Alguns estudos tratam a variável $\mathrm{P}_{\text {DINÂMICA }} / \mathrm{P}_{\text {ESTÁTICA, formalmente, como uma }}$ variável aleatória que segue uma distribuição log-normal (Likins et al, 1996; McVay et al, 2000).

A tabela a seguir compila a média e o desvio-padrão da variável $\mathrm{P}_{\text {DINÂMICA }} / \mathrm{P}_{\text {ESTÁTICA, }}$ com base em vários autores, para a cravação e para a recravação, com a carga de ruptura da prova estática obtida pelo critério de Davisson nos casos onde não houve ruptura física. 


\begin{tabular}{|c|c|c|c|}
\hline MOMENTO & FONTE & Média[Pdin/Pestat] & Desvio[Pdin/Pestat] \\
\hline \multirow{8}{*}{$\begin{array}{c}\text { Fim da } \\
\text { Cravação }\end{array}$} & $E^{E N R^{1}}-77$ casos (McVay et al, 2000) & 4,170 & 1,900 \\
\hline & ENR modificado - 61 casos (McVay et al, 2000) & 3,110 & 1,920 \\
\hline & FDOT $^{2}, 1991$ apud McVay et al, 2000 - 72 casos & 0,590 & 0,360 \\
\hline & Gates, 1957 apud McVay et al, $2000-74$ casos & 0,730 & 0,400 \\
\hline & Paikowsky, 1994 apud McVay et al, $2000-27$ casos & 1,000 & 0,320 \\
\hline & CAPWAP cases - 44 casos (McVay et al, 2000) & 0,700 & 0,230 \\
\hline & PDA - 48 casos (McVay et al, 2000) & 0,820 & 0,250 \\
\hline & Sakai, 1996 apud McVay, $2000-21$ casos & 1,050 & 0,610 \\
\hline \multirow{11}{*}{$\begin{array}{l}\text { Início da } \\
\text { recravação }\end{array}$} & ENR - 77 casos (McVay et al, 2000) & 5,350 & 2,230 \\
\hline & ENR modificado - 61 casos (McVay et al, 2000) & 3,550 & 1,830 \\
\hline & FDOT,1991 apud McVay et al, $2000-72$ casos & 0,500 & 0,290 \\
\hline & Gates, 1957 apud McVay et al, $2000-74$ casos & 0,610 & 0,230 \\
\hline & Paikowsky, 1994 apud McVay et al, 2000 - 27 casos & 1,330 & 0,410 \\
\hline & CAPWAP cases - 44 casos (McVay et al, 2000) & 0,880 & 0,260 \\
\hline & PDA - 48 casos (McVay et al, 2000) & 1,040 & 0,260 \\
\hline & Sakai, 1996 apud McVay, $2000-21$ casos & 0,860 & 0,450 \\
\hline & $\mathrm{SW}^{3}$ (todas as estacas) - 143 casos (Likins e Rausche,2004) & 0,993 & 0,164 \\
\hline & CAPWAP cases - 77 casos (Globe et al, 1980) & 1,010 & 0,170 \\
\hline & CAPWAP cases - 83 casos (Likins et al, 1996) & 0,964 & 0,215 \\
\hline Notas: & $\begin{array}{l}\text { 1- ENR é a sigla de "Engineering News Re } \\
\text { - FDOT é a sigla de "Florida Department of Trans } \\
3 \text { - Dados obtidos nos } 6 \text { Stresswave Conference }\end{array}$ & $\begin{array}{l}\text { tation" } \\
\text { SW) }\end{array}$ & \\
\hline
\end{tabular}

Tabela 5.1 - Valores da variável da média e desvio da variável Pdin/Pestat com base em vários autores, para a cravação e recravação. Carga de ruptura da prova estática obtida utilizando-se o critério de Davisson (MacVay et al, 2000).

Existe certo consenso no meio técnico no sentido de aceitar que os resultados das provas estáticas são mais confiáveis que aqueles obtidos por provas dinâmicas, em razão das interferências às quais este último tipo de prova de carga está sujeito. Essa afirmação pode ser corroborada no fato de que recorrentemente as provas de carga estáticas são utilizadas como paradigma para calibração de diversos métodos de previsão da capacidade de carga. Mesmo as provas de carga de carga dinâmicas são, correntemente, aferidas pelas provas de carga estáticas (Hachich, 1998a).

Vrouwenvelder (1992) considerou que a prova de carga estática fornece a verdadeira capacidade de carga da estaca, decorrendo em uma incerteza nula. O referido Autor também considerou que o coeficiente de variação da capacidade de carga obtida por prova de carga dinâmica é da ordem de 15 a 25\%, como apresenta a Tabela 5.2 . 


\begin{tabular}{c|c}
\hline Método & $\begin{array}{c}\text { Coeficiente de vaniação da } \\
\text { estimativa da capacidade de } \\
\text { carga }-\boldsymbol{V}(\boldsymbol{m})\end{array}$ \\
\hline Prova de carga estática & 0,00 \\
\hline Cálculo $^{\text {Prova de carga dinâmica }}{ }^{(\mathrm{a})}$ & $0,10-0,20$ \\
\hline Pile Driving Analysis - PD A $^{(\mathrm{b})}$ & $0,15-0,25$ \\
\hline Fórmulas dinâmicas & $0,20-0,30$ \\
\hline Nega & $0,25-0,35$ \\
\hline \hline
\end{tabular}

(a) Após o "set up"

(b) Após a recravação

Tabela 5.2 - Coeficientes de variação de diversos métodos de estimativa da capacidade de carga (Vrouwenvelder, 1992).

Importante ressaltar que os valores propostos são baseados simplesmente na intuição de Vrouwenvelder. Inclusive, pode-se observar que o referido autor considera que a incerteza associada à previsão da capacidade de carga por algum método de cálculo (por exemplo, aqueles baseados no SPT) pode ser menor que a incerteza relativa à estimativa da capacidade de carga através de provas de carga dinâmicas, consideração essa que, de certa forma, contradiz a prática corrente.

Em vista dessa maior incerteza relativamente às provas de carga dinâmicas seria importante reconhecer explicitamente a distinção entre os fatores de segurança a serem aplicados aos resultados de provas dinâmicas e estáticas.

Essa diferenciação já é contemplada em algumas normas internacionais, tanto em termos de Fator de Segurança Global quanto em termos de Fatores de Segurança Parciais, como mostram as tabelas a seguir, extraídas do trabalho de Bilfinger (2002).

\begin{tabular}{c|c}
\hline Método & Fator de Segurança Global \\
\hline Provas de carga estáticas & 1,8 \\
\hline Provas de carga dinâmicas & 2,0 \\
\hline Cálculos empíricos ou analíticos & $2,2^{*}$ \\
\hline \hline
\end{tabular}

* D everão ser utilizados no mínimo dois métodos independentes, sendo aplicado o fator de segurança global ao método que resultou na menor capacidade de carga

Tabela 5.3 - Fatores de segurança global preconizados na norma Finlandesa (Bilfinger, 2002). 


\begin{tabular}{c|c}
\hline Método de Previsão da Capacidade de Carga & Fator de Segurança Parcial \\
\hline Cálculos Estáticos & 2,50 \\
\hline Prova de Carga Estática & 1,67 \\
\hline Análises D inâmicas & 2,50 \\
\hline Ensaios PDA $^{(\text {a) }}$ & 2,00 \\
\hline \hline
\end{tabular}

(a) PDA é a abreviação de Pile D riving Analyser.

Tabela 5.4 - Fatores de Segurança Parciais preconizados pela Ontário Bridge Code (Bilfinger, 2002).

Para a obtenção do fator de segurança a ser aplicado aos resultados de provas de carga dinâmicas, será necessário utilizar relações do tipo $\mathrm{P}_{\text {din }} / \mathrm{P}_{\text {prev }}$, onde $\mathrm{P}_{\mathrm{din}}$ é a capacidade de carga medida por prova dinâmica e $\mathrm{P}_{\text {prev }}$ é a capacidade de carga prevista por algum método empírico ou teórico. Normalmente, para calibração dos métodos de previsão de capacidade de carga de estacas, são utilizadas provas de carga estáticas em detrimento de ensaios de carregamento dinâmico, resultando na relativa exigüidade de dados referente à variável $\mathrm{P}_{\text {din }} / \mathrm{P}_{\text {prev }}$. Tendo em vista este fato, a obtenção da variável $\mathrm{P}_{\text {din }} / \mathrm{P}_{\text {prev }}$ será feita através de relações com a variável $\mathrm{P}_{\text {din }} / \mathrm{P}_{\text {estat }}$, como apresentado na figura a seguir:

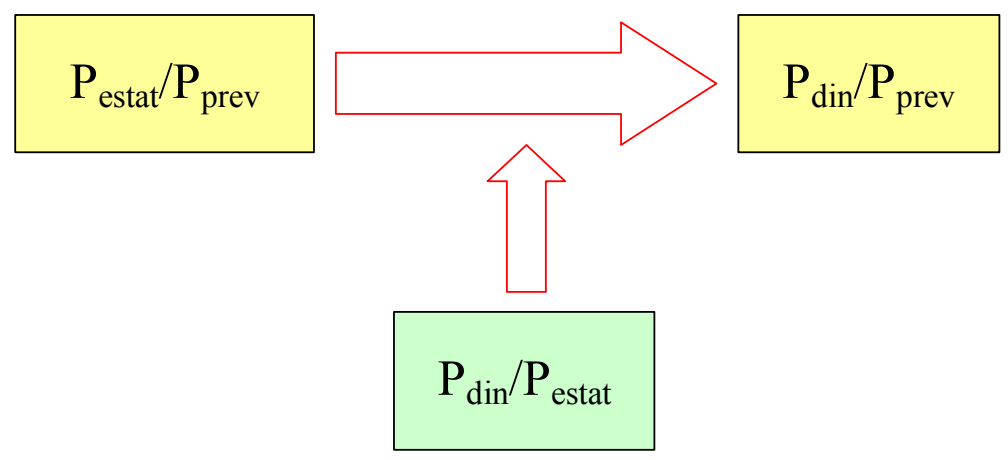

Figura 5.3 - Esquema de obtenção da variável Pdin/Pprev à partir das variáveis Pestat/Pprev e Pdin/Pestat.

Para tal feito, será utilizada a seguinte formulação:

$\frac{P_{\text {din }}}{P_{\text {prev }}}=\frac{P_{\text {din }}}{P_{\text {estat }}} \cdot \frac{P_{\text {estat }}}{P_{\text {prev }}}$

Da expressão supra, nota-se que a variável $\mathrm{P}_{\text {din }} / \mathrm{P}_{\text {prev }}$ pode ser obtida através de $\mathrm{P}_{\text {estat }} / \mathrm{P}_{\text {prev }}$ e da relação entre os resultados de provas dinâmicas e estáticas, representada por $\mathrm{P}_{\text {din }} / \mathrm{P}_{\text {estat }}$

Para se determinar os dois primeiros momentos (média e variância) da variável $\mathrm{P}_{\text {din }} / \mathrm{P}_{\text {prev }}$, pode-se utilizar as seguintes propriedades da esperança e da variância do produto de 
variáveis aleatórias, considerando-se independência (Benjamin e Cornell, 1970):

$E(X Y)=E(X) \cdot E(Y)$

$\operatorname{VAR}[X Y]=m_{x}^{2} \sigma_{y}^{2}+m_{y}^{2} \sigma_{x}^{2}+\sigma_{x}^{2} \sigma_{y}^{2}$

Onde $\mathrm{XY}=\mathrm{P}_{\text {din }} / \mathrm{P}_{\text {prev }}, \mathrm{X}=\mathrm{P}_{\text {din }} / \mathrm{P}_{\text {estat }}$ e $\mathrm{Y}=\mathrm{P}_{\text {estat }} / \mathrm{P}_{\text {prev }}$.

Utilizando-se as expressões supra aos informes da variável $\mathrm{P}_{\text {estat }} / \mathrm{P}_{\text {prev }}$ para alguns métodos de previsão da capacidade de carga e considerando-se as diversas fontes para a

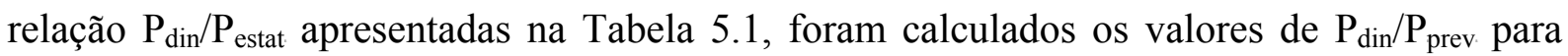
alguns métodos de previsão de capacidade de carga. Os cálculos estão sintetizados no APÊNDICE A.

O gráfico a seguir apresenta as distribuições log-normais da variável $\mathrm{P}_{\mathrm{din}} / \mathrm{P}_{\text {prev }}$, com fulcro em diversas relações entre prova dinâmica e estática para o fim da cravação $\left(\mathrm{P}_{\mathrm{din}} / \mathrm{P}_{\text {estat }}\right)$ e considerando-se o método Decourt-Quaresma, o qual fornece $E\left[\mathrm{P}_{\text {estat }} / \mathrm{P}_{\text {prev }}\right]=1,058$ e $\sigma\left[\mathrm{P}_{\text {estat }} / \mathrm{P}_{\text {prev }}\right]=0,341$ (Decourt e Quaresma, 1978):

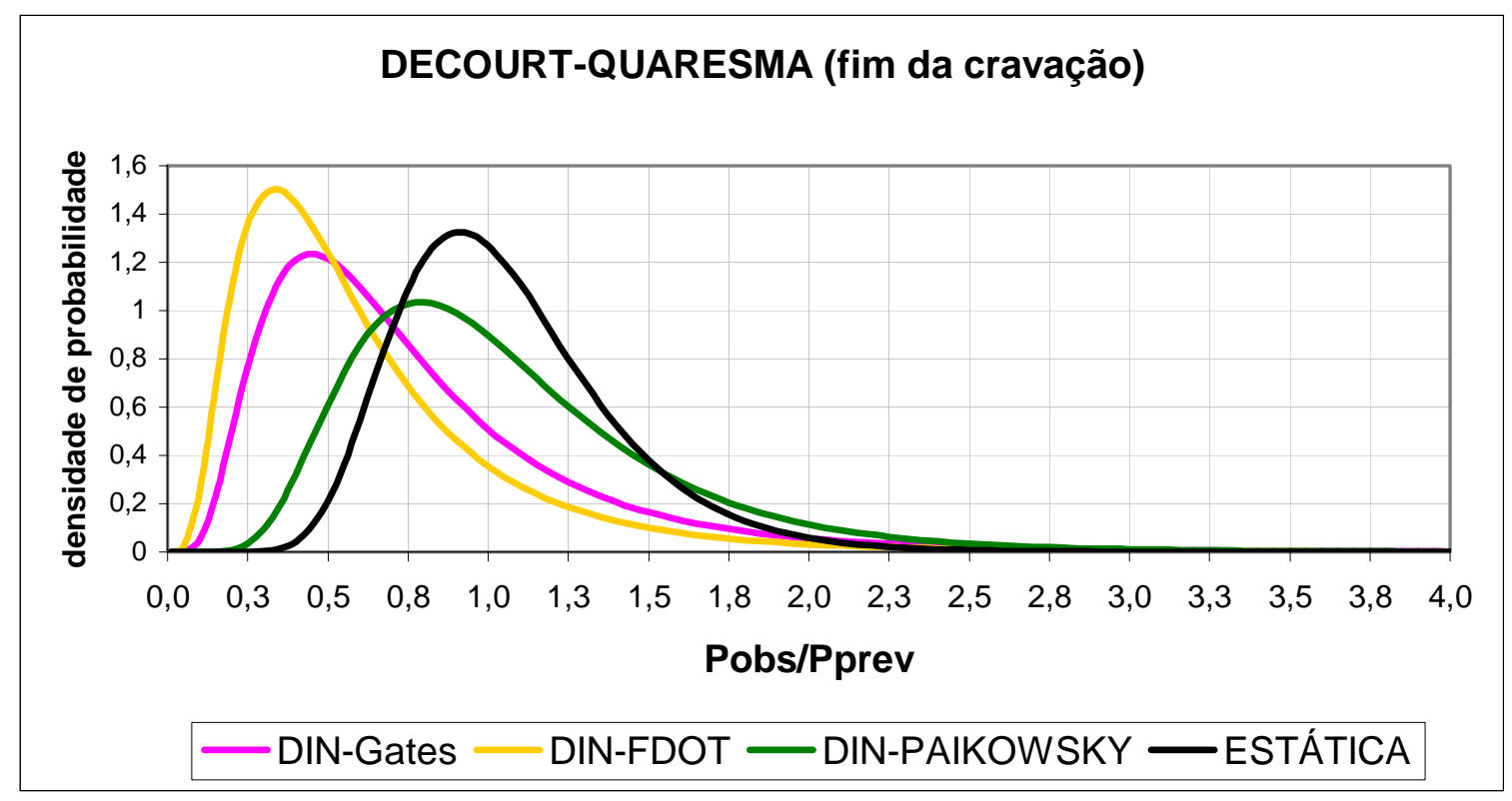

Figura 5.4 - Distribuições log-normais da variável Pobs/Pprev para prova de carga estática e para ensaios dinâmicos, considerando-se várias fontes de informação para a variável Pdin/Pestat (por exemplo, DIN-Gates significa capacidade de carga observada por ensaio dinâmico, considerando-se a relação entre Pdin/Pestat informada por Gates). 
Analisando-se a figura supra, observa-se que os valores de $\mathrm{P}_{\text {obs }} / \mathrm{P}_{\text {prev }}$ para o método de Decourt-Quaresma se concentram em torno de um, considerando-se a execução de provas de carga estática, ao passo que os valores de $\mathrm{P}_{\text {obs }} / \mathrm{P}_{\text {prev }}$ para ensaios dinâmicos tendem a ser consideravelmente menores que a unidade. Nota-se também que a curva referente à variável $\mathrm{P}_{\text {obs }} / \mathrm{P}_{\text {prev }}$ para provas de carga estática é mais afilada que as curvas relativas às provas dinâmicas, configurando a maior incerteza relativamente aos ensaios de carregamento dinâmico.

Valores da variável $\mathrm{P}_{\text {din }} / \mathrm{P}_{\text {prev, }}$ para os métodos de previsão de Aoki-Veloso e Decourt-Quaresma serão utilizados no modelo bayesiano, para proposição de fatores de segurança a serem aplicados aos resultados de provas de carga dinâmicas. O capítulo seguinte apresenta alguns exemplos nos quais são aplicados os conceitos da inferência bayesiana para o estudo da segurança de estacas, após a execução de provas de carga estáticas e dinâmicas. 


\section{EXEMPLOS DE SIMULAC̄̃̃O}

Pretende-se no presente capítulo apresentar alguns exemplos de aplicação da atualização bayesiana e, através desses exemplos, apresentar alguns resultados da aplicação das formulações bayesianas.

Para esse mister será considerada uma obra hipotética, com um grande número de estacas cravadas, de modo que os resultados das provas de carga efetuadas forneçam subsídios para a reavaliação da segurança das estacas a serem ainda executadas, inobstante ao fato de que a atual norma brasileira de fundações obsta procedimentos como esse.

Os exemplos serão focados nos métodos de Aoki-Veloso (Aoki e Veloso, 1975) e Decourt-Quaresma (Decourt e Quaresma, 1978), dois dos métodos mais utilizados no país para a previsão de capacidade de carga de estacas. Além disso, os exemplos objetivarão ilustrar a influência do tipo e do número de provas de carga, bem como da precisão intracanteiro, no fator de segurança demandado.

Serão também consideradas as duas possibilidades de aplicação da formulação bayesiana: com variância desconhecida e com variância conhecida.

\subsection{EXEMPLO 01: PROVA DE CARGA ESTÁTICA E PRECISÃO INTRA- CANTEIRO DESCONHECIDA}

Neste primeiro exemplo, as previsões de capacidade de carga fornecidas pelos métodos de Aoki-Veloso e Decourt-Quaresma serão combinadas aos resultados de provas de carga estática, fornecendo fatores de segurança atualizados à luz da inferência bayesiana, admitindo-se que a precisão intra-canteiro seja desconhecida.

Suponha-se que, para duas estacas da obra hipotética, as quais serão denotadas por E1 e E2, fez-se estimativas da capacidade de carga através dos métodos de Aoki-Veloso e Decourt-Quaresma. Para simplificar o problema, será admitido que, para os dois métodos de 
previsão retro, as capacidades de carga estimadas para as estacas E1 e E2 foram idênticas, de $80 \mathrm{kN}$ e $100 \mathrm{kN}$ respectivamente.

\subsubsection{Informações anteriores referentes à variabilidade intra-canteiro}

Diante da falta de informações oriundas de estudos anteriores, será adotada, para efeito de simulação, a mesma distribuição Gama identificada por "mais fechada" no artigo de Baecher e Rackwitz (1982), a qual possui os seguintes parâmetros:

- $v^{\prime} / 2=4,64 \Rightarrow v^{\prime}=9,28$

- $v^{\prime} v^{\prime} / 2=0,0705 \Rightarrow v^{\prime}=0,0152$

E vem representada pela seguinte densidade de probabilidades:

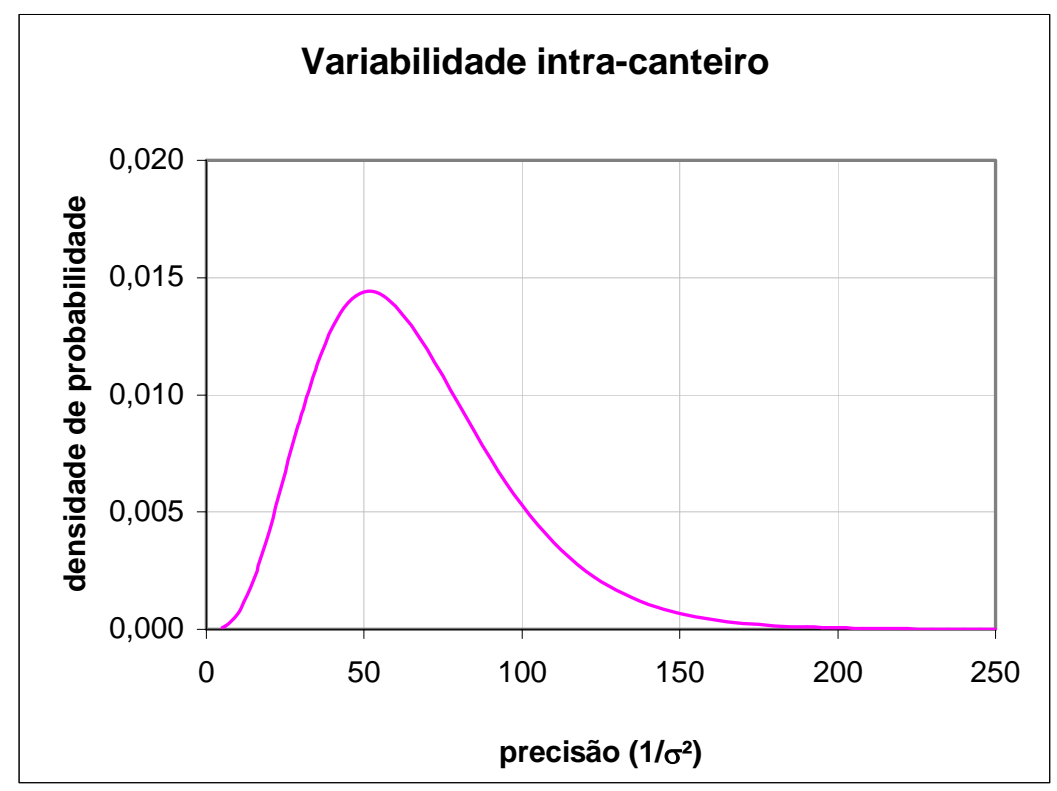

Figura 6.1 - Função densidade do tipo Gama, representativa da precisão intra-canteiro $\left(1 / \sigma^{2}\right)($ Baecher e Rackwitz, 1982).

\subsubsection{Informações anteriores relativas ao método de previsão}

Admita-se que o engenheiro envolvido com o projeto dessa obra hipotética disponha de informações prévias que lhe permita considerar que os valores da média e do desvio das variáveis $\mathrm{K}=\mathrm{P}_{\mathrm{obs}} / \mathrm{P}_{\text {prev }}$ e $\mathrm{R}=\log \left(\mathrm{P}_{\mathrm{obs}} / \mathrm{P}_{\text {prev }}\right)$ são os mesmos daqueles decorres dos informes dos trabalhos originais de Aoki e Veloso (1975) e Decourt e Quaresma (1978), quais sejam: 


\begin{tabular}{c|c|c|c|c}
\hline \multirow{2}{*}{$\begin{array}{c}\text { Método } \\
\text { (referência) }\end{array}$} & \multicolumn{2}{|c|}{$\mathrm{K}=\mathrm{P}_{\text {obs }} / \mathrm{P}_{\text {prev }}$} & \multicolumn{2}{c}{$\mathrm{R}=\log \left(\mathrm{P}_{\text {obs }} / \mathrm{P}_{\text {prev }}\right)$} \\
\cline { 2 - 5 } & Média[K] & Desvio[K] & Média[R] & Desvio[R] \\
\hline $\begin{array}{c}\text { Aoki-Veloso } \\
\text { (Aoki e Veloso, 1975) }\end{array}$ & 1,014 & 0,235 & $-0,0051$ & 0,0976 \\
\hline $\begin{array}{c}\text { Decourt-Quaresma } \\
\text { (Decourt e Quaresma, 1978) }\end{array}$ & 1,058 & 0,341 & 0,0061 & 0,1240 \\
\hline
\end{tabular}

Tabela $\overline{6.1}$ - Valores de $\mathrm{K}=$ Pobs/Pprev e $\mathrm{R}=\log \mathrm{K}$ decorrentes das publicaçôes originais de Aoki eVeloso (1975) e Decourt e Quaresma (1978).

De posse das informações da tabela anterior, pode-se calcular o valor de n', o tamanho equivalente da distribuição a priori de R. A variável n' pode ser entendida como o "tamanho" da informação anterior disponível.

Ehlers (2003) mostra que o valor de n’ pode ser obtido pela expressão 4.26 aplicada aos hiperparâmetros anteriores, a saber:

$V[r]=\frac{v^{\prime}}{v^{\prime}-2} \cdot \frac{v^{\prime}}{\mathrm{n}^{\prime}}$

Onde V[r] é a variância relacionada ao método de previsão da capacidade de carga e v' e v' são parâmetros da distribuição anterior relativa à variabilidade intra-canteiro (no caso em tela, $v^{\prime}=9,28$ e $v^{\prime}=0,0152$ ) . Considerando-se os desvios expostos na tabela 6.1, relativos aos dois métodos de previsão da capacidade de carga ora enfocados, tem-se, com fulcro na expressão 6.1, os seguintes valores de n’:

- Método de Aoki-Veloso: n' = 2,03;

- Método de Decourt-Quaresma: n’ = 1,26.

\subsubsection{Previsão e resultados de provas de carga estática}

Suponha-se que sejam feitas provas de carga estática sobre as estacas E1 e E2, com critério de ruptura dado pelo método de Davisson, obtendo-se as cargas últimas de, digamos, $40 \mathrm{kN}$ e $150 \mathrm{kN}$. À luz desses resultados, apresenta-se o seguinte quadro resumo: 


\begin{tabular}{|c|c|c|c|c|}
\hline \multicolumn{5}{|c|}{ SÍNTESE DOS RESULTADOS DAS PROVAS DE CARGA } \\
\hline Estaca & $\operatorname{Pprev}(\mathrm{kN})$ & $\operatorname{Pobs}(\mathrm{kN})$ & $\mathrm{K}={ }_{\text {Pobs }} / \mathrm{P}_{\text {prev }}$ & $\mathrm{R}=\log \mathrm{K}$ \\
\hline E1 & 80 & 40 & 0,5 & $-0,3010$ \\
\hline E2 & 100 & 150 & 1,5 & 0,1760 \\
\hline \multicolumn{4}{|c|}{ Média de $\mathrm{R}-\mathrm{m}_{\mathrm{R}}$} & $-0,0625$ \\
\hline \multicolumn{4}{|c|}{ Variância de $\mathrm{R}-\mathrm{S}_{\mathrm{R}}^{2}$} & 0,1138 \\
\hline
\end{tabular}

Tabela 6.2 - Síntese dos resultados das provas de carga efetuadas nas duas estacas da obra hipotética.

\subsubsection{Atualização bayesiana}

O processo de atualização bayesiana tem por base as equações 4.17 a 4.20, 4.24, 4.27 e 4.30. Com fulcro nas referidas equações e considerando-se um índice de confiabilidade $\beta=3$, obtêm-se os valores expostos na seguinte tabela, para os dois métodos e previsão ora em comento:

\begin{tabular}{|c|c|c|}
\hline & \multicolumn{2}{|c|}{ MÉTODO } \\
\hline & AOKI-VELOSO & DECOURT-QUARESMA \\
\hline $\mathrm{n}^{\prime}$ & 2,03 & 1,26 \\
\hline$\mu^{\prime}$ & $-0,0051$ & 0,0061 \\
\hline $\mathrm{k} 1$ & 0,5 & 0,5 \\
\hline $\mathrm{k} 2$ & 1,5 & 1,5 \\
\hline $\mathrm{r} 1$ & $-0,3010$ & $-0,3010$ \\
\hline $\mathrm{r} 2$ & 0,1761 & 0,1761 \\
\hline$m_{R}$ & $-0,0625$ & $-0,0625$ \\
\hline $\mathrm{s}^{2}$ & 0,1138 & 0,1138 \\
\hline n" (Eq. 4.17) & 4,03 & 3,26 \\
\hline$\mu "$ (Eq. 4.18) & $-0,0335$ & $-0,0625$ \\
\hline$v^{\prime \prime}$ (Eq. 4.19) & 11,28 & 11,28 \\
\hline v" (Eq. 4.20) & 0,0229 & 0,0229 \\
\hline H (Eq. 4.24) & 35,009 & 33,392 \\
\hline$\beta$ & 3 & 3 \\
\hline $\mathrm{r}_{\mathrm{o}}$ (Eq. 4.27) & $-0,54$ & $-0,55$ \\
\hline FS (Eq. 4.30) & 3,47 & 3,55 \\
\hline
\end{tabular}

Tabela 6.3 - Valores obtidos no processo de atualização dos hiperparâmetros. 
Nota-se que, para duas provas de carga que resultaram em $\mathrm{k}_{1}=0,5$ e $\mathrm{k}_{2}=1,5$, o fator de segurança necessário para garantir um índice de confiabilidade $\beta=3$ é de $F S=3,47$ e FS $=3,55$ para os métodos de Aoki-Veloso de Decourt-Quaresma, respectivamente. O maior fator de segurança associado ao método de Decourt-Quaresma relaciona-se com a maior variância de $\mathrm{R}$ da distribuição anterior associada ao referido método, como apresentado na Tabela 6.1.

De posse dos fatores de segurança a serem aplicados a cada um dos métodos, seriam obtidas as seguintes cargas admissíveis nas estacas:

\begin{tabular}{|c|c|c|c|c|}
\cline { 2 - 5 } \multicolumn{1}{c|}{} & \multicolumn{4}{|c|}{ MÉTODO } \\
\cline { 2 - 5 } & AOKI-VELOSO & \multicolumn{2}{c|}{ DECOURT-QUARESMA } \\
\cline { 2 - 5 } & E1 & E2 & E1 & E2 \\
\hline Pprev (kN) & 80 & 100 & 80 & 100 \\
\hline FS & 3,47 & 3,47 & 3,55 & 3,55 \\
\hline Padm (kN) & $\mathbf{2 3 , 0}$ & $\mathbf{2 8 , 8}$ & $\mathbf{2 2 , 5}$ & $\mathbf{2 8 , 2}$ \\
\hline
\end{tabular}

Tabela 6.4 - Cargas admissíveis nas estacas da obra hipotética.

Os fatores de segurança apresentados na tabela supra são aqueles necessários à manutenção de um índice de confiabilidade $\beta=3$.

\subsubsection{Influência da variabilidade dos resultados das provas de carga}

Interessante verificar como varia o fator de segurança em função do valor médio dos resultados das provas de carga $\left(\mathrm{K}_{\mathrm{med}}\right)$ bem como da dispersão entre os resultados de $\mathrm{k}_{1}$ e $\mathrm{k}_{2}$.

Os gráficos a seguir apresentam a variação de FS para os dois métodos de previsão enfocados em relação à média dos resultados das provas de carga, considerando-se a dispersão dos resultados das provas de carga (medida pelo coeficiente de variação - CV) variando de $0 \%$ a $20 \%$. 


\begin{tabular}{|c|c|c|c|c|}
\hline \multicolumn{4}{|c}{ MÉTODO DE AOKI-VELOSO } \\
\hline \multirow{2}{*}{ Kmed } & \multicolumn{4}{|c}{ FS para os seguintes CV } \\
\hline & $\mathbf{0} \%$ & $\mathbf{1 0 \%}$ & $\mathbf{2 0 \%}$ & $\mathbf{3 0 \%}$ \\
\hline 0,5 & 4,26 & 4,29 & 4,39 & 4,56 \\
\hline 0,8 & 2,73 & 2,75 & 2,81 & 2,92 \\
\hline 1,0 & 2,38 & 2,40 & 2,45 & 2,54 \\
\hline 1,5 & 2,15 & 2,16 & 2,19 & 2,25 \\
\hline 2,0 & 2,18 & 2,18 & 2,21 & 2,26 \\
\hline
\end{tabular}

Tabela 6.5 - Fatores de segurança em função do valor de Kmed e do Coeficiente de Variação dos resultados das provas de carga, para o método de Aoki-Veloso, considerando-se a execução de 2 provas de carga.

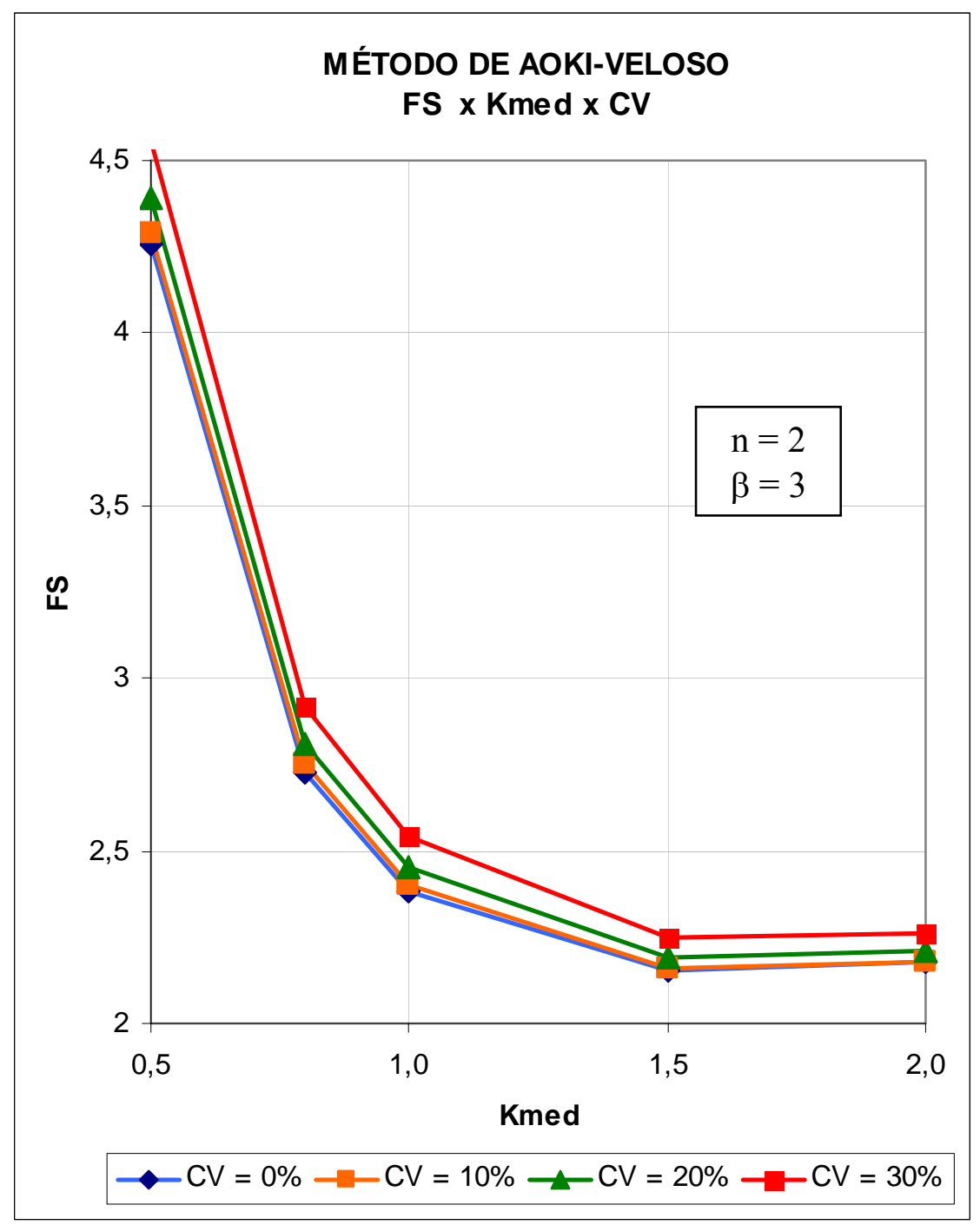

Figura 6.2 - Variação do Fator de Segurança em função da média e do Coeficiente de Variação dos resultados de duas provas de carga efetuadas na obra, considerando-se o método de Aoki-Veloso.

A tabela e gráfico supra foram construídos assumindo-se as mesmas informações anteriores relativas ao método de Aoki-Veloso e à precisão intra-canteiro (Tabela 6.1 e Figura $6.1)$. 


\begin{tabular}{c|c|c|c|c|}
\hline \multicolumn{5}{c}{ MÉTODO DE DECOURT-QUARESMA } \\
\hline \multirow{2}{*}{ Kmed } & \multicolumn{4}{c}{ FS para os seguintes CV } \\
\hline & $\mathbf{0} \%$ & $\mathbf{1 0} \%$ & $\mathbf{2 0 \%}$ & $\mathbf{3 0 \%}$ \\
\hline 0,5 & 4,51 & 4,55 & 4,66 & 4,84 \\
\hline 0,8 & 2,83 & 2,85 & 2,92 & 3,04 \\
\hline 1,0 & 2,41 & 2,42 & 2,48 & 2,57 \\
\hline 1,5 & 2,01 & 2,02 & 2,06 & 2,12 \\
\hline 2,0 & 1,90 & 1,91 & 1,94 & 1,99 \\
\hline
\end{tabular}

Tabela 6.6 - Fatores de segurança em função da média e coeficiente de variação dos resultados de K, para o método de Decourt-Quaresma.

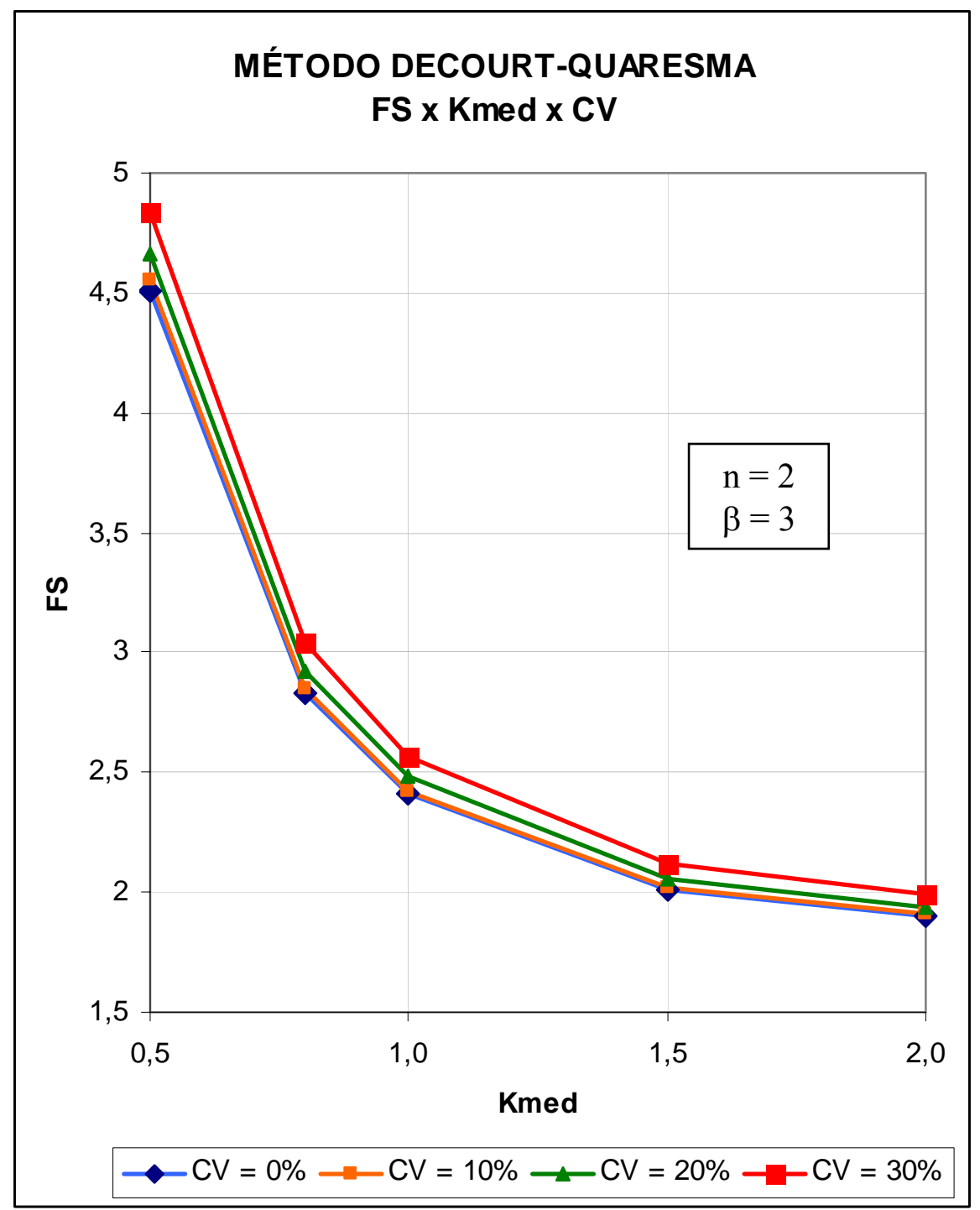

Figura 6.3 - Variação do Fator de Segurança em função da média dos resultados das provas de carga (Kmed) e da variabilidade dos resultados, aqui representada pela relação entre k2 e k1, considerando-se o método de Decourt-Quaresma.

A tabela e figura supra foram construídas com fulcro nas informações anteriores consideradas para o método de Decourt-Quaresma (Tabela 6.1 e Figura 6.1). 
Dos gráficos retro, nota-se que, coerentemente, há uma redução do fator de segurança com o aumento da média dos resultados das provas de carga. Além disso, fica evidenciado também que o fator de segurança depende não somente da média dos resultados das provas de carga, mas também da variabilidade entre os referidos resultados. Quanto maior a variabilidade dos resultados das provas de carga maior o fator de segurança exigido para a manutenção de um dado um $\beta$.

Muito inobstante, observa-se que o fator de segurança é pouco sensível à variabilidade intra-canteiro, ocorrendo aumento significativo do fator de segurança somente para elevados valores do coeficiente de variação dos resultados das provas de carga (por exemplo, para $\mathrm{CV}=30 \%$ ). Tal fato decorre, muito provavelmente, da pouca importância da variabilidade intra-canteiro frente à variabilidade inter-canteiros, ou seja, a variabilidade de capacidade de carga entre as diversas obras que deram origem às distribuições gama utilizadas.

\subsubsection{Influência do número de provas de carga executadas no fator de segurança}

Para estudar o efeito do número de provas de carga (n) no fator de segurança, aplicou-se a metodologia apresentada considerando-se a realização de até 3 provas de carga na obra hipotética, considerando-se as mesmas informações anteriores relativas à precisão intra-canteiro e ao método de Aoki-Veloso.

A Figura 6.4 apresenta uma simulação onde se realiza de 1 a 3 provas de carga que tenham resultado em um determinado Kmed e decorrido em um Coeficiente de Variação nulo $(\mathrm{CV}=0 \%)$.

Os resultados extraídos da análise da figura, a primeira vista, podem parecer inconsistentes, haja vista que o fator de segurança para 3 provas de carga pode ser até maior que o FS para 1 prova de carga, para reduzidos valores de Kmed.

Esse comportamento tem uma explicação lógica. Se, à medida que efetuamos mais provas de carga, o valor de $\mathrm{k}=$ Pobs/Pprev tenha se mostrado sempre baixo (exemplo, $\mathrm{k}=$ 0,3), significa que as provas de carga estão indicando que, no site em questão, o método de 
previsão superestima a capacidade de carga, exigindo fatores de segurança cada vez mais altos a cada confirmação de que o método superestima a capacidade de carga (a cada prova de carga com valor de "K" pequeno).

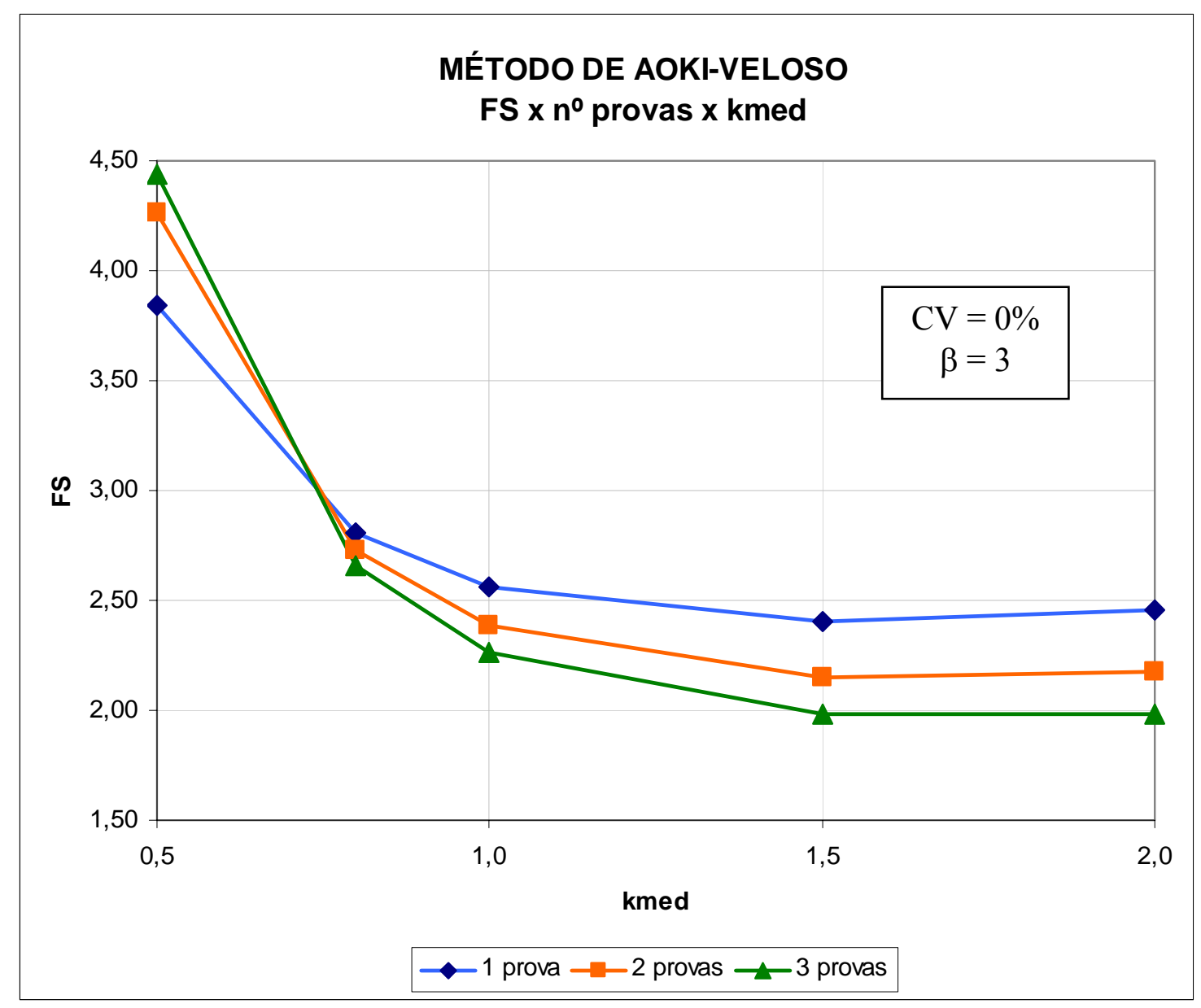

Figura 6.4 - Variação de FS com Kmed e com o número de provas de carga efetuadas, considerando-se o método de Aoki-Veloso e Coeficiente de Variação dos resultados das provas de carga seja zero $(\mathrm{CV}=0 \%)$.

O comportamento retro mencionado sugere que a execução de provas de carga adicionais em determinada obra pode redundar em significativa redução do fator de segurança nas situações em que o método de previsão da capacidade de carga não superestime, de forma sistemática, a "verdadeira" capacidade de carga (o resultado da prova de carga estática).

A Figura 6.5 é uma ampliação da Figura 6.4, destacando que, para uma faixa de valores mais prováveis para Kmed, há uma persistente redução de FS a cada prova de carga feita. 


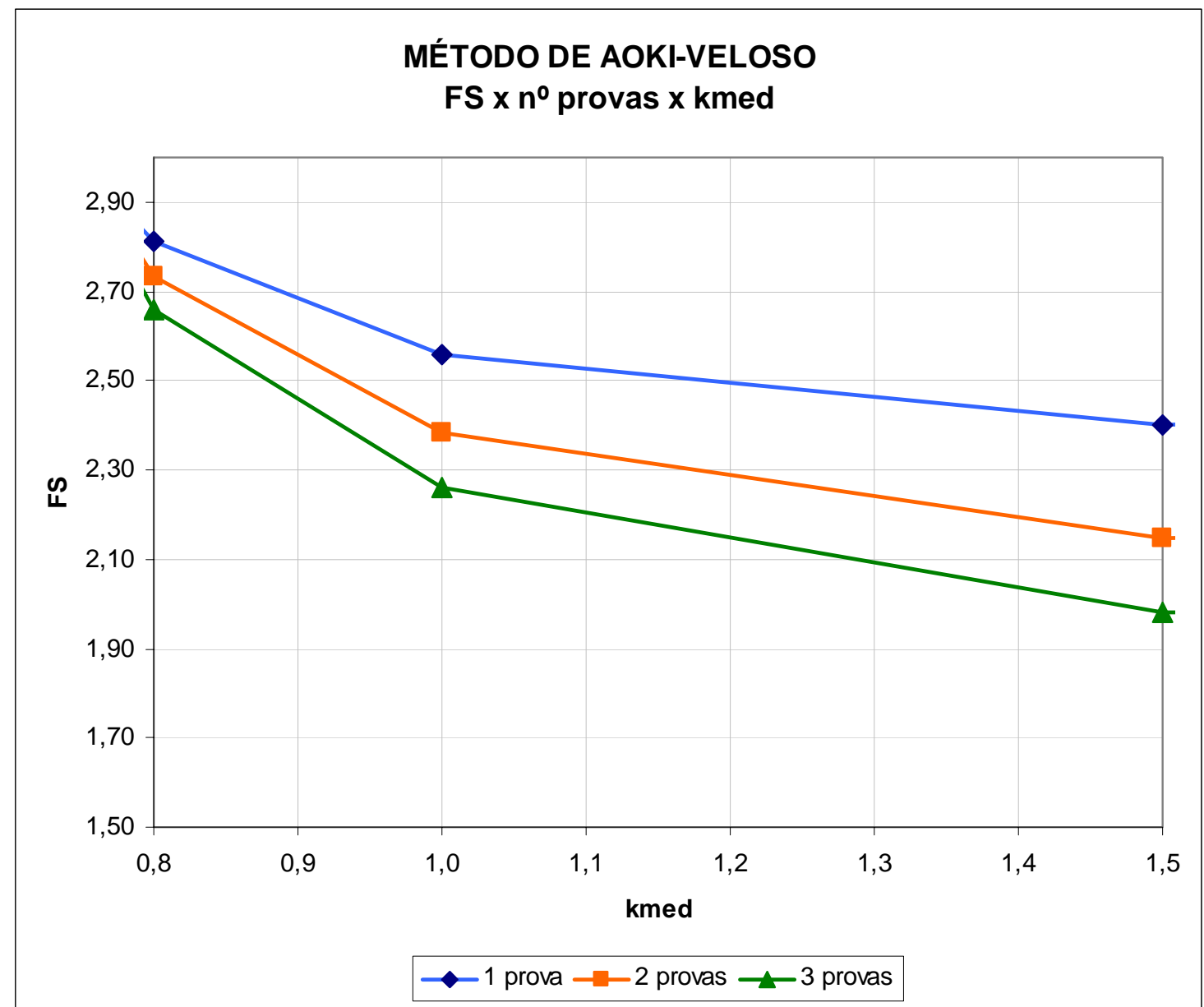

Figura 6.5 - Ampliação da figura anterior, destacando uma faixa de valores mais prováveis para Kmed.

A Figura 6.6 apresenta a variação do fator de segurança com o número de provas de carga considerando-se o coeficiente de variação dos resultados de $\mathrm{K}$ de $\mathrm{CV}=15 \%$.

Analisando-se a referida figura, observa-se que, para esse grau de dispersão dos valores de $\mathrm{K}$ no canteiro, a execução de provas de carga adicionais não resulta na redução do fator de segurança. 


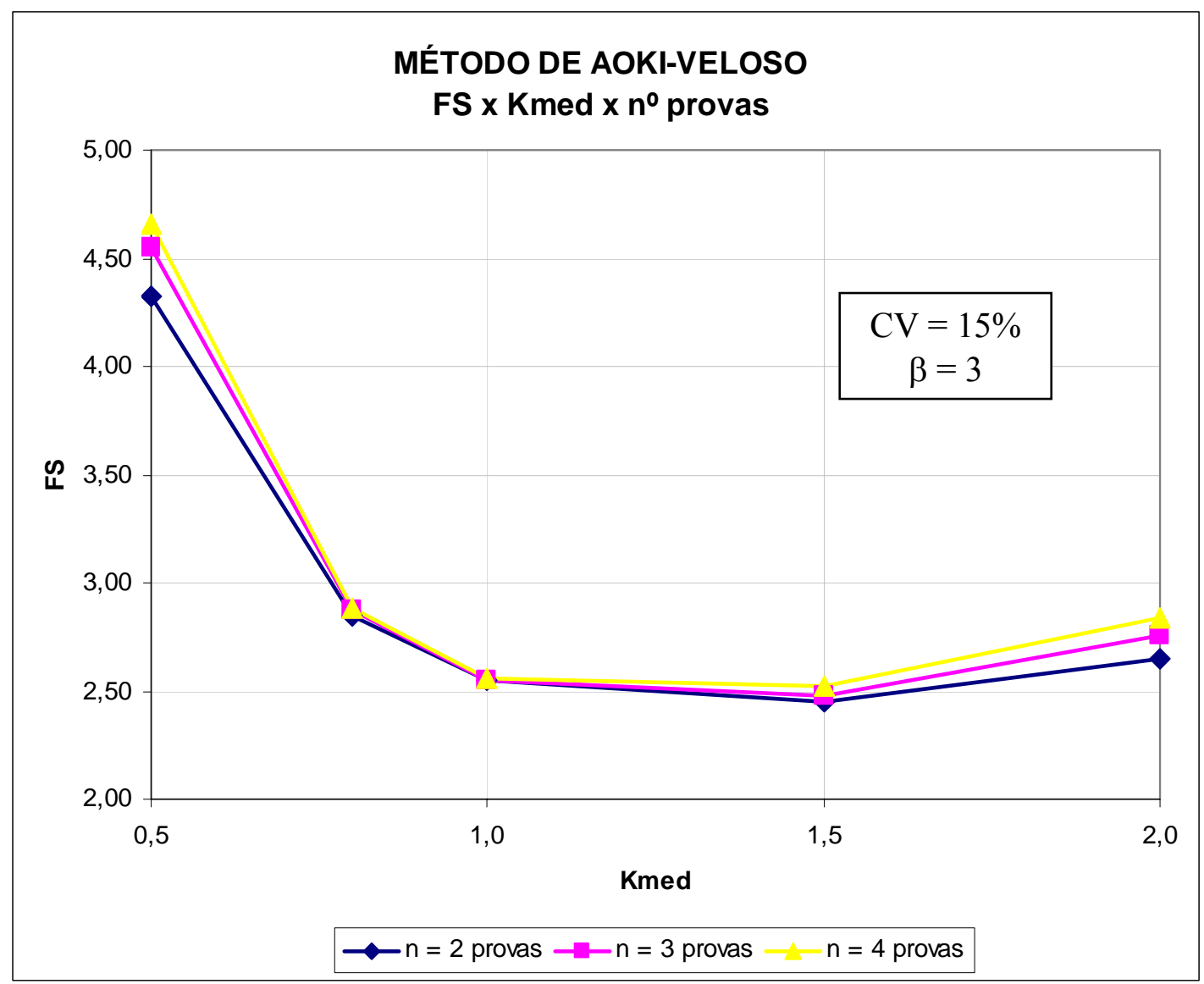

Figura 6.6 - Variação do FS com Kmed e com o número de provas efetuadas, considerando-se um coeficiente de variação da variável $\mathrm{K}$ de $\mathrm{CV}=15 \%$.

Do exposto neste exemplo, nota-se o fator de segurança a ser aplicado é dependente da média e da variabilidade da variável $\mathrm{K}=$ Pobs/Pprev no interior da obra. Quanto maior o valor de Kmed menor o fator de segurança demandado e quanto maior a variabilidade dos resultados das provas de carga $(\mathrm{CV})$ maior o fator de segurança exigido.

A influência da variabilidade dos resultados das provas de carga no fator de segurança ficou evidenciada para elevados valores do coeficiente de variação dos resultados de $\mathrm{K}=$ Pobs/Pprev em determinada obra. 


\subsection{EXEMPLO 02: PROVA DE CARGA DINÂMICA E PRECISÃO INTRA- CANTEIRO DESCONHECIDA}

Neste item serão considerados os mesmos informes utilizados no item anterior, porém com o diferencial de que serão feitas provas de carga dinâmica ao invés de provas de carga estáticas.

A maior incerteza em relação às provas de carga dinâmica foi incorporada, como já dito, através da metodologia exposta no APÊNDICE A da presente dissertação. Analisandose as tabelas constantes no referido apêndice, nota-se a grande variabilidade dos valores da média e variância da variável Pdin/Pprev, sendo Pdin a capacidade de carga da estaca apurada por ensaio dinâmico e Pprev a carga prevista para a estaca.

Uma dificuldade considerável foi obter os valores dos momentos de $\mathrm{R}=\log (\mathrm{K}) \mathrm{a}$ partir dos momentos da variável K. Dada a forte não linearidade da função logarítmica, a média da variável $\mathrm{R}$ não é igual ao logaritmo da média da variável $\mathrm{K}$.

Essa dificuldade foi superada com a utilização do Método de Primeira Ordem e Segundo Momento (FOSM - "First Order Second Moment"), como apresentado no APÊNDICE B.

Aplicando-se as formulações bayesianas para o caso de variância desconhecida aos informes da variável $\mathrm{R}$ relativos aos métodos de Aoki-Veloso e Decourt-Quaresma apresentados na Tabela B1 (APÊNDICE B), para uma prova de carga e $\beta=3$, obtém-se os fatores de segurança apresentados nas tabelas e figuras que se seguem.

\begin{tabular}{c|c|c|c|c|}
\hline \multicolumn{5}{|c}{ FS PARA MÉTODO DE AOKI-VELOSO } \\
\hline Kmed & Estática & Din-Paikowsky & Din-Gates & Din-PDA cases \\
\hline 0,5 & 3,84 & 4,84 & 5,67 & 4,91 \\
\hline 0,8 & 2,81 & 3,31 & 3,94 & 3,53 \\
\hline 1,0 & 2,56 & 2,87 & 3,40 & 3,15 \\
\hline 1,5 & 2,40 & 2,37 & 2,68 & 2,72 \\
\hline 2,0 & 2,46 & 2,17 & 2,32 & 2,56 \\
\hline
\end{tabular}

Tabela 6.7 - Fatores de segurança propostos para o método de Aoki-Veloso considerando-se a realização de uma prova de carga que tenha decorrido em um valor de $K$, para $\beta=3$. Os informes de $\mathrm{R}$ relativos às provas dinâmicas estão apresentados na tabela do Apêndice B. 


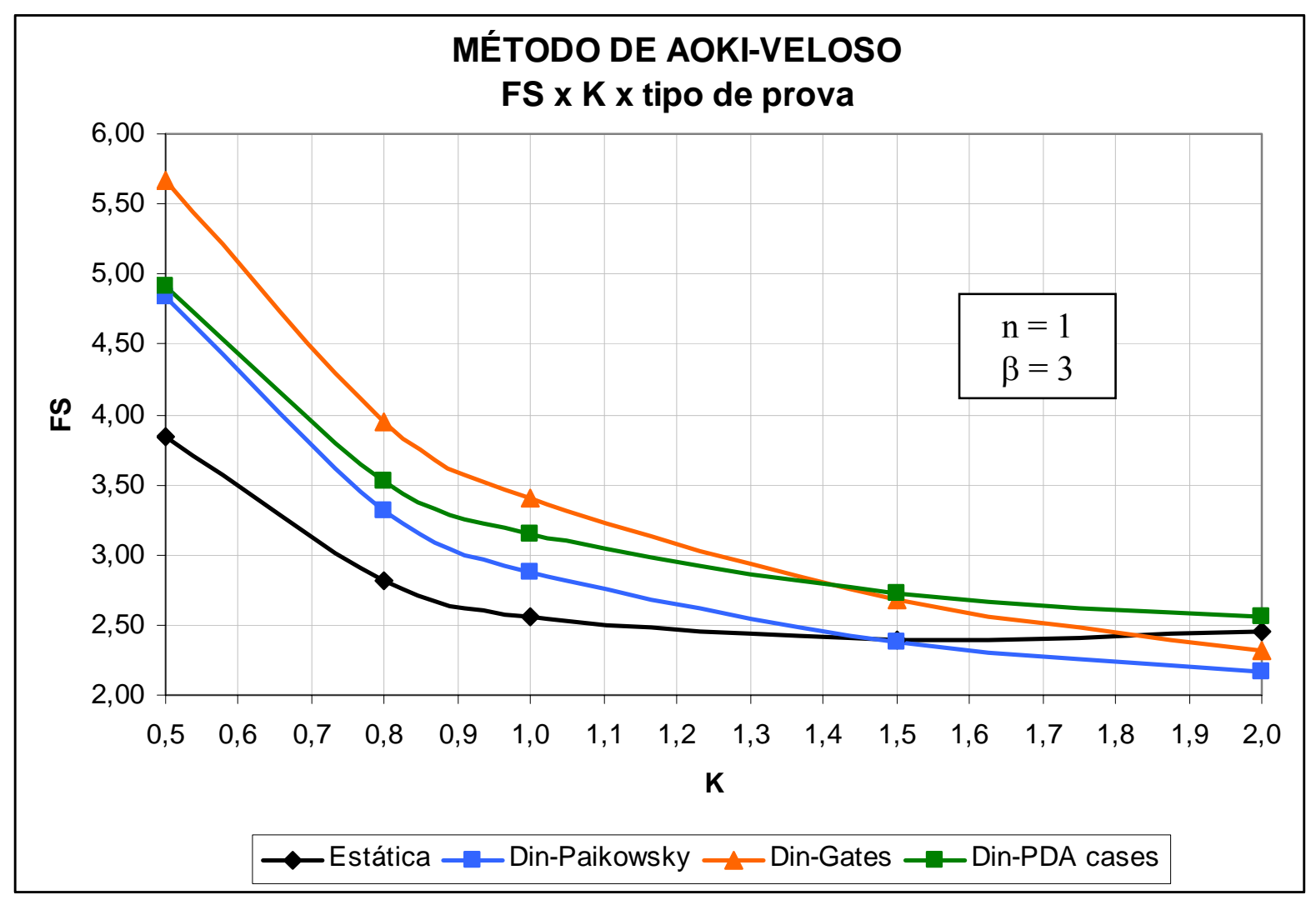

Figura 6.7 - Variação do FS com o valor de $\mathrm{K}=$ Pobs/Pprev para o método de Aoki-Veloso e em função do tipo de prova de carga, considerando-se a relação Pdin/Pestat oriunda dos bancos de dados de Paikowsky, Gates e PDA cases, como informado em MacVay et al (2000).

Analisando-se o gráfico e a tabela supra, nota-se que os fatores de segurança associados às provas de carga dinâmica tendem a ser maiores que aqueles associados às provas de carga estática, exceção para o caso de elevadores valores de $\mathrm{K}=$ Pobs/Pprev.

Essa inversão ocorrida para elevados valores de K encontra explicação no fato de que os ensaios de carregamento dinâmico tendem a subestimar a capacidade de carga da estaca em relação às provas estáticas. Desta feita, valores elevados de $\mathrm{K}$ obtidos por prova de carga dinâmica sugerem que o "verdadeiro" valor de K (aquele obtido por prova estática) seja ainda maior, possibilitando uma redução do fator de segurança para o caso de provas dinâmicas.

A tabela e a figura a seguir apresentadas mostram os fatores de segurança a serem aplicados à previsão pelo método de Decourt-Quaresma, aferidas por uma prova dinâmica, 
$\operatorname{com} \beta=3$.

\begin{tabular}{c|c|c|c|c|}
\hline \multicolumn{5}{c}{ FS PARA MÉTODO DE DECOURT-QUARESMA } \\
\hline Kmed & Estática & Din-Paikowsky & Din-Gates & Din-PDA cases \\
\hline 0,5 & 4,21 & 5,08 & 5,75 & 5,12 \\
\hline 0,8 & 2,95 & 3,40 & 3,95 & 3,58 \\
\hline 1,0 & 2,62 & 2,90 & 3,38 & 3,13 \\
\hline 1,5 & 2,31 & 2,31 & 2,62 & 2,59 \\
\hline 2,0 & 2,25 & 2,04 & 2,24 & 2,34 \\
\hline
\end{tabular}

Tabela 6.8 - Fatores de segurança propostos para o método de Decourt-Quaresma considerando-se a realização de uma prova de carga que tenha decorrido em um valor de $\mathrm{K}$, para $\beta=3$. Os informes de $\mathrm{R}$ relativos às provas dinâmicas estão apresentados na tabela do Apêndice B.

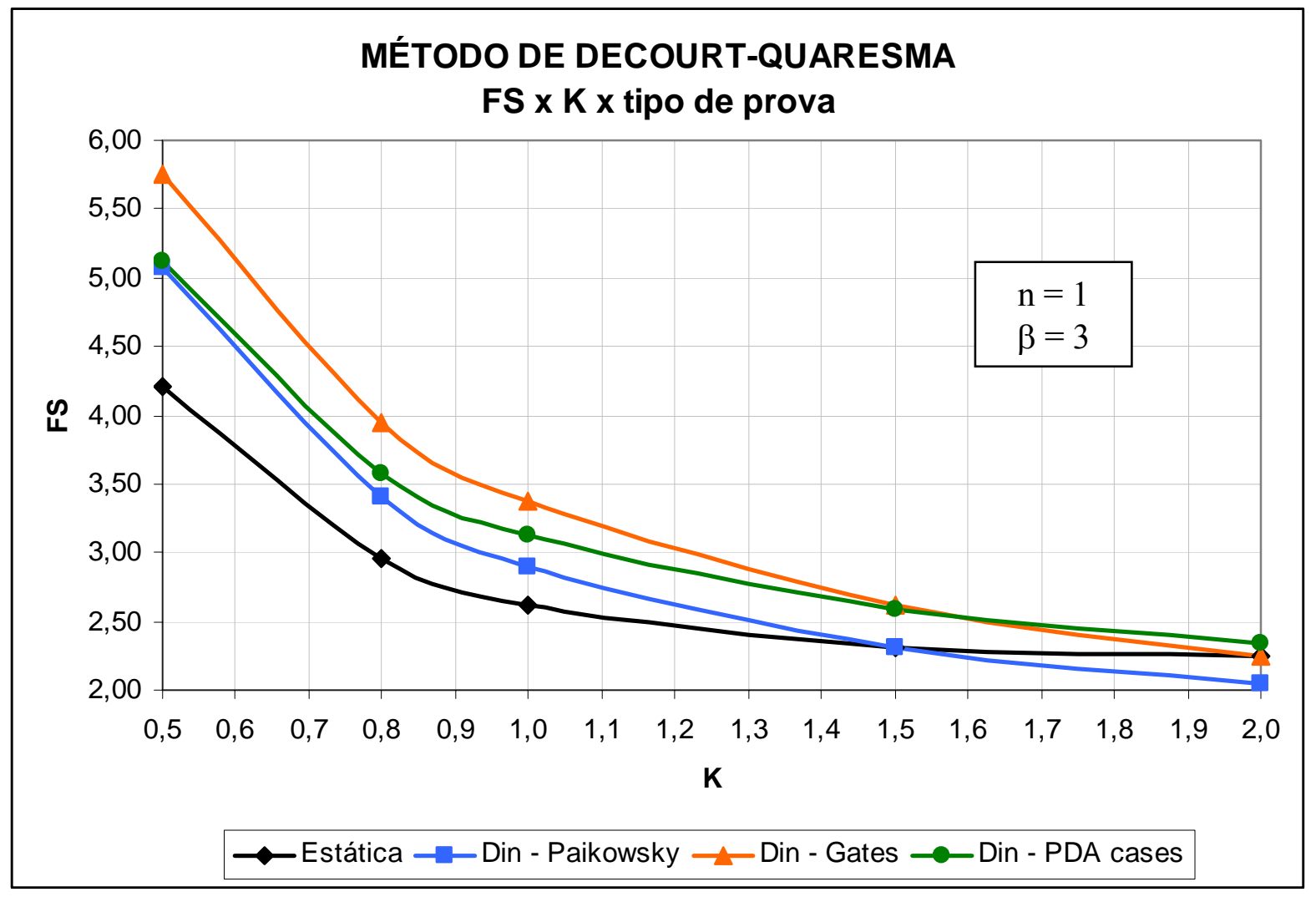

Figura 6.8 - Variação do FS com o valor de K = Pobs/Pprev para o método de Decourt-Quaresma e em função do tipo de prova de carga, considerando-se a relação Pdin/Pestat oriunda dos bancos de dados de Paikowsky, Gates e PDA cases, como informado em MacVay et al (2000).

Da figura supra, observa-se que persiste a tendência do FS para as provas dinâmicas serem maiores que aqueles associados às provas estáticas, exceção para o caso de elevados valores de $\mathrm{K}$.

Para se avaliar o efeito do número e da dispersão das provas de carga no fator de 
segurança, apresenta-se a seguir os resultados de FS considerando-se duas provas de carga, com dispersão de $\mathrm{CV}=0 \%$ e $\mathrm{CV}=20 \%$, para $\beta=3$.

\begin{tabular}{|c|c|c|c|c|}
\hline \multicolumn{5}{|c}{ FS PARA MÉTODO DE AOKI-VELOSO - CV = 0\% } \\
\hline Kmed & Estática & Din-Paikowsky & Din-Gates & Din-PDA cases \\
\hline 0,5 & 4,26 & 4,75 & 4,96 & 4,69 \\
\hline 0,8 & 2,73 & 3,00 & 3,29 & 3,12 \\
\hline 1,0 & 2,38 & 2,52 & 2,78 & 2,70 \\
\hline 1,5 & 2,15 & 1,97 & 2,10 & 2,22 \\
\hline 2,0 & 2,18 & 1,74 & 1,76 & 2,01 \\
\hline
\end{tabular}

Tabela 6.9 - Fatores de segurança propostos para o método de Aoki-Veloso considerando-se a realização de duas provas de carga que tenham decorrido em um valor de Kmed, para $\beta=3$ e CV $=0 \%(\mathrm{k} 1=\mathrm{k} 2)$.

\begin{tabular}{c|c|c|c|c|}
\hline \multicolumn{5}{c}{ FS PARA MÉTODO DE AOKI-VELOSO - CV = 20\% } \\
\hline Kmed & Estática & Din-Paikowsky & Din-Gates & Din-PDA cases \\
\hline 0,5 & 4,39 & 4,90 & 5,13 & 4,84 \\
\hline 0,8 & 2,81 & 3,10 & 3,40 & 3,22 \\
\hline 1,0 & 2,45 & 2,60 & 2,86 & 2,78 \\
\hline 1,5 & 2,19 & 2,03 & 2,16 & 2,27 \\
\hline 2,0 & 2,21 & 1,78 & 1,81 & 2,06 \\
\hline
\end{tabular}

Tabela 6.10 - Fatores de segurança propostos para o método de Aoki-Veloso considerando-se a realização de duas provas de carga que tenham decorrido em um valor de Kmed, para $\beta=3$ e CV $=20 \%$.

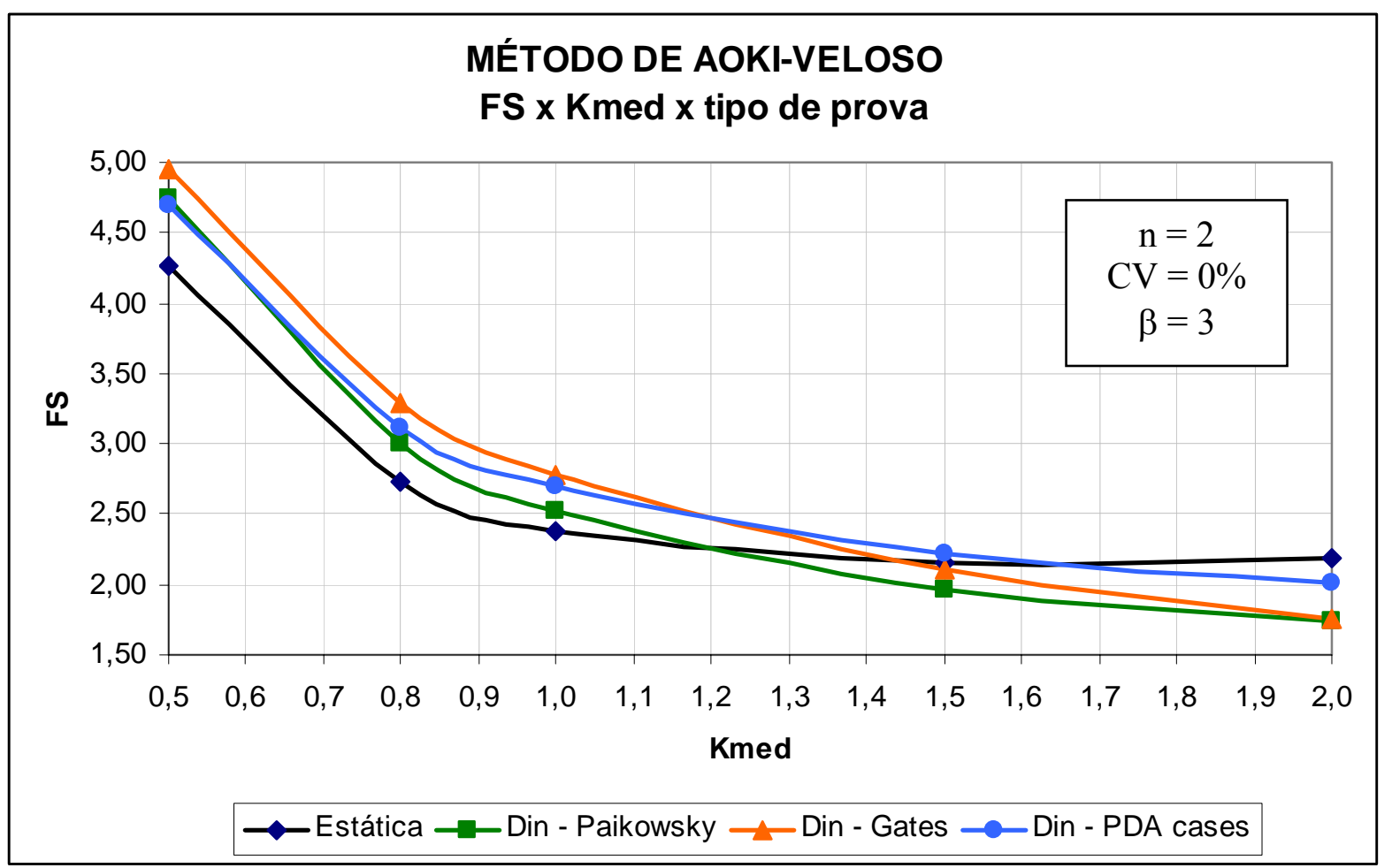

Figura 6.9 - Variação do FS com o valor de K = Pobs/Pprev para o método de Aoki-Veloso e em função do tipo de prova de carga, considerando-se duas provas de carga com $\mathrm{CV}=0 \%$. 


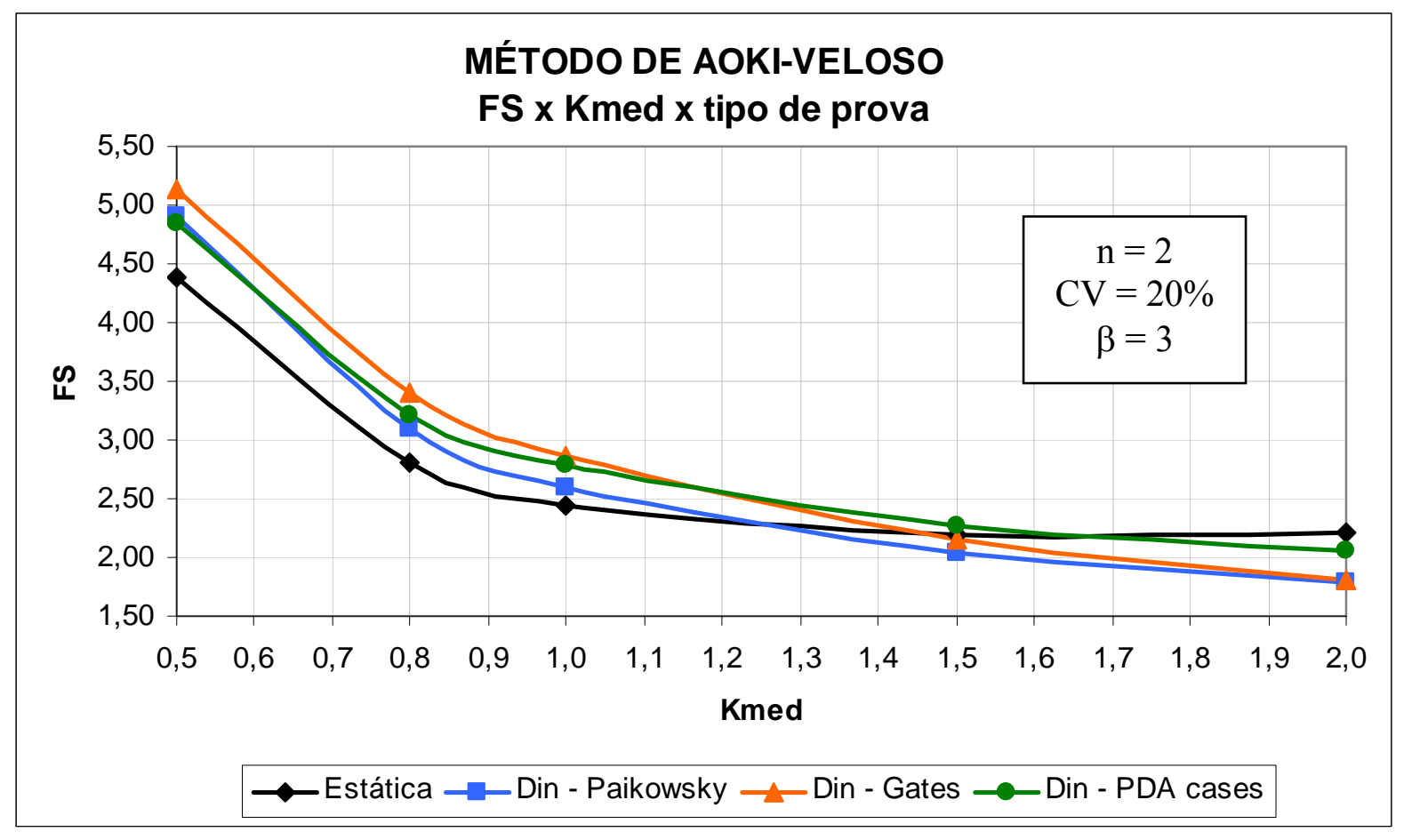

Figura 6.10 - Variação do FS com o valor de K = Pobs/Pprev para o método de Aoki-Veloso e em função do tipo de prova de carga, considerando-se duas provas de carga com $\mathrm{CV}=20 \%$.

Das figuras e tabelas supra apresentadas, constata-se que os fatores de segurança a serem aplicados aos resultados de provas dinâmicas podem ser menores que aqueles a serem aplicados aos resultados de provas de carga estática, situação essa que ocorre para elevados valores de $\mathrm{K}=$ Pobs/Pprev.

Coerentemente, os fatores de segurança aumentam com o aumento da dispersão dos resultados de $\mathrm{K}$ verificados na obra, medida através do coeficiente de variação. Maiores coeficientes de variação dos resultados de K estão associados a maiores fatores de segurança, também no caso de realização de ensaios dinâmicos.

\subsection{EXEMPLO 03: PROVA DE CARGA ESTÁTICA E PRECISÃO INTRA- CANTEIRO CONHECIDA}

Neste exemplo serão aplicadas as formulações bayesianas para o caso de variância (ou, mutatis mutandis, de precisão) conhecida, bem como se considerará que a capacidade de carga observada na obra seja obtida por prova de carga estática, conduzida até a ruptura. 
Novamente serão considerados nas simulações os métodos de Aoki-Veloso e Decourt-Quaresma.

Importante salientar que, no caso de variância intra-canteiro conhecida, a dispersão dos resultados das provas de carga executadas em determinada obra não tem influencia no fator de segurança. Destarte, caso a dispersão dos resultados de $\mathrm{K}$ em determinada obra, medida pela variância amostral, seja diferente da variância intra-canteiro (suposta conhecida), tal diferença pode ser considerada meramente casual.

\subsubsection{Informações anteriores referentes à variabilidade intra-canteiro}

Diferentemente das abordagens utilizadas nos dois exercícios anteriores, no presente exemplo a precisão intra-canteiro será admitida fixa e conhecida. Tal consideração pode perfeitamente ser feita na prática de projeto, desde que o engenheiro tenha informações anteriores suficientes acerca do local onde será erigida a obra.

Essa abordagem também permite a tabulação do fator de segurança para diferentes classes de precisão intra-canteiro de forma simples, porém sem prejuízo do rigor estatístico, de tal forma que pode subsidiar melhorias das normas e códigos de projeto e construção de estacas.

Com a finalidade de se avaliar a dependência de FS com a precisão intra-canteiro, será utilizada a divisão ad hoc para as classes de precisão intra-canteiro proposta na Tabela 6.11, com fulcro nos informes de vários autores. Os valores apresentados entre parênteses na referida tabela serão os valores representativos de cada classe de precisão intra-site.

Evidentemente que a classificação apresentada na tabela retro mencionada pode e deve ser discutida e melhorada, justificando o convite à construção de um intenso banco de dados de provas de carga, sugerida por alguns autores, para que a variabilidade intra-canteiro possa ser melhor avaliada (Alonso, 2002; De Mello et al, 2002). 


\begin{tabular}{|c|c|c|}
\hline CLASSIFICAÇ̃̃O & $\boldsymbol{\sigma}[\mathbf{R}]$ & FONTE \\
\hline Baixa Precisão & $\geq 0,20(0,20)$ & Zhang (2004) \\
\hline Média Precisão & 0,10 a $0,20(0,15)$ & $\begin{array}{c}\text { Eriksson (1991), } \\
\text { Vrouwenvelder (1992), Kay } \\
(1993) .\end{array}$ \\
\hline Alta precisão & 0 a 0,10 (0,08) & Eriksson (1991), Kay (1993) \\
\hline
\end{tabular}

Tabela 6.11 - Distinção ad hoc das classes de precisão, em função dos valores de $\sigma[R]$ apresentados por vários autores. Os valores entre parênteses serão os valores representativos de cada classe.

Com fulcro nos informes da tabela supra, os valores representativos de precisão intra-canteiro correspondentes a cada classe serão os seguintes:

- baixa precisão: $\sigma[R]=0,20$;

- média precisão: $\sigma[\mathrm{R}]=0,15$;

- alta precisão: $\sigma[\mathrm{R}]=0,08$.

\subsubsection{Informações anteriores relativas aos métodos de previsão}

Serão consideradas as mesmas informações anteriores referentes aos métodos de Aoki-Veloso e Decourt-Quaresma utilizadas nos exemplos anteriores e apresentadas na Tabela 6.1.

\subsubsection{Previsão e resultados de provas de carga estática}

Suponha-se que tenham sido feitas previsões de capacidade de carga para uma estaca da obra hipotética, identificada por E1, pelos métodos de Aoki-Veloso e Decourt-Quaresma. Por simplicidade, considere-se que ambos os métodos forneceram a mesma estimativa da capacidade de carga, de $500 \mathrm{kN}$.

Suponha-se ainda que seja feita uma prova de carga estática sobre a estaca retro mencionada, obtendo-se a carga última de, por exemplo, 550kN. À luz desse resultado, apresenta-se o seguinte quadro resumo: 


\begin{tabular}{|c|c|c|c|c|}
\hline \multicolumn{5}{|c|}{ SÍNTESE DOS RESULTADOS DAS PROVAS DE CARGA } \\
\hline Estaca & Pprev $(\mathrm{kN})$ & $\operatorname{Pobs}(\mathrm{kN})$ & $\mathrm{K}={ }_{\text {Pobs }} / \mathrm{P}_{\text {prev }}$ & $\mathrm{R}=\log \mathrm{K}$ \\
\hline E1 & 500 & 550 & 1,1 & 0,0414 \\
\hline \multicolumn{4}{|c|}{ Média de $\mathrm{R}-\mathrm{m}_{\mathrm{R}}$} & 0,0414 \\
\hline
\end{tabular}

Tabela 6.12 - Previsão da capacidade de carga e resultado da prova de carga da obra hipotética.

\subsubsection{Atualização bayesiana}

O processo de atualização bayesiana para o caso de variância conhecida tem por base as equações 4.30 a 4.33 e equação 4.35 . Com fulcro nas referidas equações, considerando-se um índice de confiabilidade $\beta=3$ e o caso de alta precisão intra-canteiro $(\sigma=0,08)$, obtêm-se os valores expostos na seguinte tabela, para os dois métodos e previsão ora em comento:

\begin{tabular}{c|c|c|c}
\hline \multicolumn{2}{c}{ PARÂMETRO } & \multicolumn{3}{c}{ A\&V } & D\&Q \\
\hline média anterior & $\mu^{\prime}$ & $-0,0051$ & 0,0061 \\
\hline desvio anterior & $\mathrm{s}^{\prime}$ & 0,0976 & 0,1240 \\
\hline variância & $\mathrm{s}^{\prime 2}$ & 0,00953 & 0,01538 \\
\hline prova 1 & $\mathrm{k} 1$ & \multicolumn{2}{c}{1,10} \\
\hline log prova1 & $\mathrm{r} 1$ & 0,041392685 \\
\hline variância posterior (Eq. 4.32) & $\mathrm{s}^{\prime 2}$ & 0,00383 & 0,00452 \\
\hline média (Eq. 4.31) & $\mu^{\prime \prime}$ & 0,02271 & 0,03102 \\
\hline variância - preditiva (Eq. 4.33) & $\sigma_{\mathrm{p}}{ }^{2}$ & 0,01023 & 0,01092 \\
\hline beta & $\beta$ & \multicolumn{2}{c}{3} \\
\hline valor extremo (Eq. 4.35) & $\mathrm{ro}$ & $-0,28069$ & $-0,28246$ \\
\hline Fator de Segurança (Eq. 4.30) & FS & $\mathbf{1 , 9 1}$ & $\mathbf{1 , 9 2}$ \\
\hline
\end{tabular}

Tabela 6.13 - Fatores de segurança obtidos para os métodos de Aoki-Veloso e Decourt-Quaresma, com fulcro nas informações anteriores apresentadas na Tabela 6.1 e nos resultados expostos na Tabela 6.12, considerando-se $\beta=3$ e $\sigma=0,08$.

Da tabela supra nota-se que o fator de segurança a ser aplicado à previsão de capacidade de carga obtida pelo método de Decourt-Quaresma é sensivelmente maior que aquele aplicado à previsão feita por Aoki-Veloso. No entanto, é importante salientar que a eventual superioridade de um método em relação a outro fica condicionada à distribuição anterior da variável $\mathrm{R}=\log (\mathrm{Pobs} / \mathrm{Pprev})$ considerada, distribuição essa que, em última análise, pode depender do local da obra, tipo de estaca e outros informes. 
Nota-se também, dos resultados apresentados na Tabela 6.13, que os fatores de segurança obtidos são maiores que o fator de segurança proposto pela NBR 6122 para o caso de execução de prova de carga $(\mathrm{FS}=1,6)$.

\subsubsection{Variação do fator de segurança com a precisão intra-canteiro}

Para se avaliar a variação do fator de segurança com a precisão intra-canteiro, as formulações bayesianas foram aplicadas ao método de Aoki-Veloso considerando-se as três classes de precisão intra-canteiro mencionadas no item 6.3.1.

O gráfico a seguir apresenta os resultados obtidos:

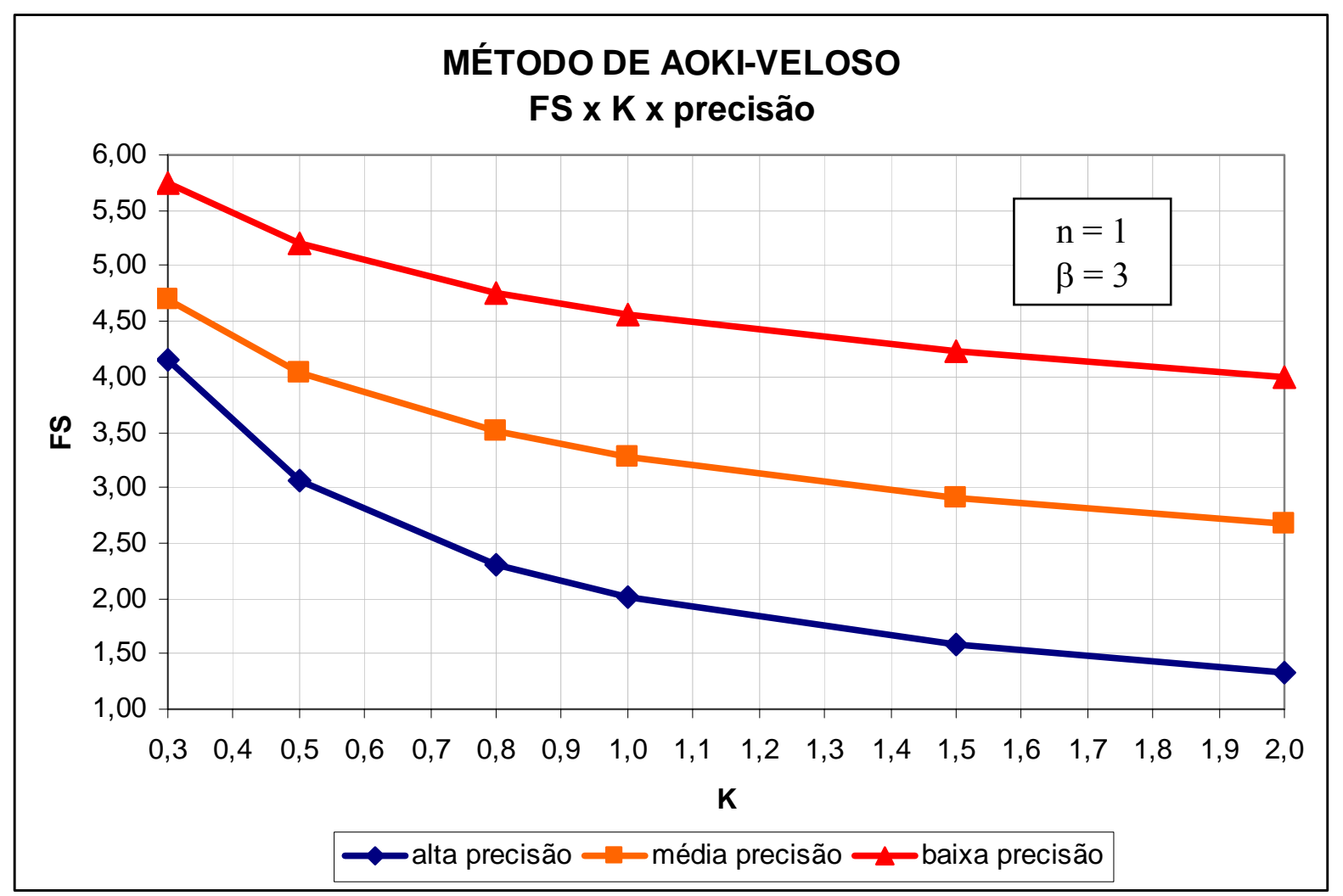

Figura 6.11 - Fatores de segurança em função de $\mathrm{K}$, para o método de $\mathrm{A} \& \mathrm{~V}$, considerando-se $\beta=3$ e a execução de uma prova de carga. Foram considerados os mesmos informes anteriores apresentados na Tabela 6.1.

Analisando-se a figura supra, nota-se que, coerentemente, quanto maior a precisão intra-canteiro (menor desvio-padrão da variável R) menor o fator de segurança exigido. 
A tabela a seguir apresenta os dados que deram origem ao gráfico retro:

\begin{tabular}{|c|c|c|c|}
\hline \multicolumn{4}{|c|}{ AOKI-VELOSO $(n=1, \beta=3)$} \\
\hline \multirow{2}{*}{ k } & \multicolumn{3}{|c|}{$\sigma[R]$ intra-canteiro } \\
\hline & 0,08 & 0,15 & 0,20 \\
\hline 0,3 & 4,15 & 4,70 & 5,75 \\
\hline 0,5 & 3,06 & 4,03 & 5,21 \\
\hline 0,8 & 2,31 & 3,51 & 4,76 \\
\hline 1,0 & 2,02 & 3,28 & 4,56 \\
\hline 1,5 & 1,59 & 2,91 & 4,22 \\
\hline 2,0 & 1,33 & 2,67 & 3,99 \\
\hline
\end{tabular}

Tabela 6.14 - Fatores de segurança para o método de Aoki-Veloso, em função do resultado de K na obra e da precisão intra-canteiro, considerando-se uma prova de carga $(\mathrm{n}=1)$ e $\beta=3$.

O gráfico a seguir apresenta a variação do fator de segurança com a precisão intracanteiro e a média da variável $\mathrm{K}=$ Pobs/Pprev para duas provas de carga, considerando-se os mesmos informes anteriores relativos à variável R para o método de Aoki-Veloso.

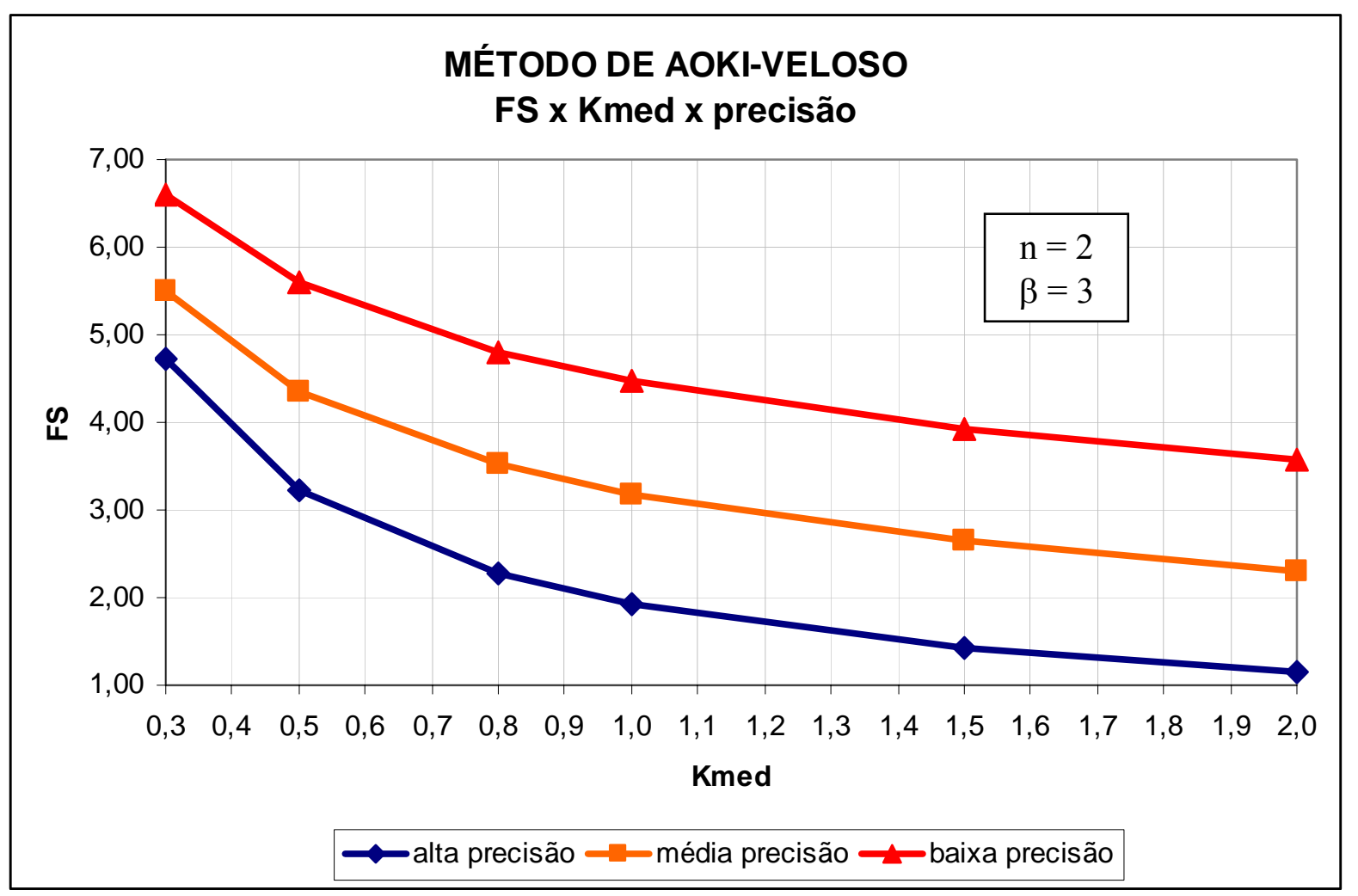

Figura 6.12 - Fatores de segurança em função de Kmed, para o método de A\&V, considerando-se $\beta=3$ e a execução de duas prova de carga.

A tabela a seguir apresenta os dados que originaram a Figura 6.12. 


\begin{tabular}{|c|c|c|c|}
\hline \multicolumn{4}{|c|}{ AOKI-VELOSO $(n=2, \beta=3)$} \\
\hline \multirow{2}{*}{ kmed } & \multicolumn{3}{|c|}{$\sigma[R]$ intra-canteiro } \\
\hline & 0,08 & 0,15 & 0,20 \\
\hline 0,3 & 4,72 & 5,51 & 6,59 \\
\hline 0,5 & 3,22 & 4,36 & 5,59 \\
\hline 0,8 & 2,27 & 3,52 & 4,80 \\
\hline 1,0 & 1,92 & 3,17 & 4,47 \\
\hline 1,5 & 1,42 & 2,64 & 3,92 \\
\hline 2,0 & 1,14 & 2,31 & 3,57 \\
\hline
\end{tabular}

Tabela 6.15 - Fatores de segurança para o método de Aoki-Veloso, em função da média dos valores de K para duas provas de carga e da precisão intra-canteiro.

Analisando-se a Figura 6.12 e a tabela supra, observa-se que, de fato, menores precisões de canteiro estão associadas a maiores fatores de segurança.

Diferentemente dos resultados obtidos para o caso de variância desconhecida, podese perceber no presente caso que o fator de segurança varia bastante em função do desviopadrão intra-canteiro (suposto conhecido).

Os resultados sugerem que o conhecimento da precisão intra-canteiro é fundamental para a correta apropriação da segurança no projeto de fundações em estacas.

\subsubsection{Variação do fator de segurança com o número de provas de carga}

Para se avaliar a variação do fator de segurança com o número de provas de carga, as formulações bayesianas foram aplicadas ao método de Aoki-Veloso considerando-se a execução de até 4 provas de carga.

O gráfico seguinte apresenta os resultados da simulação, considerando-se o desviopadrão intra-canteiro $\sigma=0,20$ (baixa precisão). 


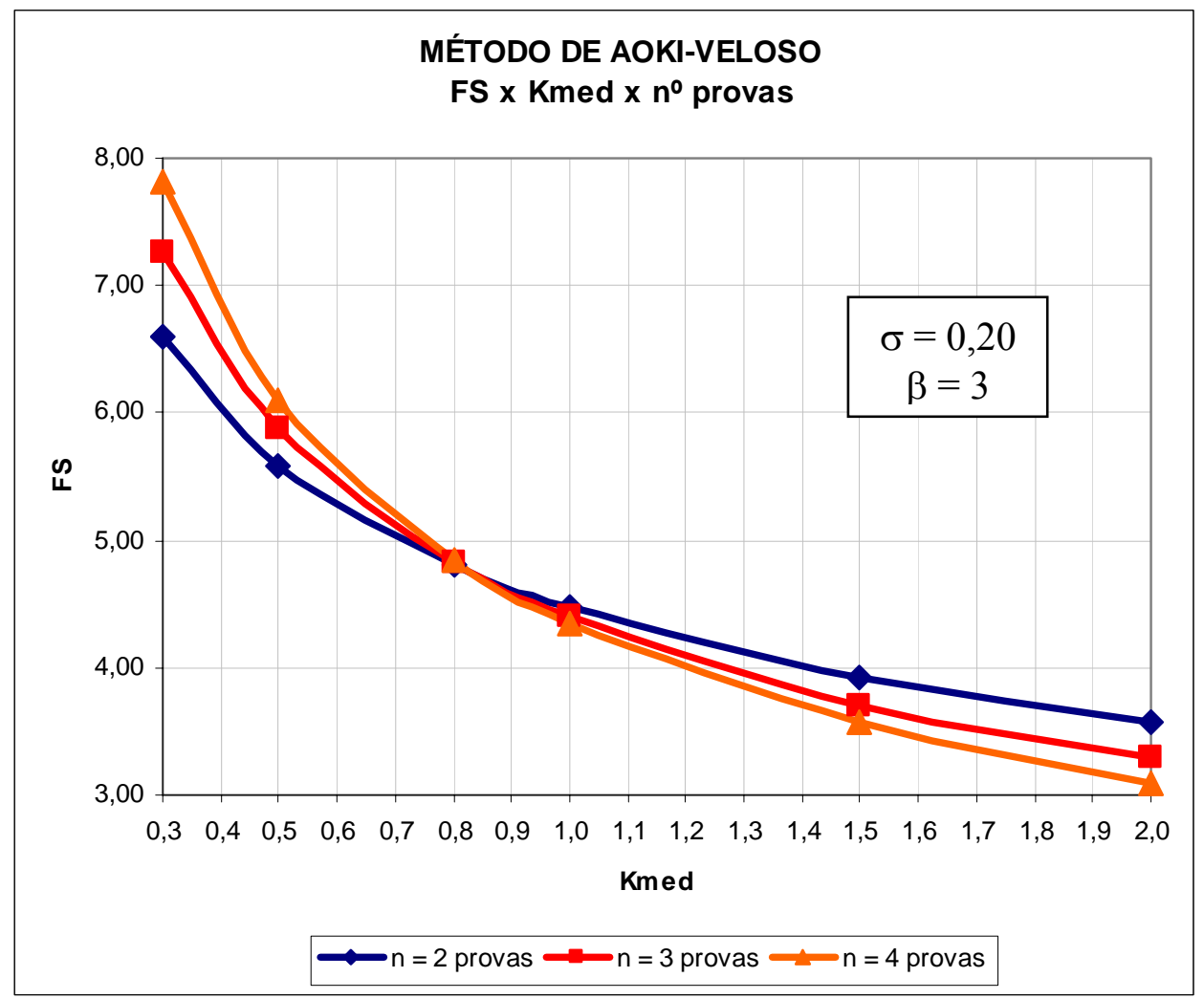

Figura 6.13 - Variação de FS com a média dos resultados dos valores de K verificados na obra e com o número de provas de carga, para o método de Aoki-Veloso.

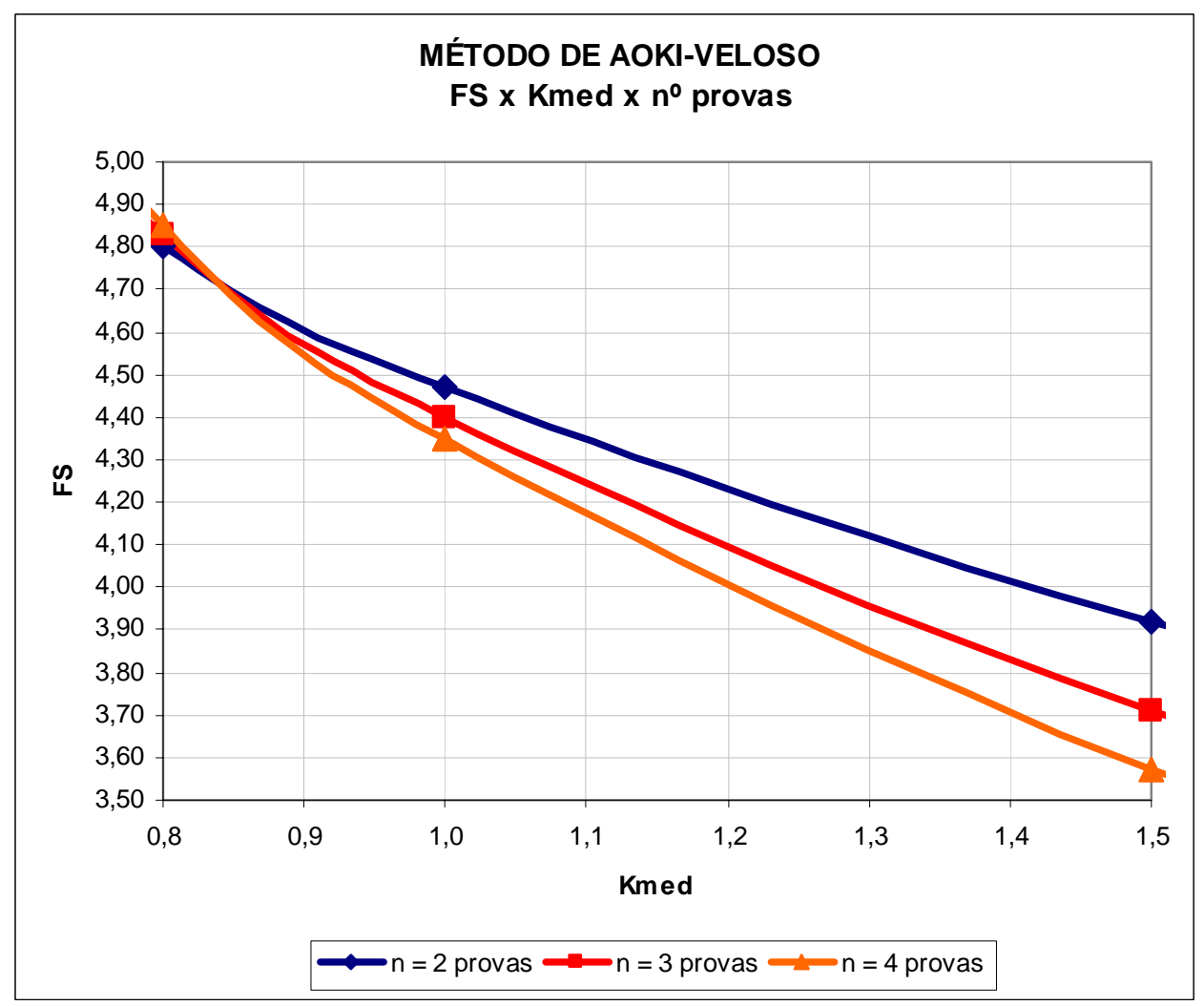

Figura 6.14 - Ampliação da figura anterior, considerando-se uma faixa mais provável de valores de Kmed. 
Analisando-se as figuras retro apresentadas, nota-se que, da mesma forma que no caso de variância intra-canteiro desconhecida, para pequenos valores de $\mathrm{Kmed}(\mathrm{Kmed}=0,3$ por exemplo) quanto maior o número de provas de carga maior o fator de segurança necessário, fenômeno cuja causa já foi explicada anteriormente e está relacionada com a superestimativa proporcionada pelo método de previsão.

Quando o método de previsão não superestima a capacidade de carga observada $(\mathrm{K}=$ Pobs/Pprev $\geq 1)$, a execução de provas de carga adicionais implica em redução do fator de segurança, como mostra a Figura 6.14.

\subsection{EXEMPLO 04: PROVA DE CARGA DINÂMICA E PRECISÃO INTRA- CANTEIRO CONHECIDA}

Neste exemplo serão aplicadas as formulações bayesianas para o caso de variabilidade intra-canteiro conhecida, bem como será considerado que a capacidade de carga observada na obra seja obtida por ensaios de carregamento dinâmico.

Para tanto, serão considerados os informes anteriores relativos à variável $\mathrm{R}=\log ($ Pobs/Pprev) apresentados na Tabela B1 do APÊNDICE B.

As tabelas a seguir apresentam os fatores de segurança demandados para o método de Aoki-Veloso, considerando-se a execução de até 4 ensaios de carregamento dinâmico e os informes relativos à variável Pdin/Pestat apresentados por Paikowsky (1994) apud McVay (2000).

\begin{tabular}{|c|c|c|c|}
\hline \multicolumn{4}{|c|}{ AOKI-VELOSO $(n=2, \beta=3)$} \\
\hline \multirow{2}{*}{ kmed } & \multicolumn{3}{|c|}{$\sigma[R]$ intra-canteiro } \\
\hline & 0,08 & 0,15 & 0,20 \\
\hline 0,3 & 5,82 & 8,23 & 10,27 \\
\hline 0,5 & 3,67 & 5,67 & 7,55 \\
\hline 0,8 & 2,40 & 4,02 & 5,68 \\
\hline 1,0 & 1,96 & 3,42 & 4,97 \\
\hline 1,5 & 1,36 & 2,54 & 3,89 \\
\hline 2,0 & 1,05 & 2,06 & 3,27 \\
\hline
\end{tabular}

Tabela 6.16 - Variação de FS com a precisão intra-canteiro e com o valor de Kmed para o método de A\&V, considerando-se a execução de 2 provas de carga dinâmicas. 


\begin{tabular}{|c|c|c|c|}
\hline \multicolumn{4}{|c|}{ AOKI-VELOSO $(n=3, \beta=3)$} \\
\hline \multirow{2}{*}{ kmed } & \multicolumn{3}{|c|}{$\sigma[R]$ intra-canteiro } \\
\hline & 0,08 & 0,15 & 0,20 \\
\hline 0,3 & 5,83 & 8,55 & 10,92 \\
\hline 0,5 & 3,61 & 5,67 & 7,66 \\
\hline 0,8 & 2,33 & 3,89 & 5,52 \\
\hline 1,0 & 1,89 & 3,25 & 4,73 \\
\hline 1,5 & 1,29 & 2,35 & 3,57 \\
\hline 2,0 & 0,99 & 1,87 & 2,92 \\
\hline
\end{tabular}

Tabela 6.17 - Variação de FS com a precisão intra-canteiro e com o valor de Kmed para o método de A\&V, considerando-se a execução de 3 provas de carga dinâmicas.

\begin{tabular}{|c|c|c|c|}
\hline \multicolumn{4}{|c|}{ AOKI-VELOSO $(n=4, \beta=3)$} \\
\hline \multirow{2}{*}{ kmed } & \multicolumn{3}{|c|}{$\sigma[R]$ intra-canteiro } \\
\hline & 0,08 & 0,15 & 0,20 \\
\hline 0,3 & 5,82 & 8,73 & 11,35 \\
\hline 0,5 & 3,58 & 5,67 & 7,72 \\
\hline 0,8 & 2,29 & 3,82 & 5,42 \\
\hline 1,0 & 1,86 & 3,16 & 4,58 \\
\hline 1,5 & 1,26 & 2,24 & 3,38 \\
\hline 2,0 & 0,96 & 1,76 & 2,72 \\
\hline
\end{tabular}

Tabela 6.18 - Variação de FS com a precisão intra-canteiro e com o valor de Kmed para o método de A\&V, considerando-se a execução de 4 provas de carga dinâmicas.

As figuras a seguir ilustram a variação de FS com o número de provas de carga e foram construídas com fulcro nas tabelas retro.

Analisando-se as referidas figuras, observa-se que o fator de segurança diminui com um maior número de provas de carga realizadas e com o valor de Kmed. 


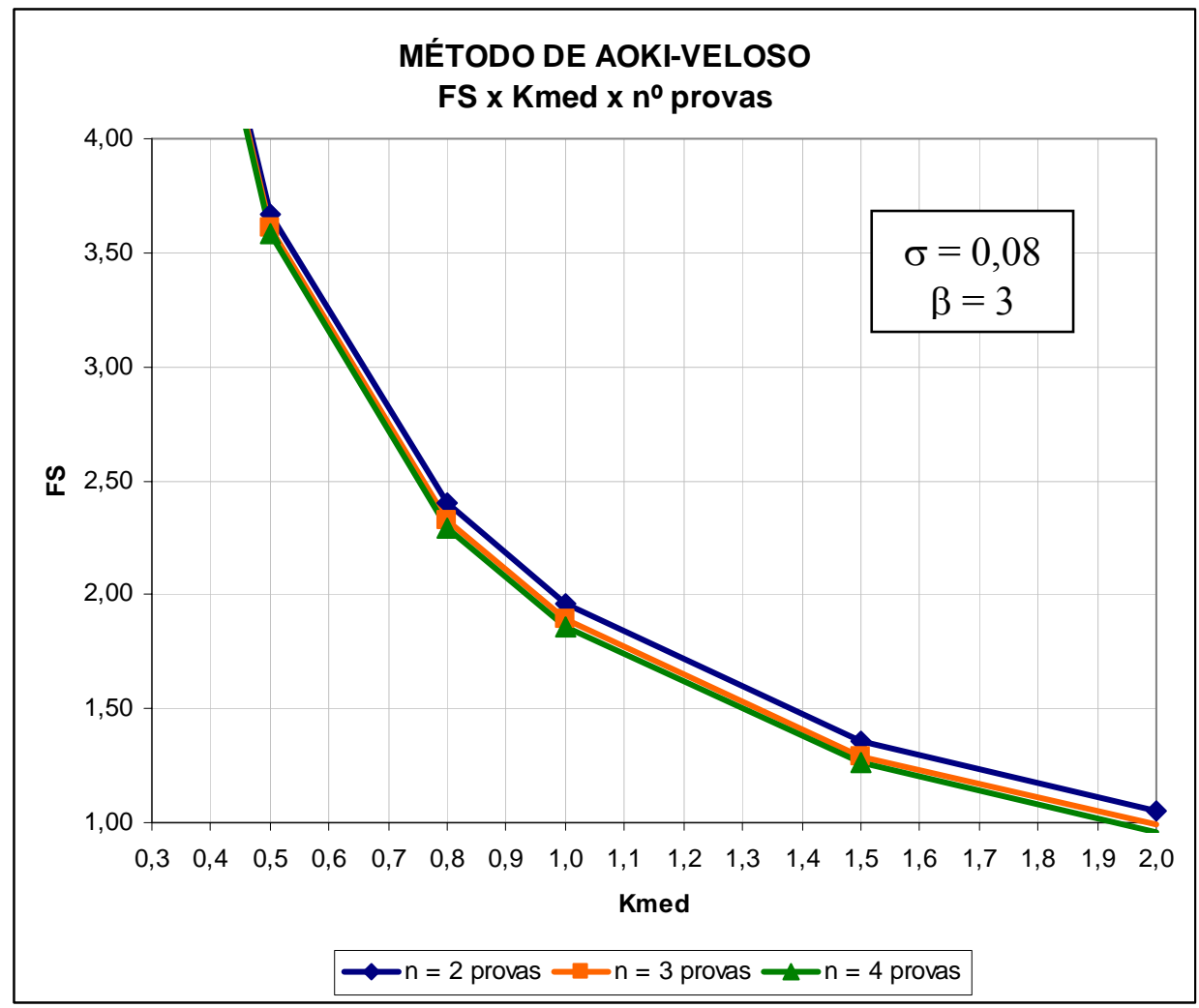

Figura 6.15 - Variação de FS com Kmed e com o número de provas de carga dinâmica, para o método de AokiVeloso, considerando-se $\sigma=0,08$ (alta precisão).

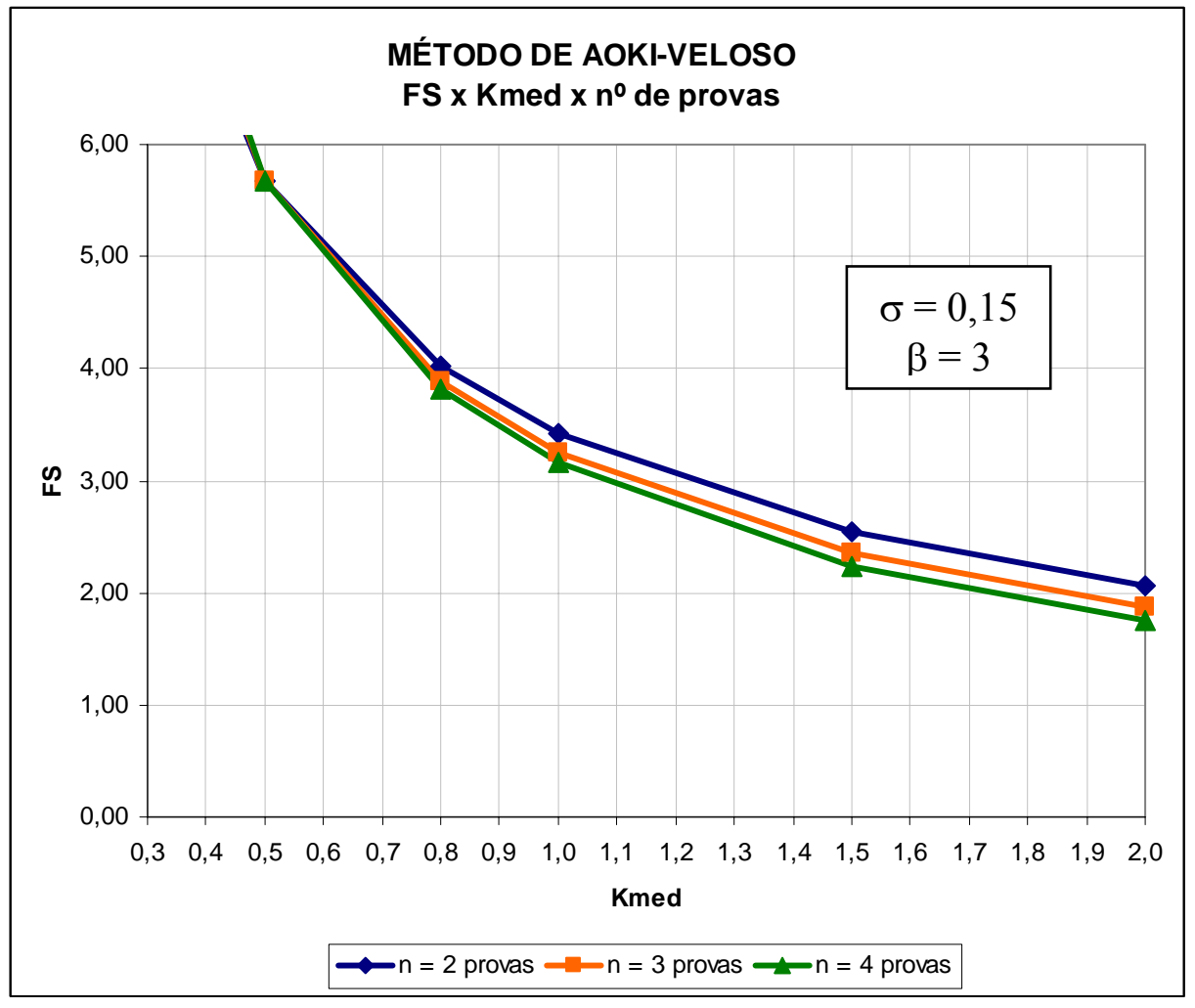

Figura 6.16 - Variação de FS com Kmed e com o número de provas de carga dinâmica, para o método de AokiVeloso, considerando-se $\sigma=0,15$ (média precisão). 
As figuras e tabelas a seguir apresentam a variação de FS com Kmed e com o tipo de prova de carga.

\begin{tabular}{c|c|c|c}
\hline \multicolumn{3}{c}{ DECOURT-QUARESMA (n=2, $\beta=3, \sigma=0,08)$} \\
\hline \multirow{2}{*}{ kmed } & \multicolumn{3}{|c}{ Tipo de prova } \\
\cline { 2 - 4 } & Estática & Din-Paikowsky & Din-Gates \\
\hline 0,3 & 5,21 & 5,98 & 6,36 \\
\hline 0,5 & 3,42 & 3,73 & 3,89 \\
\hline 0,8 & 2,31 & 2,41 & 2,47 \\
\hline 1,0 & 1,92 & 1,96 & 1,99 \\
\hline 1,5 & 1,38 & 1,34 & 1,35 \\
\hline 2,0 & 1,08 & 1,03 & 1,02 \\
\hline
\end{tabular}

Tabela 6.19 - Variação de FS com Kmed e com o tipo de prova, considerando-se a realização de 2 ensaios de carregamento dinâmico e $\sigma=0,08$ (alta precisão). Os informes relativos à variável Pdin/Pestat são decorrentes dos bancos de dados de Paikowsky e Gates, sintetizados em McVay et al (2000).

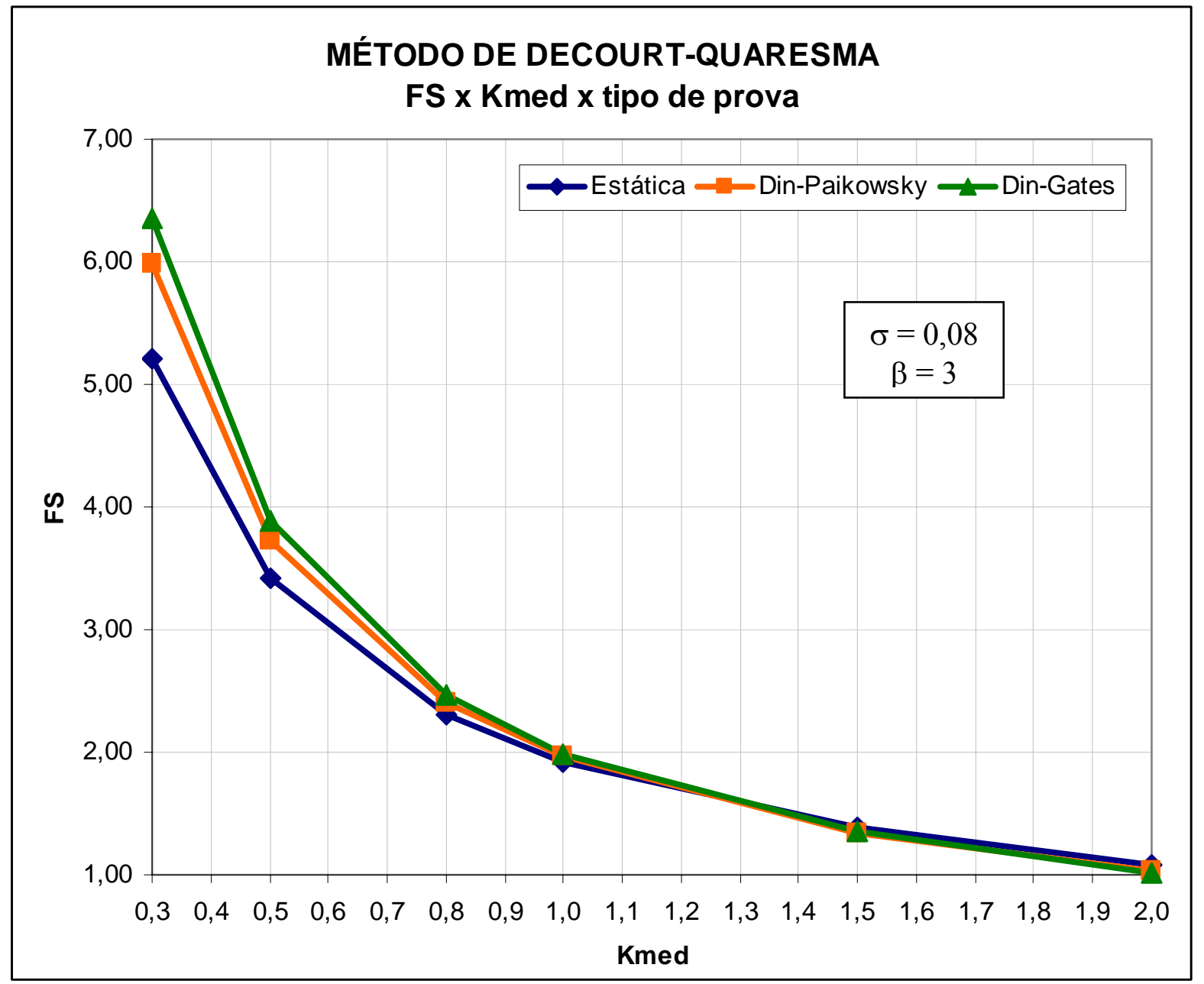

Figura 6.17 - Variação de FS com Kmed e com o tipo de prova de carga, com base nos informes apresentados na Tabela 6.19 . 


\begin{tabular}{c|c|c|c}
\hline \multicolumn{4}{c}{ DECOURT-QUARESMA ( $\mathbf{n = 2 ,} \beta=\mathbf{3}, \sigma=\mathbf{0 , 1 5})$} \\
\hline \multirow{2}{*}{ kmed } & \multicolumn{3}{|c}{ Tipo de prova } \\
\cline { 2 - 4 } & Estática & Din-Paikowsky & Din-Gates \\
\hline 0,3 & 6,46 & 8,83 & 10,59 \\
\hline 0,5 & 4,81 & 5,92 & 6,76 \\
\hline 0,8 & 3,67 & 4,09 & 4,47 \\
\hline 1,0 & 3,22 & 3,43 & 3,67 \\
\hline 1,5 & 2,55 & 2,50 & 2,57 \\
\hline 2,0 & 2,16 & 1,99 & 2,00 \\
\hline
\end{tabular}

Tabela 6.20 - Variação de FS com Kmed e com o tipo de prova, considerando-se a realização de 2 ensaios de carregamento dinâmico e $\sigma=0,15$ (média precisão).

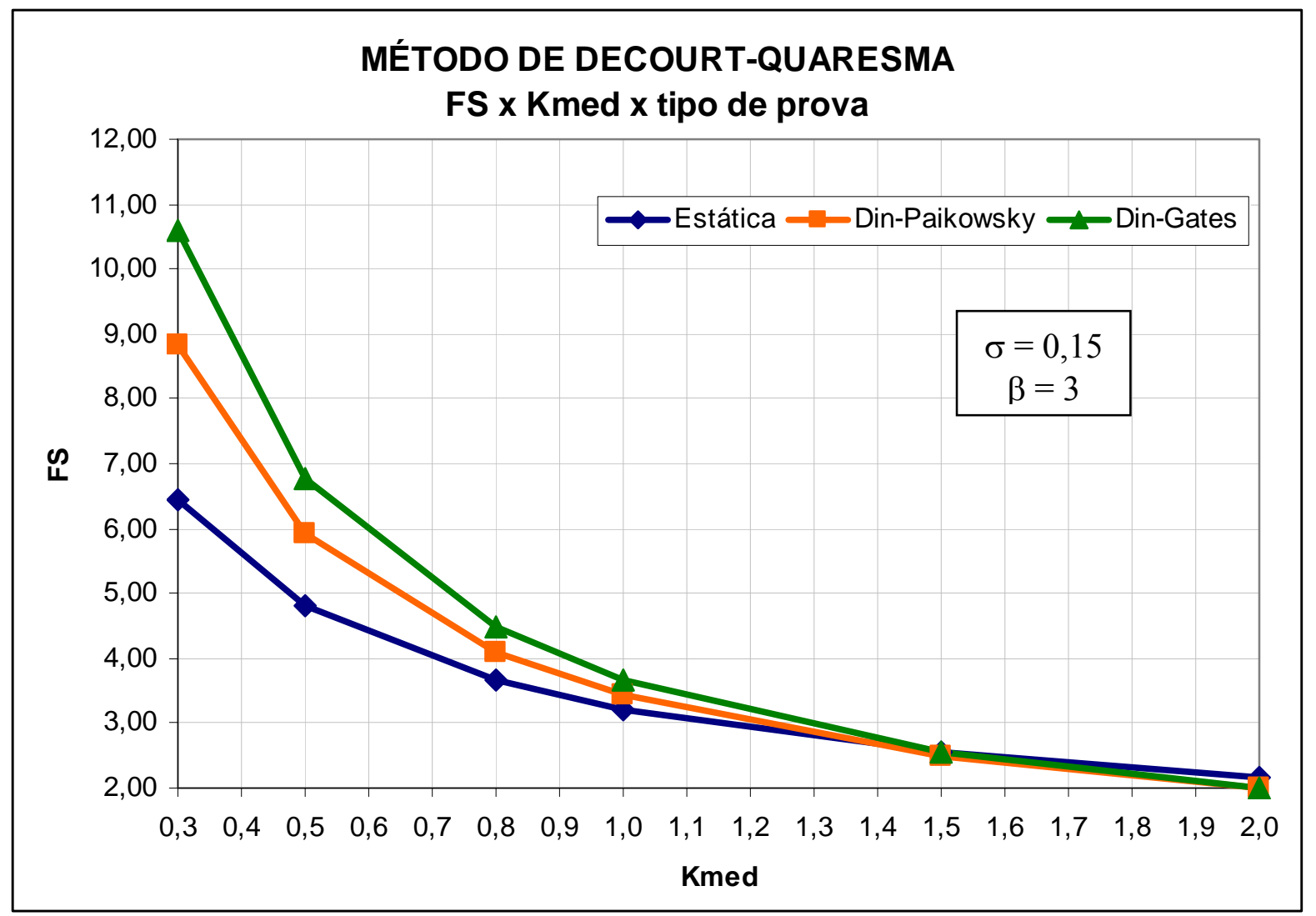

Figura 6.18 - Variação de FS com Kmed e com o tipo de prova de carga, com base nos informes apresentados na Tabela 6.20.

Analisando-se os gráficos supra apresentados, nota-se que para pequenos valores de Kmed (Kmed $=0,3$ por exemplo) os fatores de segurança associados aos resultados de ensaios de carregamento dinâmico são consideravelmente maiores que aqueles associados aos resultados de provas de carga estática. 
Também é possível apurar que, para elevados valores de Kmed, os fatores de segurança para provas estáticas tendem a ser maiores que os fatores de segurança associados aos resultados de ensaios de carregamento dinâmico. A justificativa para esse fenômeno (maior FS associado às provas estáticas) já foi devidamente apresentada no Exemplo $6.2 \mathrm{e}$ tem relação com a tendência de as provas dinâmicas subestimarem a capacidade de carga frente às provas estáticas. 


\section{CONCLUSÕES}

No presente trabalho procurou-se apresentar o uso da inferência bayesiana na incorporação das informações adicionais provenientes de provas de carga sobre estacas, tanto provas de carga estáticas quanto dinâmicas, para a reavaliação da segurança das estacas quando da obra implantada.

Iniciou-se com uma apresentação dos fatores intervenientes nos métodos de introdução da segurança, dando destaque aos diversos tipos de incerteza. Apresentou-se também a influência dos erros humanos na concorrência de colapsos e as conseqüências de uma eventual ruína.

Prosseguiu-se o trabalho apresentando os diversos métodos de introdução da segurança, dispostos segundo suas ordens evolutivas, destacando-se o método semiprobabilístico, seguido dos métodos de Nível II, também conhecidos como métodos do índice de confiabilidade, e dos métodos Nível III, nos quais, efetivamente, é feito o cálculo das probabilidades de ruína. Apresentou-se também, de forma sucinta, um quarto nível de rigor conceitual, no qual o cálculo da probabilidade de ruína decorre de uma análise de custo/benefício. Desta etapa do trabalho, restou concluído que a probabilidade de ruína está relacionada de forma biunívoca com a segurança da estrutura, constituindo-se, pois, a forma ideal de se mensurar a segurança estrutural.

No que concerne à inferência bayesiana, apresenta-se a seguir as conclusões alcançadas na presente pesquisa, consubstanciadas em todo o exposto.

a) Diante das pequenas probabilidades associadas ao evento ruína, a inferência bayesiana se apresenta com grande vantagem em relação à estatística clássica, haja vista que permite a incorporação de eventuais informações anteriores existentes, muitas vezes de caráter subjetivo, tornando o processo de inferência menos dependente de observações de colapsos de estruturas similares. Como foi apresentado, diante do fato inexorável de que o subjetivismo está sempre presente em alguma fase da concepção, cálculo ou construção de uma estrutura 
geotécnica, o método permite a incorporação, de forma racional, dessa subjetividade;

b) As informações anteriores utilizadas no modelo bayesiano provêm basicamente de duas fontes: (i) dados históricos do fator de viés $(\mathrm{K}=$ Pobs/Pprev) relativos aos diversos métodos de previsão da capacidade de carga e (ii) variabilidade intra-canteiro da capacidade de carga das estacas. Exemplos dessas informações anteriores estão apresentados na tabela 4.4 e 4.5. Diversos trabalhos tratando do tema previsão versus comportamento têm apresentado valores da variável $\mathrm{K}=$ Pobs/Pprev, para os mais diversos tipos de solo, de modo que se constituem, na prática, em importante fonte de informação apriorística. Ressalta-se que o método não exige que as informações prévias utilizadas provenham estritamente de trabalhos anteriores, como os trabalhos que subsidiaram o exemplo elucidativo apresentado na presente dissertação. Pode-se, sem prejuízo, utilizar informações subjetivas obtidas da eliciação de um expert na área em questão;

c) Também restou evidenciada a capacidade da inferência bayesiana no processamento de informações adicionais advindas da observação dos resultados de provas de carga sobre estacas, permitindo a implementação do Método Observacional na prática da engenharia de fundações. Neste contexto, como as incertezas associadas aos resultados de provas de carga são menores que aquelas associadas aos métodos de previsão da capacidade de carga, o método permite a atualização da segurança das estacas de uma determinada obra;

d) Da aplicação do método por meio de exemplos elucidativos pode-se concluir que o fator de segurança a ser aplicado aos resultados das provas de carga depende não somente da média dos resultados obtidos na experimentação (Kmed), mas também, e coerentemente, da variabilidade dos resultados das provas de carga em uma determinada obra, variabilidade essa representada pelo coeficiente de variação dos resultados de K. Destarte, quanto maior a variabilidade da variável $\mathrm{K}=$ Pobs/Pprev em determinada obra, maior será o fator de segurança exigido para a manutenção de certo índice de confiabilidade. As figuras 6.2 e 6.3 bem como as tabelas 6.5 e 6.6 dão suporte à essa conclusão;

e) Também ficou demonstrado que nem sempre um maior número de provas de carga executadas em uma mesma obra traduz, inequivocadamente, redução do fator de segurança. A redução do fator de segurança com o aumento do número de provas de carga somente é percebida quando o método de previsão não superestima, de forma sistemática, a capacidade 
de carga das estacas no local da obra. Quando o método de previsão superestima sistematicamente a capacidade de carga das estacas em uma obra, nota-se que o fator de segurança necessário aumenta a cada realização de uma prova de carga, ou seja, a cada confirmação da superestimativa proporcionada pelo método. As figuras 6.4 e 6.5 para o caso de variância desconhecida e as figuras 6.13 e 6.14 para o caso de variância intra-canteiro conhecida corroboram essa assertiva.

Com fulcro nas assertivas retro pode-se consignar que o método bayesiano permite a formalização da redução da incerteza com o aumento do número de provas de carga, em alternativa aos métodos ad-hoc que têm sido utilizados para este fim, mesmo em normas técnicas.

Também é possível concluir em relação a este tema que nem sempre redução da incerteza resulta em redução do fator de segurança;

f) Nos exemplos relacionados ao caso de precisão intra-canteiro conhecida propôs-se a consideração de 3 classes de precisão intra-canteiro, denotadas por alta precisão, média precisão e baixa precisão, para as quais foram obtidos os fatores de segurança necessários para a manutenção de um índice de confiabilidade $\beta=3$. Coerentemente, quanto maior a precisão intra-canteiro (representada pelo desvio-padrão da variável $\mathrm{R}=\log (\mathrm{Pobs} / \mathrm{Pprev})$ ) menor o fator de segurança demandado, como mostram as figuras 6.11 e 6.12. A tabulação dos fatores de segurança em função das diversas classes de precisão intra-canteiro poderia ser um primeiro passo para a consideração da variabilidade intra-canteiro em normas e códigos de projeto e construção de fundações, de forma relativamente simples e fundamentada;

g) Confrontando-se os resultados obtidos para o caso de variância desconhecida com o caso de variância conhecida, pode-se notar que, no primeiro caso, a variabilidade do valor de $\mathrm{K}$ em determinada obra $(\sigma[\mathrm{K}])$ não tem grande influência no fator de segurança. Esse comportamento decorre do fato de que, no caso de variância desconhecida, a distribuição Gama utilizada para representar a precisão intra-site é obtida por comparação entre diversas obras, em locais distintos. Desta feita, a variabilidade inter-site prevalece sobre a variabilidade intra-site, de forma que o desvio-padrão dos resultados de $\mathrm{K}$ em um obra em particular não altera o fator de segurança de forma significativa. 
A consideração de diversas obras para a concepção da distribuição Gama representativa da precisão intra-canteiro pode se constituir um óbice para a utilização do caso de variância desconhecida na prática da engenharia de fundações, de modo que a inferência com variância conhecida pode representar uma alternativa mais apropriada;

h) Outra conclusão importante se refere à distinção entre os fatores de segurança a serem aplicados aos resultados de provas de carga estática e aos resultados de ensaios de carregamento dinâmico. Restou consignado que, quando o método de previsão superestima a "verdadeira" capacidade de carga da estaca, os maiores fatores de segurança estão associados aos ensaios de carregamento dinâmico. Esse mesmo comportamento ocorre para valores de Kmed muito próximos da unidade. Quando os valores de Kmed são muito elevados (por exemplo, Kmed =2), os fatores de segurança a serem aplicados aos resultados de ensaios de carregamento dinâmico podem ser até menores que aqueles a serem aplicados aos resultados de provas de carga estática. Esse comportamento, como discutido no corpo da presente dissertação, tem relação com a tendência de as provas de carga dinâmica subestimarem a capacidade de carga da estaca frente às provas de carga estática.

As figuras 6.8 a 6.10 corroboram o que foi supra apresentado.

No entanto, cumpre salientar que a diferença dos fatores de segurança a serem aplicados às provas de carga estáticas e dinâmicas varia muito em função da média e desviopadrão da variável Pdin/Pestat. Os diversos trabalhos que procuraram relacionar os resultados de provas de carga estática com os resultados de prova dinâmica apontam para a grande variabilidade dos valores da média e desvio-padrão da referida variável, de forma que a distinção entre os fatores de segurança para provas estáticas e dinâmicas demandará estudos adicionais sobre o comportamento dessa variável.

Como sugestões para pesquisas futuras, podem ser destacadas as seguintes:

- Avaliação experimental da precisão intra-canteiro, mediante a execução de um elevado número de provas de carga em uma mesma obra e quantificação do desvio-padrão da variável $R(\sigma[R])$ : este procedimento, efetuado em diversas obras, permitirá a distinção das obras em sítios de alta, média e baixa precisão, possibilitando a proposição de fatores de segurança específicos para cada uma dessas classes de precisão; 
- Estudos adicionais referentes ao comportamento da variável Pdin/Pestat, ou seja, a relação entre as capacidades de carga obtida por ensaio de carregamento dinâmico e provas de carga estática: tais estudos teriam por finalidade avaliar melhor a distinção entre os fatores de segurança a serem aplicados aos ensaios de carregamento dinâmico e provas de carga estática;

- Incorporação, no modelo bayesiano, das possíveis correlações espaciais entre os resultados de $\mathrm{K}=$ Pobs/Pprev obtidos em determinada obra: o estudo das correlações espaciais, valendose de modelos de decaimento da variância, permitiria a adoção de um desvio-padrão da variável $R(\sigma[R])$ menor que aquele obtido sob a hipótese de independência, propiciando melhor quantificação da segurança;

- Incorporação das incertezas relacionadas aos resultados das provas de carga estática: muito embora o presente estudo tenha considerado que as provas de carga estática forneçam a "verdadeira" capacidade de carga da estaca, o fato é que existe incerteza mesmo no caso de utilização de prova estática, especialmente quando da necessidade de se extrapolar a curva carga $\mathrm{x}$ recalque;

- Aplicação do método a grupos de estacas, com fulcro nos conceitos relativos à confiabilidade de sistemas. 


\section{BIBLIOGRAFIA}

AASHTO. LRFD bridge design specifications. Washington, D.C., 1999.

ASSOCIAÇÃO BRASILEIRA DE NORMAS TÉCNICAS. NBR 12131: Estacas - Prova de carga estática. Rio de Janeiro, 1991.

ASSOCIAÇÃO BRASILEIRA DE NORMAS TÉCNICAS. NBR 13208: Estacas - Ensaio de carregamento dinâmico. Rio de Janeiro, 1994.

ALONSO, U.R. Previsão e Controle das Fundações. 2a ed., Edgard Blücher, 1991.

ALONSO, U.R. Complementação do banco de dados de provas de carga estática em estacas hélice contínua. In: XII COBRAMSEG - CONGRESSO BRASILEIRO DE MECÂNICA DOS SOlOS E ENGENHARIA GEOTÉCNICA, ABMS, São Paulo, 2002. Anais, São Paulo, 2002, p. 1557-68.

ANG, A.H-S.; TANG, W.H. Probability Concepts in Engineering Planning and Design: Decision, risk and reliability. New York: John Wiley \& Sons, v. 2, 1984. 562 p.

AOKI, N. e VELOSO, D.A. An Approximate Method to Estimate the Bearing Capacity of Piles. In: $\mathrm{V}$ PanAmCSMFE $-5^{\mathrm{TH}}$ PANAMERICAN CONFERENCE ON SOIL MECHANICS AND FOUNDATION ENGINEERING, Buenos Aires, 1975. Anais, Buenos Aires, 1975. p. 367-75.

AOKI, N. Determinação da Capacidade de Carga Última de Estacas Cravadas em Ensaio de Carregamento Dinâmico de Energia Crescente. Tese (Doutorado) Escola de Engenharia de São Carlos, Universidade de São Paulo. São Carlos, 1997. 
AOKI, N.; MENEGOTTO, M.L.; CINTRA, J.C.A. Probabilidade de ruína como critério para definir o coeficiente de segurança a ser usado na previsão da carga admissível de fundações por estacas. In: XII COBRAMSEG - CONGRESSO BRASILEIRO DE MECÂNICA DOS SOLOS E ENGENHARIA GEOTÉCNICA, São Paulo, 2002. Anais, São Paulo, 2002. v. 3. p. $1471-81$.

BAECHER, G.B. e RACKWITZ, R. Factors of safety and pile load tests, In: International Journal for Numerical and Analytical Methods in Geomechanics. v. 06, 1982. p. 409424.

BAECHER, G.B. e CHRISTIAN, J.T. Reliability and Statistics in Geotechnical Engineering. John Wiley \& Sons, 2003.

BEKMAN, O. R.; COSTA NETO, P. L. O. Análise Estatística da Decisão. Edgard Blücher, 1980.

Benjamin, J.R. e CORNELL, C.A. Probability, Statistics and Decision for Civil Engineers. McGraw-Hill, 1970.

BILFINGER,W. Critérios de Segurança de Fundações em Estacas Cravadas com Consideração de Controles Executivos. Tese de Doutorado. Departamento de Engenharia de Estruturas e Fundações da Escola Politécnica da USP, 2002.

BORGES, J.R. e CASTANHETA, M. Structural Safety. 2a ed., LNEC, março, 1971.

BRINCH HANSEN, J. Limit Design and Safety Factors in Soil Mechanics. The Danish Geotechnical Institute, Bulletin N.1, 1956.

BRINCH HANSEN, J. The philosophy of foundation design: design criteria, safety factors and settlement limits. SYMPOSIUM ON BEARING CAPACITY AND SETTLEMENT OF FOUNDATIONS. Anais, Duke University, 1967. 
BRUCY, F.; MEUNIER, J.; NAUROY, J-F. Behaviour of a pile plug in sandy soils during and after driving. OFFSHORE TECHNOLOGY CONFERENCE, Houston, 1991. Anais, Houston, 1991. p. 145-154.

CARDOSO, A.S. Segurança e Fiabilidade. Workshop W1 - Análise de Risco em Obras Geotécnicas. In: $8^{\circ}$ CONGRESSO NACIONAL DE GEOTECNIA, Lisboa, 2002. Anais, Lisboa, 2002. v.4, p. 2263-2294.

CASAGRANDE, A. Role of the "Calculated Risk" in Earthworks and Foundation Engineering. Journal of the Soil Mechanics Divison - ASCE, v. 91, No SM4, 1965.

CHRISTIAN, J.T. Geotechnical Engineering Reliability: How Well Do We Know What We Are Doing? Journal of Geotechnical and Geoenvironmental Engineering - ASCE, 2004, p. $985-1003$.

CINTRA, J.C. e AOKI, N. Carga Admissível em Fundações Profundas. EESC-USP, Projeto REENGE, São Carlos, 1999.

CORNELL, C.A. Structural Safety Specification based on Second-Moment Reliability Analysis. IABSE Symposium. Anais, London, 1969.

COSTA NETO, P.L.O. Estatística. 2a ed., Edgard Blücher, 2002.

DECOURT, L. e QUARESMA, A.R. Capacidade de Carga de Estacas a partir de Valores de SPT. In: VI COBRAMSEF - $6^{\circ}$ CONGRESSO BRASILEIRO DE MECÂNICA DOS SOLOS E ENGENHARIA DE FUNDAÇÕES, Rio de Janeiro. Anais, Rio de Janeiro, 1978, p. $45-53$.

DE MELLO, V.F.B. Reconstruindo as Bases para a Geotecnia Prática Comparativa Difundindo Estatística-Probabilidades (EP) Simples e Convidativas para Tudo. In: XII COBRAMSEG - CONGRESSO BRASILEIRO DE MECÂNICA DOS SOLOS E ENGENHARIA GEOTÉCNICA, ABMS, São Paulo. Anais, São Paulo, 2002, p. 1271-94. 
DE ZAGOTTIS, D. Introdução da Segurança no Projeto Estrutura. Departamento de Livros e Publicações do Grêmio Politécnico, São Paulo, 1974.

DUNCAN, J.M. Factors of safety and reliability in geotechnical engineering. Journal of Geotechnical and Geoenvironmental Engineering - ASCE, 2000, v. 126, No 4, p. 307-316.

EDDE, R.D; FELlENIUS, B. H. Static or Dynamic Test - Which to Trust? The 1990 Cleveland Users Day and Geotechnical News Magazine, 1992, vol. 08, No 4, p. 28-32.

EHLERS, R.S. Introdução à Inferência Bayesiana. Departamento de Estatística da UFPR, 2003.

ERIKSSON, H.E. Design values for bearing capacities of piles derived by use of statistical methods. In: $4^{\mathrm{TH}}$ INTERNATIONAL DFI CONFERENCE. Anais, Rotterdam, 1991. p. 9-12.

FELLENIUS, B. H. The Analysis of Results from Routine Pile Load Tests. Ground Engineering, 1980, v.13, n.6, p. 19-31.

HACHICH, W. Sobre a segurança nos projetos de Geotecnia. Dissertação de Mestrado, Departamento de Engenharia de Estruturas e Fundações, Escola Politécnica da USP, 1978.

$\mathrm{HACHICH}$, W. Seepage related reliability of embankment dams. Tese de doutorado. Dept. of Civil Engineering, MIT, 1981.

HACHICH, W. Segurança das Fundações e Escavações, In: Hachich et al. Fundações Teoria e Prática, ABEF-ABMS, $2^{a}$ ed., São Paulo, 1998a.

HACHICH, W. Modelos Matemáticos e Probabilistas em Engenharia Geotécnica - Uma sistematização em forma de sonata. Tese apresentada no concurso de Livre Docência do Departamento de Engenharia de Estruturas e Fundações da Escola Politécnica da USP, 1998b.

HASOFER, A.M.; LIND,N.C. Exact and invariant second moment code format. Journal of the Engineering Mechanics Division - ASCE, v.100, n.EM1, February, 1974, p. 111-121. 
KAWANO, A. An application of Design of Experiments Concepts to the Inspection Planning of Structures. SEVENTH INTERNATIONAL OFFSHORE AND POLAR ENGINEERING CONFERENCE, Honolulu, USA. Anais, Honolulu, 1997, p. 167-173.

KAY, J.N. Safety factor evaluation for single piles in sand. Journal of the Geotechnical Engineering Division - ASCE, 1976, v. 102. p. 1093-1108.

KAY, J.N. Factor of safety for piles in cohesive soils. IX INTERNATIONAL CONFERENCE ON SOIL MECHANICS AND FOUNDATION ENGINEERING. Anais, Tóquio, 1977.

KAY, J.N. Probabilistic design of foundations and earth structures. In: Li, K.S. \& Lo, S-C.R. (editors). Probabilistic Methods in Geotechnical Engineering, Balkema, Rotterdam, 1993, p. $49-62$.

KONDZIOLKA, R.E.; KANDARIS, P.M. Capacity predictors for full scale transmission line test foundations. Uncertainty in the geologic environment: From theory to practice, ASCE, Reston, 1996, p. 695-709.

LACASSE, S. e GOULOIS, A. Reliability analysis of axial pile capacity. Proceedings of the XII INTERNATIONAL CONFERENCE ON SOIL MECHANICS AND FOUNDATION ENGINEERING, Rio de Janeiro, 1989. Anais, Rotterdam, 1989.

LEPORATI, E. The Assessment of Structural Safety - A comparative statistical study and use of Level 3, Level 2 and Level 1. In: Andrew Short, J.P., Series in Cement and Concrete Research, v. 1, Research Studies Press, 1979, 133 p.

LI, K.S.; LEE,I.K. e LO, S-C.R. Limit state design in geotechnics. In: Li, K.S. \& Lo, S-C.R. (editors). Probabilistic Methods in Geotechnical Engineering, Balkema, Rotterdam, 1993. p. $29-42$. 
LIKINS, G. E. e RAUSCHE, F. Correlation of Capwap with Static Load Tests. In: $7^{\mathrm{TH}}$. INTERNATIONAL CONFERENCE ON THE APPLICATION OF STRESSWAVE THEORY TO PILES, 2004. Anais, Petaling Jaya, Selangor, Malysia, 2004. p. 423-28.

LIKINS, G. E. Pile Testing - Selection and Economy of Safety Factors. Current Practices and Future Trends in Deep Foundations, Geotechnical Special Publication $\mathrm{n}^{\mathbf{0}} 125$, American Society of Civil Engineers: Reston, VA, 2004. p 239-52.

LIKINS, G.E; RAUSCHE, F.; THENDEAN, G.; SVINKIN, M. Capwap Correlation Studies. In: $5^{\text {TH }}$ INTERNATIONAL CONFERENCE ON THE APPLICATION OF STRESS WAVE THEORY TO PILES, 1996. Anais, 1996. p. 477-64.

MADSEN, H.O.; KRENK,S.; LIND, N.C. Methods of Structural Safety. Prentice-Hall, Inc., Englewood Cliffs, New Jersey, 1986. 403 p.

MARANHA DAS NEVES, E. Estados limites e segurança em geotecnia. Geotecnia, no 72, Lisboa, 1994.

MARTZ, H.F. e WALLER, R. A. Bayesian reliability analysis. John Wiley \& Sons, 1982.

McVAY, M.C. et al. Load and Resistance Factor Design (LRFD) for Driven Piles Using Dynamic Methods: A Florida Perspective. Geotechnical Testing Journal, v. 23, № 1, 2000. p. 55-66.

MEYER, P.L. Probabilidade - Aplicações à Estatística, 2a ed., Livros Técnicos e Científicos, 1983.

MONTGOMERY, D.C. e RUNGER, G.C. Estatística Aplicada e Probabilidade para Engenheiros, $2^{\mathrm{a}}$ ed., LTC, 2003.

NIYAMA, S. e AOKI, N. Correlação entre Provas de Carga Dinâmica e Estática no Campo Experimental da EPUSP/ABEF. In: SEFE II $-2^{\circ}$ SEMINÁRIO DE ENGENHARIA DE FUNDAÇÕES ESPECIAIS, São Paulo, 1991. Anais, São Paulo, 1991. p. 285-93. 
OLSON, R.E. e FLAATE, K.S. Pile driving formulas for friction piles in sand. Journal of the Soil Mechanics and Foundations Division - ASCE, v. 93, nº SM6, 1964. p. 279-96.

PAULINO, C.R.; TURKMAN, M.A.A.; MURTEIRA, B. Estatística Bayesiana. Fundação Calouste Gulbenkian, Lisboa, 2003.

PECK, R.B. Ninth Rankine Lecture: Advantages and limitations of the observational method in applied soil mechanics. Geotechnique, 19(2), 1969. p. 171-187.

RAIFFA, H. e SCHLAIFER, R. Applied Statistical Decision Theory. Harvard University Press, Cambridge, Massachusetts, 1961.

RAO, S.S. Reliability-based design. McGraw Hill, New York, 1992.

ROCHA FILHO, P. Interpretação de Provas de Carga Utilizando-se de Formulação Tipo Meio Homogêneo Equivalente. In: SEFE - SEMINÁRIO DE ENGENHARIA DE FUNDAÇÕES ESPECIAIS, São Paulo, 1985. Anais, São Paulo, 1985, p. 133-45.

SÁNCHEZ-SILVA, M. e RACKWITZ, R. Socioeconomic Implications of Life Quality Index in Design of Optimun Structures to Withstand Earthquakes. Journal of Structural Engineering - ASCE, 2004, p. 969-977.

STUCCHI, F.R. Responsabilidade civil e a nova NB1/2002. Apresentação feita na disciplina PEF 2503 - Estruturas Danificadas: segurança e ações corretivas, 2002. Disponível em www.lmc.ep.usp.br/people/cmazzi/PEF2503/Aula14-05.ppt. Acesso em 30/06/2006.

TERZAGHI, K. Effect of minor geological details on the stability of dams. Technical publication $\mathrm{N}^{\mathrm{o}} 215$, American Institute of Mining and Metallurgical Engineers, New York, 1929. p. 31-44.

VENEZIANO, D. Statistical Inference in Second-Moment Reliability. Research Report R 74-33, MIT, Cambrigde, 1974. 
VICK, S.G. Degrees of belief: Subjective probability and engineering judgment. ASCE, Reston, Va, 2002.

VROUWENVELDER, A. Effects of inspection on the reliability of foundation piles. In: Barends, F.B.J. (ed), Application of Stress Wave Theory to Piles, Rotterdam, 1992.

WHITMAN, R.V. Evaluating calculated risk in geotechnical engineering. Journal of Geotechnical Engineering, ASCE, 110(2), 1984. p. 145-188.

ZHANG, L.; TANG, W.H.; Ng.W.W, C. Reliability of Axially Loaded Driven Pile Groups. Journal of Geotechnical and Geoenvironmental Engineering, ASCE, 2001, p. 1051-1060.

ZHANG, L. Reliability Verification Using Proof Pile Load Tests. Journal of Geotechnical and Geoenvironmental Engineering, ASCE, 2004. p. 1203-1212.

ZHANG, L.; TANG, W.; ZHANG, LuLu; ZHENG, J. Reducing Uncertainty of Prediction from Empirical Correlations. Journal of Geotechnical and Geoenvironmental Engineering, ASCE, 2004. p. 526-533. 


\section{APÊNDICE A}

O presente apêndice tem por finalidade apresentar a metodologia para o cálculo de $\mathrm{P}_{\text {din }} / \mathrm{P}_{\text {prev }}$ através dos valores de $\mathrm{P}_{\text {din }} / \mathrm{P}_{\text {estat }}$ e de $\mathrm{P}_{\text {estat }} / \mathrm{P}_{\text {prev }}$.

Para tanto, foi utilizada as seguintes propriedades do produto de duas variáveis aleatórias, como apresentado por Benjamin e Cornell, 1970:

$E(X Y)=E(X) \cdot E(Y)$

$\operatorname{VAR}[X Y]=m_{x}^{2} \sigma_{y}^{2}+m_{y}^{2} \sigma_{x}^{2}+\sigma_{x}^{2} \sigma_{y}^{2}$

Onde $\mathrm{XY}=\mathrm{P}_{\text {din }} / \mathrm{P}_{\text {prev }}, \mathrm{X}=\mathrm{P}_{\text {din }} / \mathrm{P}_{\text {estat }}$ e $\mathrm{Y}=\mathrm{P}_{\text {estat }} / \mathrm{P}_{\text {prev }}$.

Os valores de $\mathrm{P}_{\text {estat }} / \mathrm{P}_{\text {prev }}$ e de $\mathrm{P}_{\text {din }} / \mathrm{P}_{\text {estat }}$ estão expostos na tabela abaixo e na tabela 5.1 do corpo da Dissertação, respectivamente.

Aplicando-se as expressões (a) e (b) aos valores expostos nas tabelas supra referidas, tem-se os resultados apresentados nas tabelas da página seguinte.

\begin{tabular}{c|c|c}
\hline Método & $\mathrm{E}[\mathrm{Y}]$ & $\sigma[\mathrm{Y}]$ \\
\hline Aoki-Veloso (Aoki e Veloso, 1975) & 1,014 & 0,235 \\
\hline Decourt-Quaresma (Decourt e Quaresma, 1978) & 1,058 & 0,341 \\
\hline Janbu (Olson e Flaate, 1964) & 1,13 & 0,69 \\
\hline Gates (Olson e Flaate, 1964) & 1,33 & 0,615 \\
\hline
\end{tabular}

Tabela A1 - Valores da média e desvio da variável Y = Pesta/Pprev, para diversos métodos (reprodução parcial da Tabela 4.2 da dissertação). 


\begin{tabular}{|c|c|c|c|}
\hline \multicolumn{2}{|c|}{$\begin{array}{c}\text { Aoki-Veloso } \\
\text { (Aoki eVeloso, 1975) }\end{array}$} & $\begin{array}{c}\text { Decourt-Quaresma } \\
\text { (Decourt e Quaresma, 1978) }\end{array}$ \\
\hline E[ DIN $\left._{\text {DIN }} / P_{\text {AV }}\right]$ & $V_{\text {Var[ }}\left[P_{\text {DIN }} / P_{\text {AV }}\right]$ & $\left.E_{\text {DIN }} / P_{\text {DQ }}\right]$ & Var[ $\left.P_{\text {DIN }} / P_{\text {DQ }}\right]$ \\
\hline 4,228 & 4,871 & 4,412 & 6,483 \\
\hline 3,154 & 4,528 & 3,290 & 5,680 \\
\hline 0,598 & 0,160 & 0,624 & 0,201 \\
\hline 0,740 & 0,203 & 0,772 & 0,260 \\
\hline 1,014 & 0,166 & 1,058 & 0,243 \\
\hline 0,710 & 0,084 & 0,741 & 0,122 \\
\hline 0,831 & 0,105 & 0,868 & 0,155 \\
\hline 1,065 & 0,464 & 1,111 & 0,588 \\
\hline 5,425 & 6,968 & 5,660 & 9,473 \\
\hline 3,600 & 4,324 & 3,756 & 5,603 \\
\hline 0,507 & 0,105 & 0,529 & 0,133 \\
\hline 0,619 & 0,078 & 0,645 & 0,109 \\
\hline 1,349 & 0,280 & 1,407 & 0,413 \\
\hline 0,892 & 0,116 & 0,931 & 0,174 \\
\hline 1,055 & 0,133 & 1,100 & 0,209 \\
\hline 0,872 & 0,260 & 0,910 & 0,336 \\
\hline 1,007 & 0,084 & 1,051 & 0,148 \\
\hline 1,024 & 0,088 & 1,069 & 0,154 \\
\hline 0,977 & 0,101 & 1,020 & 0,165 \\
\hline & & & \\
\hline
\end{tabular}

Tabela A2 - Momentos da variável XY = Pdin/Pprev para os métodos de Aoki-Veloso e Decourt Quaresma, considerando-se os informes apresentados na Tabela A2 relativos aos referidos métodos. Considerou-se as várias fontes da média e desvio da variável X $=$ Pdin/Pestat apresentadas na Tabela 5.1 da dissertação. 


\begin{tabular}{|c|c|c|c|c|c|c|c|}
\hline & & & & & & & \\
\hline & & & & $\begin{array}{r}\mathrm{Ja} \\
\text { (Olson e F }\end{array}$ & $\begin{array}{l}\text { nbu } \\
\text { laate, 1964) }\end{array}$ & $\begin{array}{r}\mathrm{Ga} \\
\text { (Olson e FI }\end{array}$ & $\begin{array}{l}\text { ates } \\
\text { Ilaate, 1964) }\end{array}$ \\
\hline $\begin{array}{l}\text { Momento da prova de } \\
\text { carga dinâmica }\end{array}$ & $\begin{array}{c}\text { Fonte dos valores de média e desvio da variável } \\
\text { Pdin/Pestat }(X)\end{array}$ & $\mathrm{E}[\mathrm{X}]$ & $\operatorname{Var}[\mathrm{X}]$ & $E\left[P_{D I N} / P_{J}\right]$ & $\operatorname{Var}\left[\mathrm{P}_{\mathrm{DIN}} / \mathrm{P}_{\mathrm{J}}\right]$ & $E\left[P_{D I N} / P_{G}\right]$ & $\operatorname{Var}\left[\mathrm{P}_{\mathrm{DIN}} / \mathrm{P}_{\mathrm{G}}\right]$ \\
\hline & ENR $^{1}-77$ casos (McVay et al, 2000) & 4,170 & 3,610 & 4,712 & 14,607 & 5,546 & 13,479 \\
\hline & ENR modificado - 61 casos (McVay et al, 2000) & 3,110 & 3,686 & 3,514 & 11,067 & 4,136 & 10,706 \\
\hline & FDOT $^{2}, 1991$ apud McVay et al, 2000 - 72 casos & 0,590 & 0,130 & 0,667 & 0,393 & 0,785 & 0,379 \\
\hline Fim da cravacão & Gates, 1957 apud McVay et al, $2000-74$ casos & 0,730 & 0,160 & 0,825 & 0,534 & 0,971 & 0,507 \\
\hline & Paikowsky, 1994 apud McVay et al, 2000 - 27 casos & 1,000 & 0,102 & 1,130 & 0,656 & 1,330 & 0,574 \\
\hline & CAPWAP cases - 44 casos (McVay et al, 2000) & 0,700 & 0,053 & 0,791 & 0,326 & 0,931 & 0,286 \\
\hline & PDA - 48 casos (McVay et al, 2000) & 0,820 & 0,063 & 0,927 & 0,430 & 1,091 & 0,374 \\
\hline & Sakai, 1996 apud McVay, 2000 - 21 casos & 1,050 & 0,372 & 1,187 & 1,177 & 1,397 & 1,128 \\
\hline & ENR - 77 casos (McVay et al, 2000) & 5,350 & 4,973 & 6,046 & 22,345 & 7,116 & 20,334 \\
\hline & ENR modificado - 61 casos (McVay et al, 2000) & 3,550 & 3,349 & 4,012 & 11,871 & 4,722 & 11,170 \\
\hline & FDOT,1991 apud McVay et al, 2000 - 72 casos & 0,500 & 0,084 & 0,565 & 0,266 & 0,665 & 0,255 \\
\hline & Gates, 1957 apud McVay et al, 2000 - 74 casos & 0,610 & 0,053 & 0,689 & 0,270 & 0,811 & 0,242 \\
\hline & Paikowsky, 1994 apud McVay et al, $2000-27$ casos & 1,330 & 0,168 & 1,503 & 1,137 & 1,769 & 0,990 \\
\hline Início da recravação & CAPWAP cases - 44 casos (McVay et al, 2000) & 0,880 & 0,068 & 0,994 & 0,487 & 1,170 & 0,422 \\
\hline & PDA - 48 casos (McVay et al, 2000) & 1,040 & 0,068 & 1,175 & 0,633 & 1,383 & 0,538 \\
\hline & Sakai, 1996 apud McVay, 2000 - 21 casos & 0,860 & 0,203 & 0,972 & 0,707 & 1,144 & 0,667 \\
\hline & $\mathrm{SW}^{3}$ - 143 casos (Likins e Rausche,2004) & 0,993 & 0,027 & 1,122 & 0,517 & 1,321 & 0,424 \\
\hline & CAPWAP cases - 77 casos (Globe et al, 1980) & 1,010 & 0,029 & 1,141 & 0,536 & 1,343 & 0,441 \\
\hline & CAPWAP cases - 83 casos (Likins et al, 1996) & 0,964 & 0,046 & 1,089 & 0,523 & 1,282 & 0,440 \\
\hline
\end{tabular}

Tabela A3 - Momentos da variável XY = Pdin/Pprev para os métodos de Janbu e Gates, considerando-se os informes apresentados na Tabela A1 relativos aos referidos métodos. Considerou-se as várias fontes da média e desvio da variável $\mathrm{X}=$ Pdin/Pestat apresentadas na Tabela 5.1 da dissertação. 
Os gráficos a seguir apresentam as distribuições da variável $\mathrm{P}_{\text {din }} / \mathrm{P}_{\text {prev }}$, para os métodos de Aoki-Veloso e Decourt-Quaresma e os valores de $\mathrm{P}_{\text {din }} / \mathrm{P}_{\text {estat }}$ informados por fontes diversas, assumindo-se que a variável $\mathrm{P}_{\text {din }} / \mathrm{P}_{\text {prev }}$ tenha distribuição log-normal (assim como a variável $\left.\mathrm{P}_{\text {estat }} / \mathrm{P}_{\text {prev }}\right)$.

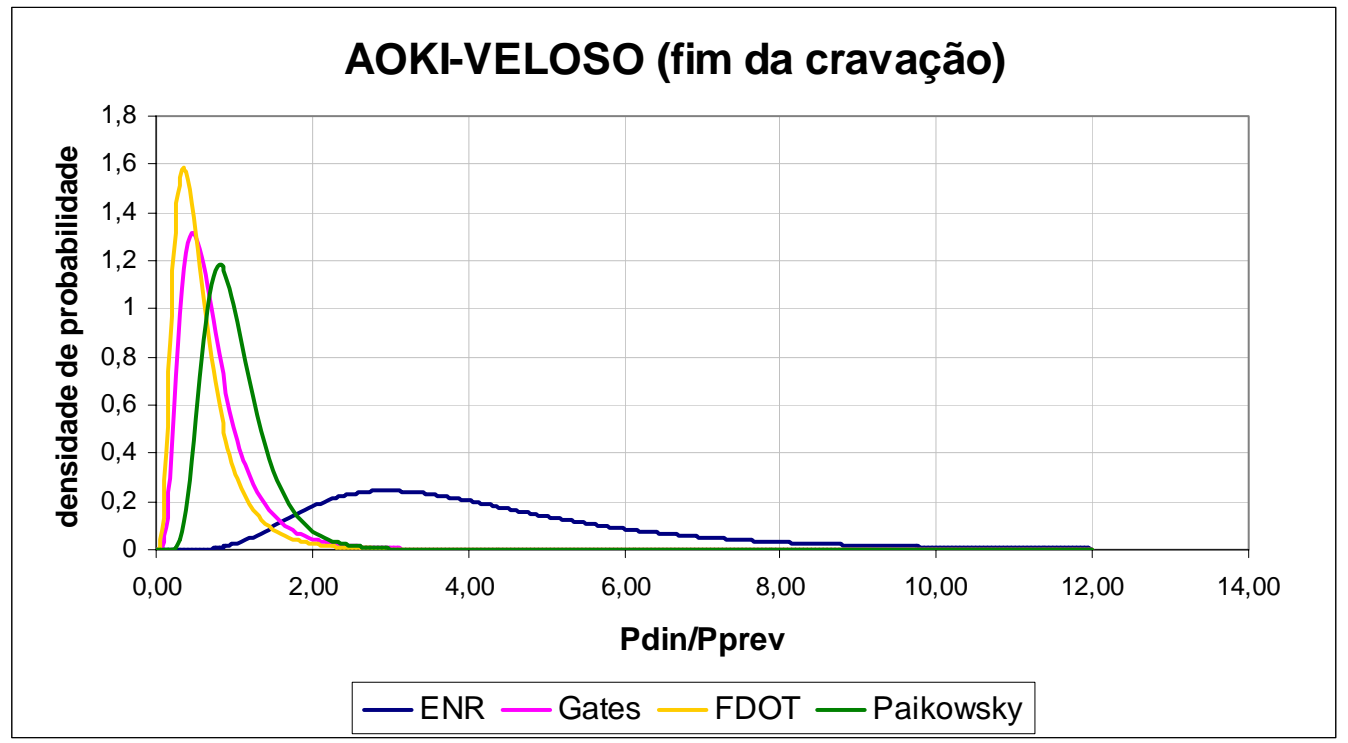

Figura A1 - Distribuições log-normais da variável Pdin/Pprev para o método de Aoki-Veloso e fim da cravação, considerando-se os informes da variável Pdin/Pestat apresentados pelo Engineering News Record apud MacVay (2000), Gates apud MacVay (2000), FDOT apud MacVay (2000) e Paikowsky apud MacVay (2000).

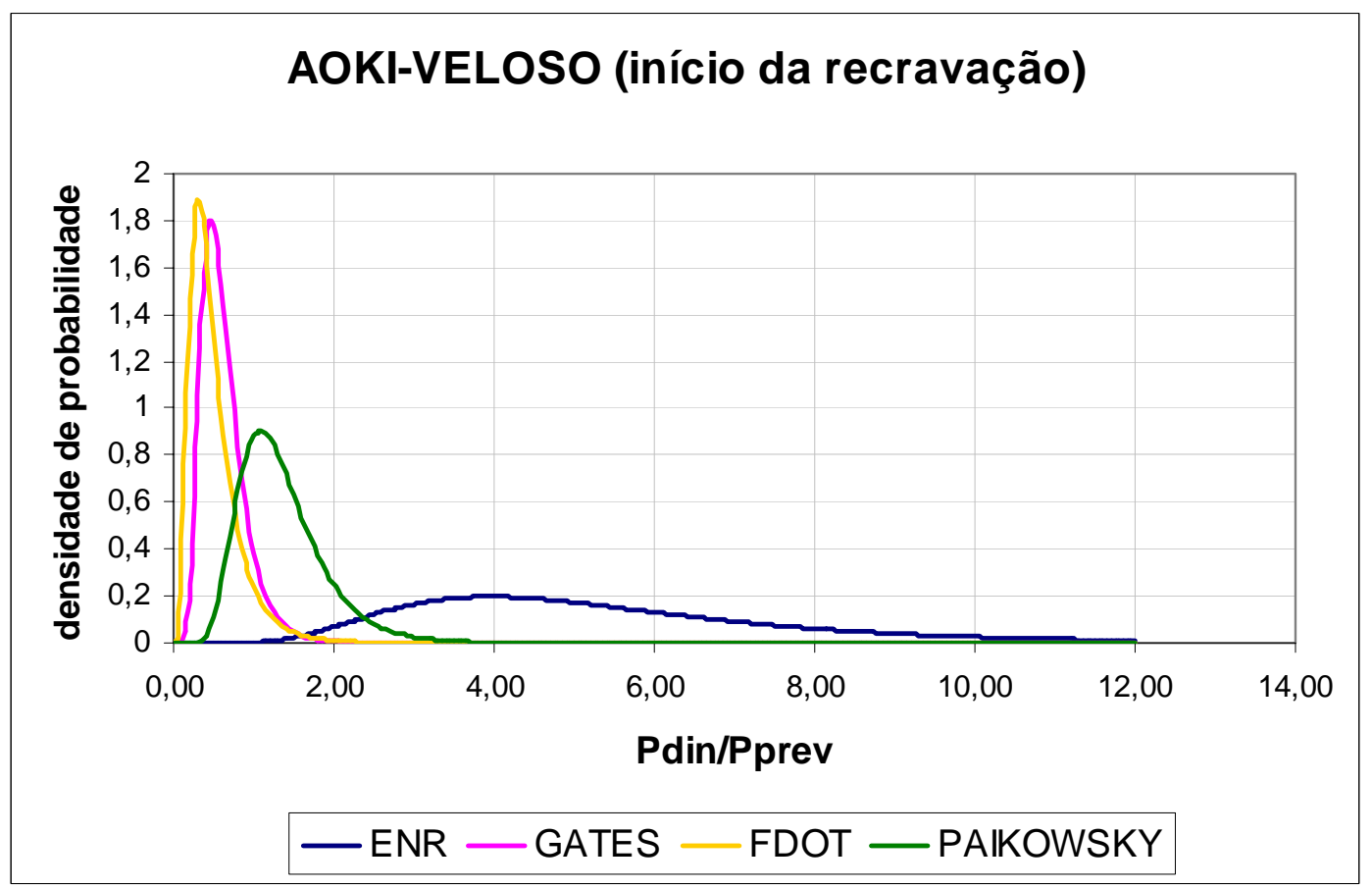

Figura A2 - Distribuições log-normais da variável Pdin/Pprev para o método de Aoki-Veloso e início da recravação, considerando-se os informes da variável Pdin/Pestat apresentados pelo Engineering News Record apud MacVay (2000), Gates apud MacVay (2000), FDOT apud MacVay (2000) e Paikowsky apud MacVay (2000). 


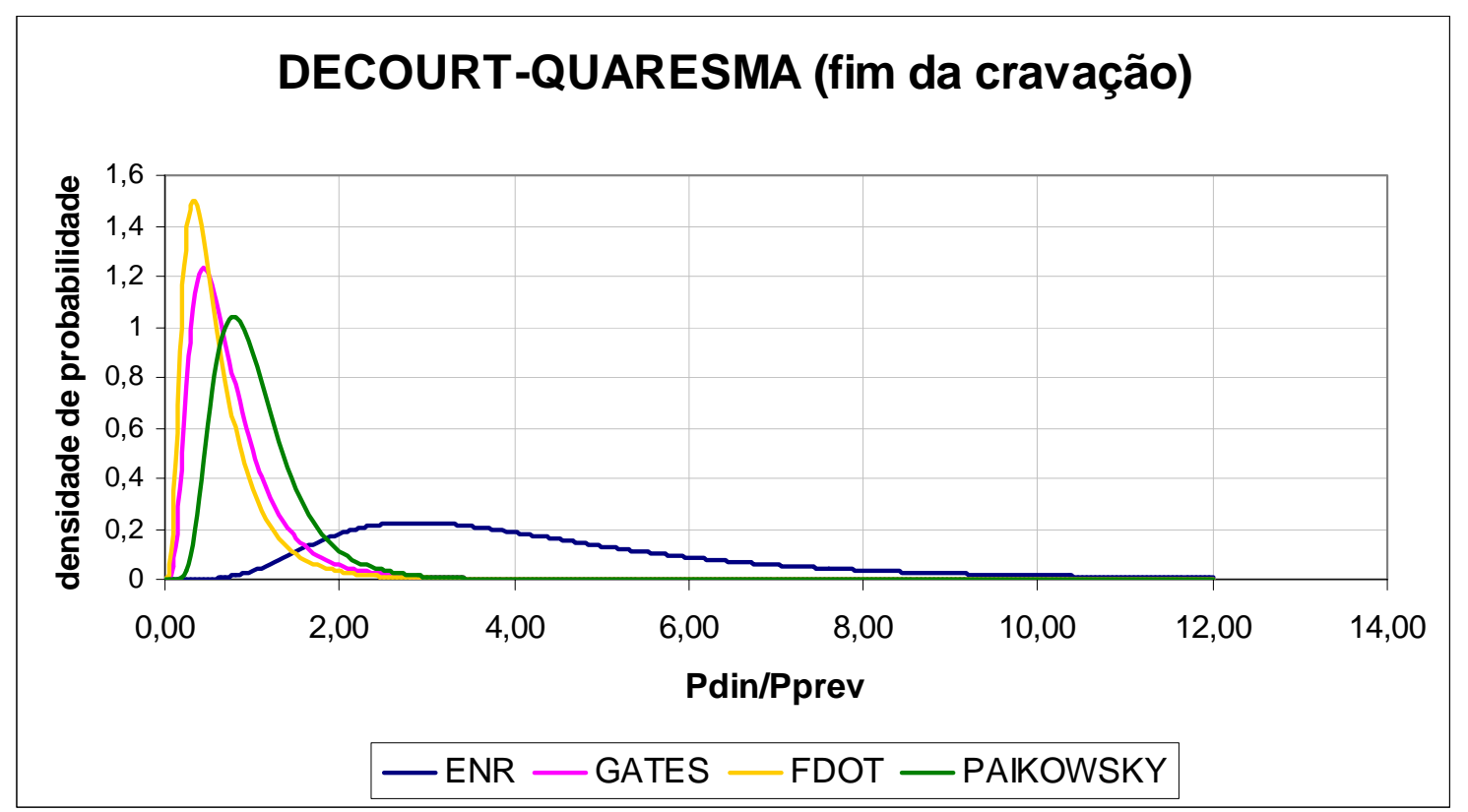

Figura A3 - Distribuições log-normais da variável Pdin/Pprev para o método de Decout-Quaresma e fim da cravação, considerando-se os informes da variável Pdin/Pestat apresentados pelo Engineering News Record apud MacVay (2000), Gates apud MacVay (2000), FDOT apud MacVay (2000) e Paikowsky apud MacVay (2000).

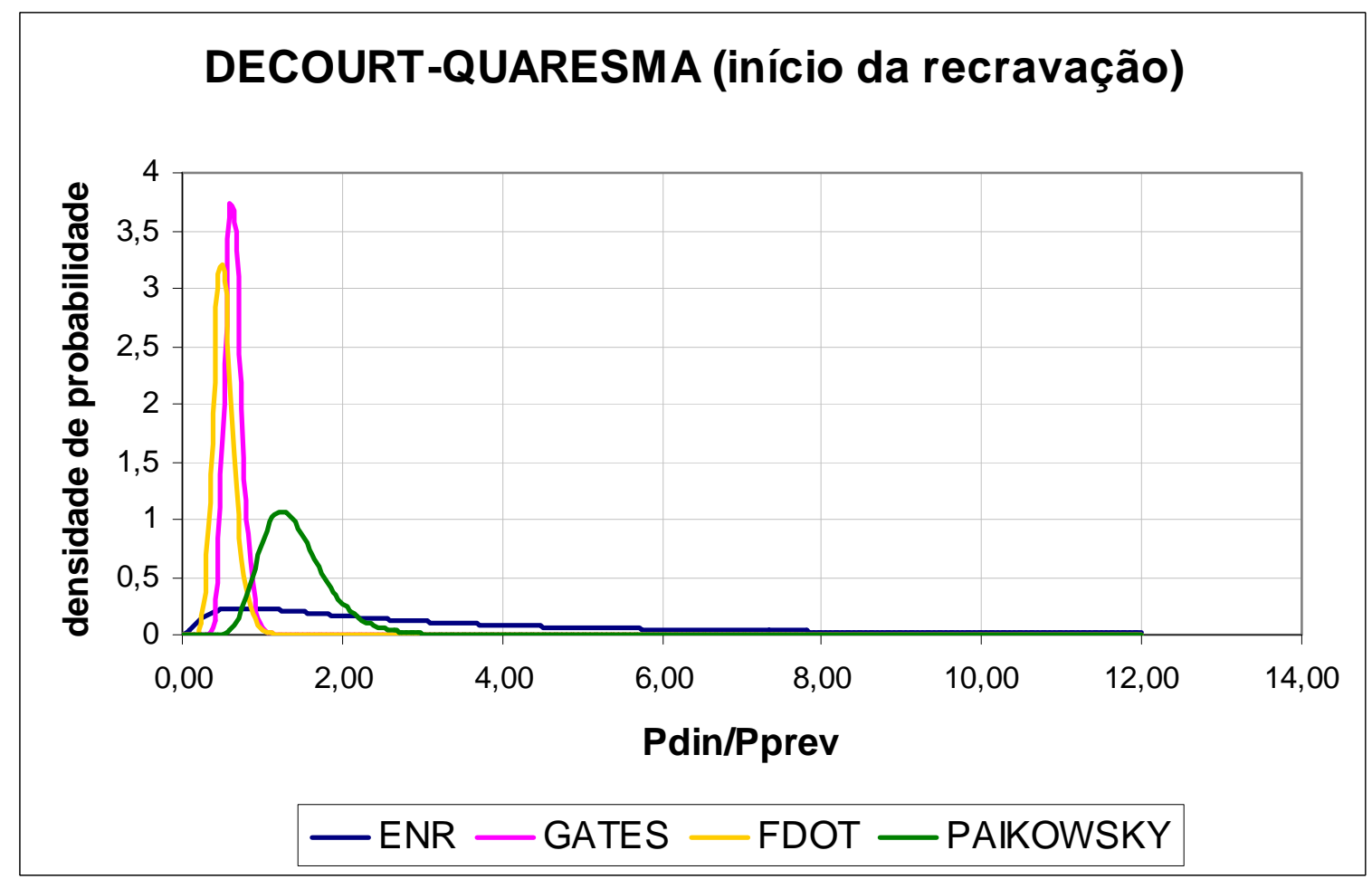

Figura A4 - Distribuições log-normais da variável Pdin/Pprev para o método de Decourt-Quaresma e início da recravação, considerando-se os informes da variável Pdin/Pestat apresentados pelo Engineering News Record apud MacVay (2000), Gates apud MacVay (2000), FDOT apud MacVay (2000) e Paikowsky apud MacVay (2000).

Analisando-se os gráficos retro, pode-se consignar que o comportamento da variável Pdin/Pprev é bastante dependente da média e do desvio da variável Pdin/Pestat. 


\section{APÊNDICE B}

O presente apêndice tem por objetivo apresentar a metodologia utilizada para obter os momentos (média e variância) da variável $\mathrm{R}=\log (\mathrm{K})$ a partir dos momentos da variável $\mathrm{K}$.

Benjamin e Cornell (1970), utilizando a expansão de Taylor, apresentaram as seguintes expressões para a média e variância de uma variável dependente Y qualquer:

$$
\begin{aligned}
& \mathrm{E}[\mathrm{R}] \approx \mathrm{g}_{\mathrm{R}}\left(\mathrm{m}_{\mathrm{x} 1}, \mathrm{~m}_{\mathrm{x} 2}, \ldots . ., \mathrm{m}_{\mathrm{xn}}\right)+\left.\frac{1}{2} \sum_{\mathrm{i}=1}^{\mathrm{n}} \frac{\partial \mathrm{g}_{\mathrm{R}}{ }^{2}}{\partial \mathrm{x}_{\mathrm{i}}{ }^{2}}\right|_{\mathrm{mx}_{\mathrm{i}}} \cdot \operatorname{Var}[\mathrm{xi}] \\
& \operatorname{Var}[\mathrm{R}] \approx \sum_{\mathrm{i}=1}^{\mathrm{n}}\left(\left.\frac{\partial \mathrm{g}_{\mathrm{R}}}{\partial \mathrm{x}_{\mathrm{i}}}\right|_{\mathrm{mx}_{\mathrm{i}}}\right)^{2} \cdot \operatorname{Var}[\mathrm{xi}]
\end{aligned}
$$

Onde $\mathrm{mx}_{1}, \mathrm{mx}_{2}, \ldots ., \mathrm{mx}_{\mathrm{n}}$ são os valores médios das " $\mathrm{n}$ " variáveis independentes da função $\mathrm{Y}=\mathrm{g}_{\mathrm{R}}\left(\mathrm{x}_{1}, \mathrm{x}_{2}, \ldots, \mathrm{x}_{\mathrm{n}}\right)$.

Considerando a função $\mathrm{Y}=\log \mathrm{X}$, teríamos, com base nas expressões (a) e (b) supra, os seguintes resultados:

$$
\begin{aligned}
& \mathrm{E}[\mathrm{R}] \approx \log (\mathrm{K})-\frac{1}{2} \cdot\left(\frac{1}{\ln 10 \cdot \mathrm{E}[\mathrm{K}]^{2}}\right) \cdot \operatorname{Var}[\mathrm{K}] \\
& \operatorname{Var}[\mathrm{R}] \approx\left(\frac{1}{\ln 10 \cdot \mathrm{E}[\mathrm{K}]}\right)^{2} \cdot \operatorname{Var}[\mathrm{K}]
\end{aligned}
$$

As expressões (c) e (d) retro permitem calcular diretamente os momentos de $\mathrm{R}$ a partir dos momentos de $\mathrm{K}$.

Utilizando-se as referidas expressões aos momentos de $\mathrm{K}$ para o método de AokiVeloso e Decourt-Quaresma apresentados na Tabela A2 do APÊNDICE A, considerando-se as relações entre Pdin/Pestat decorrentes do banco de dados de Paikowsky, Gates e PDA cases 
(MacVay et al, 2000), obtém-se os informes apresentados na seguinte tabela.

\begin{tabular}{|c|c|c|c|c|c|}
\hline \multirow{2}{*}{$\begin{array}{c}\text { Método } \\
\text { (referência) }\end{array}$} & \multirow{2}{*}{$\begin{array}{c}\text { Fonte da Média e } \\
\text { Desvio da variável } \\
\text { Pdin/Pestat }\end{array}$} & \multicolumn{2}{|c|}{$\mathrm{K}=\mathrm{P}_{\mathrm{din}} / \mathrm{P}_{\text {prev }}$} & \multicolumn{2}{|c|}{$\mathrm{R}=\log \left(\mathrm{P}_{\text {din }} / \mathrm{P}_{\text {prev }}\right)$} \\
\hline & & média[K] & desvio $[\mathrm{K}]$ & média[R] & desvio[R] \\
\hline $\begin{array}{c}\text { Aoki-Veloso } \\
\text { (Aoki e Veloso, 1975) }\end{array}$ & $\begin{array}{c}\text { Paikowsky } \\
\text { (apud MacVay, 2000) }\end{array}$ & 1,014 & 0,4074 & $-0,029$ & 0,1745 \\
\hline $\begin{array}{c}\text { Aoki-Veloso } \\
\text { (Aoki e Veloso, 1975) }\end{array}$ & $\begin{array}{c}\text { Gates } \\
\text { (apud MacVay, 2000) }\end{array}$ & 0,740 & 0,4505 & $-0,2112$ & 0,2644 \\
\hline $\begin{array}{c}\text { Aoki-Veloso } \\
\text { (Aoki e Veloso, 1975) }\end{array}$ & $\begin{array}{c}\text { PDA cases } \\
\text { (MacVay et al, 2000) }\end{array}$ & 0,831 & 0,3240 & $-0,1134$ & 0,1693 \\
\hline $\begin{array}{c}\text { D\&Q } \\
\text { Decourt e Quaresma } \\
(1978)\end{array}$ & $\begin{array}{c}\text { Paikowsky } \\
\text { (apud MacVay, 2000) }\end{array}$ & 1,058 & 0,4929 & $-0,0226$ & 0,2023 \\
\hline $\begin{array}{c}\text { D\&Q } \\
\text { Decourt e Quaresma } \\
(1978)\end{array}$ & $\begin{array}{c}\text { Gates } \\
\text { (apud MacVay, 2000) }\end{array}$ & 0,772 & 0,5099 & $-0,2071$ & 0,2868 \\
\hline $\begin{array}{c}\text { D\&Q } \\
\text { Decourt e Quaresma } \\
(1978)\end{array}$ & $\begin{array}{c}\text { PDA cases } \\
\text { (MacVay et al, 2000) }\end{array}$ & 0,868 & 0,3937 & $-0,1061$ & 0,1969 \\
\hline
\end{tabular}

Tabela B1 - Valores de K e R para os métodos de Aoki-Veloso e Decourt-Quaresma, considerando-se os informes da variável Pdin/Pestat oriundos de Paikowsky, Gates e PDA cases (MacVay et al, 2000). 